\title{
Clinical Antiviral Drug Arbidol Inhibits Infection by SARS-CoV-2 and Variants through Direct Binding to the Spike Protein
}

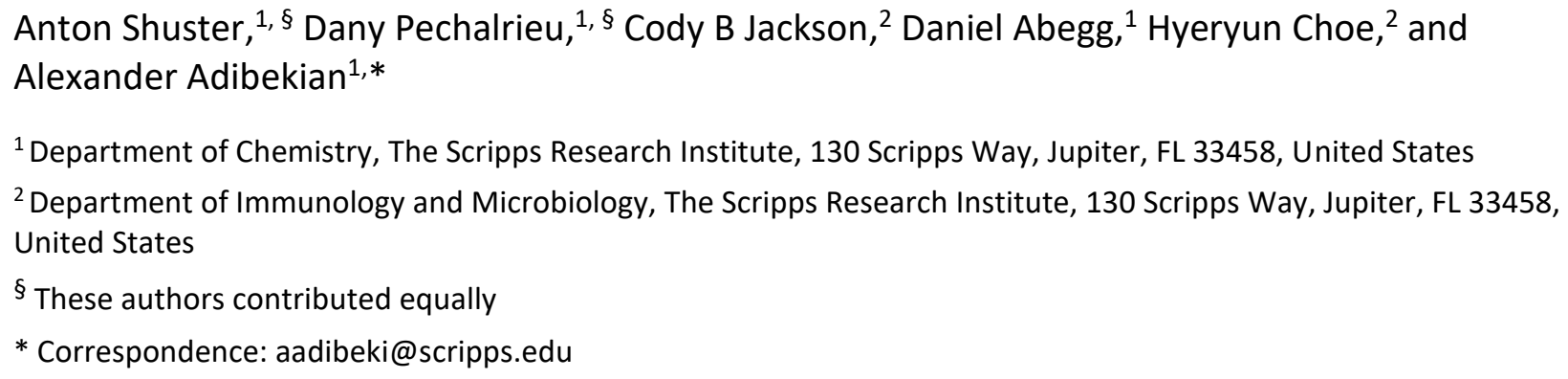

\section{Supporting Information}

\section{$\underline{\text { Table of Contents }}$}

Materials and General Methods .......................................................... 2

Experimental Details and Procedures ..................................................... 2

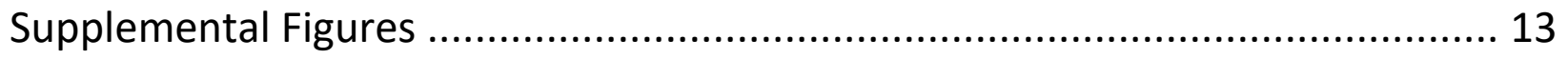

Supplemental Tables................................................................ 22

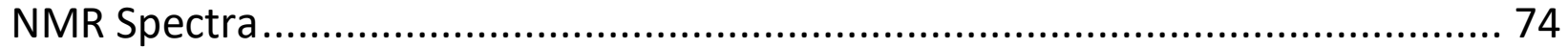

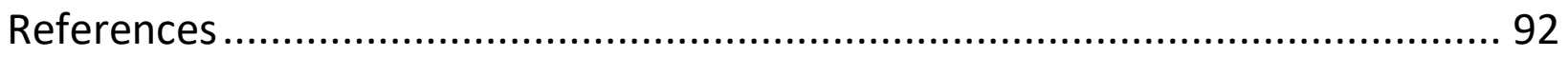




\section{Materials and General Methods}

All commercial reagents were purchased from Sigma-Aldrich, Combi-Blocks and Oakwood Chemical of the highest purity grade, unless otherwise noted. All reagents were weighed and handled in air and used without further purification, unless otherwise noted. Liquid reagents were transferred with stainless steel syringes or cannula. Thin layer chromatography (TLC) was performed on plates of silica gel $60 \AA \mathrm{F}_{254}$ from Merck using short-wave UV light as the visualizing agent, $\mathrm{KMnO}_{4}$, ninhydrin or phosphomolybdic acid and heat as developing agents. Flash chromatography was performed using silica gel 40-63 $\mu \mathrm{m}(230-400$ mesh) from Silicycle.

${ }^{1} \mathrm{H},{ }^{19} \mathrm{~F}$ and ${ }^{13} \mathrm{C}$ NMR spectra were recorded on a Bruker Avance $400 \mathrm{MHz}$ spectrometer. Chemical shifts $(\delta)$ are expressed in ppm relative with the solvent resonance used as internal reference, and coupling constants $(J)$ are reported in hertz (Hz). Multiplicities were defined as s (singlet), d (doublet), dd (doublet of doublets), t (triplet), q (quartet), m (multiplet) or br (broad). High resolution mass spectra data (HRMS) were recorded on a Q Exactive HF-X mass spectrometer (Thermo Scientific). Semi preparative HPLC was performed on a 1260 Infinity II system (Agilent Technologies). $C_{18}$ reversed-phase column (Dr Maisch GmbH, Reprosil 100 $\mathrm{C}_{18}, 5 \mu \mathrm{m}, 250 \times 10 \mathrm{~mm}$ ) were used for semi preparative HPLC with a binary gradient elution (solvent $\mathrm{A}: \mathrm{H}_{2} \mathrm{O} / 0.1 \%$ formic acid (FA) and solvent B: MeCN/0.1\% FA), a flow rate of $4 \mathrm{~mL} / \mathrm{min}$ and the chromatogram was monitored at $254 \mathrm{~nm}$.

DMEM/High glucose media with GlutaMAX (with sodium pyruvate), Ham's F-12K (Kaighn's) Medium, phosphate buffered saline (PBS), MEM Non-Essential Amino Acids, Penicillin Streptomycin (Pen/Strep) and Trypsin-EDTA were obtained from Life Technologies. Protein concentration was determined using the Bradford assay (Bio-Rad) or BCA assay (Thermo Fisher Scientific). The plasmids, unless otherwise stated, were prepared using the QIAprep Spin Miniprep Kit (Qiagen). For all PCR reactions, Q5 High-Fidelity DNA Polymerase (New England BioLabs Inc) was used as recommended by manufacturer.

\section{Experimental Details and Procedures}

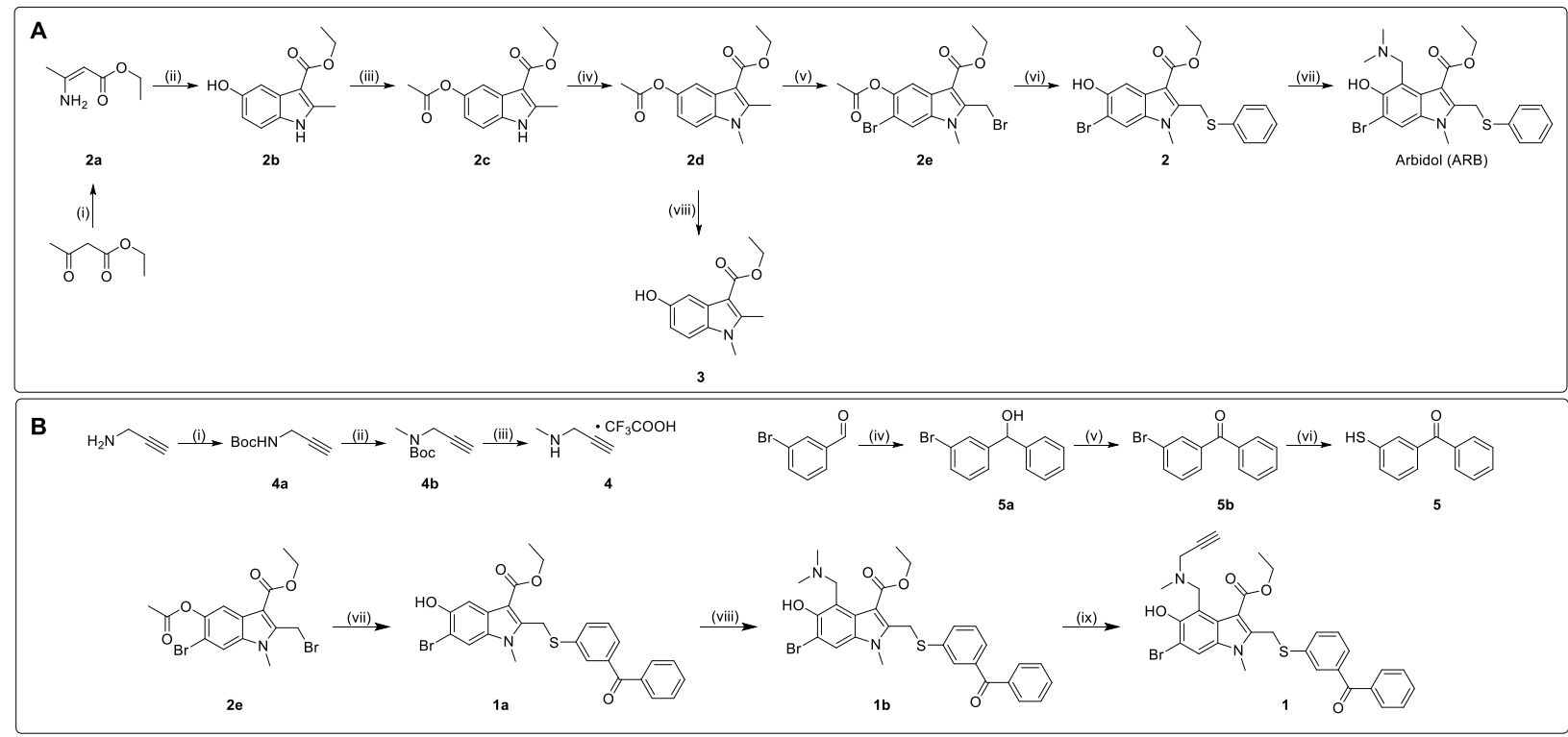

Scheme S1. Synthetic routes to Arbidol, its derivatives, 2 and 3 and probe 1. A) General synthetic routes to Arbidol and its derivatives, 2 and 3. Reaction conditions: (i) ammonia, $\mathrm{H}_{2} \mathrm{O}, \mathrm{RT}, 12 \mathrm{~h}, 62 \%$; (ii) 1,4-benzoquinone, acetic acid, RT, 8 h, 75\%; (iii) acetic anhydride, pyridine, reflux, $2 \mathrm{~h}, 89 \%$; (iv) methyl iodide, $\mathrm{NaH}, \mathrm{DMF}, 4^{\circ} \mathrm{C}, 3 \mathrm{~h}, 85 \%$; (v) bromine, $\mathrm{CCl}_{4}, \mathrm{reflux}, 12 \mathrm{~h}, 95 \%$; (vi) $\mathrm{KOH}$, thiophenol, $\mathrm{MeOH}, \mathrm{DCM}, 4^{\circ} \mathrm{C}, 6 \mathrm{~h}, 74 \%$; (vii) $N, N, N^{\prime}, N^{\prime}$-tetramethyldiaminomethane, 1,4-dioxane, reflux, $6 \mathrm{~h}, 78 \%$; (viii) $\mathrm{KOH}, \mathrm{MeOH}, \mathrm{DCM}, \mathrm{RT}, 2 \mathrm{~h}, 61 \%$. B) General synthetic route to the probe 1. Reaction conditions: (i) Boc $2 \mathrm{O}, \mathrm{DCM}, \mathrm{RT}, 3 \mathrm{~h}, 91 \%$; (ii) methyl iodide, NaH, DMF, RT, 2 h, 87\%; (iii) TFA, DCM, RT, 1 h, crude product yield 99\%; (iv) phenylmagnesium bromide, THF, $4^{\circ} \mathrm{C}$, $1 \mathrm{~h}, 88 \%$; (v) PCC, DCM, RT, $4 \mathrm{~h}, 73 \%$; (vi) $\mathrm{CuSO}_{4} \cdot 5 \mathrm{H}_{2} \mathrm{O}, \mathrm{Cs}_{2} \mathrm{CO}_{3}, 1$,2-ethanedithiol, DMSO, $110^{\circ} \mathrm{C}, 12 \mathrm{~h}, 41 \%$; (vii) $\mathrm{KOH}$, thiophenol derivative, $\mathrm{MeOH}, \mathrm{DCM}, 4^{\circ} \mathrm{C}, 6 \mathrm{~h}, 68 \%$; (viii) $N, N, N^{\prime}, N^{\prime}$-tetramethyldiaminomethane, 1,4-dioxane, reflux, $6 \mathrm{~h}, 76 \%$; (ix) amine, 
DIPEA, 1,4-dioxane, $50^{\circ} \mathrm{C}, 12 \mathrm{~h}, 59 \%$. The synthesis of ARB and the core structure of 1 was done based on the previous work of Wright et al. ${ }^{1}$

\section{Ethyl (Z)-3-aminobut-2-enoate (2a)}<smiles>CCOC(=O)C=C(C)N</smiles>

Ammonia ( $28 \%$ aqueous solution, $5.61 \mathrm{~mL}, 1.57 \mathrm{~g}, 92.2 \mathrm{mmol}$ ) was added dropwise to a mixture of ethyl acetoacetate $(9.72 \mathrm{~mL}$, $10.00 \mathrm{~g}, 76.8 \mathrm{mmol})$ and silica gel $(0.80 \mathrm{~g})$ and then stirred at room temperature overnight. The reaction mixture was filtered, diluted with water and extracted with dichloromethane three times. The combined organic layers were washed with brine, dried over $\mathrm{Na}_{2} \mathrm{SO}_{4}$, filtered and concentrated in vacuo. The crude residue was purified by flash chromatography on silica gel (ethyl acetate-hexanes $2: 8)$ to afford ethyl (Z)-3-aminobut-2-enoate (2a) $(6.15 \mathrm{~g}, 62 \%)$ as a white solid. ${ }^{1} \mathrm{H} \mathrm{NMR}\left(400 \mathrm{MHz} \mathrm{CDCl}{ }_{3}\right) \delta 4.41$ $(\mathrm{s}, 1 \mathrm{H}), 4.00(\mathrm{q}, J=7.1 \mathrm{~Hz}, 2 \mathrm{H}), 1.81(\mathrm{~s}, 3 \mathrm{H}), 1.16(\mathrm{t}, J=7.2 \mathrm{~Hz}, 3 \mathrm{H}) ;{ }^{13} \mathrm{C} \mathrm{NMR}\left(100 \mathrm{MHz}, \mathrm{CDCl}_{3}\right) \delta 170.2,159.9,83.7,58.4,22.1,14.5$. HRMS (ESI): Calculated for $\mathrm{C}_{6} \mathrm{H}_{12} \mathrm{NO}_{2}[\mathrm{M}+\mathrm{H}]^{+} 130.0863$, found: 130.0863 .

\section{Ethyl 5-hydroxy-2-methyl-1H-indole-3-carboxylate (2b)}<smiles>CCOC(=O)c1c(C)[nH]c2ccc(O)cc12</smiles>

1,4-benzoquinone (1.67 g, $15.5 \mathrm{mmol}$ ) was dissolved in acetic acid $(30 \mathrm{~mL})$, stirred at room temperature for two hours and then ethyl (Z)-3-aminobut-2-enoate (2a) $(2.00 \mathrm{~g}, 15.5 \mathrm{mmol})$ was added portionwise. The reaction mixture was stirred at room temperature for six hours. Upon completion, the reaction mixture was filtered and the solid washed with acetic acid and hexanes. The crude product was purified by flash chromatography on silica gel (ethyl acetate-hexanes 1:2) to afford ethyl 5-hydroxy-2methyl-1H-indole-3-carboxylate (2b) $(2.55 \mathrm{~g}, 75 \%)$ as a tan solid. ${ }^{1} \mathrm{H} \mathrm{NMR}\left(400 \mathrm{MHz}, \mathrm{MeOD} / \mathrm{CDCl}_{3}\right) \delta 7.44(\mathrm{dd}, \mathrm{J}=0.5,2.4 \mathrm{~Hz}, 1 \mathrm{H})$, $7.12(\mathrm{dd}, J=0.5,8.6 \mathrm{~Hz}, 1 \mathrm{H}), 6.68(\mathrm{dd}, J=2.5,8.6 \mathrm{~Hz}, 1 \mathrm{H}), 4.31(\mathrm{q}, J=7.1 \mathrm{~Hz}, 2 \mathrm{H}), 2.62(\mathrm{~s}, 3 \mathrm{H}), 1.40(\mathrm{t}, J=7.2 \mathrm{~Hz}, 3 \mathrm{H}) ;{ }^{13} \mathrm{C} \mathrm{NMR}$ $\left(100 \mathrm{MHz}, \mathrm{MeOD} / \mathrm{CDCl}_{3}\right) \delta 167.8,152.3,146.0,130.3,128.9,111.9,111.7,106.1,103.3,59.9,14.7,14.2$. HRMS (ESI): Calculated for $\mathrm{C}_{12} \mathrm{H}_{14} \mathrm{NO}_{3}[\mathrm{M}+\mathrm{H}]^{+} 220.0968$, found: 220.0968 .

Ethyl 5-acetoxy-2-methyl-1H-indole-3-carboxylate (2c)

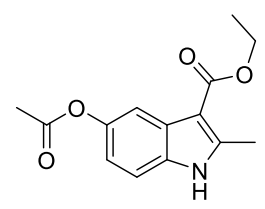

A mixture of ethyl 5-hydroxy-2-methyl-1H-indole-3-carboxylate (2b) (2.00 g, $9.12 \mathrm{mmol})$, acetic anhydride $(2.16 \mathrm{~mL}, 228 \mathrm{mmol})$ and pyridine $(3.69 \mathrm{~mL}, 45.6 \mathrm{mmol})$ was heated to reflux for two hours. The reaction mixture was then cooled to room temperature, diluted with saturated sodium bicarbonate solution and extracted with ethyl acetate three times. The combined organic layers were washed with water, brine, dried over $\mathrm{Na}_{2} \mathrm{SO}_{4}$, filtered and concentrated in vacuo. The crude residue was purified by flash chromatography on silica gel (ethyl acetate-hexanes 4:6) to afford ethyl 5-acetoxy-2-methyl-1H-indole-3carboxylate $(2 \mathrm{c})(2.12 \mathrm{~g}, 89 \%)$ as a white solid. ${ }^{1} \mathrm{H} \mathrm{NMR}\left(400 \mathrm{MHz}, \mathrm{CDCl}_{3}\right) \delta 9.13(\mathrm{~s}, 1 \mathrm{H}), 7.71-7.66(\mathrm{~m}, 1 \mathrm{H}), 7.01-6.94(\mathrm{~m}, 1 \mathrm{H})$, $6.83-7.76(\mathrm{~m}, 1 \mathrm{H}), 4.39(\mathrm{q}, J=7.1 \mathrm{~Hz}, 2 \mathrm{H}), 2.57(\mathrm{~s}, 3 \mathrm{H}), 2.38(\mathrm{~s}, 3 \mathrm{H}), 1.45(\mathrm{t}, J=7.2 \mathrm{~Hz}, 3 \mathrm{H}) ;{ }^{13} \mathrm{C} \mathrm{NMR}\left(100 \mathrm{MHz}, \mathrm{CDCl}_{3}\right) \delta 171.4$, 166.0, 145.9, 145.4, 132.5, 127.7, 115.6, 113.2, 111.7, 104.2, 59.6, 21.3, 14.6, 14.1. HRMS (ESI): Calculated for $\mathrm{C}_{14} \mathrm{H}_{16} \mathrm{NO}_{4}[\mathrm{M}+\mathrm{H}]^{+}$ 262.1074, found: 262.1072 . 


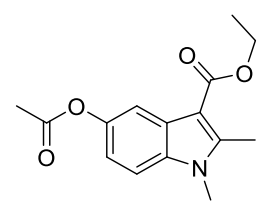

Methyl iodide $(2.00 \mathrm{~mL}, 32.1 \mathrm{mmol})$ was added to a solution of ethyl 5-acetoxy-2-methyl-1H-indole-3-carboxylate (2c) (2.10 g, $8.04 \mathrm{mmol})$ in DMF $(25 \mathrm{~mL})$ and cooled on ice. Sodium hydride $(0.289 \mathrm{~g}, 12.1 \mathrm{mmol})$ was added and the reaction mixture was stirred on ice for three hours. After quenching with water, the reaction mixture was extracted with ethyl acetate three times. The combined organic layers were washed with brine, dried over $\mathrm{Na}_{2} \mathrm{SO}_{4}$, filtered and concentrated in vacuo. The crude residue was purified by flash chromatography on silica gel (ethyl acetate-hexanes 4:6) to afford ethyl 5-acetoxy-1,2-dimethyl-1H-indole-3carboxylate (2d) $(1.88 \mathrm{~g}, 85 \%)$ as a yellow solid. ${ }^{1} \mathrm{H} \mathrm{NMR}\left(400 \mathrm{MHz}, \mathrm{CDCl}_{3}\right) \delta 7.73(\mathrm{~d}, J=2.2 \mathrm{~Hz}, 1 \mathrm{H}), 6.99(\mathrm{~d}, J=8.7 \mathrm{~Hz}, 1 \mathrm{H}), 6.82$ $(\mathrm{dd}, J=2.4,8.7 \mathrm{~Hz}, 1 \mathrm{H}), 4.33(\mathrm{q}, J=7.2 \mathrm{~Hz}, 2 \mathrm{H}), 3.31(\mathrm{~s}, 3 \mathrm{H}), 2.51(\mathrm{~s}, 3 \mathrm{H}), 2.29(\mathrm{~s}, 3 \mathrm{H}), 1.40(\mathrm{t}, J=7.2 \mathrm{~Hz}, 3 \mathrm{H}) ;{ }^{13} \mathrm{C} \mathrm{NMR}(100 \mathrm{MHz}$, $\left.\mathrm{CDCl}_{3}\right) \delta 170.1,165.4,146.2,145.6,133.9,126.7,115.6,113.4,109.2,103.5,59.1,29.2,21.0,14.5,11.5$. HRMS (ESI): Calculated for $\mathrm{C}_{15} \mathrm{H}_{18} \mathrm{NO}_{4}[\mathrm{M}+\mathrm{H}]^{+} 276.1230$, found: 276.1228 .

\section{Ethyl 5-acetoxy-6-bromo-2-(bromomethyl)-1-methyl-1H-indole-3-carboxylate (2e)}<smiles>CCOC(=O)c1c(CBr)n(C)c2cc(Br)c(OC(C)=O)cc12</smiles>

Ethyl 5-acetoxy-1,2-dimethyl-1H-indole-3-carboxylate (2d) (1.88 g, $6.83 \mathrm{mmol}$ ) was dissolved in $\mathrm{CCl}_{4}$ (190 $\left.\mathrm{mL}\right)$ and bromine (1.05 $\mathrm{mL}, 20.5 \mathrm{mmol}$ ) was slowly added. The reaction mixture was heated to reflux overnight. The reaction mixture was then cooled to room temperature, diluted with aqueous sodium thiosulphate, stirred for $30 \mathrm{~min}$ and the organic layer was separated. The organic layer was washed with water, brine, dried over $\mathrm{Na}_{2} \mathrm{SO}_{4}$, filtered and concentrated in vacuo. The crude residue was purified by flash chromatography on silica gel (ethyl acetate-hexanes 2:8) to afford ethyl 5-acetoxy-6-bromo-2-(bromomethyl)-1-methyl$\mathbf{1 H}$-indole-3-carboxylate (2e) $(2.81 \mathrm{~g}, 95 \%)$ as a yellow solid. ${ }^{1} \mathrm{H}$ NMR $\left(400 \mathrm{MHz}, \mathrm{CDCl}_{3}\right) \delta 7.85(\mathrm{~s}, 1 \mathrm{H}), 7.52(\mathrm{~s}, 1 \mathrm{H}), 5.03(\mathrm{~s}, 2 \mathrm{H})$, $4.41(\mathrm{q}, J=7.1 \mathrm{~Hz}, 2 \mathrm{H}), 3.67(\mathrm{~s}, 3 \mathrm{H}), 2.39(\mathrm{~s}, 3 \mathrm{H}), 1.45(\mathrm{t}, J=7.1 \mathrm{~Hz}, 3 \mathrm{H}) ;{ }^{13} \mathrm{C} \mathrm{NMR}\left(100 \mathrm{MHz}, \mathrm{CDCl}_{3}\right) \delta 169.5,164.4,143.5,142.7$, 135.6, 125.7, 116.3, 114.0, 112.1, 105.7, 60.3, 30.1, 20.9, 20.7, 14.6. HRMS (ESI): Calculated for $\mathrm{C}_{15} \mathrm{H}_{16} \mathrm{Br}_{2} \mathrm{NO}_{4}[\mathrm{M}+\mathrm{H}]+433.9420$, found: 433.9417.

\section{Ethyl 6-bromo-5-hydroxy-1-methyl-2-((phenylthio)methyl)-1H-indole-3-carboxylate (2)}<smiles>CCOC(=O)c1c(CSc2ccccc2)n(C)c2cc(Br)c(O)cc12</smiles>

A methanolic solution $(1.0 \mathrm{~mL})$ of potassium hydroxide $(77.7 \mathrm{mg}, 1.39 \mathrm{mmol})$ was added to thiophenol $(47.4 \mu \mathrm{L}, 0.46 \mathrm{mmol})$ and stirred for $30 \mathrm{~min}$. This solution was then cooled down on ice and a solution of ethyl 5-acetoxy-6-bromo-2-(bromomethyl)-1methyl-1H-indole-3-carboxylate (2e) $(200.0 \mathrm{mg}, 0.46 \mathrm{mmol})$ in DCM $(2.5 \mathrm{~mL})$ was added and stirred on ice for six hours. Upon completion, the reaction mixture was neutralized with acetic acid, diluted with DCM and the organic layer was separated. The organic layer was washed with water, brine, dried over $\mathrm{Na}_{2} \mathrm{SO}_{4}$, filtered and concentrated in vacuo. The crude residue was purified by flash chromatography on silica gel (ethyl acetate-hexanes 2:8) to afford ethyl 6-bromo-5-hydroxy-1-methyl-2((phenylthio)methyl)-1H-indole-3-carboxylate (2) (143.6 mg, 74\%) as a yellow solid. ${ }^{1} \mathrm{H} N M R\left(400 \mathrm{MHz}, \mathrm{DMSO}-\mathrm{d}_{6}\right) \delta 9.82(\mathrm{~s}, 1 \mathrm{H})$, $7.73(\mathrm{~s}, 1 \mathrm{H}), 7.56(\mathrm{~s}, 1 \mathrm{H}), 7.36-7.33(\mathrm{~m}, 2 \mathrm{H}), 7.31-7.24(\mathrm{~m}, 3 \mathrm{H}), 4.78(\mathrm{~s}, 2 \mathrm{H}), 4.18(\mathrm{q}, J=7.1 \mathrm{~Hz}, 2 \mathrm{H}), 3.67(\mathrm{~s}, 3 \mathrm{H}), 1.29(\mathrm{t}, J=7.0$ $\mathrm{Hz}, 3 \mathrm{H}) ;{ }^{13} \mathrm{C}$ NMR $(100 \mathrm{MHz}$, DMSO-d 6 ) $\delta 164.2,149.3,143.4,134.2,131.5,131.1,129.0,127.2,126.0,114.2,106.4,106.3,103.1$, 59.1, 30.2, 28.3, 14.3. HRMS (ESI): Calculated for $\mathrm{C}_{19} \mathrm{H}_{19} \mathrm{BrNO}_{3} \mathrm{~S}[\mathrm{M}+\mathrm{H}]^{+} 420.0264$, found: 420.0259 . 
Ethyl 6-bromo-4-((dimethylamino)methyl)-5-hydroxy-1-methyl-2-((phenylthio)methyl)-1H-indole-3-carboxylate (Arbidol ARB)

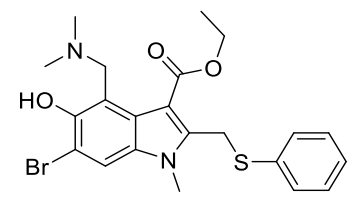

Ethyl 6-bromo-5-hydroxy-1-methyl-2-((phenylthio)methyl)-1H-indole-3-carboxylate (2) (136.0 mg, $0.032 \mathrm{mmol})$ was dissolved

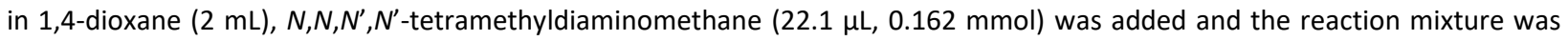
heated to reflux for six hours. The solvent was removed and the residue was purified by reversed phase HPLC using a linear acetonitrile gradient with $0.1 \%$ of FA $(0 \rightarrow 90 \% \mathrm{MeCN})$ to afford ethyl 6-bromo-4-((dimethylamino)methyl)-5-hydroxy-1-methyl2-((phenylthio)methyl)-1H-indole-3-carboxylate (Arbidol - ARB) (120.5 mg, 78\%) as a yellow solid. ${ }^{1} \mathrm{H} \mathrm{NMR} \mathrm{(400} \mathrm{MHz,}$ $\left.\mathrm{MeOD} / \mathrm{CDCl}_{3}\right) \delta 7.60(\mathrm{~s}, 1 \mathrm{H}), 7.31-7.21(\mathrm{~m}, 5 \mathrm{H}), 4.55(\mathrm{~s}, 2 \mathrm{H}), 4.47(\mathrm{~s}, 2 \mathrm{H}), 4.19(\mathrm{q}, J=7.1 \mathrm{~Hz}, 2 \mathrm{H}), 3.55(\mathrm{~s}, 3 \mathrm{H}), 2.62(\mathrm{~s}, 6 \mathrm{H}), 1.31$ $(\mathrm{t}, J=7.2 \mathrm{~Hz}, 3 \mathrm{H}) ;{ }^{13} \mathrm{C}$ NMR $\left(100 \mathrm{MHz}, \mathrm{MeOD} / \mathrm{CDCl}_{3}\right) \delta 167.1,152.6,144.5,135.1,133.7,132.9,129.8,128.8,125.9,115.3,111.9$, 109.7, 106.0, 61.4, 58.3, 43.5, 31.2, 30.6, 14.5. HRMS (ESI): Calculated for $\mathrm{C}_{22} \mathrm{H}_{26} \mathrm{BrN}_{2} \mathrm{O}_{3} \mathrm{~S}[\mathrm{M}+\mathrm{H}]+477.0842$, found: 477.0838 .

Ethyl 5-hydroxy-1,2-dimethyl-1H-indole-3-carboxylate (3)<smiles>CCOC(=O)c1c(C)n(C)c2ccc(O)cc12</smiles>

Ethyl 5-acetoxy-1,2-dimethyl-1H-indole-3-carboxylate (2d) (100.0 mg, $0.36 \mathrm{mmol})$ was dissolved in DCM (1.5 mL) and added to a methanolic solution $(1 \mathrm{~mL})$ of potassium hydroxide $(81.5 \mathrm{mg}, 1.45 \mathrm{mmol})$. The reaction mixture was stirred at room temperature for two hours and then neutralized with acetic acid. The reaction mixture was diluted with DCM, the organic layer was separated and washed with water, brine, dried over $\mathrm{Na}_{2} \mathrm{SO}_{4}$, filtered and concentrated in vacuo. The crude residue was purified by flash chromatography on silica gel (ethyl acetate-hexanes 4:6) to afford ethyl 5-hydroxy-1,2-dimethyl-1H-indole-3-carboxylate (3) (51.7 mg, 61\%) as a yellow solid. ${ }^{1} \mathrm{H}$ NMR $\left(400 \mathrm{MHz}, \mathrm{DMSO}_{-} \mathrm{d}_{6}\right) \delta 8.92(\mathrm{~s}, 1 \mathrm{H}), 7.36(\mathrm{~d}, J=2.4 \mathrm{~Hz}, 1 \mathrm{H}), 7.28(\mathrm{~d}, J=8.7 \mathrm{~Hz}, 1 \mathrm{H}), 6.66$ $(\mathrm{dd}, J=2.5,8.7 \mathrm{~Hz}, 1 \mathrm{H}), 4.25(\mathrm{q}, J=7.2 \mathrm{~Hz}, 2 \mathrm{H}), 3.65(\mathrm{~s}, 3 \mathrm{H}), 2.67(\mathrm{~s}, 3 \mathrm{H}), 1.34(\mathrm{t}, J=7.0 \mathrm{~Hz}, 3 \mathrm{H}) ;{ }^{13} \mathrm{C} \mathrm{NMR}\left(100 \mathrm{MHz}, \mathrm{DMSO}-\mathrm{d}_{6}\right) \delta$ 165.1, 152.6, 145.2, 130.6, 127.0, 111.2, 110.3, 105.4, 101.8, 58.6, 29.6, 14.5, 11.7. HRMS (ESI): Calculated for $\mathrm{C}_{13} \mathrm{H}_{16} \mathrm{NO}_{3}[\mathrm{M}+\mathrm{H}]^{+}$ 234.1125, found: 234.1123 .

Tert-butyl prop-2-yn-1-ylcarbamate (4a)

$\mathrm{BocHN} \widehat{\longrightarrow}$

To a solution of propargylamine $(2.91 \mathrm{~mL}, 45.4 \mathrm{mmol})$ in DCM $(90 \mathrm{~mL}), \mathrm{Boc}_{2} \mathrm{O}(9.91 \mathrm{~g}, 45.4 \mathrm{mmol})$ was added portionwise on ice. The reaction mixture was stirred at room temperature for three hours. Upon completion, the reaction mixture was concentrated in vacuo and the crude residue was purified by flash chromatography on silica gel (ethyl acetate-hexanes 1:9) to afford tert-butyl prop-2-yn-1-ylcarbamate (4a) $(6.41 \mathrm{~g}, 91 \%)$ as a yellow oil. ${ }^{1} \mathrm{H} \mathrm{NMR}\left(400 \mathrm{MHz}, \mathrm{CDCl}_{3}\right) \delta 5.51$ (brs, $\left.1 \mathrm{H}\right), 3.91$ (brs, $\left.2 \mathrm{H}\right), 2.27$ (t, $J=$ $2.6 \mathrm{~Hz}, 1 \mathrm{H}), 1.45(\mathrm{~s}, 9 \mathrm{H}) ;{ }^{13} \mathrm{C} \mathrm{NMR}\left(100 \mathrm{MHz}, \mathrm{CDCl}_{3}\right) \delta 155.3,80.1,79.4,70.9,30.0$, 28.1. HRMS (ESI): Calculated for $\mathrm{C}_{8} \mathrm{H}_{14} \mathrm{NO}_{2}$ $[\mathrm{M}+\mathrm{H}]^{+}$156.1019, found: 156.1018 .

Tert-butyl methyl(prop-2-yn-1-yl)carbamate (4b)<smiles>[R16]N(C)CC#C</smiles>

$\mathrm{NaH}$ (0.412 mg, $17.2 \mathrm{mmol}$ ) was added to a solution of tert-butyl prop-2-yn-1-ylcarbamate (4a) (2.42 g, $15.6 \mathrm{mmol})$ in DMF (20 $\mathrm{mL}$ ) on ice and stirred for one hour. Methyl iodide $(1.07 \mathrm{~mL}, 17.2 \mathrm{mmol})$ was then added dropwise and the reaction mixture was warmed up to room temperature and stirred for two more hours. After quenching with water, the reaction mixture was extracted with ethyl acetate three times. The combined organic layers were washed with brine, dried over $\mathrm{Na}_{2} \mathrm{SO}_{4}$, filtered and concentrated in vacuo. The crude residue was purified by flash chromatography on silica gel (ethyl acetate-hexanes 1:9) to afford tert-butyl methyl(prop-2-yn-1-yl)carbamate (4b) (2.29 g, 87\%) as a yellow oil. $\left.{ }^{1} \mathrm{H} \mathrm{NMR} \mathrm{(400} \mathrm{MHz,} \mathrm{CDCl}_{3}\right) \delta 4.01$ (brs, $\left.2 \mathrm{H}\right), 2.89$ (s, 
3H), $2.28(\mathrm{t}, J=2.3 \mathrm{~Hz}, 1 \mathrm{H}), 1.45(\mathrm{~s}, 9 \mathrm{H}) ;{ }^{13} \mathrm{C} \mathrm{NMR}\left(100 \mathrm{MHz}, \mathrm{CDCl}_{3}\right) \delta 154.7,79.6,78.8,71.5,37.7,33.0,28.0$. HRMS (ESI): Calculated for $\mathrm{C}_{9} \mathrm{H}_{16} \mathrm{NO}_{2}[\mathrm{M}+\mathrm{H}]^{+} 170.1176$, found: 170.1175 .

N-methylprop-2-yn-1-amine, TFA salt (4)

$\widehat{\mathrm{H}} \widehat{\mathrm{H}} \widehat{\sim} \cdot \mathrm{CF}_{3} \mathrm{COOH}$

TFA (5.2 mL) was added to a stirred solution of tert-butyl methyl(prop-2-yn-1-yl)carbamate (4b) (715.0 mg, $4.23 \mathrm{mmol}$ ) in DCM $(5.2 \mathrm{~mL})$. The reaction mixture was stirred at room temperature for 1 hour. TFA was removed by vacuum and the residue was coevaporated three times with methanol to obtain the crude product ( $766 \mathrm{mg}, 99 \%$ ) which was directly used in the next reaction without further purification. A small amount was purified by flash chromatography on silica gel (dichloromethane-methanol 9:1) to afford pure $\mathbf{N}$-methylprop-2-yn-1-amine, TFA salt (4) as a yellow oil for analytical purposes. ${ }^{1} \mathrm{H}$ NMR (400 MHz, MeOD) $\delta 3.89$ $(\mathrm{d}, J=2.6 \mathrm{~Hz}, 2 \mathrm{H}), 3.11(\mathrm{t}, J=2.5 \mathrm{~Hz}, 1 \mathrm{H}), 2.74(\mathrm{~s}, 3 \mathrm{H}) ;{ }^{19} \mathrm{~F} \mathrm{NMR}(376 \mathrm{MHz}, \mathrm{MeOD}) \delta-76.24(\mathrm{~s}, 3 \mathrm{~F}) ;{ }^{13} \mathrm{C} \mathrm{NMR}(100 \mathrm{MHz}, \mathrm{MeOD}) \delta$ 163.9 (brs), 79.0, 74.2, 38.4, 32.4. HRMS (ESI): Calculated for $\mathrm{C}_{4} \mathrm{H}_{8} \mathrm{~N}[\mathrm{M}+\mathrm{H}]^{+} 70.0651$, found: 70.0656 .

\section{(3-bromophenyl)(phenyl)methanol (5a)}<smiles>OC(c1ccccc1)c1cccc(Br)c1</smiles>

Phenylmagnesium bromide $(6.37 \mathrm{~g}, 11.7 \mathrm{~mL}$ of $3 \mathrm{M}$ solution in THF, $35.1 \mathrm{mmol}$ ) was added dropwise to a solution of 3bromobenzaldehyde $(5.00 \mathrm{~g}, 27.0 \mathrm{mmol})$ in THF $(160 \mathrm{~mL})$ on ice and then stirred for one hour. The reaction mixture was quenched by addition of an aqueous solution of $\mathrm{NH}_{4} \mathrm{Cl}$ and extracted with ethyl acetate three times. The combined organic layers were washed with water, brine, dried over $\mathrm{Na}_{2} \mathrm{SO}_{4}$, filtered and concentrated in vacuo. The crude residue was purified by flash chromatography on silica gel (ethyl acetate-hexanes 1:9) to afford (3-bromophenyl)(phenyl)methanol (5a) (6.26 g, 88\%) as a yellow oil. ${ }^{1} \mathrm{H}$ NMR $\left(400 \mathrm{MHz}, \mathrm{CDCl}_{3}\right) \delta 7.58$ (brs, $\left.1 \mathrm{H}\right), 7.47-7.18(\mathrm{~m}, 8 \mathrm{H}), 5.69(\mathrm{~s}, 1 \mathrm{H}), 3.16(\mathrm{~s}, 1 \mathrm{H}) ;{ }^{13} \mathrm{C} \mathrm{NMR}(100 \mathrm{MHz}, \mathrm{CDCl} 3) \delta$ 146.0, 143.1, 130.5, 130.0, 129.5, 128.7, 127.9, 126.6, 125.1, 122.6, 75.5. HRMS (ESI): Calculated for $\mathrm{C}_{13} \mathrm{H}_{12} \mathrm{BrO}[\mathrm{M}+\mathrm{H}]^{+} 263.0066$, found: 263.0068 .

\section{(3-bromophenyl)(phenyl)methanone (5b)}<smiles>O=C(c1ccccc1)c1cccc(Br)c1</smiles>

Pyridinium chlorochromate $(7.43 \mathrm{~g}, 34.5 \mathrm{mmol}$ ) was added portionwise to a mixture of (3-bromophenyl)(phenyl)methanol (5a) $(5.80 \mathrm{~g}, 31.3 \mathrm{mmol})$ and silica gel $(7.20 \mathrm{~g})$ in DCM $(120 \mathrm{~mL})$ at room temperature. The reaction mixture was stirred for four hours and then filtered through a short pad of silica gel. The filtrate was concentrated in vacuo and the residue was purified by flash chromatography on silica gel (ethyl acetate-hexanes 1:9) to afford (3-bromophenyl)(phenyl)methanone (5b) (4.20 g, 73\%) as a yellow solid. ${ }^{1} \mathrm{H}$ NMR $\left(400 \mathrm{MHz}, \mathrm{CDCl}_{3}\right) \delta 7.76(\mathrm{t}, \mathrm{J}=1.8 \mathrm{~Hz}, 1 \mathrm{H}), 7.62-7.58(\mathrm{~m}, 2 \mathrm{H}), 7.53-7.48(\mathrm{~m}, 2 \mathrm{H}), 7.43-7.38(\mathrm{~m}, 1 \mathrm{H}), 7.32$ $-7.26(\mathrm{~m}, 2 \mathrm{H}), 7.15(\mathrm{t}, J=7.8 \mathrm{~Hz}, 1 \mathrm{H}) ;{ }^{13} \mathrm{C} \mathrm{NMR}\left(100 \mathrm{MHz}, \mathrm{CDCl}_{3}\right) \delta$ 194.7, 139.3, 136.7, 135.1, 132.7, 132.6, 129.9, 129.8, 128.4, 128.3, 122.5. HRMS (ESI): Calculated for $\mathrm{C}_{13} \mathrm{H}_{10} \mathrm{BrO}[\mathrm{M}+\mathrm{H}]^{+} 260.9910$, found: 260.9908.

\section{(3-mercaptophenyl)(phenyl)methanone (5)}<smiles>O=C(c1ccccc1)c1cccc(S)c1</smiles>

A reaction mixture of (3-bromophenyl)(phenyl)methanone (5b) (3.88 g, $14.9 \mathrm{mmol})$, copper(II) sulfate pentahydrate (0.186 $\mathrm{g}$, $0.74 \mathrm{mmol})$, cesium carbonate $(24.2 \mathrm{~g}, 74.3 \mathrm{mmol})$ in DMSO $(31 \mathrm{~mL})$ was flushed with argon. 1,2-ethanedithiol (2.49 $\mathrm{mL}, 29.7$ $\mathrm{mmol}$ ) was added and the reaction mixture was heated at $110^{\circ} \mathrm{C}$ overnight. The reaction mixture was then cooled to room temperature, diluted with a solution of $5 \% \mathrm{HCl}$ and extracted with ethyl acetate three times. The combined organic layers were washed with water, brine, dried over $\mathrm{Na}_{2} \mathrm{SO}_{4}$, filtered and concentrated in vacuo. The crude residue was purified by flash chromatography on silica gel (ethyl acetate-hexanes 2:8) to afford (3-mercaptophenyl)(phenyl)methanone (5) (1.31 g, 41\%) as a brown oil. ${ }^{1} \mathrm{H}$ NMR $\left(400 \mathrm{MHz}, \mathrm{CDCl}_{3}\right) \delta 7.82-7.76(\mathrm{~m}, 2 \mathrm{H}), 7.71(\mathrm{t}, J=1.8 \mathrm{~Hz}, 1 \mathrm{H}), 7.63-7.46(\mathrm{~m}, 5 \mathrm{H}), 7.35(\mathrm{t}, J=7.6 \mathrm{~Hz}, 1 \mathrm{H})$, 
3.57 (s, 1H); ${ }^{13} \mathrm{C}$ NMR $\left(100 \mathrm{MHz}, \mathrm{CDCl}_{3}\right) \delta$ 196.1, 138.6, 137.4, 133.0, 132.8, 132.5, 132.0, 130.5, 130.2, 129.1, 128.5, $128.4,127.4$. HRMS (ESI): Calculated for $\mathrm{C}_{13} \mathrm{H}_{11} \mathrm{OS}[\mathrm{M}+\mathrm{H}]^{+} 215.0525$, found: 215.0527 . This compound was synthesized using an adapted procedure from Liu et al. ${ }^{2}$

Ethyl 2-(((3-benzoylphenyl)thio)methyl)-6-bromo-5-hydroxy-1-methyl-1H-indole-3-carboxylate (1a)

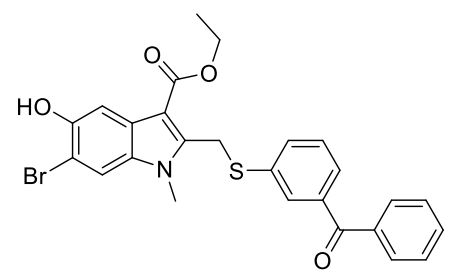

A methanolic solution $(3.0 \mathrm{~mL})$ of potassium hydroxide $(0.194 \mathrm{~g}, 3.46 \mathrm{mmol})$ was added to (3mercaptophenyl)(phenyl)methanone (5) $(0.247 \mathrm{~g}, 1.15 \mathrm{mmol})$ and stirred for $30 \mathrm{~min}$. This solution was then cooled down on ice and a solution of ethyl 5-acetoxy-6-bromo-2-(bromomethyl)-1-methyl-1H-indole-3-carboxylate (2e) (0.500 g, $1.15 \mathrm{mmol})$ in DCM $(6.6 \mathrm{~mL})$ was added and stirred on ice for six hours. Upon completion, the reaction mixture was neutralized with acetic acid, diluted with $\mathrm{DCM}$ and the organic layer was separated. The organic layer was washed with water, brine, dried over $\mathrm{Na}_{2} \mathrm{SO}_{4}$, filtered and concentrated in vacuo. The crude residue was purified by flash chromatography on silica gel (ethyl acetate-hexanes 3:7) to afford ethyl 2-(((3-benzoylphenyl)thio)methyl)-6-bromo-5-hydroxy-1-methyl-1H-indole-3-carboxylate (1a) (411.7 mg, $68 \%)$ as a yellow solid. ${ }^{1} \mathrm{H}$ NMR $\left(400 \mathrm{MHz}, \mathrm{CDCl}_{3}\right) \delta 7.60-7.51(\mathrm{~m}, 5 \mathrm{H}), 7.47-7.41(\mathrm{~m}, 2 \mathrm{H}), 7.32-7.20(\mathrm{~m}, 3 \mathrm{H}), 7.13(\mathrm{~s}, 1 \mathrm{H}), 5.23$ $(\mathrm{s}, 1 \mathrm{H}), 4.62(\mathrm{~s}, 2 \mathrm{H}), 4.12(\mathrm{q}, J=7.1 \mathrm{~Hz}, 2 \mathrm{H}), 3.54(\mathrm{~s}, 3 \mathrm{H}), 1.23(\mathrm{t}, J=7.2 \mathrm{~Hz}, 3 \mathrm{H}) ;{ }^{13} \mathrm{C} \mathrm{NMR}\left(100 \mathrm{MHz}, \mathrm{CDCl}_{3}\right) \delta 195.9,165.1,147.8$, $143.5,138.4,137.2,136.5,134.6,133.8,132.7,132.6,130.1,129.4,128.9,128.5,127.0,112.6,107.6,107.1,105.3,59.9,30.4$, 29.4, 14.6. HRMS (ESI): Calculated for $\mathrm{C}_{26} \mathrm{H}_{23} \mathrm{BrNO}_{4} \mathrm{~S}[\mathrm{M}+\mathrm{H}]^{+} 524.0526$, found: 524.0522 .

Ethyl 2-(((3-benzoylphenyl)thio)methyl)-6-bromo-4-((dimethylamino)methyl)-5-hydroxy-1-methyl-1H-indole-3-carboxylate (1b)

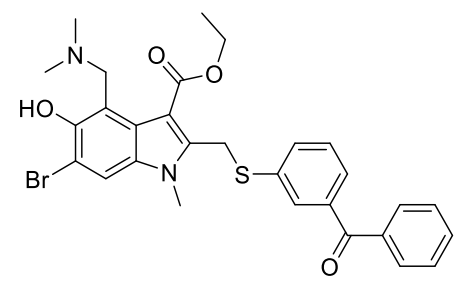

Ethyl 2-(((3-benzoylphenyl)thio)methyl)-6-bromo-5-hydroxy-1-methyl-1H-indole-3-carboxylate (1a) (204.4 mg, 0.39 mmol) was dissolved in 1,4-dioxane $(2 \mathrm{~mL}), N, N, N^{\prime}, N^{\prime}$-tetramethyldiaminomethane $(160.0 \mu \mathrm{L}, 1.17 \mathrm{mmol})$ was added and the reaction mixture was heated to reflux for six hours. The solvent was removed and the residue was purified by reversed phase HPLC using a linear acetonitrile gradient with $0.1 \%$ of FA $(0 \rightarrow 90 \% \mathrm{MeCN})$ to afford ethyl 2-(((3-benzoylphenyl)thio)methyl)-6-bromo-4((dimethylamino)methyl)-5-hydroxy-1-methyl-1H-indole-3-carboxylate (1b) $(172.3 \mathrm{mg}, 76 \%)$ as a yellow solid. ${ }^{1} \mathrm{H}$ NMR (400 $\left.\mathrm{MHz}, \mathrm{CDCl}_{3}\right) \delta 7.71-7.65(\mathrm{~m}, 4 \mathrm{H}), 7.61-7.56(\mathrm{~m}, 1 \mathrm{H}), 7.53-7.49(\mathrm{~m}, 2 \mathrm{H}), 7.45-7.34(\mathrm{~m}, 3 \mathrm{H}), 4.57(\mathrm{~s}, 4 \mathrm{H}), 4.18(\mathrm{q}, J=7.1 \mathrm{~Hz}$, $2 \mathrm{H}), 3.63(\mathrm{~s}, 3 \mathrm{H}), 2.53(\mathrm{~s}, 6 \mathrm{H}), 1.31(\mathrm{t}, J=7.1 \mathrm{~Hz}, 3 \mathrm{H}) ;{ }^{13} \mathrm{C} \mathrm{NMR}\left(100 \mathrm{MHz}, \mathrm{CDCl}_{3}\right) \delta 195.8,165.5,151.6,141.9,138.6,137.1,136.5$, 134.8, 133.9, 132.9, 132.3, 130.0, 129.6, 129.0, 128.5, 124.9, 114.0, 113.2, 60.6, 57.5, 43.4, 30.6, 30.5, 14.4. HRMS (ESI): Calculated for $\mathrm{C}_{29} \mathrm{H}_{30} \mathrm{BrN}_{2} \mathrm{O}_{4} \mathrm{~S}[\mathrm{M}+\mathrm{H}]^{+} 581.1104$, found: 581.1100 .

Ethyl 2-(((3-benzoylphenyl)thio)methyl)-6-bromo-5-hydroxy-1-methyl-4-((methyl(prop-2-yn-1-yl)amino)methyl)-1H-indole-3carboxylate (1)<smiles>C#CCN(C)Cc1c(O)c(Br)cc2c1c(C(=O)OCC)c(CSc1cccc(C(=O)c3ccccc3)c1)n2C</smiles> 
Ethyl 2-(((3-benzoylphenyl)thio)methyl)-6-bromo-4-((dimethylamino)methyl)-5-hydroxy-1-methyl-1H-indole-3-carboxylate (1b) $(57.0 \mathrm{mg}, 98.0 \mu \mathrm{mol})$ was dissolved in 1,4-dioxane $(5.5 \mathrm{~mL}), \mathbf{N}$-methylprop-2-yn-1-amine, TFA salt (4) (20.3 mg, $0.11 \mathrm{mmol})$ and DIPEA $(51.2 \mu \mathrm{L}, 0.29 \mathrm{mmol})$ were added and the reaction mixture was heated at $50^{\circ} \mathrm{C}$ overnight. The solvent was removed and the residue was purified by reversed phase HPLC using a linear acetonitrile gradient with $0.1 \%$ of FA $(0 \rightarrow 90 \% \mathrm{MeCN})$ to afford ethyl 2-(((3-benzoylphenyl)thio)methyl)-6-bromo-5-hydroxy-1-methyl-4-((methyl(prop-2-yn-1-yl)amino)methyl)-1H-indole-3carboxylate (1) $(35.1 \mathrm{mg}, 59 \%)$ as a yellow oil. ${ }^{1} \mathrm{H} \mathrm{NMR}\left(400 \mathrm{MHz}, \mathrm{CDCl}_{3}\right) \delta 7.72-7.64(\mathrm{~m}, 4 \mathrm{H}), 7.59-7.51(\mathrm{~m}, 2 \mathrm{H}), 7.43(\mathrm{~s}, 1 \mathrm{H})$, $7.41-7.35(\mathrm{~m}, 3 \mathrm{H}), 4.54(\mathrm{~s}, 2 \mathrm{H}), 4.22(\mathrm{~s}, 2 \mathrm{H}), 4.16(\mathrm{q}, J=7.2 \mathrm{~Hz}, 2 \mathrm{H}), 3.63(\mathrm{~s}, 3 \mathrm{H}), 3.39(\mathrm{~d}, J=2.6 \mathrm{~Hz}, 2 \mathrm{H}), 2.39(\mathrm{~s}, 3 \mathrm{H}), 2.27(\mathrm{t}, J=$ $2.4 \mathrm{~Hz}, 1 \mathrm{H}), 1.30(\mathrm{t}, J=6.8 \mathrm{~Hz}, 3 \mathrm{H}) ;{ }^{13} \mathrm{C} \mathrm{NMR}\left(100 \mathrm{MHz}, \mathrm{CDCl}_{3}\right) \delta 195.8,165.6,151.0,141.0,138.5,137.1,136.7,134.6,134.1$, $132.8,132.1,130.0,129.5,129.0,128.4,124.0,112.9,112.7,108.6,106.7,74.7,60.6,56.5,44.9,40.7,30.4,30.2$, 14.4. HRMS (ESI): Calculated for $\mathrm{C}_{31} \mathrm{H}_{30} \mathrm{BrN}_{2} \mathrm{O}_{4} \mathrm{~S}[\mathrm{M}+\mathrm{H}]^{+} 605.1104$, found: 605.1098 .

Plasmids and antibodies

pCMV14-3X-Flag-SARS-CoV-2 S (Wuhan strain) was a gift from Zhaohui Qian (Addgene plasmid \#145780; http://n2t.net/addgene:145780; RRID:Addgene_145780) 3. pcDNA3.4-SARS-CoV-2 S-FLAG (strains B.1.1.7 "UK" and B.1.351 "SA"; B.1.1.7 features Del69-70, Del144, N501Y, A570D, D614G, P681H, T716I, S982A, D1118H mutations and B.1.351 features D80A, K417N, E484K, N501Y, A701V mutations versus the reference Wuhan strain) were a gift from Brian Quinlan of Farzan lab. pCAGGSSARS-CoV-2 S-FLAG (Wuhan strain) used in PV experiments was codon-optimized and synthesized based on protein sequence (GenBank YP_009724390) with the addition of FLAG tag at the C-terminus. pLVX-EF1alpha-SARS-CoV-2-M-2xStrep-IRES-Puro (Addgene plasmid \#141386; http://n2t.net/addgene:141386; RRID:Addgene_141386) and pLVX-EF1alpha-SARS-CoV-2-E-2xStrepIRES-Puro (Addgene plasmid \#141385; http://n2t.net/addgene:141385; RRID:Addgene_141385) were both gifts from Nevan Krogan ${ }^{4}$. pcDNA3-SARS-CoV-2-S-RBD-8His (Addgene plasmid \#145145; http://n2t.net/addgene:145145; RRID:Addgene_145145) and pcDNA3-sACE2(WT)-8His (Addgene plasmid \#149268; http://n2t.net/addgene:149268; RRID:Addgene_149268) were both gifts from Erik Procko 5 . FLAG-tagged ORF clone of viral ORF for HA1 [Influenza A virus (A/Puerto Rico/8/1934(H1N1))] (\#VC102476) was obtained from Origene. FLAG-tagged ORF clone of Homo sapiens transmembrane protease, serine 2 (TMPRSS2) (\#OHu61060) was obtained from GenScript. Rabbit polyclonal antibody (pAb) against DYKDDDDK (FLAG) (\#2368S, 1/1,000 in 5\% milk in TBST) and mouse monoclonal antibody (mAb) against $\beta$-tubulin (\#86298S, 1/1,000 in 5\% milk in TBST) were from CST. Mouse mAb against 6*His (His-tag) (\#66005-1-lg, 1/5,000 in 5\% milk in TBST) was from Proteintech. Mouse mAb against Streptag (\#688202, 1/1,000 in 5\% milk in TBST) was from BioLegend. Secondary antibodies anti-rabbit Alexa Fluor 647 (\#711-605-152, $1 / 500$ in 5\% milk in TBST) and anti-mouse Alexa Fluor 647 (\#115-607-003, 1/500 in 5\% milk in TBST) were both from Jackson ImmunoResearch Inc.

\section{Site-Directed Mutagenesis}

pCMV14-3X-Flag-SARS-CoV-2 S (Wuhan strain) was used for PCR-based site-directed mutagenesis to generate the corresponding mutated pCMV14-3X-Flag-SARS-CoV-2 S sequences. Afterwards, the PCR reactions were incubated with Dpnl (New England BioLabs Inc., $37^{\circ} \mathrm{C}, 12$ hours followed by $80^{\circ} \mathrm{C}$ for 20 minutes) and all expression vectors were propagated via transformation into E. coli DH5 $\alpha$ strain using heat shock. F1062A, L1063A, H1064A and L1024A mutations were obtained through intermediate mutagenesis to facilitate the process with F1062S, L1063P, H1064P and L1024P mutations, respectively. The list of used primers is presented below.

\begin{tabular}{|c|c|l|}
\hline Primer & Sequences - 5' to 3' & Supplier \\
\hline Fwd-S-3xFLAG-F1062S & GTAGTGTCCCTCCACGTCACC & Genewiz \\
\hline Rv-S-3xFLAG-F1062S & GTGGAGGGACACTACTCCGTG & Genewiz \\
\hline Fwd-S-3xFLAG-F1062A & GTAGTGGCCCTCCACGTC & Genewiz \\
\hline Rv-S-3xFLAG-F1062A & GTGGAGGGCCACTACTCC & Genewiz \\
\hline Fwd-S-3xFLAG-L1063P & GTGTTCCCCCACGTCACCTAC & Genewiz \\
\hline Rv-S-3xFLAG-L1063P & GACGTGGGGGAACACTACTCC & Genewiz \\
\hline Fwd-S-3xFLAG-L1063A & GTGTTCGCCCACGTCACC & Genewiz \\
\hline Rv-S-3xFLAG-L1063A & GACGTGGGCGAACACTACTC & Genewiz \\
\hline Fwd-S-3xFLAG-H1064P & GTTCCTCCCCGTCACCTACG & Genewiz \\
\hline Rv-S-3xFLAG-H1064P & GGTGACGGGGAGGAACACTA & Genewiz \\
\hline
\end{tabular}




\begin{tabular}{|c|c|l|} 
Fwd-S-3xFLAG-H1064A & TTCCTCGCCGTCACCTACG & Genewiz \\
\hline Rv-S-3xFLAG-H1064A & GGTGACGGCGAGGAACAC & Genewiz \\
\hline Fwd-S-3xFLAG-S1021A & GAGCTGCCGCCAATCTG & Genewiz \\
\hline Rv-S-3xFLAG-S1021A & GATTGGCGGCAGCTCTAATTTCAG & Genewiz \\
\hline Fwd-S-3xFLAG-L1024P & GCCAATCCGGCTGCAACCAA & Genewiz \\
\hline Rv-S-3xFLAG-L1024P & TGCAGCCGGATTGGCG & Genewiz \\
\hline Fwd-S-3xFLAG-L1024A & GCCAATGCGGCTGCAAC & Genewiz \\
\hline Rv-S-3xFLAG-L1024A & GCAGCCGCATTGGCG & Genewiz \\
\hline Fwd-S-3xFLAG-T1027A & GCTGCAGCCAAGATGTCC & Genewiz \\
\hline Rv-S-3xFLAG-T1027A & CATCTTGGCTGCAGCCAGATT & Genewiz \\
\hline
\end{tabular}

\section{Cell culture and preparation of lysates}

HEK293T cells were maintained in DMEM media. A549 cells were cultured in Ham's F-12K media. All media were supplemented with $10 \%$ fetal calf serum (FCS), non-essential amino acids (NEAA) and penicillin/streptomycin, unless otherwise stated. Cells were grown at $37{ }^{\circ} \mathrm{C}$ under $5 \% \mathrm{CO}_{2}$ atmosphere. Cells were allowed to grow to confluence and were harvested by scraping, centrifuging at $1,500 \times \mathrm{g}$ for three $\mathrm{min}$. at $4{ }^{\circ} \mathrm{C}$ and resuspended in PBS after the centrifugation. Cells were lysed by sonication to form cell lysates, and protein concentration was determined using the Bradford assay.

\section{Preparation of proteomes for gel-based SDS-PAGE experiments}

HEK293T lysate $(2 \mathrm{mg} / \mathrm{mL}, 25 \mu \mathrm{L}$ ) was treated with indicated concentrations of 1 ( $1 \mu \mathrm{L}$ of $25 \mathrm{x}$ stock in DMSO) for one hour at r.t. followed by 20 min UV irradiation on ice. Click chemistry was initiated by the addition of TAMRA azide (Sigma-Aldrich, $125 \mu$ M, 25x stock in DMSO), tris(2-carboxyethyl)phosphine hydrochloride (TCEP, Alfa Aesar, $1 \mathrm{mM}$, fresh 50x stock in water), tris[(1benzyl-1H-1,2,3-triazol-4- yl)methyl]amine (TBTA, Sigma-Aldrich, $100 \mu \mathrm{M}, 16 x$ stock in DMSO:t-BuOH 1:4), and copper(II) sulfate ( $1 \mathrm{mM}, 50 \mathrm{x}$ stock in water) to the lysate and incubated in the dark for one hour at r.t. SDS-PAGE reducing loading buffer (4x) was added and proteins were separated using a SDS-PAGE gel. Gels were visualized using an Azure Biosystems Sapphire Biomolecular Imager, then stained using Coomassie. Images were quantified with ImageJ ${ }^{6}$ (V1.51).

\section{Gel-based in situ competitive assay}

HEK293T cells were seeded in a 6-well plate $(600,000$ cells/well in $2.5 \mathrm{~mL}$ DMEM $10 \%$ FCS without Pen/Strep) and left to attach overnight. Media was then supplemented with indicated concentrations of ARB (1,000x stock in DMSO) or DMSO and cultured for one hour followed by addition of $1(100 \mu \mathrm{M}, 1,000$ x stock in DMSO) and subsequent four-hour co-incubation. Cells were then UV-irradiated on ice for $20 \mathrm{~min}$, collected and lysed as described above. Lysate preparation, click chemistry, reducing SDS-PAGE and visualization were performed as described above.

\section{Transfection, gel-based in vitro competitive assays and western blotting}

HEK293T cells were seeded (6,000,000 cells in $18 \mathrm{~mL}$ DMEM 10\% FCS without Pen/Strep) in a $10 \mathrm{~cm}$ Petri dish and left overnight to attach. Cells were transfected using a mixture of $96 \mu \mathrm{g}$ PEI MAX 40K (Polysciences Inc.) and $24 \mu \mathrm{g}$ plasmid DNA in $2 \mathrm{~mL}$ OptiMEM. After 24 or 48 hours, cells were harvested and lysed as described above. Lysates were treated with indicated concentrations of ARB (25x stock in DMSO) for one hour at r.t. followed by 1 (100 $\mu \mathrm{M}, 25 x$ stock in DMSO) co-treatment for one hour at r.t. Subsequent UV-crosslinking, click chemistry, reducing SDS-PAGE and visualization were performed as described above. Proteins were then transferred to a PVDF membrane using a Mini Trans-Blot transfer system (Bio-Rad). Membrane was blocked with $5 \%$ milk in Tris-Buffered Saline with 0.1\% Tween 20 (TBST) for one hour. Indicated primary antibodies were then added and incubated overnight at $4^{\circ} \mathrm{C}$. Membrane was washed three times for three minutes with TBST and incubated for one hour at r.t. with the corresponding secondary antibodies. Membrane was again washed three times for three minutes with TBST and visualized with a Sapphire Biomolecular Imager (Azure Biosystems). 


\section{Competitive LC-MS/MS identification of ARB cellular protein targets}

A549 cells were plated (F-12K 10\% FCS without Pen/Strep) in a $10 \mathrm{~cm}$ Petri dish. When their confluency reached approximately $60 \%$, cell culture media was replaced and supplemented with $10 \mu \mathrm{M}$ ARB (1,000x stock in DMSO) or DMSO and cultured for one hour followed by addition of $\mathbf{1}(100 \mu \mathrm{M}, 1,000 x$ stock in DMSO) and subsequent four-hour co-incubation. Cells were then UVirradiated, collected and lysed as described above. Lysates $(2.32 \mathrm{mg} / \mathrm{mL}, 645 \mu \mathrm{L})$ were subjected to click chemistry using biotin azide (150 $\mu \mathrm{M}, 50 x$ stock in DMSO), TCEP (1 mM, 50x fresh stock in water), TBTA (100 $\mu \mathrm{M}, 16 \mathrm{x}$ stock in DMSO:t-BuOH 1:4), and copper(II) sulfate ( $1 \mathrm{mM}, 50 x$ stock in water) for one hour at $\mathrm{r}$.t. Protein was precipitated by adding methanol/chloroform/water $(4: 1: 3 \mathrm{v} / \mathrm{v})$ to the reaction mixture and the turbid mixture was centrifuged for five minutes at $14,000 \times \mathrm{g}$ at $4^{\circ} \mathrm{C}$ yielding a protein layer between the aqueous and organic layers. The protein layer was isolated, dried and solubilized in $2 \%$ SDS in PBS via sonication. The proteome was centrifuged at $4,700 \times \mathrm{g}$ for five minutes and the supernatant was transferred to a new tube. PBS was added to give a final SDS concentration of $0.2 \%$. Streptavidin agarose beads ( $150 \mu \mathrm{L}$, ProteoChem) were added and the mixture was rotated overnight at r.t. Beads were washed with $1 \%$ SDS in PBS (1x $10 \mathrm{~mL})$, PBS ( $3 \times 10 \mathrm{~mL})$, and water (3x $10 \mathrm{~mL})$. Beads were resuspended in $6 \mathrm{M}$ urea in PBS $(500 \mu \mathrm{L})$, reduced with $10 \mathrm{mM}$ neutralized TCEP (200 mM fresh stock in water) for 30 minutes at r.t. and alkylated with $25 \mathrm{mM}$ iodoacetamide ( $400 \mathrm{mM}$ fresh stock in water) for 30 minutes at r.t. in the dark. Beads were pelleted by centrifugation (1'400 x g, 2 minutes) and resuspended in $150 \mu \mathrm{L}$ of $2 \mathrm{M}$ urea in $50 \mathrm{mM} \mathrm{NH}_{4} \mathrm{HCO}_{3}, 1 \mathrm{mM} \mathrm{CaCl}$ (100x stock in water) and trypsin (Thermo Scientific, $1.5 \mu \mathrm{L}$ of $0.5 \mu \mathrm{g} / \mu \mathrm{L}$ ). The digestion was performed for 12 hours at $37^{\circ} \mathrm{C}$. Samples were acidified to a final concentration of $5 \%$ acetic acid, desalted over a self-packed $\mathrm{C}_{18}$ spin column and dried. Samples were analyzed by LC-MS/MS (described below) and the MS data were processed with MaxQuant (described below). Statistical significance analysis was performed using Perseus under false discovery rate of $5 \%$ and an $\mathrm{S}_{0}$ of 2 , indicating an adjusted $\mathrm{p}$-value of 0.05 .

\section{LC-MS/MS analysis}

Peptides were resuspended in water with $0.1 \%$ formic acid (FA) and analyzed using EASY-nLC 1200 nano-UHPLC coupled to a Q Exactive HF-X Quadrupole-Orbitrap mass spectrometer (Thermo Scientific). The chromatography column consisted of a $50 \mathrm{~cm}$ long, $75 \mu \mathrm{m}$ i.d. microcapillary capped by a $5 \mu \mathrm{m}$ tip and packed with ReproSil-Pur $120 \mathrm{C}_{18}-\mathrm{AQ} 2.4 \mu \mathrm{m}$ beads (Dr. Maisch GmbH). LC solvents were $0.1 \% \mathrm{FA}$ in $\mathrm{H}_{2} \mathrm{O}$ (Buffer $\mathrm{A}$ ) and $0.1 \% \mathrm{FA}$ in $90 \% \mathrm{MeCN}: 10 \% \mathrm{H}_{2} \mathrm{O}$ (Buffer $\mathrm{B}$ ). Peptides were eluted into the $\mathrm{MS}$ at a flow rate of $300 \mathrm{~nL} / \mathrm{min}$. over a $240 \mathrm{~min}$. linear gradient (5-35\% Buffer $\mathrm{B}$ ) at $65^{\circ} \mathrm{C}$. Data was acquired in data-dependent mode (top-20, NCE 28, $R=7,500$ ) after full MS scan ( $R=60,000, \mathrm{~m} / \mathrm{z} 400-1,300)$. For purified proteins experiments, peptides were eluted into the $\mathrm{MS}$ at a flow rate of $300 \mathrm{~nL} / \mathrm{min}$. over a $30 \mathrm{~min}$. linear gradient (5-35\% Buffer $\mathrm{B})$ at $65{ }^{\circ} \mathrm{C}$. Data was acquired in data-dependent mode (top-20, NCE 28, $R=30,000)$ after full MS scan $(R=60,000, \mathrm{~m} / \mathrm{z} 400-1,300)$. Dynamic exclusion was set to $10 \mathrm{~s}$, peptide match to prefer and isotope exclusion was enabled.

\section{Max Quant analysis}

The MS data was analyzed with MaxQuant ${ }^{7}$ (V1.6.1.0) and searched against the human proteome (Uniprot) and a common list of contaminants (included in MaxQuant). The first peptide search tolerance was set at $20 \mathrm{ppm}, 10 \mathrm{ppm}$ was used for the main peptide search and fragment mass tolerance was set to $0.02 \mathrm{Da}$. The false discovery rate for peptides, proteins and sites identification was set to $1 \%$. The minimum peptide length was set to 6 amino acids and peptide re-quantification and label-free quantification (MaxLFQ) were enabled. The minimal number of peptides per protein was set to two. Methionine oxidation was searched as a variable modification and carbamidomethylation of cysteines was searched as a fixed modification. Trypsin was used as protease allowing up to 2 miss-cleavages. For LiP experiments, both trypsin and proteinase $\mathrm{K}$ were used with up to 10 miss-cleavages.

\section{Competitive gel-based in situ S-3xFLAG, M-2xStrep and E-2xStrep 1 pulldowns}

HEK293T cells were seeded (6,000,000 cells in $18 \mathrm{~mL}$ DMEM 10\% FCS without Pen/Strep) in a $10 \mathrm{~cm}$ Petri dish and left overnight to attach. Cells were transfected using a mixture of $96 \mu \mathrm{g}$ PEI MAX 40K (Polysciences Inc.) and $24 \mu \mathrm{g}$ corresponding protein cDNA in $2 \mathrm{~mL}$ Opti-MEM. After 48 hours, compound treatment, proteome preparation and enrichment steps were carried out same as described above for LC-MS/MS-based 1 pulldown. ARB treatment was performed at final concentrations of 10 or $30 \mu \mathrm{M}$, where applicable. Washed beads were resuspended in $35 \mu \mathrm{L}$ SDS-PAGE reducing loading buffer $(4 \mathrm{x})$ and boiled at $95^{\circ} \mathrm{C}$ for 15 min to elute proteins. SDS-PAGE separation and western blotting of eluted protein samples were then performed as previously described. 


\section{Thermal Shift Assay (TSA)}

HEK293T cells were seeded (6,000,000 cells in $18 \mathrm{~mL}$ DMEM 10\% FCS without Pen/Strep) in a $10 \mathrm{~cm}$ Petri dish and left overnight to attach. S-3xFLAG, S-FLAG or E-Strep were then overexpressed as described above. At 48 hours post-transfection, cells were harvested and lysed as described above. Lysates containing overexpressed S-FLAG or E-Strep (1 mg/mL, $1.1 \mathrm{~mL}) \mathrm{were}$ treated with $30 \mu \mathrm{M}$ ARB (1,000x stock in DMSO) or DMSO for one hour at r.t. and then distributed by $100 \mu \mathrm{L}$ into PCR tubes each corresponding to the 10 temperature points of the range. Samples were heated at the designated temperatures for three min in the thermal cycler, then vortexed briefly and centrifuged at $20,000 \times \mathrm{g}$ for $20 \mathrm{~min}$ at $4{ }^{\circ} \mathrm{C}$. The supernatants containing the soluble protein fraction were transferred to a new tube and separated by SDS-PAGE, proteins were transferred on PVDF membranes and western blotting was performed as described above. The protein band signal was subsequently quantified, data were processed and the melting temperatures $\left(\Delta \mathrm{T}_{\mathrm{m}}\right)$ were determined using GraphPad Prism software.

\section{Limited Proteolysis Mass Spectrometry (LiP-MS) experiments}

Recombinant S-His protein (SinoBiological, \#40589-V08B1) in PBS $(20 \mu \mathrm{g} / \mathrm{mL} ; 50 \mu \mathrm{L})$ was incubated with $30 \mu \mathrm{M}$ ARB $(1 \mu \mathrm{L}$ of $50 \mathrm{x}$ stock in DMSO) or DMSO for one hour at r.t. Proteinase K (NEB, $1 \mu \mathrm{L}$ of 50x stock in PBS for final 1:100 w/w ratio to S-His) was then added and incubated at $24{ }^{\circ} \mathrm{C}$ for exactly one min. Samples were then boiled for $10 \mathrm{~min}$ at $95{ }^{\circ} \mathrm{C}$ to inactivate proteinase $\mathrm{K}$ and ensure only partial S-His digestion. Proteins were then denatured in $6 \mathrm{M}$ urea in $50 \mathrm{mM} \mathrm{NH}_{4} \mathrm{HCO}_{3}$, reduced with 10 mM neutralized TCEP ( $200 \mathrm{mM}$ fresh stock in water) for 30 minutes at r.t. and alkylated with $25 \mathrm{mM}$ iodoacetamide (400 mM fresh stock in water) for 30 minutes at r.t. in the dark. Samples were diluted to $2 \mathrm{M}$ urea with $50 \mathrm{mM} \mathrm{NH}_{4} \mathrm{HCO}_{3}$, and digested with trypsin (Thermo Scientific, $1 \mu \mathrm{L}$ of $50 \mathrm{ng} / \mu \mathrm{L}$ ) in the presence of $1 \mathrm{mM} \mathrm{CaCl}_{2}$ (100x stock in water). The digestion was performed for 12 hours at $37^{\circ} \mathrm{C}$. Samples were acidified to a final concentration of $5 \%$ acetic acid, desalted over a self-packed $C_{18}$ spin column, and dried. Samples were analyzed by LC-MS/MS (see above), and the MS data were processed with MaxQuant (see above). Statistical significance analysis was performed using Perseus ${ }^{8}$ under false discovery rate of $0.5 \%$ and an $S_{0}$ of 2 , indicating an adjusted $p$-value of 0.005 .

\section{Gel-based ARB analog testing on recombinant S-His}

Recombinant S-His protein in PBS $(40 \mu \mathrm{g} / \mathrm{mL} ; 25 \mu \mathrm{L})$ was incubated with indicated concentrations of ARB, 2, 3 (1 $\mu \mathrm{L}$ of $25 \mathrm{x}$ stock in DMSO) or DMSO for one hour at r.t. followed by $1(100 \mu \mathrm{M}, 25 x$ stock in DMSO) co-treatment for one hour at r.t. Subsequent UV-crosslinking, click chemistry, reducing SDS-PAGE and visualization were performed as described above. S-His was then silver stained in-gel to verify equal loading.

\section{MLV pseudovirus production (PV)}

HEK293T cells were transfected in T75 format one day after plating, at a confluency of approximately $60 \%$, by calcium phosphate method. Total DNA of $24 \mu \mathrm{g}$ per flask was comprised of the retroviral vector pQCXIX encoding firefly luciferase, a plasmid expressing MLV gag and pol (Choe lab), and SARS-CoV-2 S protein of the given strain, at a ratio of 5:5:1. Transfection complexes were washed off after 6 hours and replaced with complete DMEM (DMEM + 10\% FBS + 1\% Pen/Strep + 1X GlutaMAX-I). Culture supernatants containing PVs were harvested at 43 hours after transfection and cleared by $0.45 \mu \mathrm{m}$ filtration. PV vector genomes (vg) were quantified by RT-qPCR with High Capacity cDNA Reverse Transcription Kit (Applied Biosystems), Luna Universal Probe qPCR Master Mix (New England Biolabs), and a primer-probe set targeting the CMV promoter of pQCXIX (Fwd: TCACGGGGA TTTCCAAGTCTC, Rev: AATGGGGCGGAGTTGTTACGAC, Probe: AAACAAACTCCCATTGACGTCA). Known quantities of pQCXIX vector were used to generate a standard curve.

\section{PV Infection Assay}

hACE2-293T cells previously described ${ }^{9}$ were plated in 48-well plate such that their confluency at the time of infection was approximately $40 \%$. PVs were diluted in complete DMEM to $2.5 \times 10^{8} \mathrm{vg} / 75 \mu \mathrm{L}$ and mixed 1:1 with the test compounds or vehicle control, also prepared in complete DMEM. Virus and test compound were incubated for one hour at r.t. in the dark. For experiments in which only PVs and test compound were preincubated, cells were maintained at 37으 in complete DMEM during this time. For experiments in which both PVs and cells were preincubated with test compound, cell culture media was replaced with $140 \mu \mathrm{L}$ of the test compound preparation in complete DMEM and cells were returned to 37으 $\mathrm{C}$ wile PVs were incubated at r.t. Next, cell culture supernatant was replaced with $140 \mu \mathrm{L}$ of the PV-compound mixture per well. Cells and PVs were incubated for three hours at $37^{\circ} \mathrm{C}$ before removing the supernatant and replacing with complete DMEM. At $24 \mathrm{~h}$ post infection, luciferase activity was measured using the Luc-Pair Firefly Luciferase HS Assay Kit (GeneCopoeia) according to the manufacturer's instructions. 


\section{Transfection, in situ ARB treatment and western blotting}

HEK293T cells were seeded (600,000 cells/well in $2.5 \mathrm{~mL}$ DMEM 10\% FCS without Pen/Strep) in a 6-well plate and left overnight to attach. Cells were transfected using a mixture of $12 \mu \mathrm{g}$ PEI MAX 40K (Polysciences Inc.) and $3 \mu \mathrm{g}$ pCMV14-3X-Flag-SARS-CoV-2 $\mathrm{S}$ in $300 \mu \mathrm{L}$ Opti-MEM. After 24 hours, cell culture media was replaced and supplemented with indicated concentrations of either ARB alone (1,000x stock in DMSO) or ARB together with chloroquine (1.000x stock in DMSO) or MG132 (1,000x stock in DMSO) and cultured for 16 hours. Cells were then directly lysed in the wells with RIPA buffer, followed by western blotting as described above.

Immunofluorescence microscopy

HEK293T cells were seeded (800,000 cells/well) in a 6-well plate and left overnight to attach. S-FLAG was overexpressed using PEI MAX 40K transfection reagent according to protocol of the manufacturer. After 24 hours, S-FLAG-overexpressing cells were dissociated with trypsin, seeded (160,000 cells/well) in 24-well plate on poly-L-lysine coated coverslips and left overnight to attach. Cells were washed one time with PBS and incubated with $10 \mu \mathrm{M}$ ARB (1,000x stock in DMSO) or DMSO for 16 hours at 37 ${ }^{\circ} \mathrm{C}$. Cells were washed one time with $\mathrm{PBS}^{++}$and fixed and permeabilized with ice-cold methanol for $10 \mathrm{~min}$ at $-20^{\circ} \mathrm{C}$. Cells were then washed three times with PBS ${ }^{++}$, blocked with a $5 \%$ bovine serum albumin (BSA) solution in PBS ${ }^{++}$for 30 min at r.t. and washed one time with PBS ${ }^{++} 0.1 \%$ BSA. Rabbit FLAG-directed pAb (CST, \#2368, 1/200 in PBS ${ }^{++} 0.1 \%$ BSA) and mouse LAMP1-directed mAb (CST, \#15665, 1/200 in $\mathrm{PBS}^{++} 0.1 \%$ BSA) were added and incubated for one hour at r.t. Cells were washed three times with PBS ${ }^{++}$ $0.1 \%$ BSA and incubated for one hour at r.t. with anti-rabbit IgG Alexa Fluor 488 (Jackson ImmunoResearch Inc, \# 111-545-003, $1 / 200$ in $\mathrm{PBS}^{++}$0.1\% BSA) and anti-mouse IgG Cy ${ }^{\mathrm{TM}} 3$ (Jackson ImmunoResearch Inc, \# 715-165-150, 1/200 in PBS ${ }^{++} 0.1 \%$ BSA). Cells were washed three times with $\mathrm{PBS}^{++}$, one time with PBS, one time with water and then mounted on a slide with ProLong Gold antifade mountant with DAPI (Life Technologies). Cells were visualized with a BX53 fluorescent microscope (Olympus). 


\section{Supplemental Figures}

\begin{tabular}{l|c|c|c|}
\hline \multicolumn{1}{|c|}{ Protein name } & Gene name & $\begin{array}{c}\text { Log }_{2} \text { fold change } \\
\text { ARB/DMSO }\end{array}$ & $\begin{array}{c}\text { - } \text { Log }_{10} \text { p- } \\
\text { value }\end{array}$ \\
\hline Peroxisome biogenesis factor 10 & PEX10 & -2.41 & 3.42 \\
\hline Monoacylglycerol lipase ABHD6 & ABHD6 & -1.98 & 4.90 \\
\hline Phospholipid scramblase 1 & PLSCR1 & -1.57 & 1.02 \\
\hline Dynamin-1-like protein & DNM1L & -1.46 & 1.64 \\
\hline Transmembrane protein 256 & TMEM256 & -1.21 & 1.72 \\
\hline Mitochondrial ubiquitin ligase & MUL1 & -1.04 & 4.54 \\
\hline Neutral cholesterol ester & NCEH1 & -0.98 & 6.45 \\
\hline
\end{tabular}

Figure S1 Cellular targets of ARB (>50\% competition) identified via LC-MS/MS-based in situ 1 competitive pulldown from A549 cells. 
A

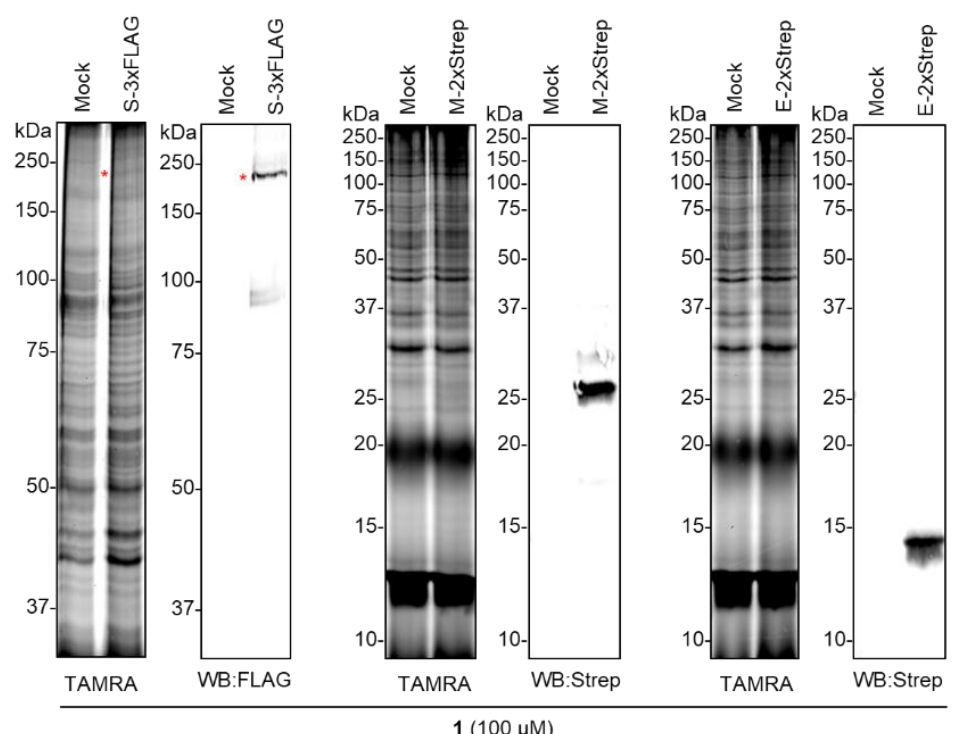

B

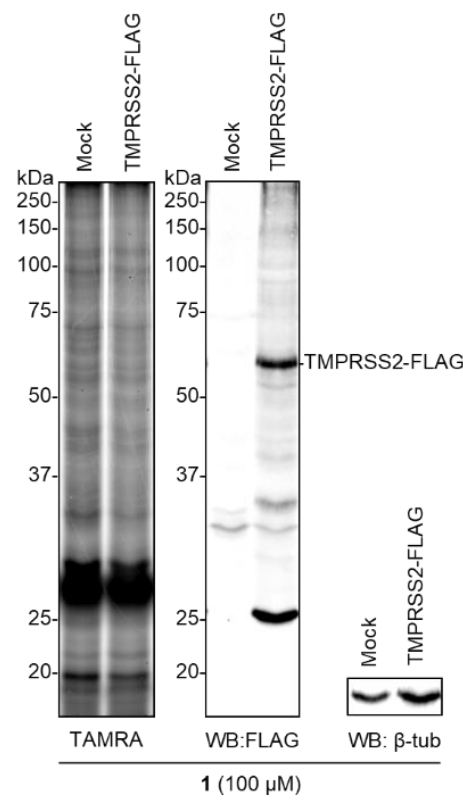

Figure S2 SDS-PAGE-based fluorescence labeling experiments validating the binding of 1 and ARB to SARS-CoV-2 S protein. (a) Full-length TAMRA 1 fluorescence and western blot profiles corresponding to their cropped versions in Fig. 2A. Asterisk indicates the protein of interest. (b) Gel-based in vitro TMPRSS2-FLAG 1 binding assay. HEK293T lysates overexpressing TMPRSS2-FLAG were treated with $100 \mu \mathrm{M} 1$ for $1 \mathrm{~h}$ followed by $20 \mathrm{~min}$ UV irradiation. TAMRA-azide was conjugated via 'click' chemistry, proteins were separated by SDS-PAGE and gel was scanned for fluorescence. Shown are the TAMRA fluorescence profile of $\mathbf{1}$ and western blot membrane probed for FLAG and $\beta$-tubulin. 
A

$$
\begin{aligned}
& \begin{array}{c}
\text { ARB }(30 \mu \mathrm{M}) \\
\text { DMSO }
\end{array} \\
& \text { WB: FLAG } \\
& \text { C }
\end{aligned}
$$

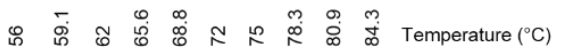

$$
\begin{aligned}
& \text { ARB }(30 \mu \mathrm{M}) \\
& \text { DMSO }
\end{aligned}
$$

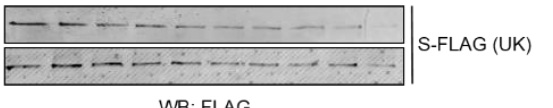

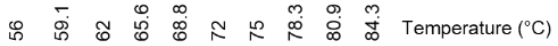

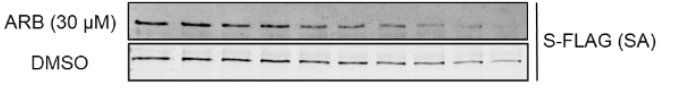

B

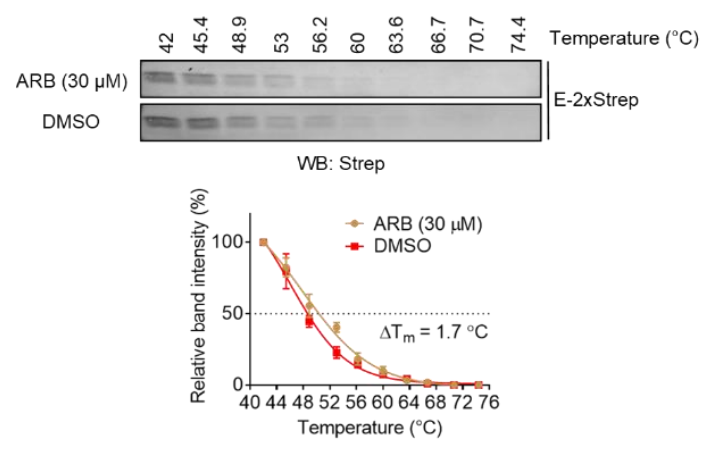

Figure S3 Thermal shift assay (TSA) experiments validating the binding of ARB to SARS-CoV-2 S protein and variants. (a) Western blot membrane probed for FLAG corresponding to the S-3xFLAG (Wuhan strain) TSA experiment quantified in Figure 2D. (b) TSA studying the effect of ARB on thermal stability of E-2xStrep. HEK293T lysates overexpressing E-2xStrep were treated with $30 \mu \mathrm{M}$ ARB or DMSO for $1 \mathrm{~h}$ followed by $3 \mathrm{~min}$ heat treatment at indicated temperatures. Soluble protein fractions were then transferred on western blot membranes, probed for Strep and bands were quantified ( $n=3$, relative values $\pm S D$ and $\Delta T_{m}$ ). (c) Western blot membranes probed for FLAG corresponding to the S-FLAG (B.1.1.7 "UK" and B.1.351 "SA" strains) TSA experiments quantified in Figure 2D. 


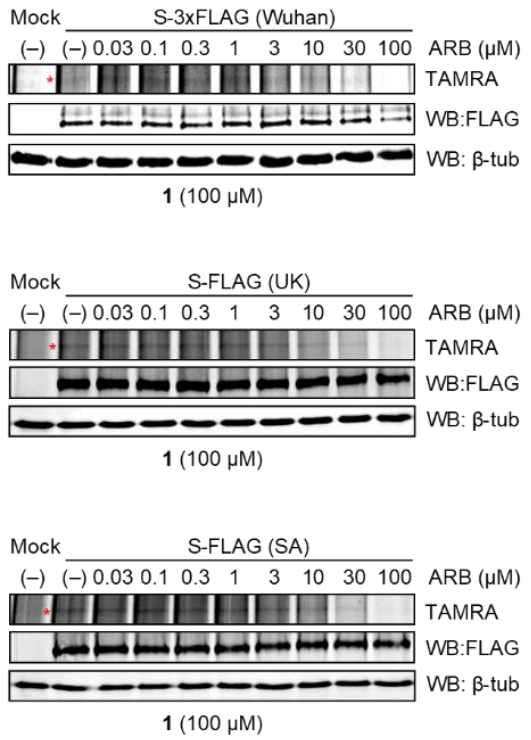

Figure S4 Gel-based competitive in vitro ARB EC 50 measurements for the S protein from SARS-CoV-2 strains Wuhan, B.1.1.7 "UK" and B.1.351 "SA". HEK293T cell lysates overexpressing the indicated S protein variant were pre-treated with indicated concentrations of ARB for $1 \mathrm{~h}$ followed by $1 \mathrm{~h}$ co-treatment with $100 \mu \mathrm{M} 1$ and subsequent 20 min UV irradiation. TAMRA azide was conjugated via 'click' chemistry, proteins were separated by SDS-PAGE and gel was scanned for fluorescence. Shown are the TAMRA fluorescence profile of $\mathbf{1}$ (top), western blot membrane probed for FLAG (middle) and $\beta$-tubulin (bottom) for each corresponding S protein variant. Asterisk indicates protein of interest. 
A

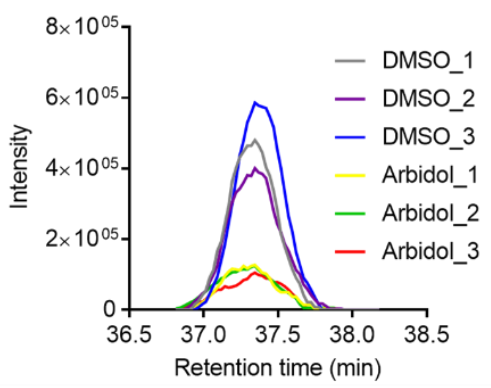

GYHLMSFPQSAPHGVVFLHVT

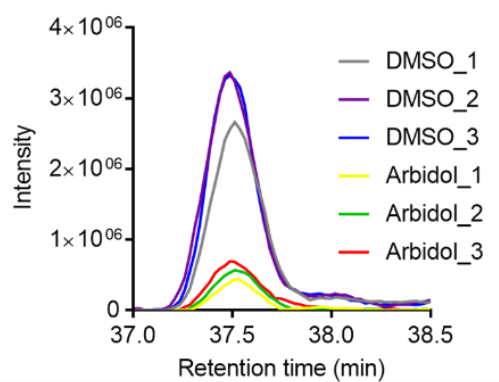

B
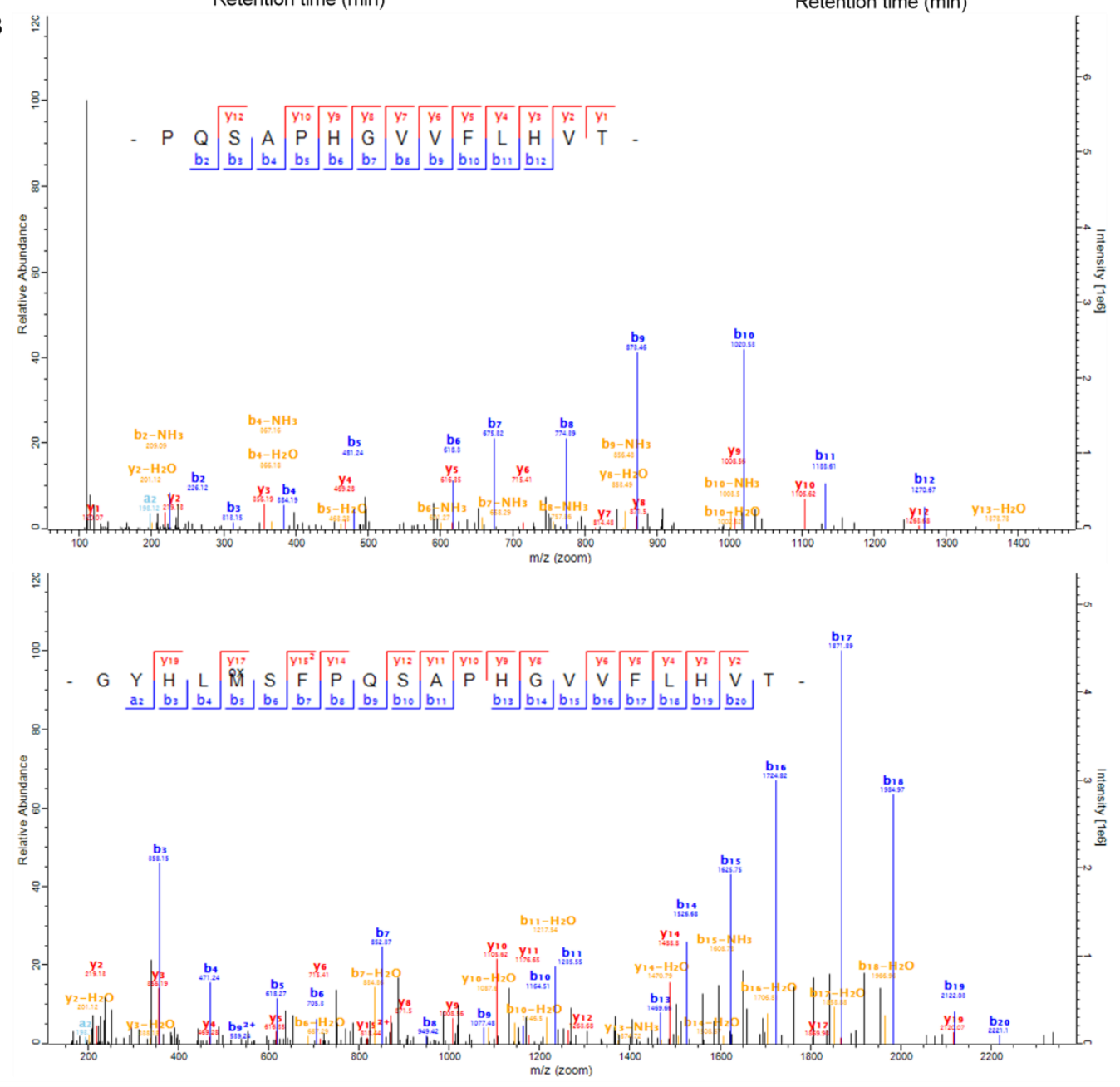

Figure S5 The MS1 extracted ion chromatograms (a) and MS2 fragmentation spectra (b) for GYHLMSFPQSAPHGVVFLHVT and PQSAPHGVVFLHVT peptides significantly decreased in ARB versus DMSO indicating proteolytic protection of the corresponding $S$ protein region by ARB in the LiP-MS experiment. 

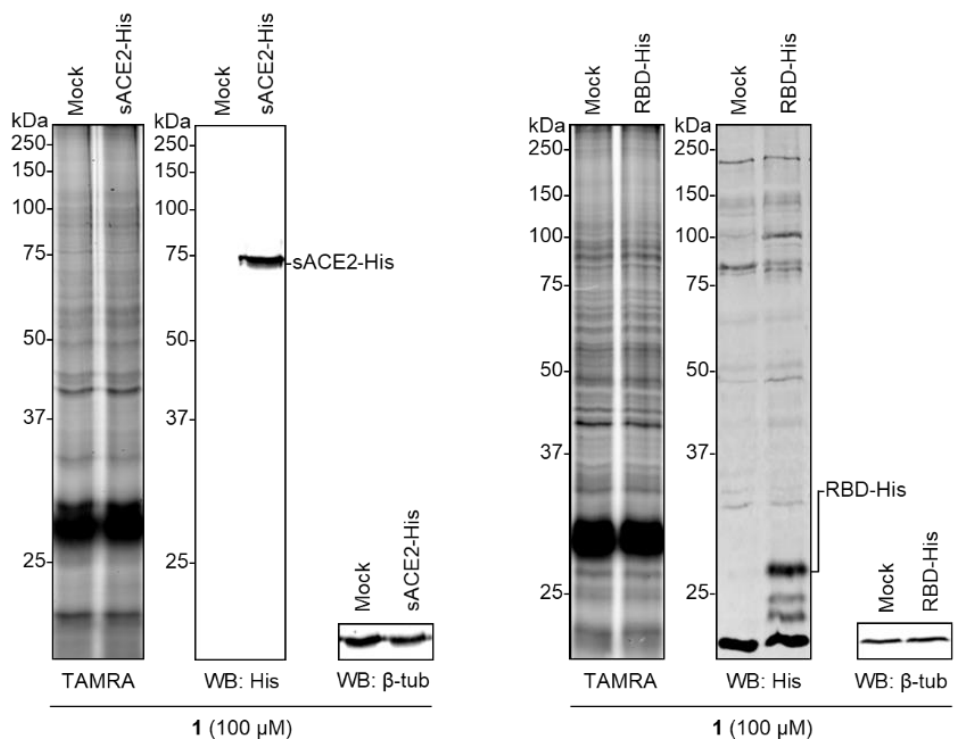

Figure S6 Gel-based in vitro SACE2-His/RBD-His 1 binding assays. HEK293T lysates overexpressing indicated proteins were treated with $100 \mu \mathrm{M} 1$ for $1 \mathrm{~h}$ followed by 20 min UV irradiation. TAMRA azide was conjugated via 'click' chemistry, proteins were separated by SDS-PAGE and gels were scanned for fluorescence. Shown are the TAMRA fluorescence profiles of 1 and western blot membranes probed for His and $\beta$-tubulin. 


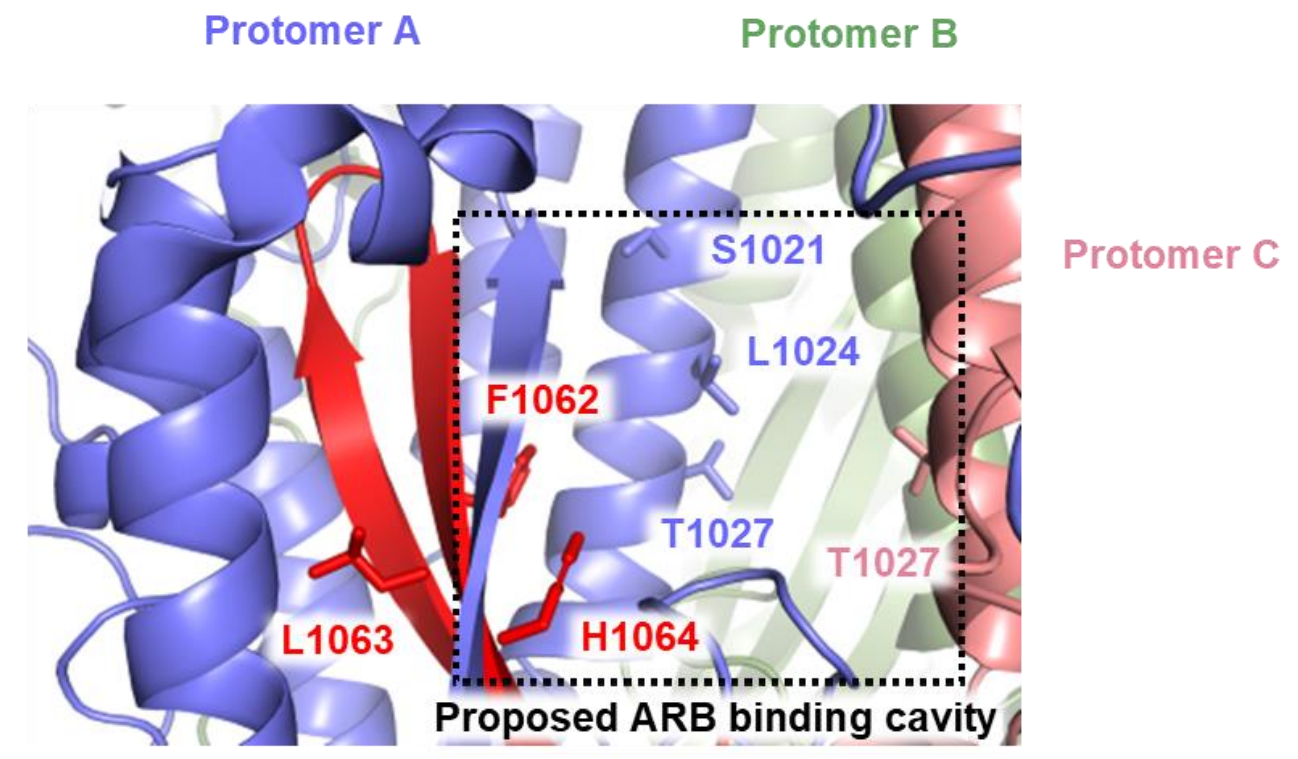

Figure S7 Proposed ARB binding cavity on the SARS-CoV-2 S protein trimerization interface was mapped into the cartoon representation of its cryo-EM structure ( $\mathrm{pdb}$ : $6 \mathrm{vxx}$ ). Protomers $\mathrm{A}, \mathrm{B}$ and $\mathrm{C}$ are shown in blue, green and pink, respectively. ARB binding site of the protomer A identified via LiP-MS [aa 1046-1066] is shown in red. Key residues are highlighted in their respective protomer colors and their side chains are represented as sticks. 


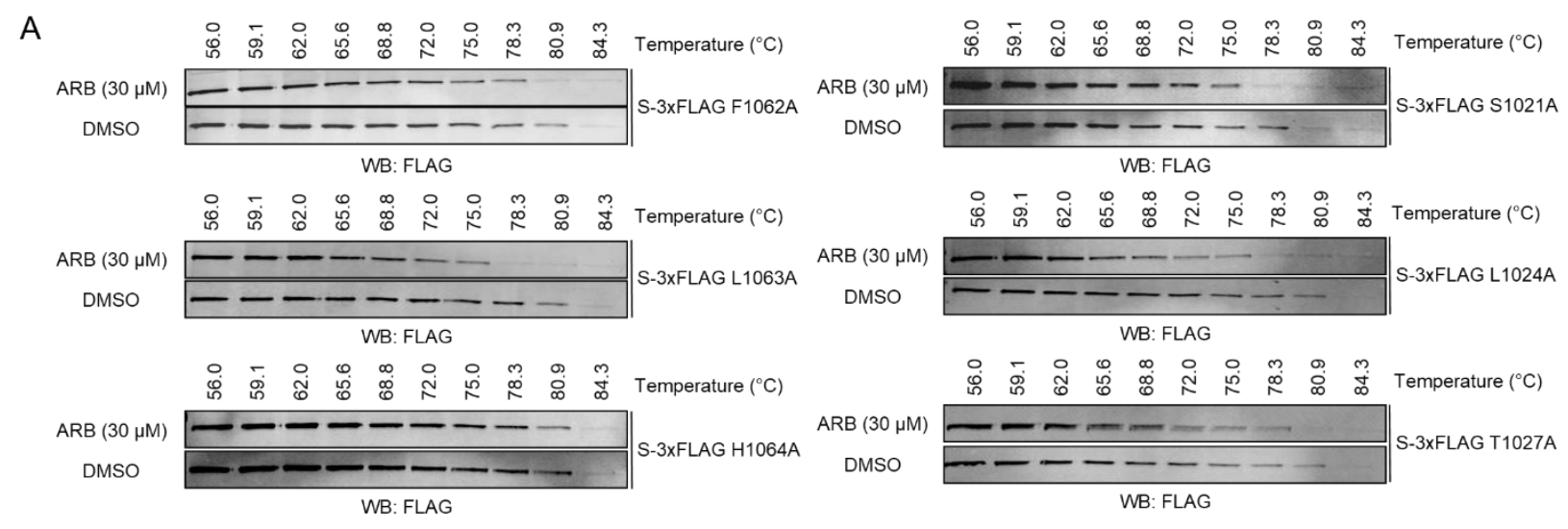

B

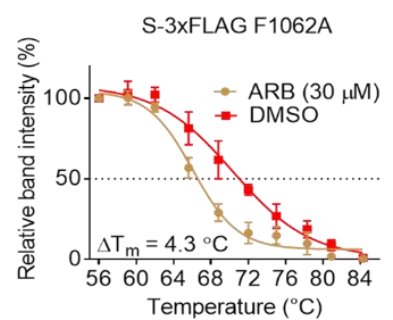

S-3xFLAG L1063A

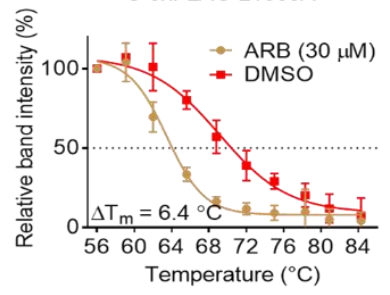

S-3xFLAG H1064A

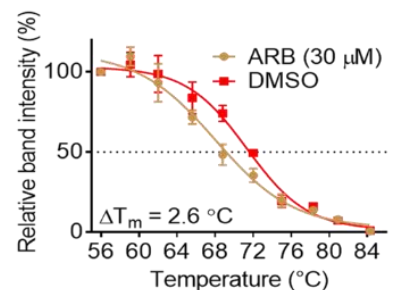

S-3XFLAG S1021A

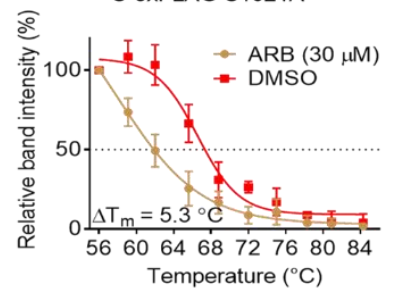

S-3xFLAG L1024A

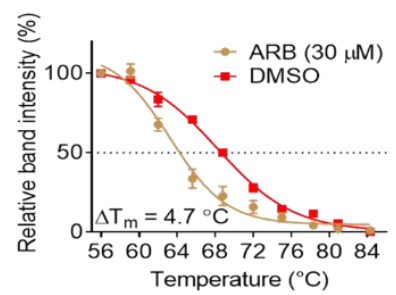

S-3XFLAG T1027A

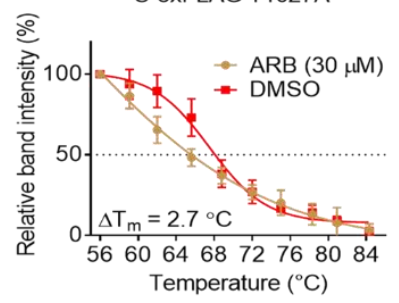

Figure S8 Thermal shift assays with SARS-CoV-2 S-3xFLAG mutants validating the binding region of ARB to the $S$ protein. (a) Western blot membranes probed for FLAG corresponding to the S-3xFLAG mutant TSA experiments and (b) their respective quantification ( $n=3$, relative values \pm SD and $\Delta T$ m). 
A

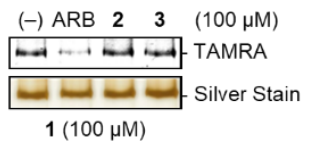

C

$(-) \quad(-) \quad 0.3 \quad 1 \quad 3 \quad 10 \quad \mathrm{MG} 132(\mu \mathrm{M})$ $(-) \quad(+)(+) \quad(+) \quad(+) \quad(+)$ ARB $(10 \mu \mathrm{M})$

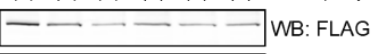

B

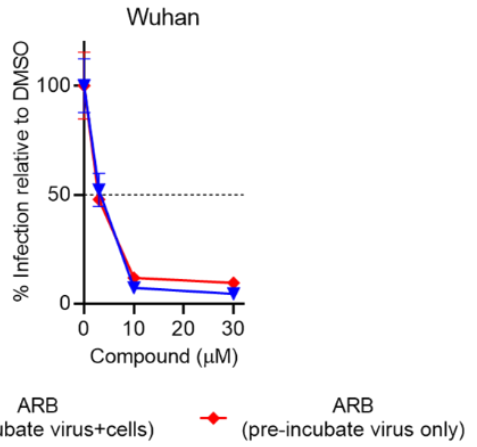

Figure S9 Additional experiments examining ARB inhibition of cell entry of S protein-pseudotyped MLV viruses and ARB-induced lysosomal degradation of the S protein. (a) Gel-based in vitro competitive assay comparing purified S-His binding efficacy of ARB and analogues. S-His was pre-treated with $100 \mu \mathrm{M}$ of indicated compounds for $1 \mathrm{~h}$ followed by $1 \mathrm{~h}$ co-treatment with $100 \mu \mathrm{M} 1$ and subsequent 20 min UV irradiation. Shown are the TAMRA fluorescence profile of 1 and the silver stain. (b) Influence of cell pre-treatment with ARB on ARB-induced inhibition of MLV PV infection. MLV PVs pseudotyped with the S protein (Wuhan strain) were pre-treated with ARB at indicated concentrations for $1 \mathrm{~h}$ and then incubated for $3 \mathrm{~h}$ with hACE2-overexpressing HEK293T cells that were also ARB pre-treated or not. Cells were lysed at $24 \mathrm{~h}$ post-infection, and lysates were probed for luciferase activity. ( $n=3$, relative values \pm SD). (c) Western blot showing no concentration-dependent effect of MG132 co-treatment on ARB-induced S-3xFLAG degradation (top) and GAPDH (bottom). S-3xFLAG overexpressing HEK293T cells were treated with $10 \mu \mathrm{M}$ ARB together with indicated concentrations of MG132 for $16 \mathrm{~h}$. 


\section{Supplemental Tables}

Table S1 List of $100 \mu \mathrm{M}$ 1-enriched proteins from the LC-MS/MS-based competitive in situ pulldown from A549 cells with the corresponding LFQ intensities, $10 \mu \mathrm{M}$ ARB/DMSO fold change ratios and $p$-values. Proteins showing significant intensity decrease in ARB versus DMSO via Perseus statistical analysis are highlighted with '+' in 'Significant' column.

$\begin{array}{cl}\text { Significant } & \text { Majority protein IDs } \\ + & \text { D6RBB0;O60683;D6RA89 } \\ + & \text { Q9BV23;C9JNE7 } \\ + & \text { H7C515;C9J9P4;C9J7K9;O151 } \\ + & \text { G2 } \\ + & \text { K8JLD5;O00429 } \\ + & \text { Q969V5 } \\ + & \text { A0A0R4J2G3;Q6PIU2;A0A0A0 } \\ + & \text { MTJ9;H7C046 } \\ & \text { Q9C0H2 } \\ & \text { Q14204 } \\ & \text { Q8TED1;E7ETY7 } \\ & \text { H3BSM7;Q96GQ5;H3BR29 } \\ & \text { HOY870;H0Y861;Q8TDQ4;Q5 } \\ & \text { SSC2;Q9H0R3;H0Y8D0 } \\ & \text { Q00765;E2QRG8 }\end{array}$

Q8TBP6

Q68D91

Q15012

H7C0X4;Q92685;C9J7S5

A8MT72;Q2NKQ5;Q16799

014494

060725

Q5VV89;014880;Q5VV87

Q9BT22;K7EID2

A0A087WUT6;060841

A0A087WT44;P30519;I3L159;I 3L1F5

A0A0A0MT32;P38571

Q8NBI6;A0A140T9D0

P68366

Q8IUH4

\section{Gene names \\ Protein names}

PEX10

ABHD6

PLSCR1

DNM1L

TMEM256

MUL1

NCEH1

TTYH3

DYNC1H1

GPX8

C16orf58

TMEM222

REEP5

SLC25A40

MBLAC2

LAPTM4A

ALG3

RTN1

PPAP2A

ICMT

MGST3

ALG1

EIF5B

HMOX2

LIPA

XXYLT1

TUBA4A

ZDHHC13
Peroxisome biogenesis factor 10

Monoacylglycerol lipase ABHD6

Phospholipid scramblase 1

Dynamin-1-like protein

Transmembrane protein

256

Mitochondrial ubiquitin ligase activator of NFKB 1 Neutral cholesterol ester hydrolase 1

Protein tweety homolog 3

Cytoplasmic dynein 1 heavy chain 1

Probable glutathione peroxidase 8;Glutathione peroxidase

RUS1 family protein

C16orf58

Transmembrane protein

222

Receptor expression-

enhancing protein

5; Receptor expression-

enhancing protein

Solute carrier family 25

member 40

Metallo-beta-lactamase

domain-containing protein 2

Lysosomal-associated

transmembrane protein $4 \mathrm{~A}$

Dol-P-

Man:Man(5)GlcNAc(2)-PP-

Dol alpha-1,3-

mannosyltransferase

Reticulon;Reticulon-1

Lipid phosphate

phosphohydrolase 1

Protein-S-isoprenylcysteine

O-methyltransferase

Microsomal glutathione S-

transferase 3

Chitobiosyldiphosphodolich

ol beta-

mannosyltransferase

Eukaryotic translation

initiation factor $5 \mathrm{~B}$

Heme oxygenase 2

Lysosomal acid

lipase/cholesteryl ester

hydrolase

Xyloside xylosyltransferase 1

Tubulin alpha-4A chain

Palmitoyltransferase

ZDHHC13
-Log10(p-value)

Log2 fold change $10 \mu \mathrm{M}$ ARB/DMSO

\begin{tabular}{|c|c|}
\hline 3.42 & -2.41 \\
\hline 4.90 & -1.98 \\
\hline 1.02 & -1.57 \\
\hline 1.64 & -1.46 \\
\hline 1.72 & -1.21 \\
\hline 4.54 & -1.04 \\
\hline 6.45 & -0.98 \\
\hline 2.44 & -0.91 \\
\hline 1.26 & -0.90 \\
\hline 5.36 & -0.86 \\
\hline 5.06 & -0.78 \\
\hline 3.03 & -0.77 \\
\hline 4.00 & -0.77 \\
\hline 2.01 & -0.77 \\
\hline 1.70 & -0.75 \\
\hline 2.44 & -0.75 \\
\hline 2.96 & -0.72 \\
\hline 1.47 & -0.68 \\
\hline 1.46 & -0.67 \\
\hline 1.98 & -0.67 \\
\hline 3.35 & -0.66 \\
\hline 2.91 & -0.65 \\
\hline 1.81 & -0.65 \\
\hline 5.26 & -0.65 \\
\hline 1.93 & -0.65 \\
\hline 2.40 & -0.63 \\
\hline 0.99 & -0.63 \\
\hline 0.67 & -0.61 \\
\hline
\end{tabular}

$-2.41$

$-1.98$

$-1.57$

$-1.46$

$-1.21$

$-1.04$

$-0.98$

$-0.91$

$-0.90$

$-0.86$

$-0.78$

$-0.77$

$-0.77$

$-0.77$

$-0.75$

$-0.75$

$-0.72$

$-0.68$

$-0.67$

$-0.67$

0.66

$-0.65$

$-0.65$

$-0.65$

$-0.65$

$-0.63$

$-0.63$

$-0.61$ 
I3L1D9;|3L4B2;O95476;|3L3K5 ;I3L4W0;I3L2R5;I3L0X6

\section{Q6NTF9}

\section{A0A140T9T7;Q03518}

Q9H845;H0Y8Z9

P03915

Q99595

A0A0G2JKZ1;A2AB90;A0A0G 2JH37;A0A0AOMSV9;O15533; Q6P1N7;C9JA35;A0A0A0MT9

Q6P1S2

Q9BRR6;H3BRS6

Q5JP53;P07437;Q5ST81

Q13445;K7EIN4;K7EQ63

P50416

Q3KQZ1

O43657;A0A087WZU5;A0A08 7WYV6

P68371

P46821;D6RA32

Q8WVQ1

Q8WUY8;M0R1E3

Q643R3;A0A0C4DGT4

P43353;A0A087X2D4

A0A087WZT2;Q6UX53

Q9UNK0;K7EQB1

Q92896

Q6ZRP7

095197

Q99567;J3KMX1

P40616;F8VYN9;B4DZG7

Q9UH99

Q14534;E7EVQ6

A0A1W2PQV5;A0A0A0MSE2; A0A0D9SFP2;E9PF18;Q16836 ;A0A1W2PNM1;A0A1W2PQC2 ;A0A1W2PRT2 Q9NVV0;A0AOAOMRS4;H7C3 B3

015120

F5H5D3;Q9BQE3;A0A1W2PQ M2;F8VVB9

B7ZL88;Q8N8Q8
CTDNEP1

RHBDD2

TAP1

ACAD9

MT-ND5

TIMM17A

TAPBP

C3orf33

ADPGK

TUBB

TMED1

CPT1A

SLC25A35

TSPAN6

TUBB4B

MAP1B

CANT1

NAT14

LPCAT4

ALDH3B1

METTL7B

STX8

GLG1

QSOX2

RTN3

NUP88

ARL1

SUN2

SQLE

HADH

TMEM38B

AGPAT2

TUBA1C;TUBA1B

cox18
CTD nuclear envelope

phosphatase 1

Rhomboid domain-

containing protein 2

Antigen peptide transporter 1

Acyl-CoA dehydrogenase family member 9 , mitochondrial

NADH-ubiquinone

oxidoreductase chain 5

Mitochondrial import inner

membrane translocase

subunit Tim17-A

Tapasin

Protein C3orf33

ADP-dependent

glucokinase

Tubulin beta chain

Transmembrane emp24

domain-containing protein 1

Carnitine O-

palmitoyltransferase 1, liver isoform

Solute carrier family 25

member 35

Tetraspanin-6

Tubulin beta-4B chain

Microtubule-associated protein 1B;MAP1B heavy chain:MAP1 light chain LC

Soluble calcium-activated nucleotidase 1

$\mathrm{N}$-acetyltransferase 14

Lysophospholipid acyltransferase LPCAT4

Aldehyde dehydrogenase

family 3 member B1

Methyltransferase-like protein 7B

Syntaxin-8

Golgi apparatus protein 1

Sulfhydryl oxidase 2

Reticulon-3

Nuclear pore complex protein Nup88

ADP-ribosylation factor-like protein 1

SUN domain-containing protein 2

Squalene monooxygenase

Hydroxyacyl-coenzyme A dehydrogenase, mitochondrial

Trimeric intracellular cation channel type B

1-acyl-sn-glycerol-3-

phosphate acyltransferase beta

Tubulin alpha-1C chain

Mitochondrial inner membrane protein COX18
3.94 


\begin{tabular}{|c|c|}
\hline P49069 & CAMLG \\
\hline A0A0C4DG89;Q7L014 & DDX46 \\
\hline Q5BJF2;Q86XC5;J3KTD1 & TMEM97 \\
\hline Q56VL3 & OCIAD2 \\
\hline Q9BRX8 & FAM213A \\
\hline O60218 & AKR1B10 \\
\hline Q9UHN6;F5H6B2 & TMEM2 \\
\hline Q3SXM5 & HSDL1 \\
\hline $\begin{array}{l}\text { P21964;E7EMS6;E7EUU8;H7 } \\
\text { BZ45 }\end{array}$ & СОMT \\
\hline P51153 & RAB13 \\
\hline $\begin{array}{l}\text { C9JFV4;Q8IZL8;E7EV54;I3L44 } \\
5\end{array}$ & PELP1 \\
\hline E9PKA7;E9PI08;Q9Y256 & RCE1 \\
\hline Q14008 & CKAP5 \\
\hline E9PGT1;Q15631;H7C1D4 & TSN \\
\hline P51798;H0Y2M6 & CLCN7 \\
\hline P24390;M0R1Y2 & KDELR1 \\
\hline A0A087WYR3;043399 & TPD52L2 \\
\hline Q8WUM0 & NUP133 \\
\hline P10301 & RRAS \\
\hline B5MDE0;Q96AA3 & RFT1 \\
\hline $\begin{array}{l}\text { E9PM75;Q9NTG7;E9PK80;E9 } \\
\text { PN58;E9PNA0 }\end{array}$ & SIRT3 \\
\hline Q99541 & PLIN2 \\
\hline Q9Y2R4 & DDX52 \\
\hline P14174 & MIF \\
\hline Q13509;A0A0B4J269 & TUBB3 \\
\hline Q9Y4W2 & LAS1L \\
\hline $\begin{array}{l}\text { A0A087WTK0;A0A087WVC6; } \\
\text { Q12913 }\end{array}$ & PTPRJ \\
\hline F5H324;F5GYY5;P51690 & ARSE \\
\hline Q8TC12;G3V2G6;G3V234 & $\mathrm{RDH} 11$ \\
\hline O60831;A6NM71 & PRAF2 \\
\hline A0A0A0MTH3;Q13418 & ILK \\
\hline O15228;Q5TBH8 & GNPAT \\
\hline Q60FE5;A0A087WWY3 & FLNA \\
\hline $\begin{array}{l}\text { Q96MH6;E5RGT2;E5RHU1;E5 } \\
\text { RJI9;E5RJN2 }\end{array}$ & TMEM68 \\
\hline Q2T/ & $\mathrm{LLC}$ \\
\hline
\end{tabular}

Calcium signal-modulating cyclophilin ligand

Probable ATP-dependent RNA helicase DDX46

Transmembrane protein 97

OCIA domain-containing

protein 2

Redox-regulatory protein

FAM213A

Aldo-keto reductase family

1 member B10

Transmembrane protein 2

Inactive hydroxysteroid

dehydrogenase-like protein 1

Catechol O-

methyltransferase

Ras-related protein Rab-13

Proline-, glutamic acid- and leucine-rich protein 1

CAAX prenyl protease 2

Cytoskeleton-associated protein 5

Translin

$\mathrm{H}(+) / \mathrm{Cl}(-)$ exchange

transporter 7

ER lumen protein-retaining receptor 1 ;ER lumen protein-retaining receptor

Tumor protein D54

Nuclear pore complex protein Nup133

Ras-related protein R-Ras

Protein RFT1 homolog

NAD-dependent protein

deacetylase sirtuin-3,

mitochondrial

Perilipin-2

Probable ATP-dependent

RNA helicase DDX52

Macrophage migration

inhibitory factor

Tubulin beta-3 chain

Ribosomal biogenesis

protein LAS1L

Protein-tyrosine-

phosphatase;Receptor-type

tyrosine-protein

phosphatase eta

Arylsulfatase $\mathrm{E}$

Retinol dehydrogenase 11

PRA1 family protein 2

Integrin-linked protein

kinase

Dihydroxyacetone

phosphate acyltransferase

0

Transmembrane protein 68

8

GDP-

Man:Man(3)GlcNAc(2)-PP-

Dol alpha-1,2-

mannosyltransferase 


\begin{tabular}{|c|c|}
\hline C9J384;Q9BQ75 & CMSS1 \\
\hline P42677;Q5T4L4 & RPS27 \\
\hline P42167;G5E972;H0YJH7 & TMPO \\
\hline C9JXB8;C9JNW5;P83731 & RPL24 \\
\hline O60637;H0YKJ9 & TSPAN3 \\
\hline O94906 & PRPF6 \\
\hline P47914 & RPL29 \\
\hline O15121 & DEGS1 \\
\hline Q8IY17 & PNPLA6 \\
\hline Q96CP7 & TLCD1 \\
\hline Q9H061;E9PI90 & TMEM126A \\
\hline $\begin{array}{l}\text { A0A0G2JNZ2;A0A0G2JPP5;Q } \\
\text { 14160;A0A0G2JMS7 }\end{array}$ & SCRIB \\
\hline O60664;K7EL96;K7ERZ3 & PLIN3 \\
\hline J3QK89;Q8IWX8 & CHERP \\
\hline Q12904 & AIMP1 \\
\hline Q8WTS1;H7BZY9 & ABHD5 \\
\hline Q9HBM0;F2Z3A6;F8W8C2 & VEZT \\
\hline Q969Z0 & TBRG4 \\
\hline Q29RF7 & PDS5A \\
\hline Q14573 & ITPR3 \\
\hline Q07065 & CKAP4 \\
\hline Q9H857 & NT5DC2 \\
\hline Q9UHG3;F8W8W4 & PCYOX1 \\
\hline Q8N755;G5E9P4;C9J4B6 & PQLC3 \\
\hline P16615;H7C5W9 & ATP2A2 \\
\hline Q9NZN4 & EHD2 \\
\hline Q5R3B4;095563 & MPC2 \\
\hline P52895;B4DK69;S4R3P0 & AKR1C2 \\
\hline $\begin{array}{l}\text { J3KNF8;O43169;H3BUX2;D6R } \\
\text { FH4 }\end{array}$ & CYB5B \\
\hline P51809 & VAMP7 \\
\hline $\begin{array}{l}\text { H0YHC3;F8W020;F8W118;F8 } \\
\text { VY35;F8VV59;B7Z9C2;F8W0J } \\
\text { 6;F5H4R6;H0YIV4;P55209;H0 } \\
\text { YH88;F8W543;F8VRJ2;F8VXI } \\
\text { 6;F8VUX1;F8VVB5 }\end{array}$ & NAP1L1 \\
\hline P37837;F2Z393 & TALDO1 \\
\hline $\begin{array}{l}\text { F8VNT9;F8VV56;F8W022;F8V } \\
\text { WK8;P08962 }\end{array}$ & CD63 \\
\hline Q7Z2W4;C9J6P4 & ZC3HAV1 \\
\hline
\end{tabular}

Protein CMSS1 $\quad 1.46$

$-0.35$

40S ribosomal protein S27

0.88

$-0.35$

Lamina-associated

polypeptide 2 , isoforms

beta/gamma;Thymopoietin;

$-0.35$

Thymopentin

60S ribosomal protein L24

0.54

$-0.34$

Tetraspanin-3

1.13

$-0.34$

Pre-mRNA-processing

factor 6

1.94

$-0.34$

60S ribosomal protein L29

1.14

$-0.34$

Sphingolipid delta(4)-

desaturase DES1

Neuropathy target esterase

2.74

$-0.34$

Calfacilitin

1.98

$-0.34$

Transmembrane protein

126A

Protein scribble homolog

Perilipin-3

Calcium homeostasis

endoplasmic reticulum

protein

Aminoacyl tRNA synthase

complex-interacting

multifunctional protein

1;Endothelial monocyte-

activating polypeptide 2

1-acylglycerol-3-phosphate

O-acyltransferase ABHD5

Vezatin

Protein TBRG4

0.92

$-0.33$

2.93

$-0.33$

0.81

$-0.33$

1.04

$-0.33$

0.52

$-0.33$

Sister chromatid cohesion protein PDS5 homolog A

Inositol 1,4,5-trisphosphate receptor type 3

Cytoskeleton-associated

protein 4

5-nucleotidase domain-

containing protein 2

Prenylcysteine oxidase 1

PQ-loop repeat-containing protein 3

Sarcoplasmic/endoplasmic

reticulum calcium ATPase 2

$\mathrm{EH}$ domain-containing

protein 2

Mitochondrial pyruvate

carrier 2

Aldo-keto reductase family

1 member $\mathrm{C} 2$

Cytochrome b5 type B

Vesicle-associated

membrane protein 7

0.73

0.59

$-0.32$

1.60

$-0.32$

2.58

$-0.32$

1.13

$-0.32$

0.40

$-0.32$

2.81

$-0.31$

0.63

$-0.31$

3.96

$-0.31$

0.70

$-0.31$

1.8

$-0.31$

2.33

$-0.30$

0.82

$-0.30$

1.78

$-0.30$

1.34

$-0.30$

1.96

$-0.30$

Nucleosome assembly protein 1-like 1

0.52

$-0.30$

Transaldolase

0.52

$-0.30$

Tetraspanin;CD63 antigen

Zinc finger $\mathrm{CCCH}$-type antiviral protein 1
$-0.30$

1.29

$-0.30$ 


\begin{tabular}{|c|c|c|c|c|}
\hline Q01780 & EXOSC10 & Exosome component 10 & 0.65 & -0.30 \\
\hline Q8TEQ8 & PIGO & $\begin{array}{l}\text { GPI ethanolamine } \\
\text { phosphate transferase } 3\end{array}$ & 2.11 & -0.30 \\
\hline $\begin{array}{l}\text { P08758;D6RBE9;D6RBL5;E9P } \\
\text { HT9 }\end{array}$ & ANXA5 & Annexin A5;Annexin & 1.05 & -0.29 \\
\hline Q9H330 & TMEM245 & $\begin{array}{l}\text { Transmembrane protein } \\
245\end{array}$ & 1.11 & -0.29 \\
\hline J3KPT4;Q9H4I3 & TRABD & $\begin{array}{l}\text { TraB domain-containing } \\
\text { protein }\end{array}$ & 1.24 & -0.29 \\
\hline Q96D53;M0R001 & ADCK4 & $\begin{array}{l}\text { AarF domain-containing } \\
\text { protein kinase } 4\end{array}$ & 1.28 & -0.29 \\
\hline $\begin{array}{l}\text { H7BXI1;A0A087WXU3;A0FGR } \\
8\end{array}$ & ESYT2 & Extended synaptotagmin-2 & 3.19 & -0.29 \\
\hline B7ZKQ9;Q8WTV0;F5H4X0 & SCARB1 & $\begin{array}{l}\text { Scavenger receptor class B } \\
\text { member } 1\end{array}$ & 1.39 & -0.29 \\
\hline Q8N3U4 & STAG2 & Cohesin subunit SA-2 & 1.10 & -0.29 \\
\hline A0A0C4DFL7;Q16850 & CYP51A1 & $\begin{array}{l}\text { Lanosterol 14-alpha } \\
\text { demethylase }\end{array}$ & 1.26 & -0.28 \\
\hline $\begin{array}{l}\text { A0A087WUC6;Q15005;E9PI68 } \\
\text {;E9PL01 }\end{array}$ & SPCS2 & $\begin{array}{l}\text { Signal peptidase complex } \\
\text { subunit } 2 \\
\text { C-1-tetrahydrofolate } \\
\text { synthase, } \\
\text { cytoplasmic;Methylenetetra } \\
\text { hydrofolate } \\
\text { dehydrogenase;Methenyltet }\end{array}$ & 3.24 & -0.28 \\
\hline F5H2F4;P11586 & MTHFD1 & $\begin{array}{l}\text { rahydrofolate } \\
\text { cyclohydrolase;Formyltetra } \\
\text { hydrofolate synthetase;C-1- } \\
\text { tetrahydrofolate synthase, } \\
\text { cytoplasmic, N-terminally } \\
\text { processed }\end{array}$ & 0.22 & -0.28 \\
\hline Q9H1C4;E9PNE5 & UNC93B1 & Protein unc-93 homolog B1 & 0.56 & -0.28 \\
\hline Q9BSF4 & C19orf52 & $\begin{array}{l}\text { Uncharacterized protein } \\
\text { C19orf52 }\end{array}$ & 1.79 & -0.28 \\
\hline J3KQ48;Q9Y3E5 & PTRH2 & $\begin{array}{l}\text { Peptidyl-tRNA hydrolase } 2 \text {, } \\
\text { mitochondrial }\end{array}$ & 1.14 & -0.28 \\
\hline $\begin{array}{l}\text { Q14728;D6RE79;D6RIZ4;D6R } \\
\text { A47 }\end{array}$ & MFSD10 & $\begin{array}{l}\text { Major facilitator superfamily } \\
\text { domain-containing protein } \\
10\end{array}$ & 1.59 & -0.28 \\
\hline Q9BSH5 & HDHD3 & $\begin{array}{l}\text { Haloacid dehalogenase-like } \\
\text { hydrolase domain- } \\
\text { containing protein } 3\end{array}$ & 0.37 & -0.28 \\
\hline Q8TEM1 & NUP210 & $\begin{array}{l}\text { Nuclear pore membrane } \\
\text { glycoprotein } 210\end{array}$ & 2.97 & -0.28 \\
\hline E9PFK5;P78316 & NOP14 & Nucleolar protein 14 & 1.48 & -0.27 \\
\hline $\begin{array}{l}\text { Q9HAW9;Q9HAW7;O60656;B } \\
\text { 5MCT4;Q9HAW8;P19224;P22 } \\
\text { 309;P35504;P35503;P22310 }\end{array}$ & $\begin{array}{l}\text { UGT1A8;UGT1A7; } \\
\text { UGT1A9;UGT1A6; } \\
\text { UGT1A10;UGT1A } \\
\text { 1;UGT1A5;UGT1A } \\
\text { 3;UGT1A4 }\end{array}$ & $\begin{array}{l}\text { UDP- } \\
\text { glucuronosyltransferase 1- } \\
\text { 8;UDP- } \\
\text { glucuronosyltransferase 1- } \\
\text { 7;UDP- } \\
\text { glucuronosyltransferase 1- } \\
\text { 9;UDP- } \\
\text { glucuronosyltransferase 1- } \\
\text { 10;UDP- } \\
\text { glucuronosyltransferase 1- } \\
\text { 6;UDP- } \\
\text { glucuronosyltransferase 1- } \\
\text { 1;UDP- } \\
\text { glucuronosyltransferase 1- } \\
\text { 5;UDP- } \\
\text { glucuronosyltransferase 1- } \\
\text { 3;UDP- } \\
\text { glucuronosyltransferase 1-4 }\end{array}$ & 1.73 & -0.27 \\
\hline J3KQL8;Q9BQE5 & APOL2 & Apolipoprotein L2 & 1.21 & -0.27 \\
\hline O43402;M0R1B0 & EMC8 & $\begin{array}{l}\text { ER membrane protein } \\
\text { complex subunit } 8\end{array}$ & 0.96 & -0.27 \\
\hline Q12789 & GTF3C1 & $\begin{array}{l}\text { General transcription factor } \\
\text { 3C polypeptide } 1\end{array}$ & 0.49 & -0.27 \\
\hline Q8NI27;A0A0C4DG98 & THOC2 & THO complex subunit 2 & 1.06 & -0.27 \\
\hline
\end{tabular}




\begin{tabular}{|c|c|c|c|c|}
\hline P28070 & PSMB4 & $\begin{array}{l}\text { Proteasome subunit beta } \\
\text { type- } 4\end{array}$ & 0.99 & -0.26 \\
\hline 014672 & ADAM10 & $\begin{array}{l}\text { Disintegrin and } \\
\text { metalloproteinase domain- } \\
\text { containing protein } 10\end{array}$ & 2.64 & -0.26 \\
\hline $\begin{array}{l}\text { Q15836;K7ENK9;K7EKX0;J3Q } \\
\text { RU4;F8WCA0;L7N2F9;P63027 }\end{array}$ & VAMP3;VAMP2 & $\begin{array}{l}\text { Vesicle-associated } \\
\text { membrane protein } \\
3 ; \text { Vesicle-associated } \\
\text { membrane protein } 2\end{array}$ & 1.51 & -0.26 \\
\hline $\begin{array}{l}\text { Q9NV66;C9J9Q4;A0A087WUV } \\
9\end{array}$ & TYW1 & $\begin{array}{l}\text { S-adenosyl-L-methionine- } \\
\text { dependent tRNA 4- } \\
\text { demethylwyosine synthase }\end{array}$ & 1.65 & -0.26 \\
\hline Q14669 & TRIP12 & $\begin{array}{l}\text { E3 ubiquitin-protein ligase } \\
\text { TRIP12 } \\
\text { Polyribonucleotide }\end{array}$ & 0.52 & -0.26 \\
\hline Q8TCS8 & PNPT1 & $\begin{array}{l}\text { nucleotidyltransferase } 1 \text {, } \\
\text { mitochondrial }\end{array}$ & 0.53 & -0.26 \\
\hline Q9NXF1 & TEX10 & $\begin{array}{l}\text { Testis-expressed sequence } \\
10 \text { protein }\end{array}$ & 1.29 & -0.26 \\
\hline P78347 & GTF2I & $\begin{array}{l}\text { General transcription factor } \\
\text { II-I }\end{array}$ & 2.03 & -0.26 \\
\hline P82933 & MRPS9 & $\begin{array}{l}28 \text { S ribosomal protein } \mathrm{S} 9 \text {, } \\
\text { mitochondrial }\end{array}$ & 0.56 & -0.26 \\
\hline Q02790 & FKBP4 & $\begin{array}{l}\text { Peptidyl-prolyl cis-trans } \\
\text { isomerase FKBP4;Peptidyl- } \\
\text { prolyl cis-trans isomerase } \\
\text { FKBP4, N-terminally } \\
\text { processed }\end{array}$ & 0.28 & -0.26 \\
\hline $\begin{array}{l}\text { HOYKD8;P46779;HOYLP6;HOY } \\
\text { MF4 }\end{array}$ & RPL28 & $60 S$ ribosomal protein L28 & 1.03 & -0.26 \\
\hline P36551 & CPOX & $\begin{array}{l}\text { Oxygen-dependent } \\
\text { coproporphyrinogen-III } \\
\text { oxidase, mitochondrial }\end{array}$ & 1.93 & -0.25 \\
\hline Q9Y6C9 & $\mathrm{MTCH} 2$ & $\begin{array}{l}\text { Mitochondrial carrier } \\
\text { homolog } 2 \\
\text { NADH dehydrogenase }\end{array}$ & 1.97 & -0.25 \\
\hline $\begin{array}{l}\text { O95298;E9PRJ5;E9PM14;A0A } \\
\text { 087WUM3;E9PQ53 }\end{array}$ & $\begin{array}{l}\text { NDUFC2;KCTD14; } \\
\text { NDUFC2-KCTD14 }\end{array}$ & $\begin{array}{l}\text { [ubiquinone] } 1 \text { subunit } \\
\text { C2;NADH dehydrogenase } \\
\text { [ubiquinone] } 1 \text { subunit C2, } \\
\text { isoform } 2\end{array}$ & 0.83 & -0.25 \\
\hline O00411 & POLRMT & $\begin{array}{l}\text { DNA-directed RNA } \\
\text { polymerase, mitochondrial }\end{array}$ & 1.16 & -0.25 \\
\hline P49792 & RANBP2 & $\begin{array}{l}\text { E3 SUMO-protein ligase } \\
\text { RanBP2 }\end{array}$ & 1.75 & -0.25 \\
\hline B0YIW6;P48444 & ARCN1 & Coatomer subunit delta & 0.53 & -0.25 \\
\hline Q13641 & TPBG & Trophoblast glycoprotein & 1.30 & -0.25 \\
\hline $\begin{array}{l}\text { E9PKG6;V9HW75;A0A087WS } \\
\text { V8;P80303;Q2L696;E9PLR0;E } \\
\text { 9PLE9 }\end{array}$ & $\begin{array}{l}\text { NUCB2;HEL-S- } \\
\text { 109;Nucb2 }\end{array}$ & Nucleobindin-2;Nesfatin-1 & 1.49 & -0.25 \\
\hline $\begin{array}{l}\text { Q96GC9;K7EL93;K7EL74;K7E } \\
\text { NU2;K7EK01;K7EMI0;K7ELS2 }\end{array}$ & VMP1 & $\begin{array}{l}\text { Vacuole membrane protein } \\
1\end{array}$ & 1.27 & -0.25 \\
\hline Q6P2E9 & EDC4 & $\begin{array}{l}\text { Enhancer of mRNA- } \\
\text { decapping protein } 4\end{array}$ & 0.52 & -0.25 \\
\hline Q9Y679 & AUP1 & Ancient ubiquitous protein 1 & 1.53 & -0.24 \\
\hline P61160;F5H6T1 & ACTR2 & Actin-related protein 2 & 0.74 & -0.24 \\
\hline E9PCY5;Q02880 & TOP2B & $\begin{array}{l}\text { DNA topoisomerase } 2 ; \mathrm{DNA} \\
\text { topoisomerase } 2 \text {-beta }\end{array}$ & 0.91 & -0.24 \\
\hline $\begin{array}{l}\text { P37268;E9PNM1;A0A1W2PQ4 } \\
7\end{array}$ & FDFT1 & Squalene synthase & 1.04 & -0.24 \\
\hline HOY4R5;Q5SNT2 & TMEM201 & $\begin{array}{l}\text { Transmembrane protein } \\
201\end{array}$ & 0.69 & -0.24 \\
\hline Q02818;H7BZI1 & NUCB1 & Nucleobindin-1 & 1.33 & -0.24 \\
\hline Q9BZF1;F8VUA7;F8VQX7 & OSBPL8 & $\begin{array}{l}\text { Nuclear pore complex } \\
\text { protein Nup98- } \\
\text { Nup96;Nuclear pore } \\
\text { complex protein } \\
\text { Nup98;Nuclear pore } \\
\text { complex protein Nup96 } \\
\text { Oxysterol-binding protein- } \\
\text { related protein 8;Oxysterol- } \\
\text { binding protein }\end{array}$ & 0.74 & -0.24 \\
\hline
\end{tabular}


Q9NWW5;A0A0S2Z5D0;H3BU

V4;A0A1B0GUD2;H3BUT1;A0

A1B0GTU6;A0A1B0GW73;H3

CLN6

Ceroid-lipofuscinosis

BNF1;A0A1B0GTV3;H3BTY4

Q96AQ6

PBXIP1

neuronal protein 6

0.46

$-0.23$

Q8NFV4

ABHD11

Pre-B-cell leukemia

transcription factor-

interacting protein 1

Alpha/beta hydrolase

Q8NFV4

domain-containing protein 11

Q53FA7;H7BZH6

TP53I3

Quinone oxidoreductase

PIG3

P07093;C9JN98

SERPINE2

Glia-derived nexin

RPLP1

P05386

605 acidic ribosomal

protein $\mathrm{P} 1$

P55884

EIF3B

F8W914;Q9NQC3;H7C106;A0

AOU1RQR6

RTN4

Eukaryotic translation

initiation factor 3 subunit B

Reticulon;Reticulon-4

Q8IYB8

SUPV3L1

ATP-dependent RNA helicase SUPV3L1, mitochondrial

P67936;K7ERG3;K7ENT6

TPM4

Q03701

CEBPZ

A0A0G2JJD3;O95870;A0A0G2 JI89

ABHD16A

Q9UGP8

SEC63

A0A087X106;CON O43790; CON_Q14533;O43790;Q1453 3;CON_Q6NT21;CON_P783 $85 ; \mathrm{P} 78385 ; \mathrm{A} 6 \mathrm{NCN} 2 ; \mathrm{CON} \_\mathrm{Q} 6$ 1726

P61020;F8VUA5

KRT81;KRT86;KR

T83;KRT87P

Tropomyosin alpha-4 chain

0.63

1.38

CCAAT/enhancer-binding

protein zeta

Abhydrolase domaincontaining protein $16 \mathrm{~A}$

Translocation protein

SEC63 homolog

Keratin, type II cuticular

Hb6; Keratin, type II

cuticular $\mathrm{Hb} 1$; Keratin, type

Il cuticular Hb3;Putative

keratin-87 protein

RAB5B

014949

UQCRQ

Q9NZJ7;HOY8C3

$\mathrm{MTCH} 1$

Ras-related protein Rab-5B

Cytochrome b-c1 complex subunit 8

Mitochondrial carrier homolog 1

Q16719

KYNU

I3L3P7;P62244

RPS15A

Kynureninase

0.70

J3KPS0;Q9NXW2;V9GYN7

DNAJB12

G5E9D5;Q9BQ52;E7ES68

ELAC2

40S ribosomal protein S15a

DnaJ homolog subfamily $B$ member 12

Zinc phosphodiesterase

ELAC protein 2

Carboxypeptidase;Lysosom al protective

protein;Lysosomal

protective protein $32 \mathrm{kDa}$

chain;Lysosomal protective

protein $20 \mathrm{kDa}$ chain

Q9UNN8;A0A0U1RQQ4;A0A0

U1RRC4

PROCR

Endothelial protein $\mathrm{C}$

receptor

Q92604

LPGAT1

Acyl-

CoA:lysophosphatidylglycer

ol acyltransferase 1

Q5UIP0;H7BZN3

RIF1

C9IZF6;P41247

PNPLA4

Telomere-associated

protein RIF

Patatin-like phospholipase domain-containing protein 4

Q9BXS5;K7EJL1;E7ENJ6

AP1M1

AP-1 complex subunit mu-1

0.34

28 S ribosomal protein $\mathrm{S} 5$, mitochondrial

Coiled-coil domain-

containing protein 51

Q96ER9

CCDC51

Exosome complex

component MTR3

Nucleoside diphosphate

kinase 3;Nucleoside

diphosphate kinase 


\begin{tabular}{|c|c|}
\hline Q8WUY1;H0YAR9 & THEM6 \\
\hline Q86VP6;A0A0C4DGH5 & CAND1 \\
\hline Q9H9P8;C9JVN9 & L2HGDH \\
\hline P36578;Н3ВM89 & RPL4 \\
\hline P08708;H0YN88;A0A075B716 & RPS17 \\
\hline Q9Y3U8;J3QSB5 & RPL36 \\
\hline $\begin{array}{l}\text { F6XEV2;A0A0U1RRK1;A0A28 } \\
\text { 6YF11;Q9BPX6;E9PQV6 }\end{array}$ & MICU1 \\
\hline Q15024 & EXOSC7 \\
\hline A0A087WVA1;P62341;Q6IAK0 & SELT \\
\hline $\begin{array}{l}\text { O14495;A0A286YF41;A0A286 } \\
\text { YEZ7;A0A286YES4 }\end{array}$ & PPAP2B \\
\hline P09543 & CNP \\
\hline B1AJQ6;Q86Y82 & STX12 \\
\hline H0Y4R1;P12268 & IMPDH2 \\
\hline O00567 & NOP56 \\
\hline Q7Z2K6;E7ER77 & ERMP1 \\
\hline H3BND4;Q6P996;Q86XE2 & PDXDC1 \\
\hline $\begin{array}{l}\text { Q16822;B4DW73;HOYML5;H0 } \\
\text { YM31 }\end{array}$ & PCK2 \\
\hline Q8IYU8 & MICU2 \\
\hline Q6NUK1 & SLC25A24 \\
\hline Q6N075;F8VV69 & MFSD5 \\
\hline Q9NUM4;C9JZ87 & TMEM106B \\
\hline $\begin{array}{l}\text { HOY5K5;Q9Y282;A0A1W2PPS } \\
\text { 8;H0Y621;H0Y802;HOY6Z0 }\end{array}$ & ERGIC3 \\
\hline $\begin{array}{l}\text { Q9UHQ4;C9JTE9;H7C5E2;B7 } \\
\text { Z2L0;C9IYK6;H0Y7N8 }\end{array}$ & BCAP29 \\
\hline P24539;Q5QNZ2 & ATP5F1 \\
\hline Q9HD33 & MRPL47 \\
\hline Q92575 & UBXN4 \\
\hline P53701 & HCCS \\
\hline Q9BU23 & LMF2 \\
\hline $\begin{array}{l}\text { R4GMT0;P61163;A0A1B0GVS } \\
3\end{array}$ & ACTR1A \\
\hline Q9BVI4;F5H303 & NOC4L \\
\hline B7Z6D5;Q96GQ7 & DDX27 \\
\hline $\begin{array}{l}\text { P18077;C9K025;F8WBS5;F8W } \\
\text { B72 }\end{array}$ & RPL35A \\
\hline P23141 & CES1 \\
\hline P52907 & CAPZA1 \\
\hline B8ZZ51;B9A041;P40925 & $\mathrm{MDH} 1$ \\
\hline $\begin{array}{l}\text { O75955;A0A140T9R1;A0A140 } \\
\text { T9W4 }\end{array}$ & FLOT1 \\
\hline
\end{tabular}

Protein THEM6 $\quad 1.00$

Cullin-associated NEDD8-

dissociated protein 1

L-2-hydroxyglutarate

dehydrogenase,

mitochondrial

60 S ribosomal protein $L 4$

40S ribosomal protein $\mathrm{S} 17$

60S ribosomal protein L36

Calcium uptake protein 1 ,

mitochondrial

Exosome complex

component RRP42

Selenoprotein $T$

Lipid phosphate

phosphohydrolase 3

2,3-cyclic-nucleotide 3-

phosphodiesterase

Syntaxin-12

Inosine-5-monophosphate

dehydrogenase 2

Nucleolar protein 56

Endoplasmic reticulum

metallopeptidase 1

Pyridoxal-dependent

decarboxylase domain-

containing protein 1

Phosphoenolpyruvate

carboxykinase [GTP],

mitochondrial

Calcium uptake protein 2 ,

mitochondrial

Calcium-binding

mitochondrial carrier protein

SCaMC-1

Molybdate-anion

transporter

Transmembrane protein

106B

Endoplasmic reticulum-

Golgi intermediate

compartment protein 3

B-cell receptor-associated

protein 29

ATP synthase $F(0)$ complex

subunit B1, mitochondrial

39S ribosomal protein L47,

mitochondrial

UBX domain-containing

protein 4

Cytochrome c-type heme

lyase

Lipase maturation factor 2

Alpha-centractin

Nucleolar complex protein 4

homolog

Probable ATP-dependent

RNA helicase DDX27

$60 S$ ribosomal protein L35a

Liver carboxylesterase 1

F-actin-capping protein

subunit alpha-1

Malate dehydrogenase,

cytoplasmic

Flotillin-1
0.42

1.27

0.93

0.36

0.53

1.05

0.00

0.45

0.86

1.37

0.83

0.50

1.48

1.04

0.44

0.57

1.31

0.96

0.78

0.52

0.25

0.59

0.87

0.00

1.08

1.19

0.53

0.54

0.45

1.52

0.75

0.44

1.15

0.85

3.92
$-0.21$

$-0.21$

$-0.21$

$-0.21$

$-0.21$

$-0.21$

$-0.21$

$-0.21$

$-0.21$

$-0.21$

$-0.21$

$-0.21$

$-0.21$

$-0.21$

$-0.21$

$-0.20$

$-0.20$

$-0.20$

$-0.20$

$-0.20$

$-0.20$

$-0.20$

$-0.20$

$-0.20$

$-0.20$

$-0.20$

$-0.20$

$-0.19$

$-0.19$

$-0.19$

$-0.19$

$-0.19$

$-0.19$

$-0.19$

$-0.19$

$-0.19$ 


\begin{tabular}{|c|c|}
\hline Q8N514 & DHRSX \\
\hline $\begin{array}{l}\text { E9PHI4;O94901;H0Y742;H0Y6 } \\
\text { N5;H7C2K3 }\end{array}$ & SUN1 \\
\hline O15118;K7EQ23 & NPC1 \\
\hline Q9P2R7;Q5T9Q5;Q5T9Q8 & SUCLA2 \\
\hline P31939 & ATIC \\
\hline Q9NYP7;A0A0A0MTI6 & ELOVL5 \\
\hline D6RCD0 & HSD17B11 \\
\hline $\begin{array}{l}\text { P27695;G3V3M6;G3V5Q1;G3 } \\
\text { V3C7 }\end{array}$ & APEX1 \\
\hline Q9NTI5 & PDS5B \\
\hline Q9BXW7 & CECR5 \\
\hline Q8N5K1;/3L1N9;D6RCF4 & CISD2 \\
\hline P60953;Q5JYX0 & CDC42 \\
\hline P15121;E9PCX2 & AKR1B1 \\
\hline Q9P0L0 & VAPA \\
\hline F8VXC8;Q8TAQ2 & SMARCC2 \\
\hline $\begin{array}{l}\text { G3V529;Q9GZR7;F5GYL3;A0 } \\
\text { A1W2PRR2;A0A087WXU8 }\end{array}$ & DDX24 \\
\hline 094919 & ENDOD1 \\
\hline Q9H078;HOYGM0 & CLPB \\
\hline F5H1S9;G8JLB3;Q9Y606 & PUS1 \\
\hline $\begin{array}{l}\text { Q9Y277;E5RJN6;E5RHZ6;E5R } \\
\text { FP6 }\end{array}$ & VDAC3 \\
\hline Q99832 & CCT7 \\
\hline 014763 & TNFRSF10B \\
\hline 060313 & OPA1 \\
\hline $\begin{array}{l}\text { A0A1W2PPX5;A0A1W2PPU6; } \\
\text { A0A1W2PQR6;A0A1W2PQB7; } \\
\text { A0A1W2PS43;A0A1W2PRS1; } \\
\text { Q14108;A0A1W2PRF6 }\end{array}$ & SCARB2 \\
\hline P07814;V9GYZ6 & EPRS \\
\hline P56589 & PEX3 \\
\hline
\end{tabular}

Dehydrogenase/reductase

SDR family member on

chromosome $X$

SUN domain-containing

protein 1

Niemann-Pick C1 protein

Succinyl-CoA ligase [ADP.

forming] subunit beta,

mitochondrial

Bifunctional purine

biosynthesis protein

PURH;Phosphoribosylamin

oimidazolecarboxamide

formyltransferase;IMP

cyclohydrolase

Elongation of very long

chain fatty acids protein

5 ;Elongation of very long

chain fatty acids protein

DNA-(apurinic or

apyrimidinic site)

lyase;DNA-(apurinic or

apyrimidinic site) lyase,

mitochondrial

Sister chromatid cohesion

protein PDS5 homolog B

Cat eye syndrome critical

region protein 5

CDGSH iron-sulfur domain-

containing protein 2

Cell division control protein

42 homolog

Aldose reductase

0.52

$-0.18$

Vesicle-associated

membrane protein-

associated protein $A$

SWI/SNF complex subunit

SMARCC2

ATP-dependent RNA

helicase DDX24

Endonuclease domain-

containing 1 protein

Caseinolytic peptidase B

protein homolog

RNA pseudouridine

synthase;tRNA

pseudouridine synthase $A$,

mitochondrial

Voltage-dependent anion-

selective channel protein 3

T-complex protein 1 subunit eta

Tumor necrosis factor

receptor superfamily

member 10B

Dynamin-like 120 kDa

protein,

mitochondrial;Dynamin-like

0.38

$-0.18$

2.18

$-0.18$

0.21

0.59

$-0.18$

1.28

0.78

$-0.18$

0.58

$-0.18$

0.78

$-0.18$

0.67

$-0.18$

0.39

$-0.18$

0.68

$-0.18$

1.10

$-0.18$

0.16

120 kDa protein, form S1

Lysosome membrane protein 2

0.38

Bifunctional

glutamate/proline--tRNA

ligase;Glutamate--tRNA

ligase;Proline--tRNA ligase

Peroxisomal biogenesis

factor 3 


\begin{tabular}{|c|c|c|c|c|}
\hline P51665;H3BNT7;H3BTM8 & PSMD7 & $\begin{array}{l}\text { 26S proteasome non- } \\
\text { ATPase regulatory subunit } \\
7\end{array}$ & 0.45 & -0.17 \\
\hline P32970 & CD70 & CD70 antigen & 0.31 & -0.17 \\
\hline 015091 & KIAA0391 & $\begin{array}{l}\text { Mitochondrial ribonuclease } \\
\text { P protein } 3 \\
\text { Dolichyl- }\end{array}$ & 1.35 & -0.17 \\
\hline A0A0C4DGS1;P39656 & DDOST & $\begin{array}{l}\text { diphosphooligosaccharide-- } \\
\text { protein glycosyltransferase } \\
48 \mathrm{kDa} \text { subunit }\end{array}$ & 0.65 & -0.17 \\
\hline $\begin{array}{l}\text { A0A087X1K9;E5RGR0;O7560 } \\
8\end{array}$ & LYPLA1 & Acyl-protein thioesterase 1 & 0.50 & -0.16 \\
\hline O14925;Q5SRD1 & TIMM23;TIMM23B & $\begin{array}{l}\text { Mitochondrial import inner } \\
\text { membrane translocase } \\
\text { subunit Tim23;Putative } \\
\text { mitochondrial import inner } \\
\text { membrane translocase } \\
\text { subunit Tim23B } \\
\text { Sorting and assembly }\end{array}$ & 0.77 & -0.16 \\
\hline Q9Y512 & SAMM50 & $\begin{array}{l}\text { machinery component } 50 \\
\text { homolog }\end{array}$ & 1.20 & -0.16 \\
\hline $\begin{array}{l}\text { E7EW69;E7EX04;B5ME97;Q9 } \\
\text { P0V9 }\end{array}$ & SEPT10 & Septin-10 & 0.29 & -0.16 \\
\hline Q9HCS7 & XAB2 & $\begin{array}{l}\text { Pre-mRNA-splicing factor } \\
\text { SYF1 }\end{array}$ & 0.52 & -0.16 \\
\hline A0A0A0MRX2;Q96HY6 & DDRGK1 & $\begin{array}{l}\text { DDRGK domain-containing } \\
\text { protein } 1\end{array}$ & 0.26 & -0.16 \\
\hline Q9NX47 & MAR5 & $\begin{array}{l}\text { E3 ubiquitin-protein ligase } \\
\text { MARCH5 }\end{array}$ & 0.70 & -0.16 \\
\hline Q6NUM9;H7BZ16;H7C3J0 & RETSAT & $\begin{array}{l}\text { All-trans-retinol 13,14- } \\
\text { reductase }\end{array}$ & 0.92 & -0.16 \\
\hline O60216 & RAD21 & $\begin{array}{l}\text { Double-strand-break repair } \\
\text { protein rad21 homolog } \\
\text { Mitochondrial import inner }\end{array}$ & 0.45 & -0.16 \\
\hline V9GYS0;O60830;V9GYU0 & TIMM17B & $\begin{array}{l}\text { membrane translocase } \\
\text { subunit Tim17-B }\end{array}$ & 0.55 & -0.16 \\
\hline Q9HBH5 & $\mathrm{RDH} 14$ & Retinol dehydrogenase 14 & 0.93 & -0.16 \\
\hline O43772;C9JPE1 & SLC25A20 & $\begin{array}{l}\text { Mitochondrial } \\
\text { carnitine/acylcarnitine } \\
\text { carrier protein } \\
\text { Actin, alpha skeletal } \\
\text { muscle;Actin, alpha cardiac }\end{array}$ & 0.26 & -0.16 \\
\hline $\begin{array}{l}\text { P68133;P68032;P63267;P627 } \\
\text { 36;A6NL76 }\end{array}$ & $\begin{array}{l}\text { ACTA1;ACTC1;AC } \\
\text { TG2;ACTA2 }\end{array}$ & $\begin{array}{l}\text { muscle } 1 ; \text { Actin, gamma- } \\
\text { enteric smooth } \\
\text { muscle;Actin, aortic smooth } \\
\text { muscle }\end{array}$ & 0.40 & -0.16 \\
\hline P61019;E9PKL7 & RAB2A & Ras-related protein Rab-2A & 0.84 & -0.16 \\
\hline O14975;G3V1R7 & SLC27A2 & $\begin{array}{l}\text { Very long-chain acyl-CoA } \\
\text { synthetase }\end{array}$ & 0.65 & -0.16 \\
\hline O00483 & NDUFA4 & $\begin{array}{l}\text { Cytochrome c oxidase } \\
\text { subunit NDUFA4 }\end{array}$ & 0.58 & -0.16 \\
\hline Q9BTX1 & NDC1 & Nucleoporin NDC1 & 0.74 & -0.16 \\
\hline $\begin{array}{l}\text { Q3ZCQ8;M0R003;M0R2F8;M0 } \\
\text { R1Y4 }\end{array}$ & TIMM50 & $\begin{array}{l}\text { Mitochondrial import inner } \\
\text { membrane translocase } \\
\text { subunit TIM50 }\end{array}$ & 0.83 & -0.16 \\
\hline Q9UH62 & ARMCX3 & $\begin{array}{l}\text { Armadillo repeat-containing } \\
\text { X-linked protein } 3\end{array}$ & 0.00 & -0.16 \\
\hline P43155 & CRAT & $\begin{array}{l}\text { Carnitine O- } \\
\text { acetyltransferase }\end{array}$ & 0.82 & -0.16 \\
\hline M0QZ12;Q96CP6 & GRAMD1A & $\begin{array}{l}\text { GRAM domain-containing } \\
\text { protein } 1 \mathrm{~A}\end{array}$ & 0.64 & -0.16 \\
\hline P04899 & GNAI2 & $\begin{array}{l}\text { Guanine nucleotide-binding } \\
\text { protein G(i) subunit alpha-2 }\end{array}$ & 0.39 & -0.15 \\
\hline Q8TDN6 & BRIX1 & $\begin{array}{l}\text { Ribosome biogenesis } \\
\text { protein BRX1 homolog }\end{array}$ & 0.64 & -0.15 \\
\hline $\begin{array}{l}\text { A0A0G2JNZ5;A0A0G2JLB3;P0 } \\
\text { 4062;A0A0G2JNZ0 }\end{array}$ & GBA & Glucosylceramidase & 0.97 & -0.15 \\
\hline Q6P587 & FAHD1 & $\begin{array}{l}\text { Acylpyruvase FAHD1, } \\
\text { mitochondrial }\end{array}$ & 0.65 & -0.15 \\
\hline $\begin{array}{l}\text { E9PCR7;Q02218;E9PDF2;A0A } \\
\text { OD9SFS3;E9PFG7 }\end{array}$ & $\mathrm{OGDH}$ & $\begin{array}{l}\text { 2-oxoglutarate } \\
\text { dehydrogenase, } \\
\text { mitochondrial }\end{array}$ & 0.26 & -0.15 \\
\hline
\end{tabular}




\begin{tabular}{|c|c|c|c|c|}
\hline Q92797;A0A087WUE9 & SYMPK & Symplekin & 0.58 & -0.15 \\
\hline Q9UNX4 & WDR3 & $\begin{array}{l}\text { WD repeat-containing } \\
\text { protein } 3\end{array}$ & 0.28 & -0.15 \\
\hline $\begin{array}{l}\text { A0A0C4DG49;P15151;A0A0A0 } \\
\text { MSA9 }\end{array}$ & PVR & Poliovirus receptor & 0.41 & -0.15 \\
\hline Q9H0U4;E9PLD0;Q92928 & RAB1B;RAB1C & $\begin{array}{l}\text { Ras-related protein Rab- } \\
\text { 1B;Putative Ras-related } \\
\text { protein Rab-1C }\end{array}$ & 0.17 & -0.15 \\
\hline $\begin{array}{l}\text { G0XQ39;Q13586;E9PNJ4;H0Y } \\
\text { DB2 }\end{array}$ & STIM1 & $\begin{array}{l}\text { Stromal interaction } \\
\text { molecule } 1\end{array}$ & 1.02 & -0.15 \\
\hline $\begin{array}{l}\text { Q96BY9;E5RHW0;HOYBH7;E5 } \\
\text { RFJ9;HOYAZ1 }\end{array}$ & SARAF & $\begin{array}{l}\text { Store-operated calcium } \\
\text { entry-associated regulatory } \\
\text { factor }\end{array}$ & 0.69 & -0.15 \\
\hline Q27J81;A0A0A0MQU1 & INF2 & Inverted formin-2 & 0.38 & -0.15 \\
\hline $\begin{array}{l}\text { A0A1B0GUD6;A0A024R3M2;J } \\
\text { 3KNL5;A0A1B0GWG7;Q3KR3 } \\
7\end{array}$ & $\begin{array}{l}\text { hCG_39893;GRA } \\
\text { MD1B }\end{array}$ & $\begin{array}{l}\text { GRAM domain-containing } \\
\text { protein } 1 \mathrm{~B}\end{array}$ & 0.41 & -0.15 \\
\hline P40227 & CCT6A & $\begin{array}{l}\text { T-complex protein } 1 \text { subunit } \\
\text { zeta } \\
\text { ATP-dependent } 6 \text { - }\end{array}$ & 1.20 & -0.15 \\
\hline Q01813 & PFKP & $\begin{array}{l}\text { phosphofructokinase, } \\
\text { platelet type }\end{array}$ & 0.16 & -0.15 \\
\hline H3BTB7;Q5JPH6 & EARS2 & $\begin{array}{l}\text { Probable glutamate--tRNA } \\
\text { ligase, mitochondrial }\end{array}$ & 0.57 & -0.15 \\
\hline P63000;P60763 & RAC1;RAC3 & $\begin{array}{l}\text { toxin substrate } 1 \text {;Ras- } \\
\text { related } \mathrm{C} 3 \text { botulinum toxin } \\
\text { substrate } 3\end{array}$ & 1.01 & -0.15 \\
\hline Q9NR30 & DDX21 & Nucleolar RNA helicase 2 & 0.61 & -0.15 \\
\hline $\begin{array}{l}\text { Q92934;F5H3B1;F5H1R6;F5G } \\
\text { YS3;A8MXU7 }\end{array}$ & BAD & $\begin{array}{l}\text { Bcl2-associated agonist of } \\
\text { cell death }\end{array}$ & 0.20 & -0.15 \\
\hline M0R061;M0QXB4;O14579 & COPE & Coatomer subunit epsilon & 0.38 & -0.15 \\
\hline P50395;Q5SX87;Q5SX91 & GDI2 & $\begin{array}{l}\text { Rab GDP dissociation } \\
\text { inhibitor beta }\end{array}$ & 0.66 & -0.15 \\
\hline P11388 & TOP2A & $\begin{array}{l}\text { DNA topoisomerase 2- } \\
\text { alpha }\end{array}$ & 0.99 & -0.15 \\
\hline Q9NYK5;C9JG87 & MRPL39 & $\begin{array}{l}39 \text { S ribosomal protein L39, } \\
\text { mitochondrial }\end{array}$ & 0.44 & -0.15 \\
\hline A5YKK6 & CNOT1 & $\begin{array}{l}\text { CCR4-NOT transcription } \\
\text { complex subunit } 1\end{array}$ & 0.18 & -0.15 \\
\hline $\begin{array}{l}\text { B7Z3Z9;E7EPM6;P33121;D6R } \\
\text { ER0 }\end{array}$ & ACSL1 & $\begin{array}{l}\text { Long-chain-fatty-acid--CoA } \\
\text { ligase } 1\end{array}$ & 0.37 & -0.15 \\
\hline $\begin{array}{l}\text { K9J957;P61289;B3KQ25;K7ES } \\
\text { G5;A0A087WTV2;K7ENH2 }\end{array}$ & PSME3 & $\begin{array}{l}\text { Proteasome activator } \\
\text { complex subunit } 3 \\
\text { Phylloquinone omega- } \\
\text { hydroxylase }\end{array}$ & 0.32 & -0.15 \\
\hline $\begin{array}{l}\text { Q9HBI6;V9GYP6;F8W978;A0A } \\
\text { 0AOMQR0;P78329 }\end{array}$ & CYP4F11;CYP4F2 & $\begin{array}{l}\text { CYP4F11; Phylloquinone } \\
\text { omega-hydroxylase } \\
\text { CYP4F2 }\end{array}$ & 0.74 & -0.15 \\
\hline $\begin{array}{l}\text { Q9Y394;A0A087X0Z7;H0YJ66; } \\
\text { H0YJE4 }\end{array}$ & DHRS7 & $\begin{array}{l}\text { Dehydrogenase/reductase } \\
\text { SDR family member } 7\end{array}$ & 0.52 & -0.15 \\
\hline Q6ZWT7;H7C5D1 & MBOAT2 & $\begin{array}{l}\text { Lysophospholipid } \\
\text { acyltransferase } 2\end{array}$ & 0.51 & -0.15 \\
\hline Q9H553 & ALG2 & $\begin{array}{l}\text { Alpha-1,3/1,6- } \\
\text { mannosyltransferase ALG2 }\end{array}$ & 0.26 & -0.15 \\
\hline P61026 & RAB10 & Ras-related protein Rab-10 & 1.17 & -0.15 \\
\hline P83111 & LACTB & $\begin{array}{l}\text { Serine beta-lactamase-like } \\
\text { protein LACTB, } \\
\text { mitochondrial }\end{array}$ & 0.50 & -0.14 \\
\hline $\begin{array}{l}\text { Q86VR2;K7ENZ6;K7EMF4;K7 } \\
\text { ELM8;K7EJ34;K7ENF4 } \\
\text { A0A1B0GW44;A0A1B0GV23;A }\end{array}$ & FAM134C & Protein FAM134C & 0.43 & -0.14 \\
\hline $\begin{array}{l}\text { 0A1B0GVD5;A0A1B0GWE8;P } \\
\text { 07339;H7C469;A0A1B0GVP3; } \\
\text { A0A1B0GU92;A0A1B0GU03;H } \\
\text { 7C1V0 }\end{array}$ & CTSD & $\begin{array}{l}\text { Cathepsin D;Cathepsin D } \\
\text { light chain;Cathepsin D } \\
\text { heavy chain }\end{array}$ & 1.35 & -0.14 \\
\hline $\begin{array}{l}\text { A0A087WU02;Q96RQ1;H0YI5 } \\
\text { 8;H0YI50 }\end{array}$ & ERGIC2 & $\begin{array}{l}\text { Endoplasmic reticulum- } \\
\text { Golgi intermediate } \\
\text { compartment protein } 2\end{array}$ & 0.55 & -0.14 \\
\hline $\begin{array}{l}\text { A0A1X7SBZ2;A0A1W2PQ51;Q } \\
92841\end{array}$ & DDX17 & $\begin{array}{l}\text { Probable ATP-dependent } \\
\text { RNA helicase DDX17 }\end{array}$ & 0.66 & -0.14 \\
\hline
\end{tabular}




\begin{tabular}{|c|c|c|c|c|}
\hline O75746 & SLC25A12 & $\begin{array}{l}\text { Calcium-binding } \\
\text { mitochondrial carrier protein } \\
\text { Aralar1 }\end{array}$ & 0.52 & -0.14 \\
\hline Q8WWC4 & C2orf47 & $\begin{array}{l}\text { Uncharacterized protein } \\
\text { C2orf } 47, \text { mitochondrial }\end{array}$ & 0.30 & -0.14 \\
\hline $\begin{array}{l}\text { Q9H936;E9PJH7;A0A0D9SFE } \\
\text { 1;A0A0D9SEI9;K4DIB8;K4DIA } \\
\text { 8;E9PS95 }\end{array}$ & SLC25A22 & $\begin{array}{l}\text { Mitochondrial glutamate } \\
\text { carrier } 1\end{array}$ & 0.40 & -0.14 \\
\hline $\begin{array}{l}\text { A0A1W2PP11;Q9H300;F8WC } \\
\text { Q4;A0A1W2PS40;C9JNP8 }\end{array}$ & PARL & $\begin{array}{l}\text { Presenilins-associated } \\
\text { rhomboid-like protein, } \\
\text { mitochondrial;P-beta }\end{array}$ & 0.51 & -0.14 \\
\hline Q96CS3 & FAF2 & FAS-associated factor 2 & 1.46 & -0.14 \\
\hline $\begin{array}{l}\text { A0A087WY96;P31641;A0A087 } \\
\text { WYN0 }\end{array}$ & SLC6A6 & $\begin{array}{l}\text { Transporter;Sodium- and } \\
\text { chloride-dependent taurine } \\
\text { transporter }\end{array}$ & 0.19 & -0.14 \\
\hline P26640;A0A140T936 & VARS & Valine--tRNA ligase & 0.33 & -0.14 \\
\hline P61006 & RAB8A & Ras-related protein Rab-8A & 0.51 & -0.14 \\
\hline Q9UQ80 & PA2G4 & $\begin{array}{l}\text { Proliferation-associated } \\
\text { protein } 2 \mathrm{G} 4\end{array}$ & 0.26 & -0.14 \\
\hline P62070;E9PK85 & RRAS2 & Ras-related protein R-Ras2 & 0.43 & -0.14 \\
\hline P53621 & COPA & $\begin{array}{l}\text { Coatomer subunit } \\
\text { alpha;:Xenin;Proxenin }\end{array}$ & 0.61 & -0.14 \\
\hline Q96TA1 & FAM129B & Niban-like protein 1 & 0.19 & -0.14 \\
\hline Q9BVG9;A0A0J9YWQ2 & PTDSS2 & $\begin{array}{l}\text { Phosphatidylserine } \\
\text { synthase } 2 \\
\text { NADH dehydrogenase }\end{array}$ & 0.42 & -0.14 \\
\hline O95169;K9J7I2;E9PQ68 & NDUFB8 & $\begin{array}{l}\text { [ubiquinone] } 1 \text { beta } \\
\text { subcomplex subunit } 8 \text {, } \\
\text { mitochondrial }\end{array}$ & 0.72 & -0.13 \\
\hline P38435 & GGCX & $\begin{array}{l}\text { Vitamin K-dependent } \\
\text { gamma-carboxylase } \\
\text { ATP-binding cassette sub- }\end{array}$ & 0.43 & -0.13 \\
\hline Q9NUT2 & ABCB8 & $\begin{array}{l}\text { family B member } 8 \text {, } \\
\text { mitochondrial } \\
1 \text {-acyl-sn-glycerol-3- }\end{array}$ & 0.99 & -0.13 \\
\hline Q99943 & AGPAT1 & $\begin{array}{l}\text { phosphate acyltransferase } \\
\text { alpha }\end{array}$ & 0.44 & -0.13 \\
\hline Q96N66 & MBOAT7 & $\begin{array}{l}\text { Lysophospholipid } \\
\text { acyltransferase } 7 \\
\text { Glycerol-3-phosphate }\end{array}$ & 0.50 & -0.13 \\
\hline P43304 & GPD2 & $\begin{array}{l}\text { dehydrogenase, } \\
\text { mitochondrial }\end{array}$ & 0.74 & -0.13 \\
\hline H7BXF4 & SMPD4 & 0 & 0.44 & -0.13 \\
\hline $\begin{array}{l}\text { A0A0A0MSS8;P42330;S4R3Z } \\
2\end{array}$ & AKR1C3 & $\begin{array}{l}\text { Aldo-keto reductase family } \\
1 \text { member } \mathrm{C} 3\end{array}$ & 0.56 & -0.13 \\
\hline Q58719 & SFT2D3 & $\begin{array}{l}\text { Vesicle transport protein } \\
\text { SFT2C }\end{array}$ & 0.31 & -0.13 \\
\hline $\begin{array}{l}\text { P62829;C9JD32;B9ZVP7;J3KT } \\
29\end{array}$ & RPL23 & $60 S$ ribosomal protein L23 & 0.70 & -0.13 \\
\hline $\begin{array}{l}\text { H7C3I1;F6VDH7;Q3KNR6;Q8I } \\
\text { ZP2;P50502;Q8NFI4 }\end{array}$ & $\begin{array}{l}\text { ST13;ST13P4;ST1 } \\
\text { 3P5 }\end{array}$ & $\begin{array}{l}\text { Putative protein } \\
\text { FAM10A4;Hsc70- } \\
\text { interacting protein; Putative } \\
\text { protein FAM10A5 }\end{array}$ & 0.11 & -0.13 \\
\hline Q9UBX3;F6RGN5 & SLC25A10 & $\begin{array}{l}\text { Mitochondrial dicarboxylate } \\
\text { carrier }\end{array}$ & 0.31 & -0.13 \\
\hline $\begin{array}{l}\text { P05388;F8VWS0;F8VU65;F8V } \\
\text { PE8;G3V210;F8VW21;F8VQY } \\
\text { 6;F8VRK7;Q8NHW5;F8VWV4; } \\
\text { F8VZS0 }\end{array}$ & RPLP0;RPLP0P6 & $\begin{array}{l}60 S \text { acidic ribosomal } \\
\text { protein } \mathrm{P0} 60 \mathrm{~S} \text { acidic } \\
\text { ribosomal protein P0-like }\end{array}$ & 0.41 & -0.13 \\
\hline P05198;H0YJS4;G3V4T5 & EIF2S1 & $\begin{array}{l}\text { Eukaryotic translation } \\
\text { initiation factor } 2 \text { subunit } 1\end{array}$ & 0.21 & -0.13 \\
\hline $\begin{array}{l}\text { H7C1N3;O15155;C9JTT8;Q68 } \\
\text { DU7 }\end{array}$ & $\begin{array}{l}\text { BET1;DKFZp781C } \\
0425\end{array}$ & BET1 homolog & 0.51 & -0.13 \\
\hline $\begin{array}{l}\text { Q8WWY3;E7EVX8;E7EU94;E7 } \\
\text { ESX0;E7EN72 }\end{array}$ & PRPF31 & $\begin{array}{l}\text { U4/U6 small nuclear } \\
\text { ribonucleoprotein Prp31 }\end{array}$ & 0.18 & -0.13 \\
\hline Q9Y2U8 & LEMD3 & $\begin{array}{l}\text { Inner nuclear membrane } \\
\text { protein Man1 }\end{array}$ & 0.62 & -0.13 \\
\hline H7C110;Q96K37 & SLC35E1 & $\begin{array}{l}\text { Solute carrier family } 35 \\
\text { member } \mathrm{E} 1\end{array}$ & 0.97 & -0.12 \\
\hline
\end{tabular}




\begin{tabular}{|c|c|}
\hline P33991 & MCM4 \\
\hline $\begin{array}{l}\text { E7ETZ4;Q9Y6E2;E9PFD4;B5 } \\
\text { MCE7;Q75MG1;B5MCH7 }\end{array}$ & BZW2 \\
\hline P13639 & EEF2 \\
\hline $\begin{array}{l}\text { Q53H12;E9PC15;E9PG39;A0A } \\
\text { 0G2JLG5 }\end{array}$ & AGK \\
\hline B5MCF9;O00541;B3KXD6 & PES1 \\
\hline $\begin{array}{l}\text { J9JIE6;Q9UM00;J3QQY2;J3K } \\
\text { S45 }\end{array}$ & TMCO1 \\
\hline Q9UNQ2;A0A0C4DGB1 & DIMT1 \\
\hline 095470 & SGPL1 \\
\hline Q8N766 & EMC1 \\
\hline Q9BSJ8 & ESYT1 \\
\hline Q8NFQ8 & TOR1AIP2 \\
\hline Q13492 & PICALM \\
\hline A0A024RA52;P25787;C9JCK5 & PSMA2 \\
\hline Q8TDD1 & DDX54 \\
\hline P62820;E7END7 & RAB1A \\
\hline P29401;A0A0B4J1R6 & TKT \\
\hline Q8NBU5 & ATAD1 \\
\hline Q9UKV5 & AMFR \\
\hline Q14257;HOYL43 & $\mathrm{RCN} 2$ \\
\hline O75844 & ZMPSTE24 \\
\hline P61158;B4DXW1 & ACTR3 \\
\hline Q8WVM8 & SCFD1 \\
\hline $\mathrm{P} 11233 ; \mathrm{H} 7 \mathrm{C} 3 \mathrm{P} 7$ & RALA \\
\hline 000267 & SUPT5H \\
\hline $\begin{array}{l}\text { F5GWX5;A0A0C4DGG9;Q148 } \\
39\end{array}$ & CHD4 \\
\hline Q5T2N8 & ATAD3C \\
\hline D6RF48;Q9P2W9 & STX18 \\
\hline Q8WTT2 & NOC3L \\
\hline A0A087WW66;Q99460 & PSMD1 \\
\hline Q06136;K7ERC8;K7EQS7 & KDSR \\
\hline $\begin{array}{l}\text { A0A096LPI6;A0A096LNH5;H7 } \\
\text { C2G3;A0A0B4J2H4;H7C1F6;A } \\
\text { OA0B4J2D5;P30042 } \\
\text { J3QR09;J3KTE4;P84098;J3QL } \\
15\end{array}$ & $\begin{array}{l}\text { C21orf33 } \\
\text { RPL19 }\end{array}$ \\
\hline O95674 & CDS2 \\
\hline Q9H0A0;A0A087WV29 & NAT10 \\
\hline P41250 & GARS \\
\hline
\end{tabular}

DNA replication licensing factor MCM4

Basic leucine zipper and

W2 domain-containing

protein 2

Elongation factor 2

Acylglycerol kinase, mitochondrial

Pescadillo homolog

Transmembrane and

coiled-coil domain-

containing protein 1

Probable

dimethyladenosine

transferase

Sphingosine-1-phosphate lyase 1

ER membrane protein

complex subunit 1

Extended synaptotagmin-1

Torsin-1A-interacting

protein 2

Phosphatidylinositol-binding

clathrin assembly protein

Proteasome subunit alpha

type;Proteasome subunit

alpha type-2

ATP-dependent RNA

helicase DDX54

Ras-related protein Rab-1A

Transketolase

ATPase family AAA

domain-containing protein 1

E3 ubiquitin-protein ligase

AMFR

Reticulocalbin-2

CAAX prenyl protease 1

homolog

Actin-related protein 3

Sec1 family domain-

containing protein 1

Ras-related protein Ral-A

Transcription elongation

factor SPT5

Chromodomain-helicase-

DNA-binding protein 4

ATPase family AAA

domain-containing protein 3C

Syntaxin-18

Nucleolar complex protein 3

homolog

26S proteasome non-

ATPase regulatory subunit

1

3-ketodihydrosphingosine

reductase

ES1 protein homolog,

mitochondrial

Ribosomal protein L19;60S

ribosomal protein $\mathrm{L} 19$

Phosphatidate

cytidylyltransferase 2

$\mathrm{N}$-acetyltransferase 10

Glycine--tRNA ligase 


\begin{tabular}{|c|c|c|c|c|}
\hline Q9Y673 & ALG5 & $\begin{array}{l}\text { Dolichyl-phosphate beta- } \\
\text { glucosyltransferase }\end{array}$ & 0.35 & -0.11 \\
\hline A0A0A0MSK5;Q5JTV8 & TOR1AIP1 & $\begin{array}{l}\text { Torsin-1A-interacting } \\
\text { protein } 1\end{array}$ & 0.39 & -0.11 \\
\hline $\begin{array}{l}\text { K7ELV2;Q96EE3;K7EPZ5;K7E } \\
\text { P88 }\end{array}$ & SEH1L & Nucleoporin SEH1 & 0.26 & -0.11 \\
\hline P55265;H0YCK3 & ADAR & $\begin{array}{l}\text { Double-stranded RNA- } \\
\text { specific adenosine } \\
\text { deaminase }\end{array}$ & 0.91 & -0.11 \\
\hline P09525;Q6P452 & ANXA4 & Annexin A4;Annexin & 0.19 & -0.11 \\
\hline Q9UHQ9;H7C0R7 & CYB5R1 & $\begin{array}{l}\mathrm{NADH} \text {-cytochrome b5 } \\
\text { reductase } 1\end{array}$ & 0.52 & -0.11 \\
\hline 095104 & SCAF4 & $\begin{array}{l}\text { Splicing factor, } \\
\text { arginine/serine-rich } 15\end{array}$ & 0.20 & -0.11 \\
\hline 015269 & SPTLC1 & $\begin{array}{l}\text { Serine palmitoyltransferase } \\
1 \\
\text { Transferrin receptor protein }\end{array}$ & 0.35 & -0.11 \\
\hline P02786;G3V0E5 & TFRC & $\begin{array}{l}1 ; \text { Transferrin receptor } \\
\text { protein } 1, \text { serum form }\end{array}$ & 0.55 & -0.11 \\
\hline $\begin{array}{l}\text { X6RGJ2;Q5SSJ5;B0QZK4;Q5 } \\
\text { SWC8 }\end{array}$ & HP1BP3 & $\begin{array}{l}\text { Heterochromatin protein } 1 \text { - } \\
\text { binding protein } 3\end{array}$ & 0.30 & -0.11 \\
\hline $\begin{array}{l}\text { A0A087X1G1;H7BYD0;Q1671 } \\
\text { 8;F8WAS3;C9IZN5 }\end{array}$ & NDUFA5 & $\begin{array}{l}\text { NADH dehydrogenase } \\
\text { [ubiquinone] } 1 \text { alpha } \\
\text { subcomplex subunit } 5\end{array}$ & 0.30 & -0.11 \\
\hline Q14152 & EIF3A & $\begin{array}{l}\text { Eukaryotic translation } \\
\text { initiation factor } 3 \text { subunit A }\end{array}$ & 1.15 & -0.11 \\
\hline P57088;D6RAA6 & TMEM33 & Transmembrane protein 33 & 0.83 & -0.11 \\
\hline $\begin{array}{l}\text { A0A087WUL2;P49720;A0A087 } \\
\text { WXQ8;A0A087WY10 }\end{array}$ & PSMB3 & $\begin{array}{l}\text { Proteasome subunit beta } \\
\text { type-3 }\end{array}$ & 0.47 & -0.11 \\
\hline P62906 & RPL10A & $60 S$ ribosomal protein $\mathrm{L} 10 \mathrm{a}$ & 0.46 & -0.11 \\
\hline P22830;K7ELX4 & $\mathrm{FECH}$ & $\begin{array}{l}\text { Ferrochelatase, } \\
\text { mitochondrial }\end{array}$ & 1.32 & -0.11 \\
\hline Q5T6Z8;Q9BXS4 & TMEM59 & Transmembrane protein 59 & 0.52 & -0.11 \\
\hline Q96CU9 & FOXRED1 & $\begin{array}{l}\text { FAD-dependent } \\
\text { oxidoreductase domain- } \\
\text { containing protein } 1\end{array}$ & 0.51 & -0.11 \\
\hline P53007;B4DP62 & SLC25A1 & $\begin{array}{l}\text { Tricarboxylate transport } \\
\text { protein, mitochondrial }\end{array}$ & 0.53 & -0.11 \\
\hline Q8NHH9;B5MCN0;C9JQQ5 & ATL2 & Atlastin-2 & 0.78 & -0.11 \\
\hline O43570;B3KUB4 & CA12 & Carbonic anhydrase 12 & 0.48 & -0.11 \\
\hline O00299 & CLIC1 & $\begin{array}{l}\text { Chloride intracellular } \\
\text { channel protein } 1\end{array}$ & 0.26 & -0.11 \\
\hline $\begin{array}{l}\text { P30838;C9JMC5;E9PNN6;|3L3 } \\
\text { I9;A8MYB8 }\end{array}$ & ALDH3A1 & $\begin{array}{l}\text { Aldehyde dehydrogenase, } \\
\text { dimeric NADP-preferring } \\
\text { Serine/threonine-protein }\end{array}$ & 0.27 & -0.11 \\
\hline Q96QC0 & PPP1R10 & $\begin{array}{l}\text { phosphatase } 1 \text { regulatory } \\
\text { subunit } 10\end{array}$ & 0.33 & -0.11 \\
\hline Q9Y3B3;A0A0A6YYA0 & $\begin{array}{l}\text { TMED7;TMED7- } \\
\text { TICAM2 }\end{array}$ & $\begin{array}{l}\text { Transmembrane emp24 } \\
\text { domain-containing protein } 7\end{array}$ & 0.31 & -0.11 \\
\hline Q08257;A6NP24;C9JH92 & CRYZ & Quinone oxidoreductase & 0.54 & -0.10 \\
\hline Q1KMD3;H3BQZ7 & $\begin{array}{l}\text { HNRNPUL2;HNR } \\
\text { NPUL2-BSCL2 }\end{array}$ & $\begin{array}{l}\text { Heterogeneous nuclear } \\
\text { ribonucleoprotein U-like } \\
\text { protein } 2\end{array}$ & 0.70 & -0.10 \\
\hline Q07960;H0YE29 & ARHGAP1 & $\begin{array}{l}\text { Rho GTPase-activating } \\
\text { protein } 1\end{array}$ & 0.25 & -0.10 \\
\hline Q5SWX8 & ODR4 & Protein odr-4 homolog & 0.29 & -0.10 \\
\hline O60488 & ACSL4 & $\begin{array}{l}\text { Long-chain-fatty-acid--CoA } \\
\text { ligase } 4\end{array}$ & 0.76 & -0.10 \\
\hline P28066 & PSMA5 & $\begin{array}{l}\text { Proteasome subunit alpha } \\
\text { type- } 5\end{array}$ & 0.25 & -0.10 \\
\hline $\begin{array}{l}\text { X1WI28;P27635;F8W7C6;A0A } \\
\text { 087WV22;H7C123;H7C2C5 }\end{array}$ & RPL10 & $60 S$ ribosomal protein $L 10$ & 0.22 & -0.10 \\
\hline Q5JR08;P08134;E9PQH6 & $\mathrm{RHOC}$ & $\begin{array}{l}\text { Rho-related GTP-binding } \\
\text { protein RhoC }\end{array}$ & 0.68 & -0.10 \\
\hline Q00325 & SLC25A3 & $\begin{array}{l}\text { Phosphate carrier protein, } \\
\text { mitochondrial }\end{array}$ & 0.56 & -0.10 \\
\hline $\begin{array}{l}\text { A0A087WXM6;J3QQT2;J3KRX } \\
\text { 5;A0A0A6YYL6;P18621;J3QL }\end{array}$ & $\begin{array}{l}\text { RPL17;RPL17- } \\
\text { C18orf32 }\end{array}$ & $60 S$ ribosomal protein $\mathrm{L} 17$ & 0.32 & -0.10 \\
\hline
\end{tabular}


C8;A0A0A0MRF8;J3KRB3;A0

A087WWH0;J3QS96;A0A087

WY81

Q9NPL8;G3XA94

K7ES61;Q9BYD3;K7EKI4;K7E

LF1;K7ELQ0;X6RAY8

E7ES33;E7EPK1;Q16181;G3V

1Q4

E9PPZ9;O43292;E9PLV6;E9P

LG8

A0A0C4DH22;Q9H4G0

P16435;H0Y4R2;E7EMD0

Q9Y678

Q6IAA8;F5GX19;F5H3Y3

Q9Y3Q3

P22314

Q86SF2;HOYAK0;HOYAH3

P42126;Q96DC0;H3BS70

B5MCR8;Q6NXT4

Q96DI7;Q9NSS8

096008

P62701

Q60FE5:A0A087WWY3

Q9Y639;Q9UFM8

P16152;E9PQ63;A8MTM1

O75323;C9K068;H7C333

Q15020;F8VV04

O60427;A0A0A0MR51;H7C2V

0

Q15800;D6RDP9;D6R952

Q8IXI2;H7BXZ6

P03905

Q8NF37;A0A0G2JQ62

H7BXY3;Q7L2E3

Q9H7B2;Q5VXN0

Q9UKM7;HOYG20;H0YGV7

P45880;A0A0A0MR02;Q5JSD 2;Q5JSD1
GALNT7

TIMMDC1

MRPL4

SEPT7

GPAA1

EPB41L1

POR

COPG1

LAMTOR1

TMED3

UBA1

$\mathrm{ECl} 1 ; \mathrm{DCl}$

SLC30A6

SNRNP40;DKFZp

434D199

TOMM40

RPS4X

FLNA

NPTN;DKFZp566

H1924

CBR1

GBAS

SART3

FADS1

MSMO1

RHOT1

MT-ND4

LPCAT1

DHX30

RPF2

MAN1B1

VDAC2
Complex I assembly factor TIMMDC1, mitochondrial $39 S$ ribosomal protein $\mathrm{L} 4$, mitochondrial

Septin-7

Glycosylphosphatidylinosito I anchor attachment 1 protein

Band 4.1-like protein 1

NADPH--cytochrome P450 reductase

Coatomer subunit gamma-1

Ragulator complex protein LAMTOR1

Transmembrane emp24

domain-containing protein 3

Ubiquitin-like modifier-

activating enzyme 1

$\mathrm{N}$ -

acetylgalactosaminyltransfe rase 7;Polypeptide N-

acetylgalactosaminyltransfe rase

Enoyl-CoA delta isomerase 1 , mitochondrial

Zinc transporter 6

U5 small nuclear

ribonucleoprotein $40 \mathrm{kDa}$

protein

Mitochondrial import

receptor subunit TOM40

homolog

40 S ribosomal protein S4,

$\mathrm{X}$ isoform

Neuroplastin

Carbonyl reductase [NADPH] 1

Protein NipSnap homolog 2

Squamous cell carcinoma antigen recognized by $\mathrm{T}$ cells 3

Fatty acid desaturase 1

$-0.09$

Methylsterol

monooxygenase 1

Mitochondrial Rho GTPase

1;Mitochondrial Rho

GTPase

NADH-ubiquinone

oxidoreductase chain 4

Lysophosphatidylcholine acyltransferase 1

Putative ATP-dependent

RNA helicase DHX30

Ribosome production factor

2 homolog

Endoplasmic reticulum

mannosyl-oligosaccharide

1,2-alpha-

mannosidase;alpha-1,2-

Mannosidase

Voltage-dependent anion-

selective channel protein 2
$-0.09$

$-0.09$

$-0.09$

$-0.09$

$-0.09$

$-0.09$

$-0.09$

$-0.09$ 


\begin{tabular}{|c|c|c|c|c|}
\hline $\begin{array}{l}\text { P25789;HOYMZ1;HOYN18;HOY } \\
\text { L69 }\end{array}$ & PSMA4 & $\begin{array}{l}\text { Proteasome subunit alpha } \\
\text { type- } 4 \text {;Proteasome subunit } \\
\text { alpha type }\end{array}$ & 0.20 & -0.09 \\
\hline O15270;H0YJV2 & SPTLC2 & $\begin{array}{l}\text { Serine palmitoyltransferase } \\
2\end{array}$ & 0.38 & -0.09 \\
\hline Q9Y2S7;B4DEM9 & POLDIP2 & $\begin{array}{l}\text { Polymerase delta- } \\
\text { interacting protein } 2\end{array}$ & 0.21 & -0.09 \\
\hline Q13162;H7C3T4 & PRDX4 & Peroxiredoxin-4 & 0.63 & -0.09 \\
\hline Q6ZXV5 & TMTC3 & $\begin{array}{l}\text { Transmembrane and TPR } \\
\text { repeat-containing protein } 3\end{array}$ & 0.67 & -0.09 \\
\hline $\begin{array}{l}\text { C9JYN0;Q16563;A0A0U1RQT } \\
\text { 9;H7C4J8 }\end{array}$ & SYPL1 & $\begin{array}{l}\text { Synaptophysin-like protein } \\
1 \\
\text { Basic leucine zipper and }\end{array}$ & 0.23 & -0.09 \\
\hline Q7L1Q6;C9IZ80 & BZW1 & $\begin{array}{l}\text { W2 domain-containing } \\
\text { protein } 1 \\
\text { Polypeptide } \mathrm{N} \text { - }\end{array}$ & 0.17 & -0.09 \\
\hline Q86SR1 & GALNT10 & $\begin{array}{l}\text { acetylgalactosaminyltransfe } \\
\text { rase } 10\end{array}$ & 0.28 & -0.09 \\
\hline P57740 & NUP107 & $\begin{array}{l}\text { Nuclear pore complex } \\
\text { protein Nup107 }\end{array}$ & 0.26 & -0.09 \\
\hline O75911;Q5SUY4 & DHRS3 & $\begin{array}{l}\text { Short-chain } \\
\text { dehydrogenase/reductase } 3\end{array}$ & 0.32 & -0.09 \\
\hline $\begin{array}{l}\text { A0A024R571;Q9H4M9;C9JC0 } \\
\text { 3;C9J2Z4 }\end{array}$ & EHD1 & $\begin{array}{l}\text { EH domain-containing } \\
\text { protein } 1\end{array}$ & 0.12 & -0.09 \\
\hline Q9NRG9;F8VZ44;H3BU82 & AAAS & Aladin & 0.59 & -0.09 \\
\hline Q6YN16 & HSDL2 & $\begin{array}{l}\text { Hydroxysteroid } \\
\text { dehydrogenase-like protein } \\
2\end{array}$ & 0.61 & -0.09 \\
\hline Q9NVH1 & DNAJC11 & $\begin{array}{l}\text { DnaJ homolog subfamily C } \\
\text { member } 11\end{array}$ & 0.18 & -0.09 \\
\hline Q15397 & KIAA0020 & $\begin{array}{l}\text { Pumilio domain-containing } \\
\text { protein KIAA0020 }\end{array}$ & 0.69 & -0.09 \\
\hline P51148;K7ERI8;K7ERQ8 & RAB5C & Ras-related protein Rab-5C & 0.48 & -0.09 \\
\hline P31930 & UQCRC1 & $\begin{array}{l}\text { Cytochrome b-c1 complex } \\
\text { subunit } 1 \text {, mitochondrial }\end{array}$ & 0.46 & -0.09 \\
\hline Q9NXH8 & TOR4A & Torsin- $4 \mathrm{~A}$ & 0.86 & -0.09 \\
\hline P49755;G3V2K7 & TMED10 & $\begin{array}{l}\text { Transmembrane emp24 } \\
\text { domain-containing protein } \\
10\end{array}$ & 0.60 & -0.09 \\
\hline Q969V3;K7EMW4;K7ENM2 & NCLN & Nicalin & 0.30 & -0.09 \\
\hline P25445 & FAS & $\begin{array}{l}\text { Tumor necrosis factor } \\
\text { receptor superfamily } \\
\text { member } 6\end{array}$ & 0.12 & -0.08 \\
\hline P48449;A0A0G2JQD0 & LSS & Lanosterol synthase & 0.47 & -0.08 \\
\hline O43143 & DHX15 & $\begin{array}{l}\text { Pre-mRNA-splicing factor } \\
\text { ATP-dependent RNA } \\
\text { helicase DHX15 }\end{array}$ & 0.37 & -0.08 \\
\hline O94874 & UFL1 & E3 UFM1-protein ligase 1 & 0.33 & -0.08 \\
\hline P30837 & ALDH1B1 & $\begin{array}{l}\text { Aldehyde dehydrogenase } \\
\mathrm{X}, \text { mitochondrial }\end{array}$ & 0.70 & -0.08 \\
\hline P30050 & RPL12 & $60 S$ ribosomal protein L12 & 0.23 & -0.08 \\
\hline P09211;A8MX94 & GSTP1 & Glutathione S-transferase P & 0.22 & -0.08 \\
\hline Q9Y289 & SLC5A6 & $\begin{array}{l}\text { Sodium-dependent } \\
\text { multivitamin transporter }\end{array}$ & 0.36 & -0.08 \\
\hline $\begin{array}{l}\text { D6RDV0;D6RA37;A0A0A0MT } \\
\text { C2;D6RIY7;Q13454 }\end{array}$ & TUSC3 & $\begin{array}{l}\text { Tumor suppressor } \\
\text { candidate } 3\end{array}$ & 0.25 & -0.08 \\
\hline P04406;E7EUT5 & GAPDH & $\begin{array}{l}\text { Glyceraldehyde-3- } \\
\text { phosphate dehydrogenase }\end{array}$ & 0.54 & -0.08 \\
\hline P40938 & RFC3 & $\begin{array}{l}\text { Replication factor } \mathrm{C} \text { subunit } \\
3 \\
\text { Actin, cytoplasmic } 2 \text {;Actin, } \\
\text { cytoplasmic } 2, \mathrm{~N} \text {-terminally }\end{array}$ & 0.31 & -0.08 \\
\hline $\begin{array}{l}\text { P63261;P60709;|3L3I0;|3L1U9; } \\
\text { I3L4N8 }\end{array}$ & ACTG1;ACTB & $\begin{array}{l}\text { processed;Actin, } \\
\text { cytoplasmic } 1 ; \text { Actin, } \\
\text { cytoplasmic } 1, \mathrm{~N} \text {-terminally } \\
\text { processed }\end{array}$ & 1.09 & -0.08 \\
\hline Q8IXM6;H0Y6T6 & NRM & Nurim & 0.50 & -0.08 \\
\hline
\end{tabular}


P00338;F5GXY2;F5GYU2;F5G

$\mathrm{XH} 2$

F8W1A4;P54819;G3V213;F8V

ZG5;F8VY04

A2A2G4;Q9Y672;S4R350

Q8N6M3

Q15582;HOY8L3

P49368;B4DUR8;Q5SZX6

Q15061

Q13283

F8VQW0;F8VX73;F8VPI1;F8W 201;F8W086;F8VR05;F8VQQ5 ;F8VSI7;F8VVJ4;P55061;F8W $1 \mathrm{G} 3$

Q9Y6M9;E9PH64;E7EWZ0;E9 PF49

075874

Q12965

Q16795

Q9UJ83;C9J306;C9JJM7;B3K

PX4

P61224;P62834;E7ESV4;F5H7

Y6;A6NIZ1;F5GX62;F5H4H0;F 5GYH7;F5H077;F5GWU8;F5H 491;F5H0B7;F5H500;F5H823; B7ZB78;F5GZG1;F5H6R7;F5H 004;A0A075B6Q0;F5GYB5

Q9Y2Z4;HOYHS6

A0A087WXC5;E7ESZ7;09529

Q9UJS0

Q8NBX0

P22087;M0R299;M0QXL5;M0 R2Q4;MOROP1;MOR2U2;M0R1 H0;MOR2B0

O43159;E9PPY3

Q9UBI6

Q92598;A0A0AOMSM0

Q5VTE0;P68104:A0A087WVQ 9;A0A087WV01

014684

P33527;I3L4X2;A0A0A0MS99
ALG6

LDHA

AK2

FITM2

TGFBI

СCT3

WDR43

G3BP1

TMBIM6

NDUFB9

IDH1

MYO1E

NDUFA9

HACL1

RAP1B;RAP1A

YARS2

NDUFA10

SLC25A13

SCCPDH

FBL

RRP8

GNG12

HSPH1

EEF1A1P5;EEF1A 1

PTGES

ABCC1
L-lactate dehydrogenase $\mathrm{A}$

chain

0.24

$-0.08$

Adenylate kinase 2,

mitochondrial;Adenylate

kinase 2,

mitochondrial;Adenylate

0.58

$-0.08$

kinase 2, mitochondrial, $\mathrm{N}$ -

terminally processed

Dolichyl pyrophosphate

Man9GlcNAc2 alpha-1,3-

glucosyltransferase

Fat storage-inducing

transmembrane protein 2

Transforming growth factor-

beta-induced protein ig-h3

T-complex protein 1 subunit gamma

WD repeat-containing

protein 43

Ras GTPase-activating

protein-binding protein 1

Bax inhibitor 1

NADH dehydrogenase

[ubiquinone] 1 beta

subcomplex subunit 9

Isocitrate dehydrogenase [NADP] cytoplasmic

Unconventional myosin-le

0.46

$-0.08$

NADH dehydrogenase

[ubiquinone] 1 alpha

subcomplex subunit 9 , mitochondrial

2-hydroxyacyl-CoA lyase 1

0.19

Ras-related protein Rap-

$1 \mathrm{~b}$;Ras-related protein Rap-

$1 \mathrm{~A}$;Ras-related protein

0.44

$-0.07$

Rap-1b-like protein

Tyrosine--tRNA ligase,

mitochondrial;Tyrosine--

tRNA ligase

NADH dehydrogenase

[ubiquinone] 1 alpha

subcomplex subunit 10

mitochondrial

Calcium-binding

mitochondrial carrier protein

Aralar2

0.50

$-0.08$

0.30

$-0.08$

Saccharopine

dehydrogenase-like

oxidoreductase

rRNA 2-O-

methyltransferase fibrillarin

Ribosomal RNA-processing protein 8

0.28

$-0.07$

Guanine nucleotide-binding protein $\mathrm{G}(\mathrm{I}) / \mathrm{G}(\mathrm{S}) / \mathrm{G}(\mathrm{O})$

subunit gamma-12

Heat shock protein $105 \mathrm{kDa}$

0.56

$-0.07$

Putative elongation factor

1-alpha-like 3;Elongation

factor 1-alpha 1;Elongation factor 1-alpha

Prostaglandin E synthase

$-0.07$

0.48

$-0.07$

0.28

$-0.07$

0.19

$-0.07$

0.11

$-0.07$

0.14

$-0.07$

Multidrug resistance-

associated protein 1
0.18

$-0.07$

0.17

$-0.07$

0.45

$-0.07$ 


P01112
G3V583
H7C131;P09110;C9JDE9
Q12788;J3KNP2
E9PLL6;P46776;E9PJD9
O95297;Q9UEL6
A0A1B0GTB8;A0A1B0GWC0;
A0A1B0GVF3;P23786;A0A1B0
GV75
A0A1W2PS12;A0A1W2PRL0;
A0A1W2PPG5;A0A1W2PPP5;
A0A1W2PPG1;A0A1W2PQM3;
A0A1W2PS81;E7EQ34;I3NI02;
O14653;A0A1W2PNV3;A0A1
W2PPJ0;A0A1W2PRE6;A0A1
W2PRV0;I3LOK1;I3L4Z6;A0A1
W2PRC2;A0A1W2PQP2;A0A1
W2PQE0;A0A1W2PR23;A0A1
W2PPW8;A0A1W2PR02;A0A1
X7SBU8;A0A1W2PRP7
G3V198;O12769;E9PR16

G3V198;Q12769;E9PR16

P47897

F8WAJ0;Q9H8H2
Q96S52
A0A0C4DGX4;Q13616
P62917;E9PKZ0;G3V1A1;E9P
KU4
Q9HCU5;B5MC98

Q9HCU5;B5MC98

P21912;A0A087WXX8;A0A087 WWT1

Q92769

P39748;|3L3E9

O95602;B9ZVN9

Q12797

B4DGU4;P35222

Q9UG63

P10809

Q9NSD9

Q9HD20

B4DXZ6;P51114;E7EU85;E9P

FF5

Q00839;A0A1W2PPS1;A0A1X 7SBS1;Q5RI18;A0A1W2PP35; A0A1W2PPL4;A0A1W2PPH7; A0A1W2PQL0;A0A1W2PP34; A0A1W2PQ74;A0A1W2PRZ7; A0A1W2PQD4

P07195;A8MW50;C9J7H8
HRAS

FAM177A1

ACAA1

TBL3

RPL27A

MPZL1

CPT2

NUP160

QARS

DDX31

PIGS

CUL1

RPL8

PREB

SDHB

HDAC2

FEN1

POLR1A

ASPH

CTNNB1

ABCF2

HSPD1

FARSB

ATP13A1

FXR1

HNRNPU

LDHB
GTPase HRas;GTPase

HRas, N-terminally

processed

0.19

$-0.07$

3-ketoacyl-CoA thiolase, 0

Transducin beta-like protein

60S ribosomal protein L27a

0.24

$-0.07$

Myelin protein zero-like protein 1

Prornitine O-

palmitoyltransferase 2 , mitochondrial

0.25

$-0.07$

Golgi SNAP receptor

complex member 2

0.24

$-0.07$

Nuclear pore complex protein Nup160

Glutamine--tRNA ligase

1.46

$-0.07$

Probable ATP-dependent

RNA helicase DDX31

0.00

$-0.07$

GPI transamidase

component PIG-S

$-0.07$

Cullin-1

0.23

$-0.07$

605 ribosomal protein L8

0.09

$-0.07$

Prolactin regulatory element-binding protein

Succinate dehydrogenase [ubiquinone] iron-sulfur subunit, mitochondrial

Histone deacetylase 2

0.20

$-0.07$

0.40

$-0.07$

0.35

$-0.07$

Flap endonuclease 1

0.43

$-0.07$

DNA-directed RNA

polymerase I subunit

RPA1;DNA-directed RNA

polymerase

Aspartyl/asparaginyl betahydroxylase

0.12

$-0.07$

Catenin beta-1

$-0.07$

ATP-binding cassette subfamily $\mathrm{F}$ member 2

$60 \mathrm{kDa}$ heat shock protein, mitochondrial

Phenylalanine--tRNA ligase beta subunit

Manganese-transporting

ATPase 13A1

Fragile $\mathrm{X}$ mental retardation syndrome-related protein 1

$-0.07$

0.40

$-0.07$

0.28

$-0.06$

0.11

$-0.06$

0.19

$-0.06$

0.08

$-0.06$

Heterogeneous nuclear ribonucleoprotein U

0.45

$-0.06$

L-lactate dehydrogenase $B$ chain;L-lactate

dehydrogenase 


\begin{tabular}{|c|c|c|c|c|}
\hline $\begin{array}{l}\text { A6NLN1;P26599;A0A0U1RRM } \\
4\end{array}$ & PTBP1 & $\begin{array}{l}\text { Polypyrimidine tract-binding } \\
\text { protein } 1\end{array}$ & 0.23 & -0.06 \\
\hline Q9BVC6 & TMEM109 & $\begin{array}{l}\text { Transmembrane protein } \\
109\end{array}$ & 0.20 & -0.06 \\
\hline Q96K19;E9PP55 & RNF170 & $\begin{array}{l}\text { E3 ubiquitin-protein ligase } \\
\text { RNF170 }\end{array}$ & 0.16 & -0.06 \\
\hline O75369;E7EN95 & FLNB & Filamin-B & 0.79 & -0.06 \\
\hline Q13724;C9J8D4 & MOGS & $\begin{array}{l}\text { Mannosyl-oligosaccharide } \\
\text { glucosidase }\end{array}$ & 0.22 & -0.06 \\
\hline P46060 & RANGAP1 & $\begin{array}{l}\text { Ran GTPase-activating } \\
\text { protein } 1\end{array}$ & 0.22 & -0.06 \\
\hline F8W7U8;P49959;F5GXT0 & MRE11A & $\begin{array}{l}\text { Double-strand break repair } \\
\text { protein MRE11A }\end{array}$ & 0.31 & -0.06 \\
\hline Q15286;F5H157 & RAB35 & Ras-related protein Rab-35 & 0.18 & -0.06 \\
\hline $\begin{array}{l}\text { O75251;A0A087WXF6;A0A087 } \\
\text { WTI3;F5H5N1;F5GXJ1 }\end{array}$ & NDUFS7 & $\begin{array}{l}\text { NADH dehydrogenase } \\
\text { [ubiquinone] iron-sulfur } \\
\text { protein } 7, \text { mitochondrial }\end{array}$ & 0.35 & -0.06 \\
\hline Q6NVY1 & $\mathrm{HIBCH}$ & $\begin{array}{l}\text { 3-hydroxyisobutyryl-CoA } \\
\text { hydrolase, mitochondrial }\end{array}$ & 0.51 & -0.06 \\
\hline C9JJ19;P82930 & MRPS34 & $\begin{array}{l}28 \mathrm{~S} \text { ribosomal protein S34, } \\
\text { mitochondrial }\end{array}$ & 0.14 & -0.06 \\
\hline A0A087X2I1;P62333;H0YJC0 & PSMC6 & $\begin{array}{l}26 \mathrm{~S} \text { protease regulatory } \\
\text { subunit } 10 \mathrm{~B}\end{array}$ & 0.23 & -0.06 \\
\hline E9PF10;O75694 & NUP155 & $\begin{array}{l}\text { Nuclear pore complex } \\
\text { protein Nup155 }\end{array}$ & 0.37 & -0.06 \\
\hline $\begin{array}{l}\text { P47755;C9JUG7;F8W9N7;A0A } \\
\text { OD9SET8 }\end{array}$ & CAPZA2 & $\begin{array}{l}\text { F-actin-capping protein } \\
\text { subunit alpha-2 }\end{array}$ & 0.20 & -0.06 \\
\hline Q9H3P7 & ACBD3 & $\begin{array}{l}\text { Golgi resident protein } \\
\text { GCP60 }\end{array}$ & 0.30 & -0.06 \\
\hline Q14137 & BOP1 & $\begin{array}{l}\text { Ribosome biogenesis } \\
\text { protein BOP1 }\end{array}$ & 0.19 & -0.06 \\
\hline Q9P035;H3BS72;H3BPZ1 & HACD3 & $\begin{array}{l}\text { Very-long-chain (3R)-3- } \\
\text { hydroxyacyl-CoA } \\
\text { dehydratase } 3\end{array}$ & 0.34 & -0.06 \\
\hline O14936;Q5JS74;Q5JS72 & CASK & $\begin{array}{l}\text { Peripheral plasma } \\
\text { membrane protein CASK }\end{array}$ & 0.08 & -0.06 \\
\hline Q15149 & PLEC & Plectin & 0.29 & -0.06 \\
\hline P48735;H0YL11 & $\mathrm{IDH} 2$ & $\begin{array}{l}\text { Isocitrate dehydrogenase } \\
\text { [NADP], mitochondrial }\end{array}$ & 0.61 & -0.06 \\
\hline Q9Y399;Q5T8A0 & MRPS2 & $\begin{array}{l}\text { 28S ribosomal protein S2, } \\
\text { mitochondrial }\end{array}$ & 0.16 & -0.06 \\
\hline Q8NBM4;X6R5E5 & UBAC2 & $\begin{array}{l}\text { Ubiquitin-associated } \\
\text { domain-containing protein } 2 \\
\text { Acyl-coenzyme A }\end{array}$ & 0.19 & -0.06 \\
\hline Q9Y305;H7C5Q2 & АСОT9 & $\begin{array}{l}\text { thioesterase 9, } \\
\text { mitochondrial }\end{array}$ & 0.23 & -0.06 \\
\hline A0A087WVQ6;Q00610 & CLTC & $\begin{array}{l}\text { chain;Clathrin heavy chain } \\
1\end{array}$ & 0.35 & -0.06 \\
\hline $\begin{array}{l}\text { A0A0A0MRK6;Q13505;A0A0C } \\
\text { 4DFQ1 }\end{array}$ & MTX1 & Metaxin-1 & 0.22 & -0.05 \\
\hline $\begin{array}{l}\text { P51572;C9JSP1;C9JQ75;C9J0 } \\
\text { M4 }\end{array}$ & BCAP31 & $\begin{array}{l}\text { B-cell receptor-associated } \\
\text { protein } 31\end{array}$ & 0.36 & -0.05 \\
\hline P52272;A0A087X0X3 & HNRNPM & $\begin{array}{l}\text { Heterogeneous nuclear } \\
\text { ribonucleoprotein } \mathrm{M}\end{array}$ & 0.21 & -0.05 \\
\hline Q8NEW0;H0Y362 & SLC30A7 & Zinc transporter 7 & 0.18 & -0.05 \\
\hline P41252;J3KR24;A0A0A0MSX9 & IARS & $\begin{array}{l}\text { Isoleucine--tRNA ligase, } \\
\text { cytoplasmic }\end{array}$ & 0.19 & -0.05 \\
\hline 015400 & STX7 & Syntaxin-7 & 0.13 & -0.05 \\
\hline $\begin{array}{l}\text { Q15019;B5MCX3;C9J2Q4;C9J } \\
\text { 938;H7C310;C9JB25 }\end{array}$ & SEPT2 & Septin-2 & 0.13 & -0.05 \\
\hline Q9BUP3;E9PI87 & HTATIP2 & Oxidoreductase HTATIP2 & 0.23 & -0.05 \\
\hline $\begin{array}{l}\text { K7EP65;K7EKS7;K7ELC4;K7E } \\
\text { MH1;K7ERI7;P35268;K7EJT5 }\end{array}$ & RPL22 & $60 S$ ribosomal protein L22 & 0.14 & -0.05 \\
\hline A0A0B4J2E5;Q15269 & PWP2 & $\begin{array}{l}\text { Periodic tryptophan protein } \\
2 \text { homolog }\end{array}$ & 0.14 & -0.05 \\
\hline A0A087WXS7;043681 & ASNA1 & ATPase ASNA1 & 0.17 & -0.05 \\
\hline J3QLD9;E7EMK3;Q14254 & FLOT2 & Flotillin-2 & 0.16 & -0.05 \\
\hline
\end{tabular}




\begin{tabular}{|c|c|c|c|c|}
\hline $\begin{array}{l}\text { P15559;B4DLR8;H3BNV2;H3B } \\
\text { RK3 }\end{array}$ & NQO1 & $\begin{array}{l}\mathrm{NAD}(\mathrm{P}) \mathrm{H} \text { dehydrogenase } \\
\text { [quinone] } 1 \\
\text { Sulfide:quinone }\end{array}$ & 0.17 & -0.05 \\
\hline Q9Y6N5;H3BNX3 & SQRDL & $\begin{array}{l}\text { oxidoreductase, } \\
\text { mitochondrial }\end{array}$ & 0.29 & -0.05 \\
\hline P04920 & SLC4A2 & Anion exchange protein 2 & 0.16 & -0.05 \\
\hline 015438 & ABCC3 & $\begin{array}{l}\text { Canalicular multispecific } \\
\text { organic anion transporter } 2\end{array}$ & 0.08 & -0.05 \\
\hline Q9H6R4;A0A0A0MRW6 & NOL6 & Nucleolar protein 6 & 0.12 & -0.05 \\
\hline O96005 & CLPTM1 & $\begin{array}{l}\text { Cleft lip and palate } \\
\text { transmembrane protein } 1\end{array}$ & 0.12 & -0.05 \\
\hline O94826 & TOMM70A & $\begin{array}{l}\text { Mitochondrial import } \\
\text { receptor subunit TOM70 }\end{array}$ & 0.24 & -0.05 \\
\hline J3KTA4;P17844 & DDX5 & $\begin{array}{l}\text { Probable ATP-dependent } \\
\text { RNA helicase DDX5 }\end{array}$ & 0.16 & -0.05 \\
\hline Q9H9B4 & SFXN1 & Sideroflexin-1 & 0.41 & -0.05 \\
\hline Q9BTV4 & TMEM43 & Transmembrane protein 43 & 0.24 & -0.05 \\
\hline Q9Y6A1;Q5JT02 & POMT1 & $\begin{array}{l}\text { Protein O-mannosyl- } \\
\text { transferase } 1\end{array}$ & 0.10 & -0.05 \\
\hline Q13423;E9PCX7 & NNT & $\begin{array}{l}N A D(P) \text { transhydrogenase, } \\
\text { mitochondrial }\end{array}$ & 0.20 & -0.05 \\
\hline $\begin{array}{l}\text { A0A0A0MRA5;B7Z4B8;Q9BUJ } \\
\text { 2;MOR3F1;M0QYZ0 }\end{array}$ & HNRNPUL1 & $\begin{array}{l}\text { Heterogeneous nuclear } \\
\text { ribonucleoprotein U-like } \\
\text { protein } 1\end{array}$ & 0.44 & -0.05 \\
\hline K7ELL7;P14314 & PRKCSH & Glucosidase 2 subunit beta & 0.07 & -0.05 \\
\hline P25786;F5GX11 & PSMA1 & $\begin{array}{l}\text { Proteasome subunit alpha } \\
\text { type- } 1 \\
\text { Pentatricopeptide repeat }\end{array}$ & 0.11 & -0.05 \\
\hline Q96EY7 & PTCD3 & $\begin{array}{l}\text { domain-containing protein } \\
3 \text {, mitochondrial }\end{array}$ & 0.27 & -0.05 \\
\hline K7EJE8;K7EKE6;P36776 & LONP1 & $\begin{array}{l}\text { Lon protease homolog, } \\
\text { mitochondrial }\end{array}$ & 0.21 & -0.05 \\
\hline P14735 & IDE & Insulin-degrading enzyme & 0.12 & -0.05 \\
\hline Q8IXI1;H3BST5;I3L2C6 & RHOT2 & $\begin{array}{l}\text { Mitochondrial Rho GTPase } \\
2\end{array}$ & 0.23 & -0.05 \\
\hline Q86VI4 & LAPTM4B & $\begin{array}{l}\text { Lysosomal-associated } \\
\text { transmembrane protein 4B }\end{array}$ & 0.11 & -0.05 \\
\hline $\begin{array}{l}\text { A0A024R4E5;Q00341;H0Y394 } \\
\text {;H7COA4 }\end{array}$ & HDLBP & Vigilin & 0.09 & -0.05 \\
\hline 095373 & IPO7 & Importin-7 & 0.20 & -0.04 \\
\hline A0A0A0MRR7;P09234 & SNRPC & $\begin{array}{l}\text { U1 small nuclear } \\
\text { ribonucleoprotein C }\end{array}$ & 0.07 & -0.04 \\
\hline Q6PI48 & DARS2 & $\begin{array}{l}\text { Aspartate--tRNA ligase, } \\
\text { mitochondrial }\end{array}$ & 0.19 & -0.04 \\
\hline $\begin{array}{l}\text { Q92979;V9GYP5;A0A087WW } \\
\text { Q2;A0A087WVM7 }\end{array}$ & EMG1 & $\begin{array}{l}\text { Ribosomal RNA small } \\
\text { subunit methyltransferase } \\
\text { NEP1 } \\
\text { Pyruvate dehydrogenase }\end{array}$ & 0.12 & -0.04 \\
\hline P08559 & PDHA1 & $\begin{array}{l}\text { E1 component subunit } \\
\text { alpha, somatic form, } \\
\text { mitochondrial }\end{array}$ & 0.15 & -0.04 \\
\hline Q96HV5;H7BXL1;F8WDE2 & TMEM41A & $\begin{array}{l}\text { Transmembrane protein } \\
41 \mathrm{~A} \\
\text { Dihydrolipoyllysine-residue } \\
\text { succinyltransferase }\end{array}$ & 0.10 & -0.04 \\
\hline P36957 & DLST & $\begin{array}{l}\text { component of } 2 \text { - } \\
\text { oxoglutarate } \\
\text { dehydrogenase complex, } \\
\text { mitochondrial }\end{array}$ & 0.19 & -0.04 \\
\hline $\begin{array}{l}\text { P31946;Q4VY20;Q4VY19;A0A } \\
\text { 0J9YWE8 }\end{array}$ & YWHAB & $\begin{array}{l}\text { 14-3-3 protein } \\
\text { beta/alpha;14-3-3 protein } \\
\text { beta/alpha, N-terminally } \\
\text { processed }\end{array}$ & 0.07 & -0.04 \\
\hline Q7L2H7;J3KNJ2;HOYCQ8 & EIF3M & $\begin{array}{l}\text { Eukaryotic translation } \\
\text { initiation factor } 3 \text { subunit M }\end{array}$ & 0.05 & -0.04 \\
\hline Q86SJ2 & AMIGO2 & $\begin{array}{l}\text { Amphoterin-induced protein } \\
2\end{array}$ & 0.21 & -0.04 \\
\hline $\begin{array}{l}\text { Q9NR28;A0A024RBT2;F5H79 } \\
\text { 6;F5GXT8 }\end{array}$ & DIABLO & $\begin{array}{l}\text { Diablo homolog, } \\
\text { mitochondrial }\end{array}$ & 0.14 & -0.04 \\
\hline
\end{tabular}




\begin{tabular}{|c|c|c|c|c|}
\hline Q9NP72;A0A087X163;H0Y6T8 & RAB18 & Ras-related protein Rab-18 & 0.33 & -0.04 \\
\hline P43686 & PSMC4 & $\begin{array}{l}26 \mathrm{~S} \text { protease regulatory } \\
\text { subunit } 6 \mathrm{~B}\end{array}$ & 0.13 & -0.04 \\
\hline Q8TAD4;Q9BY48 & SLC30A5 & Zinc transporter 5 & 0.10 & -0.04 \\
\hline Q2NL82 & TSR1 & $\begin{array}{l}\text { Pre-rRNA-processing } \\
\text { protein TSR1 homolog } \\
\text { Sterol-4-alpha-carboxylate }\end{array}$ & 0.09 & -0.04 \\
\hline Q15738;C9JDR0 & NSDHL & $\begin{array}{l}\text { 3-dehydrogenase, } \\
\text { decarboxylating }\end{array}$ & 0.27 & -0.04 \\
\hline P14927;B7Z2R2 & UQCRB & $\begin{array}{l}\text { Cytochrome b-c1 complex } \\
\text { subunit } 7\end{array}$ & 0.13 & -0.04 \\
\hline P46778;G3V1B3;M0R181 & RPL21 & $60 S$ ribosomal protein L21 & 0.08 & -0.04 \\
\hline Q5T8U5;O15260 & SURF4 & Surfeit locus protein 4 & 0.07 & -0.04 \\
\hline Q9UBV2 & SEL1L & Protein sel-1 homolog 1 & 0.11 & -0.04 \\
\hline P62330 & ARF6 & ADP-ribosylation factor 6 & 0.16 & -0.04 \\
\hline A8MXV4 & NUDT19 & $\begin{array}{l}\text { Nucleoside diphosphate- } \\
\text { linked moiety X motif } 19 \text {, } \\
\text { mitochondrial }\end{array}$ & 0.06 & -0.04 \\
\hline $\begin{array}{l}\text { E7EWV1;Q5H8A4;E7EM50;D6 } \\
\text { RFE8 }\end{array}$ & PIGG & $\begin{array}{l}\text { GPI ethanolamine } \\
\text { phosphate transferase } 2\end{array}$ & 0.13 & -0.04 \\
\hline $\mathrm{P} 13010$ & XRCC5 & $\begin{array}{l}\text { X-ray repair cross- } \\
\text { complementing protein } 5\end{array}$ & 0.29 & -0.04 \\
\hline O75751 & SLC22A3 & $\begin{array}{l}\text { Solute carrier family } 22 \\
\text { member } 3\end{array}$ & 0.08 & -0.04 \\
\hline F6T1Q0;Q6L8Q7 & PDE12 & 2,5-phosphodiesterase 12 & 0.17 & -0.04 \\
\hline P35606 & COPB2 & Coatomer subunit beta & 0.09 & -0.04 \\
\hline O75616;J3QSB2;J3QRV9 & ERAL1 & GTPase Era, mitochondrial & 0.16 & -0.04 \\
\hline P38646 & HSPA9 & $\begin{array}{l}\text { Stress- } 70 \text { protein, } \\
\text { mitochondrial } \\
\text { Polypeptide N- } \\
\text { acetylgalactosaminyltransfe }\end{array}$ & 0.26 & -0.04 \\
\hline Q10471 & GALNT2 & $\begin{array}{l}\text { rase } 2 \text {;Polypeptide } \mathrm{N} \text { - } \\
\text { acetylgalactosaminyltransfe } \\
\text { rase } 2 \text { soluble form } \\
\text { Alkyldihydroxyacetonephos }\end{array}$ & 0.09 & -0.04 \\
\hline O00116;A0A1B0GWA2 & AGPS & $\begin{array}{l}\text { phate synthase, } \\
\text { peroxisomal }\end{array}$ & 0.15 & -0.04 \\
\hline Q9P2J5 & LARS & $\begin{array}{l}\text { Leucine--tRNA ligase, } \\
\text { cytoplasmic } \\
\text { LETM1 and EF-hand }\end{array}$ & 0.23 & -0.04 \\
\hline 095202 & LETM1 & $\begin{array}{l}\text { domain-containing protein } \\
1 \text {, mitochondrial }\end{array}$ & 0.14 & -0.04 \\
\hline Q15046 & KARS & Lysine--tRNA ligase & 0.13 & -0.04 \\
\hline P53396 & ACLY & ATP-citrate synthase & 0.09 & -0.04 \\
\hline P23526 & $\mathrm{AHCY}$ & Adenosylhomocysteinase & 0.07 & -0.04 \\
\hline $\begin{array}{l}\text { A0A087WVM4;B7ZM99;Q6UB } \\
35\end{array}$ & MTHFD1L & $\begin{array}{l}\text { Monofunctional C1- } \\
\text { tetrahydrofolate synthase, } \\
\text { mitochondrial }\end{array}$ & 0.22 & -0.03 \\
\hline $\begin{array}{l}\text { P0CG08;B7ZAQ6;A0A087WW } \\
\text { 78;A0A087WW82;U3KPV2;E9 } \\
\text { PKY3 }\end{array}$ & GPR89B;GPR89A & $\begin{array}{l}\text { Golgi } \mathrm{pH} \text { regulator } \mathrm{B} ; \mathrm{Golgi} \\
\mathrm{pH} \text { regulator } \mathrm{A}\end{array}$ & 0.05 & -0.03 \\
\hline $\begin{array}{l}\text { P43307;C9J3L8;C9J5W0;E9P } \\
\text { AL7;C9IZQ1 }\end{array}$ & SSR1 & $\begin{array}{l}\text { Translocon-associated } \\
\text { protein subunit alpha }\end{array}$ & 0.08 & -0.03 \\
\hline $\begin{array}{l}\text { P48643;B7ZAR1;E9PCA1;E7E } \\
\text { NZ3 }\end{array}$ & CCT5 & $\begin{array}{l}\text { T-complex protein } 1 \text { subunit } \\
\text { epsilon }\end{array}$ & 0.22 & -0.03 \\
\hline Q9Y2X3 & NOP58 & Nucleolar protein 58 & 0.12 & -0.03 \\
\hline E9PDF6;O43795 & MYO1B & Unconventional myosin-lb & 0.10 & -0.03 \\
\hline Q9BTU6;E9PAM4 & PI4K2A & $\begin{array}{l}\text { Phosphatidylinositol 4- } \\
\text { kinase type 2-alpha }\end{array}$ & 0.06 & -0.03 \\
\hline $\begin{array}{l}\text { K7EIV0;A0A075B7C0;K7ELJ7; } \\
\text { A0A0C4DGQ5;P04632;U3KQE } \\
\text { 2;K7EM73;K7EKD8 }\end{array}$ & CAPNS1 & Calpain small subunit 1 & 0.06 & -0.03 \\
\hline G5E994;Q5VW38 & GPR107 & Protein GPR107 & 0.07 & -0.03 \\
\hline
\end{tabular}



Q8IX12;A0A0C4DGG8;F5H1H
2;F5H2E6

H7BXK9;Q9NP58

P67775;P62714

Q53S58

S4R329;HOYK61;HOYNKO;HOY

NK8;Q5J8M3;HOYLP8

F5GYQ1;P61421;J3QL14;R4G

N72

Q8NC44;F8WE68;F8WAL5

Q92538

Q9BW27;J3KT10;J3QL54;F5H

OW7

P84090;G3V279

Q8J015;M0QYS1;P40429;Q6N

VV1

P12236

Q01082;A0A087WUZ3

Q07973

Q8IZV5;E5RK48

Q9BZG1;C9JY26;C9JBG0;Q96 PJ7;E7ES60

P26447

P05141

Q08J23

P07099

B3KY94;014735

Q13151

Q96A33

O96000;H3BPJ9;H3BV16

A0A0G2JL47;A0A024RCR6;A0 A0G2JK23;P46379;F6S6P2;X6 REW1;A0A0G2JJM1

B4DJV2;O75390;A0A0C4DGI3

P39023;G5E9G0;H7C422;H7C

3M2;B5MCW2

B1AK87;B1AK88;P47756;B1A $\mathrm{K} 85$

Q8NFW8
CCAR1

Cell division cycle and

apoptosis regulator protein

ATP-binding cassette subfamily B member 6 ,

Serine/threonine-protein phosphatase 2A catalytic subunit alpha

PPP2CA:PPP2CB

isoform;Serine/threonine-

0.08

$-0.03$

protein phosphatase $2 A$

catalytic subunit beta

isoform

TMEM177

Transmembrane protein

EMC4

ATP6V0D1

FAM134A

GBF1

NUP85

$\mathrm{ERH}$

RPL13a;RPL13A;

RPL13AP3

SLC25A6

SPTBN1

CYP24A1

$\mathrm{RDH} 10$

RAB34

S100A4

SLC25A5

NSUN2

EPHX1

CDIPT

HNRNPAO

CCDC47

NDUFB10

BAT3;BAG6

CS

RPL3

CAPZB

CMAS
177

ER membrane protein

complex subunit 4

V-type proton ATPase

subunit d 1

Protein FAM134A

Golgi-specific brefeldin A-

resistance guanine

nucleotide exchange factor

Nuclear pore complex

protein Nup85

Enhancer of rudimentary

homolog

605 ribosomal protein

L13a;Putative 60S

ribosomal protein $\mathrm{L} 13 \mathrm{a}$

protein RPL13AP3

ADP/ATP translocase

3;ADP/ATP translocase 3,

$\mathrm{N}$-terminally processed

Spectrin beta chain, non-

erythrocytic 1

1,25-dihydroxyvitamin $\mathrm{D}(3)$

24-hydroxylase,

mitochondrial

Retinol dehydrogenase 10

Ras-related protein Rab-34

Protein S100-A4

ADP/ATP translocase

2;ADP/ATP translocase 2,

$\mathrm{N}$-terminally processed

tRNA (cytosine (34)-C(5))-

methyltransferase

Epoxide hydrolase 1

0.05

$-0.03$

0.07

$-0.03$

0.08

$-0.03$

0.07

$-0.03$

0.00

$-0.03$

0.05

$-0.03$

0.06

$-0.03$

0.07

$-0.03$

0.11

$-0.03$

0.07

$-0.03$

0.18

$-0.03$

0.07

$-0.03$

0.12

$-0.03$

0.06

$-0.03$

0.09

$-0.03$

0.06

$-0.03$

CDP-diacylglycerol--inositol

3-phosphatidyltransferase

Heterogeneous nuclear

ribonucleoprotein A0

Coiled-coil domain-

containing protein 47

NADH dehydrogenase

[ubiquinone] 1 beta

subcomplex subunit 10

Large proline-rich protein BAG6

Citrate synthase;Citrate synthase, mitochondrial

60S ribosomal protein L3

F-actin-capping protein

subunit beta

$\mathrm{N}$-acylneuraminate cytidylyltransferase
0.04

0.15

$-0.03$

0.08

$-0.03$

0.05

$-0.03$

0.07

$-0.03$

0.09

$-0.03$

$-0.02$

0.11

$-0.02$

0.11

$-0.02$

0.08

$-0.02$

0.04

$-0.02$ 


P49748
P12235;V9GYG0
P02649;H0Y7L5
F5H365;Q15436
P48651
P51149;C9J8S3;C9J592;C9J4
V0;C9IZZ0
P63104;E7EX29;B0AZS6;B7Z
2E6;H0YB80

A6NEM2:P51610

MOQWZ7;Q9NP81;M0R2C6;M OR259

Q08211

A0A1B0GW05;Q2PZI1

P56192

Q9Y3I0

Q3LIE7;Q15392

Q8NBS9

Q5VZU9;P29144

I3LON3;P46459

P62854;Q5JNZ5

Q86U38

Q8N2K0

Q8N0U8

P00533;E9PFD7;Q504U8

Q9UHB9

A0A0U1RQF0;P49327
ACADVL

SLC25A4

APOE

SEC23A

PTDSS1

RAB7A

YWHAZ

HCFC1

SARS2

DHX9

DPY19L1

MARS

RTCB

Nbla03646;DHCR

24

TXNDC5

TPP2

NSF

RPS26;RPS26P11

NOP9

ABHD12

VKORC1L1

EGFR

SRP68

FASN
Very long-chain specific acyl-CoA dehydrogenase, mitochondrial

ADP/ATP translocase 1

0.20

$-0.02$

Apolipoprotein E

0.06

$-0.02$

Protein transport protein

Sec23A

Phosphatidylserine

synthase 1

0.06

$-0.02$

Ras-related protein Rab-7a

0.06

$-0.02$

0.09

$-0.02$

14-3-3 protein zeta/delta

0.03

$-0.02$

Host cell factor $1 ; \mathrm{HCF} \mathrm{N-}$

terminal chain 1 ; HCF N-

terminal chain 2; HCF N-

terminal chain 3; HCF N-

terminal chain $4 ; \mathrm{HCF} \mathrm{N-}$

terminal chain 5 ; HCF N-

terminal chain 6 ; HCF C-

terminal chain 1 ; HCF C-

terminal chain 2; HCF C-

terminal chain 3; HCF C-

terminal chain 4 ; HCF C-

terminal chain 5; HCF C-

terminal chain 6

Serine--tRNA ligase,

mitochondrial

ATP-dependent RNA

helicase A

Probable C-

mannosyltransferase

DPY19L1

Methionine--tRNA ligase,

cytoplasmic

tRNA-splicing ligase RtcB homolog

Delta(24)-sterol reductase

Thioredoxin domain-

containing protein 5

Tripeptidyl-peptidase 2

Vesicle-fusing ATPase

$40 \mathrm{~S}$ ribosomal protein

S26;Putative $40 S$ ribosomal protein S26-like 1

Nucleolar protein 9

0.07

$-0.02$

0.07

$-0.02$

0.07

$-0.02$

0.09

$-0.02$

0.06

$-0.02$

0.05

$-0.02$

0.10

$-0.02$

0.03

$-0.02$

0.08

$-0.02$

0.03

$-0.02$

0.06

$-0.02$

Monoacylglycerol lipase

ABHD12

Vitamin $\mathrm{K}$ epoxide

reductase complex subunit

1-like protein 1

Epidermal growth facto

receptor;Receptor protein-

tyrosine kinase

Signal recognition particle

subunit SRP68

Fatty acid synthase;[Acyl-

carrier-protein] S-

acetyltransferase;[Acyl-

carrier-protein] S-

malonyltransferase;3-

oxoacyl-[acyl-carrier-

protein] synthase;3-

oxoacyl-[acyl-carrier-

protein] reductase;3-

hydroxyacyl-[acyl-carrier-

protein] dehydratase;Enoyl-

[acyl-carrier-protein]

reductase;Oleoyl-[acyl-

carrier-protein] hydrolase
0.09

$-0.02$

0.05

$-0.02$

0.10

$-0.02$

0.02

$-0.02$

0.03

$-0.02$ 


\begin{tabular}{|c|c|c|c|c|}
\hline 043242 & PSMD3 & $\begin{array}{l}26 \mathrm{~S} \text { proteasome non- } \\
\text { ATPase regulatory subunit } \\
3\end{array}$ & 0.07 & -0.02 \\
\hline P32322;E2QRB3 & PYCR1 & $\begin{array}{l}\text { Pyrroline-5-carboxylate } \\
\text { reductase } 1 \text {, mitochondrial }\end{array}$ & 0.05 & -0.01 \\
\hline Q6PI78 & TMEM65 & Transmembrane protein 65 & 0.10 & -0.01 \\
\hline $\begin{array}{l}\text { M0R3D6;M0R1A7;Q02543;M0 } \\
\text { R117;M0R0P7 }\end{array}$ & RPL18A & $60 \mathrm{~S}$ ribosomal protein $\mathrm{L} 18 \mathrm{a}$ & 0.03 & -0.01 \\
\hline Q16698;E5RJG7;E5RFV2 & DECR1 & $\begin{array}{l}\text { 2,4-dienoyl-CoA reductase, } \\
\text { mitochondrial }\end{array}$ & 0.05 & -0.01 \\
\hline M0R0Y2;P54920;M0R2M1 & NAPA & $\begin{array}{l}\text { Alpha-soluble NSF } \\
\text { attachment protein } \\
\text { Procollagen-lysine,2- }\end{array}$ & 0.05 & -0.01 \\
\hline Q02809 & PLOD1 & $\begin{array}{l}\text { oxoglutarate 5-dioxygenase } \\
1\end{array}$ & 0.03 & -0.01 \\
\hline $\begin{array}{l}\text { P04075;J3KPS3;H3BQN4;H3B } \\
\text { PS8;H3BUH7;H3BR04 }\end{array}$ & ALDOA & $\begin{array}{l}\text { Fructose-bisphosphate } \\
\text { aldolase A;Fructose- } \\
\text { bisphosphate aldolase }\end{array}$ & 0.04 & -0.01 \\
\hline O95831;E9PMA0 & AlFM1 & $\begin{array}{l}\text { Apoptosis-inducing factor } 1 \text {, } \\
\text { mitochondrial }\end{array}$ & 0.13 & -0.01 \\
\hline Q9H3N1 & TMX1 & $\begin{array}{l}\text { Thioredoxin-related } \\
\text { transmembrane protein } 1\end{array}$ & 0.06 & -0.01 \\
\hline Q9Y3T9 & NOC2L & $\begin{array}{l}\text { Nucleolar complex protein } 2 \\
\text { homolog }\end{array}$ & 0.04 & -0.01 \\
\hline $\begin{array}{l}\text { A0A0A0MRV0;Q9P2E9;A0A08 } \\
\text { 7WVV2;F8W7S5 }\end{array}$ & RRBP1 & Ribosome-binding protein 1 & 0.05 & -0.01 \\
\hline $\begin{array}{l}\text { Q16891;B9A067;C9J406;H7C4 } \\
63\end{array}$ & IMMT & $\begin{array}{l}\text { MICOS complex subunit } \\
\text { MIC60 }\end{array}$ & 0.04 & -0.01 \\
\hline P30040;F8VY02 & ERP29 & $\begin{array}{l}\text { Endoplasmic reticulum } \\
\text { resident protein } 29\end{array}$ & 0.05 & -0.01 \\
\hline $\begin{array}{l}\text { O43760;K7ELD9;K7ENG9;K7E } \\
\text { LS8 }\end{array}$ & SYNGR2 & Synaptogyrin-2 & 0.05 & -0.01 \\
\hline Q7KZF4 & SND1 & $\begin{array}{l}\text { Staphylococcal nuclease } \\
\text { domain-containing protein } 1\end{array}$ & 0.04 & -0.01 \\
\hline Q9BWH2 & FUNDC2 & $\begin{array}{l}\text { FUN14 domain-containing } \\
\text { protein } 2\end{array}$ & 0.04 & -0.01 \\
\hline O00425 & IGF2BP3 & $\begin{array}{l}\text { Insulin-like growth factor } 2 \\
\text { mRNA-binding protein } 3\end{array}$ & 0.02 & -0.01 \\
\hline $\begin{array}{l}\text { P35613;A0A087WUV8;A0A087 } \\
\text { X2B5;I3L192 }\end{array}$ & BSG & Basigin & 0.03 & -0.01 \\
\hline P31327 & CPS1 & $\begin{array}{l}\text { Carbamoyl-phosphate } \\
\text { synthase [ammonia], } \\
\text { mitochondrial }\end{array}$ & 0.05 & -0.01 \\
\hline P23378 & GLDC & $\begin{array}{l}\text { Glycine dehydrogenase } \\
\text { (decarboxylating), } \\
\text { mitochondrial }\end{array}$ & 0.02 & -0.01 \\
\hline $\begin{array}{l}\text { A0A0G2JN29;A0A087X117;Q1 } \\
\text { 5155;J3KN36;P69849;Q5JPE7 } \\
\text {;A0A0G2JP90;A0A087WW46 }\end{array}$ & $\begin{array}{l}\text { NOMO1;NOMO3; } \\
\text { NOMO2 }\end{array}$ & $\begin{array}{l}\text { Nodal modulator 1; Nodal } \\
\text { modulator 3;Nodal } \\
\text { modulator } 2\end{array}$ & 0.04 & -0.01 \\
\hline P28838;H0Y9Q1 & LAP3 & Cytosol aminopeptidase & 0.10 & -0.01 \\
\hline Q16762 & TST & $\begin{array}{l}\text { Thiosulfate } \\
\text { sulfurtransferase }\end{array}$ & 0.05 & -0.01 \\
\hline $\begin{array}{l}\text { A0A0C4DGQ8;Q6IAN0;J3KRS } \\
1\end{array}$ & DHRS7B & $\begin{array}{l}\text { Dehydrogenase/reductase } \\
\text { SDR family member 7B }\end{array}$ & 0.02 & -0.01 \\
\hline $\begin{array}{l}\text { Q9Y619;A0A087WTU3;C9JXQ } \\
\text { 7;C9JHH5 }\end{array}$ & TEX264 & $\begin{array}{l}\text { Testis-expressed sequence } \\
264 \text { protein }\end{array}$ & 0.02 & -0.01 \\
\hline P62424;Q5T8U3;Q5T8U2 & RPL7A & $60 S$ ribosomal protein $\mathrm{L} 7 \mathrm{a}$ & 0.02 & -0.01 \\
\hline Q9UHD8;K7EL40 & SEPT9 & Septin-9 & 0.01 & -0.01 \\
\hline 015144 & ARPC2 & $\begin{array}{l}\text { Actin-related protein } 2 / 3 \\
\text { complex subunit } 2\end{array}$ & 0.03 & -0.01 \\
\hline P24534 & EEF1B2 & Elongation factor 1-beta & 0.02 & -0.01 \\
\hline Q9BPW8;H7C2U6 & NIPSNAP1 & Protein NipSnap homolog 1 & 0.02 & -0.01 \\
\hline Q12846;C9JFM5 & STX4 & Syntaxin-4 & 0.02 & -0.01 \\
\hline Q96SQ9 & CYP2S1 & Cytochrome P450 2S1 & 0.02 & -0.01 \\
\hline Q9Y5Y0 & FLVCR1 & $\begin{array}{l}\text { Feline leukemia virus } \\
\text { subgroup } C \text { receptor- } \\
\text { related protein } 1\end{array}$ & 0.02 & -0.01 \\
\hline
\end{tabular}




\begin{tabular}{|c|c|c|c|c|}
\hline Q6NUQ4 & TMEM214 & $\begin{array}{l}\text { Transmembrane protein } \\
214\end{array}$ & 0.03 & -0.01 \\
\hline O75439;G3V0E4 & PMPCB & $\begin{array}{l}\text { Mitochondrial-processing } \\
\text { peptidase subunit beta }\end{array}$ & 0.02 & -0.01 \\
\hline P62873;B1AKQ8;F6UT28 & GNB1 & $\begin{array}{l}\text { Guanine nucleotide-binding } \\
\text { protein } \mathrm{G}(\mathrm{I}) / \mathrm{G}(\mathrm{S}) / \mathrm{G}(\mathrm{T}) \\
\text { subunit beta-1 }\end{array}$ & 0.01 & -0.01 \\
\hline $\begin{array}{l}\text { Q96G23;Q5SZE1;H0YNU7;Q5 } \\
\text { SZE3;H0YKH6;Q5SZE4;Q5SZ } \\
\text { E2 }\end{array}$ & CERS2 & Ceramide synthase 2 & 0.02 & -0.01 \\
\hline $\begin{array}{l}\text { A0A0J9YXF2;J3QT77;A0A0J9 } \\
\text { YYG4;Q15165;G3XAK4 }\end{array}$ & PON2 & $\begin{array}{l}\text { Serum } \\
\text { paraoxonase/arylesterase } 2\end{array}$ & 0.03 & -0.01 \\
\hline $\begin{array}{l}\text { Q5BJH7;K7ERQ0;K7ERY2;K7 } \\
\text { EJQ6 }\end{array}$ & YIF1B & Protein YIF1B & 0.02 & -0.01 \\
\hline Q96ES6 & MFSD3 & $\begin{array}{l}\text { Major facilitator superfamily } \\
\text { domain-containing protein } 3\end{array}$ & 0.02 & -0.01 \\
\hline Q6WCQ1 & MPRIP & $\begin{array}{l}\text { Myosin phosphatase Rho- } \\
\text { interacting protein }\end{array}$ & 0.00 & -0.01 \\
\hline Q86UE4;E5RJU9 & MTDH & Protein LYRIC & 0.02 & 0.00 \\
\hline P08574 & CYC1 & $\begin{array}{l}\text { Cytochrome c1, heme } \\
\text { protein, mitochondrial }\end{array}$ & 0.02 & 0.00 \\
\hline $\begin{array}{l}\text { Q5VZR0;Q9H4G4;A0A087WU } \\
\text { M5 }\end{array}$ & GLIPR2 & $\begin{array}{l}\text { Golgi-associated plant } \\
\text { pathogenesis-related } \\
\text { protein } 1\end{array}$ & 0.01 & 0.00 \\
\hline & & $\begin{array}{l}\text { NADH-cytochrome b5 } \\
\text { reductase 3;NADH- } \\
\text { cytochrome b5 reductase } 3\end{array}$ & & \\
\hline P00387;B1AHF3 & CYB5R3 & $\begin{array}{l}\text { membrane-bound } \\
\text { form;NADH-cytochrome b5 } \\
\text { reductase } 3 \text { soluble form }\end{array}$ & 0.02 & 0.00 \\
\hline 015371 & EIF3D & $\begin{array}{l}\text { Eukaryotic translation } \\
\text { initiation factor } 3 \text { subunit D }\end{array}$ & 0.01 & 0.00 \\
\hline 015173 & PGRMC2 & $\begin{array}{l}\text { progesterone receptor } \\
\text { component } 2\end{array}$ & 0.02 & 0.00 \\
\hline $\begin{array}{l}\text { O00560;G5EA09;B4DHN5;E9P } \\
\text { BU7 }\end{array}$ & SDCBP & Syntenin-1 & 0.01 & 0.00 \\
\hline Q6Y1H2 & HACD2 & $\begin{array}{l}\text { Very-long-chain (3R)-3- } \\
\text { hydroxyacyl-CoA } \\
\text { dehydratase } 2\end{array}$ & 0.00 & 0.00 \\
\hline $\begin{array}{l}\text { Q53GQ0;A0A1B0GVY6;A0A1B } \\
\text { 0GV93 }\end{array}$ & HSD17B12 & $\begin{array}{l}\text { Very-long-chain 3-oxoacyl- } \\
\text { CoA reductase } \\
\text { NADH dehydrogenase }\end{array}$ & 0.01 & 0.00 \\
\hline G3V0I5;P49821;B4DE93 & NDUFV1 & $\begin{array}{l}\text { [ubiquinone] flavoprotein } 1 \text {, } \\
\text { mitochondrial }\end{array}$ & 0.01 & 0.00 \\
\hline O43660 & PLRG1 & Pleiotropic regulator 1 & 0.00 & 0.00 \\
\hline Q9NYL9;H0YKU1;H0YNJ8 & TMOD3 & Tropomodulin-3 & 0.00 & 0.00 \\
\hline Q8TCJ2 & STT3B & $\begin{array}{l}\text { Dolichyl- } \\
\text { diphosphooligosaccharide-- } \\
\text { protein glycosyltransferase } \\
\text { subunit STT3B }\end{array}$ & 0.00 & 0.00 \\
\hline Q96KA5;G5E9Z2 & CLPTM1L & $\begin{array}{l}\text { Cleft lip and palate } \\
\text { transmembrane protein } 1 \text { - } \\
\text { like protein }\end{array}$ & 0.00 & 0.00 \\
\hline Q09161 & NCBP1 & $\begin{array}{l}\text { Nuclear cap-binding protein } \\
\text { subunit } 1 \\
\text { Hippocalcin-like protein }\end{array}$ & 0.00 & 0.00 \\
\hline P37235;P84074 & HPCAL1;HPCA & $\begin{array}{l}\text { 1;Neuron-specific calcium- } \\
\text { binding protein hippocalcin }\end{array}$ & 0.00 & 0.00 \\
\hline Q13435;E9PPJ0 & SF3B2 & Splicing factor 3B subunit 2 & 0.00 & 0.00 \\
\hline P54652 & HSPA2 & $\begin{array}{l}\text { Heat shock-related } 70 \mathrm{kDa} \\
\text { protein } 2\end{array}$ & 0.01 & 0.00 \\
\hline P26196 & DDX6 & $\begin{array}{l}\text { Probable ATP-dependent } \\
\text { RNA helicase DDX6 } \\
\text { Probable C- }\end{array}$ & 0.00 & 0.00 \\
\hline Q6ZPD9;K7ELH8 & DPY19L3 & $\begin{array}{l}\text { mannosyltransferase } \\
\text { DPY19L3 }\end{array}$ & 0.00 & 0.00 \\
\hline Q6UXN9 & WDR82 & $\begin{array}{l}\text { WD repeat-containing } \\
\text { protein } 82\end{array}$ & 0.01 & 0.00 \\
\hline Q03252 & LMNB2 & Lamin-B2 & 0.01 & 0.00 \\
\hline
\end{tabular}




\begin{tabular}{|c|c|c|c|c|}
\hline P51648;J3QRD1;I3L1M4 & ALDH3A2 & $\begin{array}{l}\text { Fatty aldehyde } \\
\text { dehydrogenase }\end{array}$ & 0.02 & 0.00 \\
\hline P78371;F5GWF6;F8VQ14 & CCT2 & $\begin{array}{l}\text { T-complex protein } 1 \text { subunit } \\
\text { beta }\end{array}$ & 0.02 & 0.00 \\
\hline Q5HYK3;F8VVX6;B4DP72 & COQ5 & $\begin{array}{l}\text { 1,4-benzoquinol methylase, } \\
\text { mitochondrial }\end{array}$ & 0.01 & 0.00 \\
\hline E7ETU9 & PLOD2 & 0 & 0.01 & 0.00 \\
\hline P62937;F8WE65;C9J5S7 & PPIA & $\begin{array}{l}\text { Peptidyl-prolyl cis-trans } \\
\text { isomerase A;Peptidyl-prolyl } \\
\text { cis-trans isomerase A, N- } \\
\text { terminally } \\
\text { processed;Peptidyl-prolyl } \\
\text { cis-trans isomerase }\end{array}$ & 0.02 & 0.00 \\
\hline $\begin{array}{l}\text { E9PKG1;H7C211;Q99873;E9P } \\
\text { Q98;E9PIX6;E9PNR9;H0YDE4 } \\
\text {;A0A087X1W2 }\end{array}$ & PRMT1 & $\begin{array}{l}\text { Protein arginine } \mathrm{N}- \\
\text { methyltransferase } 1\end{array}$ & 0.01 & 0.00 \\
\hline P46087 & NOP2 & $\begin{array}{l}\text { Probable } 28 S \text { rRNA } \\
\text { (cytosine }(4447)-\mathrm{C}(5)) \text { - } \\
\text { methyltransferase }\end{array}$ & 0.02 & 0.01 \\
\hline Q6DD88;F5H6I7 & ATL3 & Atlastin-3 & 0.04 & 0.01 \\
\hline Q06830;A0A0AOMSI0 & PRDX1 & Peroxiredoxin-1 & 0.01 & 0.01 \\
\hline Q8NCW5 & APOA1BP & $\begin{array}{l}\mathrm{NAD}(\mathrm{P}) \mathrm{H} \text {-hydrate } \\
\text { epimerase }\end{array}$ & 0.02 & 0.01 \\
\hline $\begin{array}{l}\text { Q4ZIN3;U3KPY4;A0A0A0MTU } \\
3\end{array}$ & TMEM259 & Membralin & 0.01 & 0.01 \\
\hline $\begin{array}{l}\text { P20340;Q9NRW1;C9JU14;J3K } \\
\text { R73 }\end{array}$ & RAB6A;RAB6B & $\begin{array}{l}\text { Ras-related protein Rab- } \\
6 A ; \text { Ras-related protein } \\
\text { Rab-6B }\end{array}$ & 0.03 & 0.01 \\
\hline Q8WWI5 & SLC44A1 & $\begin{array}{l}\text { Choline transporter-like } \\
\text { protein } 1\end{array}$ & 0.02 & 0.01 \\
\hline Q99805 & TM9SF2 & $\begin{array}{l}\text { Transmembrane } 9 \\
\text { superfamily member } 2\end{array}$ & 0.03 & 0.01 \\
\hline P52292;J3QLL0;J3KS65 & KPNA2 & Importin subunit alpha-1 & 0.04 & 0.01 \\
\hline O60264 & SMARCA5 & $\begin{array}{l}\text { SWI/SNF-related matrix- } \\
\text { associated actin-dependent } \\
\text { regulator of chromatin } \\
\text { subfamily A member } 5\end{array}$ & 0.03 & 0.01 \\
\hline Q9Y5M8;H7C4H2 & SRPRB & $\begin{array}{l}\text { Signal recognition particle } \\
\text { receptor subunit beta }\end{array}$ & 0.06 & 0.01 \\
\hline Q96DV4 & MRPL38 & $\begin{array}{l}\text { 39S ribosomal protein L38, } \\
\text { mitochondrial } \\
\text { U3 small nucleolar }\end{array}$ & 0.03 & 0.01 \\
\hline Q9NV31 & IMP3 & $\begin{array}{l}\text { ribonucleoprotein protein } \\
\text { IMP3 }\end{array}$ & 0.02 & 0.01 \\
\hline P05556 & ITGB1 & Integrin beta-1 & 0.02 & 0.01 \\
\hline P00505 & GOT2 & $\begin{array}{l}\text { Aspartate } \\
\text { aminotransferase, } \\
\text { mitochondrial }\end{array}$ & 0.04 & 0.01 \\
\hline O75691 & UTP20 & $\begin{array}{l}\text { Small subunit processome } \\
\text { component } 20 \text { homolog } \\
\text { Small nuclear } \\
\text { ribonucleoprotein- }\end{array}$ & 0.03 & 0.01 \\
\hline J3QLE5;P63162;P14678 & SNRPN;SNRPB & $\begin{array}{l}\text { associated protein } \mathrm{N} ; \text { Small } \\
\text { nuclear ribonucleoprotein- } \\
\text { associated proteins B and } \\
\text { B }\end{array}$ & 0.03 & 0.01 \\
\hline Q6UWP7 & LCLAT1 & $\begin{array}{l}\text { Lysocardiolipin } \\
\text { acyltransferase } 1\end{array}$ & 0.05 & 0.01 \\
\hline Q8N2G8;K7ESN3 & GHDC & $\begin{array}{l}\text { GH3 domain-containing } \\
\text { protein } \\
\text { Gamma- } \\
\text { glutamyltranspeptidase } \\
1 ; \text { Gamma- } \\
\text { glutamyltranspeptidase } 1\end{array}$ & 0.04 & 0.01 \\
\hline $\begin{array}{l}\text { P19440;B5MCK8;E7ET76;A6N } \\
\text { GU5;P36268 }\end{array}$ & $\begin{array}{l}\text { GGT1;GGT2;GGT } \\
3 P\end{array}$ & $\begin{array}{l}\text { heavy chain;Gamma- } \\
\text { glutamyltranspeptidase } 1 \\
\text { light chain;Putative gamma- } \\
\text { glutamyltranspeptidase } \\
\text { 3;Putative gamma- } \\
\text { glutamyltranspeptidase } 3\end{array}$ & 0.03 & 0.01 \\
\hline
\end{tabular}




Q6P4A7
B5MDF5;J3KQE5;P62826;F5H
018;H0YFC6
Q9GZP9;I3L3R8;I3L4W7;K7E
QE8;I3L1W3;I3L1S8;I3L1T3;I3
L0R8
Q9BQG0;I3L1L3
P17987;E7ERF2;E7EQR6;F5H
282
C9JRZ6;F8WAR4;Q9NX63
P21980
Q6P1A2;F5H0M4

P62979;J3QS39;J3QTR3;F5H
6Q2;F5GYU3;F5H2Z3;F5H2665
;B4DV12;F5H388;F5H747;F5G
XK7;J3QKN0;Q5PY61;Q96C32
;P62987;P0CG47;P0CG48;M0
R1V7;Q49A90;MOR1M6;M0R2
S1;J3QSA3;F5GZ39

Q8TB36

Q9Y276;C9J8G3

P60903

P08240

Q4VXZ8;Q9NUI1;A0A0J9YWI0

A0A0A0MTS2;P06744;K7EQ4 8;A0A0J9YXP8;A0A0J9YX90; A0A0J9YYH3

Q9NW15

Q9NZ01

Q9Y2P8

Q9UQE7

075643

P50990

Q96IX5

P00558

Q13347

Q9UJX2

B7Z911;Q5T4U5;P11310

Q9H6K4

Q15006
SFXN4

RAN

DERL2

MYBBP1A

TCP1

$\mathrm{CHCHD} 3$

TGM2

LPCAT3

RPS27A;UBB;UB C;UBA52

GDAP1

BCS1L

S100A10

SRPR

DECR2

GPI

ANO10

TECR

RCL1

SMC3

SNRNP200

СCT8

USMG5

PGK1

EIF3I

CDC23

ACADM

OPA3

EMC2 heavy chain;Putative

gamma-

glutamyltranspeptidase 3

light chain;Inactive gamma-

glutamyltranspeptidase 2

Sideroflexin-4 $\quad 0.00$

0.01

GTP-binding nuclear

protein Ran

0.03

0.01

Derlin-2

0.03

0.01

Myb-binding protein $1 \mathrm{~A}$

0.05

0.01

T-complex protein 1 subunit alpha

MICOS complex subunit

MIC19

0.04

0.01

0.03

0.01

Protein-glutamine gamma-

glutamyltransferase 2

Lysophospholipid

acyltransferase 5

Ubiquitin-40S ribosomal

protein S27a;Ubiquitin;40S

ribosomal protein

S27a;Ubiquitin-60S

ribosomal protein

L40;Ubiquitin;60S

ribosomal protein

L40;Polyubiquitin-

B;Ubiquitin;Polyubiquitin-

C;Ubiquitin

Ganglioside-induced

differentiation-associated

protein 1

Mitochondrial chaperone

BCS1

0.02

0.01

0.03

0.01

Protein S100-A10

Signal recognition particle receptor subunit alpha

Peroxisomal 2,4-dienoyl-

CoA reductase

Glucose-6-phosphate

isomerase

Anoctamin-10

0.03

0.01

Very-long-chain enoyl-CoA reductase

RNA 3-terminal phosphate cyclase-like protein

Structural maintenance of chromosomes protein 3

U5 small nuclear

ribonucleoprotein $200 \mathrm{kDa}$ helicase

T-complex protein 1 subunit theta

Up-regulated during

skeletal muscle growth protein 5

Phosphoglycerate kinase 1

Eukaryotic translation initiation factor 3 subunit I

Cell division cycle protein

23 homolog

Medium-chain specific acyl-

CoA dehydrogenase,

mitochondrial

Optic atrophy 3 protein

0.03

0.01

0.05

0.01

0.03

0.01

0.04

0.01

0.04

0.01

0.03

0.01

0.03

0.01

0.07

0.01

0.04

0.01

0.05

0.01

0.05

0.01

0.09

0.02

0.05

0.02

0.04

0.02

0.05

0.02

0.05

0.02

0.07

0.02

ER membrane protein

complex subunit 2
0.05

0.02

0.07

0.02 


\begin{tabular}{|c|c|c|c|c|}
\hline A0A0B4J2A4;P42765;K7EME0 & ACAA2 & $\begin{array}{l}\text { 3-ketoacyl-CoA thiolase, } \\
\text { mitochondrial }\end{array}$ & 0.06 & 0.02 \\
\hline J3KQI6;Q9BX79;I3NI08 & STRA6 & $\begin{array}{l}\text { Stimulated by retinoic acid } \\
\text { gene } 6 \text { protein homolog }\end{array}$ & 0.05 & 0.02 \\
\hline Q14696 & MESDC2 & LDLR chaperone MESD & 0.08 & 0.02 \\
\hline Q8N163;H0YB24;G3V119 & CCAR2 & $\begin{array}{l}\text { Cell cycle and apoptosis } \\
\text { regulator protein } 2 \\
\text { Serine/threonine-protein } \\
\text { phosphatase PP1-alpha }\end{array}$ & 0.13 & 0.02 \\
\hline P62136;E9PMD7 & PPP1CA & $\begin{array}{l}\text { catalytic } \\
\text { subunit;Serine/threonine- } \\
\text { protein phosphatase }\end{array}$ & 0.15 & 0.02 \\
\hline Q96LJ7;H0YNC2 & DHRS1 & $\begin{array}{l}\text { Dehydrogenase/reductase } \\
\text { SDR family member } 1\end{array}$ & 0.03 & 0.02 \\
\hline P13797;A0A0A0MSQ0 & PLS3 & Plastin-3 & 0.07 & 0.02 \\
\hline Q96HE7 & ERO1L & ERO1-like protein alpha & 0.08 & 0.02 \\
\hline P63092;Q5JWF2 & GNAS & $\begin{array}{l}\text { Guanine nucleotide-binding } \\
\text { protein } \mathrm{G}(\mathrm{s}) \text { subunit alpha } \\
\text { isoforms short;Guanine } \\
\text { nucleotide-binding protein } \\
\text { G(s) subunit alpha isoforms } \\
\text { XLas }\end{array}$ & 0.09 & 0.02 \\
\hline Q13637 & RAB32 & Ras-related protein Rab-32 & 0.05 & 0.02 \\
\hline Q9H0D6 & XRN2 & 5-3 exoribonuclease 2 & 0.10 & 0.02 \\
\hline Q9NQZ5 & STARD7 & $\begin{array}{l}\text { StAR-related lipid transfer } \\
\text { protein } 7 \text {, mitochondrial }\end{array}$ & 0.05 & 0.02 \\
\hline $\begin{array}{l}\text { A0A0G2JIW1;P0DMV9;P0DM } \\
\text { V8;V9GZ37 }\end{array}$ & HSPA1B;HSPA1A & $\begin{array}{l}\text { Heat shock } 70 \mathrm{kDa} \text { protein } \\
1 \mathrm{~B} ; \text {;eat shock } 70 \mathrm{kDa} \\
\text { protein } 1 \mathrm{~A}\end{array}$ & 0.06 & 0.02 \\
\hline O43615;M0QXU7 & TIMM44 & $\begin{array}{l}\text { Mitochondrial import inner } \\
\text { membrane translocase } \\
\text { subunit TIM44 }\end{array}$ & 0.07 & 0.02 \\
\hline Q96RP9;C9IZ01;F8WAU4 & GFM1 & $\begin{array}{l}\text { Elongation factor } \mathrm{G} \text {, } \\
\text { mitochondrial }\end{array}$ & 0.05 & 0.02 \\
\hline 095573 & ACSL3 & $\begin{array}{l}\text { Long-chain-fatty-acid--CoA } \\
\text { ligase } 3\end{array}$ & 0.18 & 0.02 \\
\hline Q9UPY5 & SLC7A11 & $\begin{array}{l}\text { Cystine/glutamate } \\
\text { transporter }\end{array}$ & 0.13 & 0.02 \\
\hline P26641 & EEF1G & Elongation factor 1-gamma & 0.05 & 0.02 \\
\hline Q14165;F5H1S8;H0YG07 & MLEC & Malectin & 0.09 & 0.02 \\
\hline O15042;E7ET15 & U2SURP & $\begin{array}{l}\text { U2 snRNP-associated } \\
\text { SURP motif-containing } \\
\text { protein }\end{array}$ & 0.13 & 0.02 \\
\hline A0A0A0MTB8;Q8NI36 & WDR36 & $\begin{array}{l}\text { WD repeat-containing } \\
\text { protein } 36\end{array}$ & 0.05 & 0.02 \\
\hline Q05048;A0A0A0MSZ9 & CSTF1 & $\begin{array}{l}\text { Cleavage stimulation factor } \\
\text { subunit } 1\end{array}$ & 0.11 & 0.02 \\
\hline Q9HD26;F5H1Y4 & GOPC & $\begin{array}{l}\text { Golgi-associated PDZ and } \\
\text { coiled-coil motif-containing } \\
\text { protein }\end{array}$ & 0.10 & 0.02 \\
\hline Q15388 & TOMM20 & $\begin{array}{l}\text { Mitochondrial import } \\
\text { receptor subunit TOM20 } \\
\text { homolog }\end{array}$ & 0.14 & 0.03 \\
\hline $\begin{array}{l}\text { G3V5Z7;P60900;G3V295;G3V } \\
\text { 3I1;G3V3U4 }\end{array}$ & PSMA6 & $\begin{array}{l}\text { Proteasome subunit alpha } \\
\text { type;Proteasome subunit } \\
\text { alpha type-6 }\end{array}$ & 0.09 & 0.03 \\
\hline P28074 & PSMB5 & $\begin{array}{l}\text { Proteasome subunit beta } \\
\text { type- } 5\end{array}$ & 0.09 & 0.03 \\
\hline Q9NZB2;A0A0C4DH52 & FAM120A & $\begin{array}{l}\text { Constitutive coactivator of } \\
\text { PPAR-gamma-like protein } 1\end{array}$ & 0.08 & 0.03 \\
\hline $\begin{array}{l}\text { A0A087X253;P63010;A0A087 } \\
\text { WYD1;A0A087WU93;A0A087 } \\
\text { WZQ6 }\end{array}$ & AP2B1 & AP-2 complex subunit beta & 0.13 & 0.03 \\
\hline $\begin{array}{l}\text { P15880;H0YEN5;E9PQD7;E9P } \\
\text { MM9 }\end{array}$ & RPS2 & $40 S$ ribosomal protein $\mathrm{S} 2$ & 0.09 & 0.03 \\
\hline Q99797 & MIPEP & $\begin{array}{l}\text { Mitochondrial intermediate } \\
\text { peptidase }\end{array}$ & 0.05 & 0.03 \\
\hline $\begin{array}{l}\text { A0A0A0MS41;A0A1P0AYU5;Q } \\
\text { 9BWM7;S4R3N9 }\end{array}$ & SFXN3 & Sideroflexin;Sideroflexin-3 & 0.17 & 0.03 \\
\hline
\end{tabular}




\begin{tabular}{|c|c|}
\hline X6RM59;Q9H0P0 & NT5C3A \\
\hline Q96JJ7 & TMX3 \\
\hline $\begin{array}{l}\text { A0A1B0GW68;A0A1B0GV06;A } \\
\text { OA1B0GTP7;A0A1B0GUE3;A0 } \\
\text { A1B0GUG1;A0A1B0GUW4;E7 } \\
\text { EMM4;A0A1B0GUA4;A0A1B0 } \\
\text { GTM3;A0A1B0GTZ5;A0A1B0G } \\
\text { UH5;Q13510 }\end{array}$ & ASAH1 \\
\hline P00352 & ALDH1A1 \\
\hline P10620;F5H7F6;F5H6X2 & MGST1 \\
\hline P12955 & PEPD \\
\hline HOYEL5;C9JQD4;O43447 & $\mathrm{PPIH}$ \\
\hline Q92504;A2AAT0 & SLC39A7 \\
\hline $\begin{array}{l}\text { A0A1W2PPH1;P23368;A0A1W } \\
\text { 2PQT3;A0A1W2PQH3;A0A1W } \\
\text { 2PQY8;A0A1W2PQF8;A0A1W } \\
\text { 2PR68;A0A1W2PQ37 }\end{array}$ & ME2 \\
\hline Q9NS69 & TOMM22 \\
\hline P30153;B3KQV6;C9J9C1 & PPP2R1A \\
\hline $\begin{array}{l}\text { F8WCF6;P59998;F8WDD7;H7 } \\
\text { COA3;A0A0A6YY9;R4GN08 }\end{array}$ & $\begin{array}{l}\text { ARPC4- } \\
\text { TTLL3;ARPC4 }\end{array}$ \\
\hline P06733 & ENO1 \\
\hline P25705 & ATP5A1 \\
\hline P52209;K7EMN2;K7EM49 & PGD \\
\hline Q9P2X0 & DPM3 \\
\hline 095292 & VAPB \\
\hline P54136 & RARS \\
\hline Q96LW7 & C9orf89 \\
\hline Q9UJZ1;A0A087WYB4 & STOML2 \\
\hline Q13011;M0R248 & $\mathrm{ECH} 1$ \\
\hline Q9H6X2 & ANTXR1 \\
\hline P40939 & HADHA \\
\hline O43747 & AP1G1 \\
\hline Q9NPJ3 & ACOT13 \\
\hline Q14764 & MVP \\
\hline Q10713 & PMPCA \\
\hline Q86Y07;E7ERS5 & VRK2 \\
\hline
\end{tabular}

5-nucleotidase;Cytosolic 5nucleotidase $3 \mathrm{~A}$

Protein disulfide-isomerase TMX3

0.05

0.03

Acid ceramidase;Acid ceramidase subunit alpha;Acid ceramidase subunit beta

Retinal dehydrogenase 1

Microsomal glutathione Stransferase 1

0.04

0.03

Xaa-Pro dipeptidase

0.10

0.03

Peptidyl-prolyl cis-trans

isomerase;Peptidyl-prolyl

0.05

0.03

cis-trans isomerase $\mathrm{H}$

0.06

0.03

Zinc transporter SLC39A7

0.04

0.03

NAD-dependent malic

enzyme, mitochondrial

0.03

Mitochondrial import

receptor subunit TOM22

homolog

Serine/threonine-protein

phosphatase $2 \mathrm{~A} 65 \mathrm{kDa}$

regulatory subunit $A$ alpha

isoform

Actin-related protein 2/3

complex subunit 4

Alpha-enolase

0.09

ATP synthase subunit

alpha, mitochondrial

6-phosphogluconate

dehydrogenase,

decarboxylating

Dolichol-phosphate

mannosyltransferase

subunit 3

Vesicle-associated

membrane protein-

associated protein $\mathrm{B} / \mathrm{C}$

Arginine--tRNA ligase,

cytoplasmic

Bcl10-interacting CARD

protein

0.06

0.03

0.08

0.03

0.15

0.03

0.08

0.03

0.36

0.03

0.05

0.03

Stomatin-like protein 2

mitochondrial

Delta(3,5)-Delta(2,4)-

dienoyl-CoA isomerase, mitochondrial

Anthrax toxin receptor 1

Trifunctional enzyme

subunit alpha,

mitochondrial;Long-chain

enoyl-CoA hydratase;Long

chain 3-hydroxyacyl-CoA

dehydrogenase

AP-1 complex subunit

gamma-1

Acyl-coenzyme A

thioesterase 13;Acyl-

coenzyme A thioesterase

$13, \mathrm{~N}$-terminally processed

Major vault protein

0.07

0.03

0.10

0.03

0.12

0.03

0.06

0.03

0.13

0.03

0.18

0.03

0.06

0.03

Mitochondrial-processing

peptidase subunit alpha

Serine/threonine-protein

kinase VRK2 


\begin{tabular}{|c|c|}
\hline P56182 & RRP1 \\
\hline $\begin{array}{l}\text { A0A087X2D5;Q9BRJ2;A0A0G } \\
\text { 2JMS5;A0A087WU62 }\end{array}$ & MRPL45 \\
\hline P28331;B4DJ81 & NDUFS1 \\
\hline Q86W42 & THOC6 \\
\hline $\begin{array}{l}\text { J3QQ67;Q07020;G3V203;H0Y } \\
\text { HA7;F8VYV2;A0A075B7A0;F8 } \\
\text { VUA6 }\end{array}$ & RPL18 \\
\hline Q6P1M0 & SLC27A4 \\
\hline 014773 & TPP1 \\
\hline Q53EU6 & AGPAT9 \\
\hline Q8N1F7;H3BVG0 & NUP93 \\
\hline P28288 & $\mathrm{ABCD} 3$ \\
\hline O15145;C9JZD1;F8VR50 & ARPC3 \\
\hline Q8NI60 & ADCK3 \\
\hline Q14684 & RRP1B \\
\hline 075306 & NDUFS2 \\
\hline Q13488;E9PNA6;E9PM12 & TCIRG1 \\
\hline Q9UL25 & RAB21 \\
\hline P20337 & RAB3B \\
\hline P27824 & CANX \\
\hline Q969Q5;F8W8H5 & RAB24 \\
\hline Q9H7Z7;A6NHH0;X6RJ95 & PTGES2 \\
\hline Q08945 & SSRP1 \\
\hline Q9NZ45 & CISD1 \\
\hline Q9Y6V7 & DDX49 \\
\hline O75431;C9JNK6;C9JAZ1 & MTX2 \\
\hline F5H6E2;O00159 & MYO1C \\
\hline P07900 & HSP90AA1 \\
\hline Q15008 & PSMD6 \\
\hline P84077;P61204;F5H423 & ARF1;ARF3 \\
\hline J3QL56;O75880 & ScO1 \\
\hline $\begin{array}{l}\text { P14618;B4DNK4;H3BTN5;H3B } \\
\text { Q34;H3BR70 }\end{array}$ & PKM \\
\hline P50991 & ССТ4 \\
\hline Q9Y490 & TLN1 \\
\hline Q16740;M0R208 & CLPP \\
\hline
\end{tabular}

Ribosomal RNA processing

protein 1 homolog $A$

39S ribosomal protein L45,

mitochondrial

$\mathrm{NADH}$-ubiquinone

oxidoreductase $75 \mathrm{kDa}$

subunit, mitochondrial

THO complex subunit 6

homolog

60S ribosomal protein L18

Long-chain fatty acid

transport protein 4

Tripeptidyl-peptidase 1

Glycerol-3-phosphate

acyltransferase 3

Nuclear pore complex

protein Nup93

ATP-binding cassette sub-

family D member 3

Actin-related protein 2/3

complex subunit 3

Atypical kinase ADCK3,

mitochondrial

Ribosomal RNA processing

protein 1 homolog $B$

NADH dehydrogenase

[ubiquinone] iron-sulfur

protein 2, mitochondrial

V-type proton ATPase 116

$\mathrm{kDa}$ subunit a isoform 3 ; $\mathrm{V}$ -

type proton ATPase subunit a

Ras-related protein Rab-21

Prostaglandin E synthase

2;Prostaglandin E synthase

2 truncated form

FACT complex subunit

SSRP1

CDGSH iron-sulfur domain-

containing protein 1

Probable ATP-dependent

RNA helicase DDX49

Metaxin-2

Unconventional myosin-lc

Heat shock protein HSP 90alpha

26S proteasome non-

ATPase regulatory subunit 6

ADP-ribosylation factor

1;ADP-ribosylation factor 3

Protein SCO1 homolog,

mitochondrial

Pyruvate kinase

PKM;Pyruvate kinase

T-complex protein 1 subunit delta

Talin-1

ATP-dependent Clp

protease proteolytic

subunit, mitochondrial;ATPdependent Clp protease proteolytic subunit
0.29

0.12

0.17

0.06

0.14

0.03

0.03

0.03

0.03

0.03

0.03

0.04

0.04

0.04

0.04

0.04

0.04

0.04

0.04

0.04

0.04

0.04

0.04

0.04

0.04

0.15

0.04

0.10

0.04

0.09

0.04

0.10

0.04

0.16

0.04

0.07

0.04

0.15

0.04

0.07

0.04

0.18

0.04

0.10

0.04

0.20

0.04

0.11

0.04

0.10

0.04 
A0A182DWI4;E9PN30;Q9BQE Q9BXP5;H7C3A1

Q86UL3

E5RGS2;Q9H6H4

B3KSI3;O15382;MOQXF9;M0Q Z10;M0QZP4

$\mathrm{P} 48047 ; \mathrm{H} 7 \mathrm{COC} 1$

000487

P60174

P43490;A0A0C4DFS8

Q8TAT6

A8MXZ4;A0A0C4DFY5;Q9NQ 84;J9JIE0

Q9GZY8

Q9HDC9;H0Y512

E9PC52;Q16576

P22695;H3BRG4;H3BSJ9

Q9BUB7

J3KQ45;F8W8W7;O43493

Q96S66

Q9Y2R0;K7EPV0

Q9HA77

Q9BQB6;I3L3B4;F8W9H0;E9P LN8

C9JP16;075718

Q2TAY7

O75909;G3V5E1;G3V2Q3

P02792

Q7Z7K6

R4GMY8;E5RHG8;Q15369

P49768;E7ES96;G3V3Z0;G3V 499;G3V2G7

Q9NRX5

P49207
ATP5O

PSMD14

VIMP

SRRT

AGPAT6

REEP4

BCAT2

TPI1

NAMPT

NPLOC4

GPRC5C

MFF

APMAP

RBBP7

UQCRC2

TMEM70

TGOLN2

CLCC1

COA3

CARS2

VKORC1

CRTAP

SMU1

CCNK

FTL

CENPV

TCEB1

PSEN1

SERINC1

RPL34
Selenoprotein S

Serrate RNA effector

molecule homolog

Glycerol-3-phosphate

acyltransferase 4

Receptor expression-

enhancing protein;Receptor expression-enhancing

protein 4

Branched-chain-amino-acid aminotransferase;Branched

-chain-amino-acid

aminotransferase,

mitochondrial

ATP synthase subunit $O$, mitochondrial

26S proteasome non-

ATPase regulatory subunit 14

Triosephosphate isomerase

Nicotinamide

phosphoribosyltransferase

Nuclear protein localization protein 4 homolog

G-protein coupled receptor family $\mathrm{C}$ group 5 member $\mathrm{C}$

Mitochondrial fission factor

Adipocyte plasma

membrane-associated

protein

Histone-binding protein

RBBP7

Cytochrome b-c1 complex subunit 2, mitochondrial

Transmembrane protein 70 , mitochondrial

Trans-Golgi network

integral membrane protein 2

Chloride channel CLIC-like protein 1

Cytochrome c oxidase

assembly factor 3 homolog, mitochondrial

Probable cysteine--tRNA

ligase, mitochondrial

Vitamin K epoxide

reductase complex subunit 1

Cartilage-associated

protein

WD40 repeat-containing protein SMU1;WD40

repeat-containing protein SMU1, N-terminally

processed

Cyclin-K

Ferritin light chain

Centromere protein $\mathrm{V}$

Transcription elongation factor B polypeptide 1 Presenilin-1;Presenilin-1 NTF subunit;Presenilin-1 CTF subunit;Presenilin-1 CTF12;Presenilin

Serine incorporator 1

60S ribosomal protein L34 


\begin{tabular}{|c|c|}
\hline Q92887 & ABCC2 \\
\hline P61981 & YWHAG \\
\hline $\begin{array}{l}\text { P35232;C9JW96;E9PCW0;C9J } \\
\text { Z20;E7ESE2 }\end{array}$ & PHB \\
\hline P37802;X6RJP6 & TAGLN2 \\
\hline O60832;C9IYT0;H7C0M1 & DKC1 \\
\hline $\begin{array}{l}\text { A0A0U1RQH7;G3XAC6;Q1449 } \\
\text { 8;H0Y4X3;A0A0U1RQW2 }\end{array}$ & RBM39 \\
\hline P11177;C9J634 & PDHB \\
\hline Q13155;A8MU58;F8W950 & AIMP2 \\
\hline Q969M3;E5RGR9;E5RHH4 & YIPF5 \\
\hline G3XAN4;Q15629 & TRAM1 \\
\hline P13667 & PDIA4 \\
\hline P21796;C9JI87 & VDAC1 \\
\hline P20339 & RAB5A \\
\hline P18031;B4DSN5 & PTPN1 \\
\hline P46777 & RPL5 \\
\hline P09874 & PARP1 \\
\hline Q14974;J3KTM9 & KPNB1 \\
\hline $\begin{array}{l}\text { J3QRG5;J3KSJ5;Q9BQA9;J3K } \\
\text { TF4;J3QLB7;J3QKS6;J3QRZ2 } \\
\text { E9PCW1;G5E9T8;O95249;K7 } \\
\text { EJC8;B4DQA8 }\end{array}$ & $\begin{array}{l}\text { C17orf62 } \\
\text { GOSR1 }\end{array}$ \\
\hline Q15067 & AcOX 1 \\
\hline G3V1U5;Q9Y3E0;F5H6U7 & GOLT1B \\
\hline $\begin{array}{l}\text { P11413;E7EUI8;E9PD92;E7E } \\
\text { M57 }\end{array}$ & G6PD \\
\hline Q9Y320 & TMX2 \\
\hline $\begin{array}{l}\text { X5CMH5;A0A0G2JLV0;A0A08 } \\
\text { 7WYD6;Q03519;A0A140T9S0; } \\
\text { E7ENX8 }\end{array}$ & TAP2 \\
\hline Q14126 & DSG2 \\
\hline P04181 & OAT \\
\hline Q13200 & PSMD2 \\
\hline O15126;A0A087WXB0 & SCAMP1 \\
\hline P35270 & SPR \\
\hline Q9NSE4 & IARS2 \\
\hline Q15125;C9J719;C9JJ78 & EBP \\
\hline
\end{tabular}

Canalicular multispecific

organic anion transporter 1

14-3-3 protein gamma; $14-$

3-3 protein gamma, N-

terminally processed

Prohibitin

Transgelin-2

$\mathrm{H} / \mathrm{ACA}$ ribonucleoprotein complex subunit 4

RNA-binding protein 39

Pyruvate dehydrogenase

E1 component subunit

beta, mitochondrial

Aminoacyl tRNA synthase

complex-interacting

multifunctional protein 2

Protein YIPF5; Protein YIPF

Translocating chain-

associated membrane

protein 1

Protein disulfide-isomerase

A4

Voltage-dependent anionselective channel protein 1

Ras-related protein Rab-5A

Tyrosine-protein phosphatase non-receptor type 1;Tyrosine-protein phosphatase non-receptor type

60 S ribosomal protein $L 5$

Poly [ADP-ribose]

polymerase 1

Importin subunit beta-1

Uncharacterized protein

C17orf62

Golgi SNAP receptor

complex member 1

Peroxisomal acyl-

coenzyme A oxidase 1

Vesicle transport protein

GOT1B

Glucose-6-phosphate 1-

dehydrogenase

Thioredoxin-related

transmembrane protein 2

Antigen peptide transporter 2

Desmoglein-2

Ornithine aminotransferase,

mitochondrial;Ornithine

aminotransferase, hepatic

form;Ornithine

aminotransferase, renal

form

26S proteasome non-

ATPase regulatory subunit

2

Secretory carrier-

associated membrane

protein 1

Sepiapterin reductase

Isoleucine--tRNA ligase,

mitochondrial

3-beta-hydroxysteroid-

Delta(8),Delta(7)-isomerase 


F8VX04;Q9H2H9
D6RIY6;Q06265;H0Y9L5;D6R
905
P31948;F5H783
F5GZN3;Q08431;X6R3G6;H0Y
KS8
P07954
Q8WWV3;G3V1R2
P84095
Q9H583;Q5T3Q7
Q9HD45;Q5TB53
P30260;G5EA36;I3L328
P8WIRF;;F8W809;A0A087WSW
9630A182DWI3;A0A087WSY9;
Q16881;E2QRB9;E9PKD3
Q14697;F5H6X6;E9PKU7
Q9NTJ5;E9PGZ4
Q82241;Q5JR95
Q12874
Q9Y287

SLC38A1
EXOSC9
STIP1
MFGE8
FH
RTN4IP1
RHOG
HEATR1
TM9SF3
CDC27
ITM2B

TRMT10C

LGALS3BP

B4GALT1

EIF3F

ALDH2

TMX4

NIP7

SNTB2

$\mathrm{EI} 24$

SF3A3

GNAI1

RPS3

PSPC1

TXNRD1

GANAB

SACM1L

RPS8

TMEM167A
Sodium-coupled neutral amino acid transporter 1

Exosome complex component RRP45

Stress-induced-

phosphoprotein 1

Lactadherin;Lactadherin

short form;Medin

Fumarate hydratase,

mitochondrial

Reticulon-4-interacting

protein 1, mitochondrial

Rho-related GTP-binding

protein RhoG

HEAT repeat-containing

protein 1 ;HEAT repeat-

containing protein $1, \mathrm{~N}$ -

terminally processed

Transmembrane 9

superfamily member 3

Cell division cycle protein

27 homolog

Integral membrane protein

2B;BRI2, membrane

form;BRI2 intracellular

domain;BRI2C, soluble

form;Bri23 peptide

Mitochondrial ribonuclease

P protein 1

Galectin-3-binding protein

Beta-1,4-

galactosyltransferase

1 ; Lactose synthase A

protein; $\mathrm{N}$-acetyllactosamine

synthase;Beta-N-

acetylglucosaminylglycopep

tide beta-1,4-

galactosyltransferase;Beta-

$\mathrm{N}$-acetylglucosaminyl-

glycolipid beta-1,4-

galactosyltransferase;Proce

ssed beta-1,4-

galactosyltransferase 1

Eukaryotic translation

initiation factor 3 subunit $F$

Aldehyde dehydrogenase,

mitochondrial

transmembrane protein 4

605 ribosome subunit

biogenesis protein NIP7

homolog

Beta-2-syntrophin

0.23

0.07

Etoposide-induced protein 2.4 homolog

Splicing factor $3 \mathrm{~A}$ subunit 3

Guanine nucleotide-binding protein $\mathrm{G}$ (i) subunit alpha-1

40 S ribosomal protein S3

0.32

0.07

0.33

0.07

0.18

0.07

0.21

0.07

0.16

0.07

0.18

0.07

0.43

0.07

0.42

0.07

Paraspeckle component 1

0.19

0.07

0.26

0.07

Thioredoxin reductase 1, cytoplasmic

0.37

0.07

Neutral alpha-glucosidase

AB

Phosphatidylinositide phosphatase SAC1

40S ribosomal protein S8

Protein kish-A

.06

07

07

07

07

07

07

07

07

07

07

07
Thioredoxin-related

0.07 


\begin{tabular}{|c|c|c|c|c|}
\hline P08670;B0YJC4 & VIM & Vimentin & 0.42 & 0.07 \\
\hline P04843;B7Z4L4 & RPN1 & $\begin{array}{l}\text { Dolichyl- } \\
\text { diphosphooligosaccharide-- } \\
\text { protein glycosyltransferase } \\
\text { subunit } 1\end{array}$ & 0.30 & 0.07 \\
\hline P48509;E9PMR4 & CD151 & CD151 antigen;Tetraspanin & 0.24 & 0.07 \\
\hline O43172 & PRPF4 & $\begin{array}{l}\text { U4/U6 small nuclear } \\
\text { ribonucleoprotein Prp4 }\end{array}$ & 0.30 & 0.07 \\
\hline P22626;A0A087WUI2 & HNRNPA2B1 & $\begin{array}{l}\text { Heterogeneous nuclear } \\
\text { ribonucleoproteins A2/B1 }\end{array}$ & 0.27 & 0.07 \\
\hline $\begin{array}{l}\text { F8W1R7;J3KND3;G8JLA2;G3 } \\
\text { V1V0;B7Z6Z4;P60660;F8VPF3 } \\
\text {;G3V1Y7;F8VZU9;F8W180 }\end{array}$ & MYL6 & Myosin light polypeptide 6 & 0.14 & 0.08 \\
\hline Q9UMS4 & PRPF19 & $\begin{array}{l}\text { Pre-mRNA-processing } \\
\text { factor } 19\end{array}$ & 0.43 & 0.08 \\
\hline Q9NYU2 & UGGT1 & $\begin{array}{l}\text { UDP-glucose:glycoprotein } \\
\text { glucosyltransferase } 1 \\
\text { Sodium/potassium- }\end{array}$ & 0.30 & 0.08 \\
\hline P05026 & ATP1B1 & $\begin{array}{l}\text { transporting ATPase } \\
\text { subunit beta-1 }\end{array}$ & 0.23 & 0.08 \\
\hline Q8IYS2 & KIAA2013 & $\begin{array}{l}\text { Uncharacterized protein } \\
\text { KIAA2013 }\end{array}$ & 0.28 & 0.08 \\
\hline Q16643;D6R9W4 & DBN1 & Drebrin & 0.31 & 0.08 \\
\hline P51991 & HNRNPA3 & $\begin{array}{l}\text { Heterogeneous nuclear } \\
\text { ribonucleoprotein } \mathrm{A} 3\end{array}$ & 0.37 & 0.08 \\
\hline Q9Y230;M0R0Y3 & RUVBL2 & RuvB-like 2 & 0.22 & 0.08 \\
\hline $\begin{array}{l}\text { E9PSI1;O15321;E9PMQ9;E9P } \\
\text { QY7;E9PS99;E9PL78;E9PJM1 } \\
\text {;G3V1B9;E9PJC4 }\end{array}$ & TM9SF1 & $\begin{array}{l}\text { Transmembrane } 9 \\
\text { superfamily member } 1\end{array}$ & 0.15 & 0.08 \\
\hline O75489 & NDUFS3 & $\begin{array}{l}\text { NADH dehydrogenase } \\
\text { [ubiquinone] iron-sulfur } \\
\text { protein } 3, \text { mitochondrial }\end{array}$ & 0.47 & 0.08 \\
\hline P35579 & MYH9 & Myosin-9 & 0.20 & 0.08 \\
\hline Q9H9J2 & MRPL44 & $\begin{array}{l}39 S \text { ribosomal protein } L 44 \text {, } \\
\text { mitochondrial }\end{array}$ & 0.49 & 0.08 \\
\hline $\begin{array}{l}\text { B5MDU6;Q9H6V9;C9JHU6;B5 } \\
\text { MCE2;C9JUM0;B4DRG3;B5M } \\
\text { CU4;A0A0A0MSH6 }\end{array}$ & $\begin{array}{l}\text { LDAH;C2orf43;FLJ } \\
21820\end{array}$ & UPF0554 protein C2orf43 & 0.39 & 0.08 \\
\hline $\begin{array}{l}\text { A0A1B0GVW3;F5H7N0;P2847 } \\
\text { 2;A0A1B0GU30;E7EV50;P185 } \\
\text { 05;P47870 }\end{array}$ & $\begin{array}{l}\text { GABRB3;GABRB2 } \\
\text {;GABRB1 }\end{array}$ & $\begin{array}{l}\text { Gamma-aminobutyric acid } \\
\text { receptor subunit beta- } \\
3 ; \text { Gamma-aminobutyric } \\
\text { acid receptor subunit beta- } \\
1 ; \text { Gamma-aminobutyric } \\
\text { acid receptor subunit beta-2 }\end{array}$ & 0.33 & 0.08 \\
\hline D6R9Z7;P15954 & cox7C & $\begin{array}{l}\text { Cytochrome c oxidase } \\
\text { subunit } 7 \mathrm{C} \text {, mitochondrial }\end{array}$ & 0.12 & 0.08 \\
\hline P55011;G3XAL9 & SLC12A2 & $\begin{array}{l}\text { Solute carrier family } 12 \\
\text { member } 2\end{array}$ & 0.31 & 0.08 \\
\hline P14923 & JUP & Junction plakoglobin & 0.37 & 0.08 \\
\hline Q5JRX3;A0A0A0MRX9 & PITRM1 & $\begin{array}{l}\text { Presequence protease, } \\
\text { mitochondrial }\end{array}$ & 0.20 & 0.08 \\
\hline P46940;A0A0J9YXZ5;HOYLE8 & IQGAP1 & $\begin{array}{l}\text { Ras GTPase-activating-like } \\
\text { protein IQGAP1 } \\
\text { cAMP-dependent protein }\end{array}$ & 0.31 & 0.08 \\
\hline P13861 & PRKAR2A & $\begin{array}{l}\text { kinase type II-alpha } \\
\text { regulatory subunit }\end{array}$ & 0.31 & 0.08 \\
\hline P27105 & STOM & $\begin{array}{l}\text { Erythrocyte band } 7 \text { integral } \\
\text { membrane protein }\end{array}$ & 0.36 & 0.08 \\
\hline P35610;B1APM4 & SOAT1 & Sterol O-acyltransferase 1 & 0.54 & 0.08 \\
\hline Q9ULV4;B4E3S0 & CORO1C & Coronin-1C;Coronin & 0.33 & 0.08 \\
\hline O95758 & PTBP3 & $\begin{array}{l}\text { Polypyrimidine tract-binding } \\
\text { protein } 3\end{array}$ & 0.17 & 0.08 \\
\hline $\begin{array}{l}\text { Q9GZT3;A0A087WUN7;H0YJ4 } \\
\text { 0;G3V4X6;G3V2S9;H0YJW7 }\end{array}$ & SLIRP & $\begin{array}{l}\text { SRA stem-loop-interacting } \\
\text { RNA-binding protein, } \\
\text { mitochondrial }\end{array}$ & 0.15 & 0.08 \\
\hline P62913;Q5VVC9;Q5VVC8 & RPL11 & $60 S$ ribosomal protein $\mathrm{L} 11$ & 0.29 & 0.08 \\
\hline Q15717;M0QZR9 & ELAVL1 & ELAV-like protein 1 & 0.35 & 0.08 \\
\hline
\end{tabular}




\begin{tabular}{|c|c|c|c|c|}
\hline Q9H490 & PIGU & $\begin{array}{l}\text { Phosphatidylinositol glycan } \\
\text { anchor biosynthesis class U } \\
\text { protein }\end{array}$ & 0.17 & 0.08 \\
\hline O95168;F2Z3P9;C9JXQ9 & NDUFB4 & $\begin{array}{l}\text { NADH dehydrogenase } \\
\text { [ubiquinone] } 1 \text { beta } \\
\text { subcomplex subunit } 4\end{array}$ & 0.24 & 0.08 \\
\hline $\begin{array}{l}\text { P50454;E9PPV6;E9PR70;E9P } \\
\text { KH2 }\end{array}$ & SERPINH1 & Serpin $\mathrm{H} 1$ & 0.31 & 0.08 \\
\hline $\begin{array}{l}\text { A0A087WX29;Q13148;B1AKP } \\
\text { 7;G3V162;A0A087X260;A0A08 } \\
\text { 7WYY0;K7EJM5;K7EN94 }\end{array}$ & TARDBP & $\begin{array}{l}\text { TAR DNA-binding protein } \\
43\end{array}$ & 0.33 & 0.08 \\
\hline Q8TEQ6 & GEMIN5 & Gem-associated protein 5 & 0.15 & 0.08 \\
\hline $\begin{array}{l}\text { F8W6I7;P09651;F8VZ49;Q32P } \\
\text { 51;F8VTQ5 }\end{array}$ & $\begin{array}{l}\text { HNRNPA1;HNRN } \\
\text { PA1L2 }\end{array}$ & $\begin{array}{l}\text { Heterogeneous nuclear } \\
\text { ribonucleoprotein } \\
\text { A1;Heterogeneous nuclear } \\
\text { ribonucleoprotein A1, N- } \\
\text { terminally } \\
\text { processed;Heterogeneous } \\
\text { nuclear ribonucleoprotein } \\
\text { A1-like } 2\end{array}$ & 0.21 & 0.09 \\
\hline P14868 & DARS & $\begin{array}{l}\text { Aspartate--tRNA ligase, } \\
\text { cytoplasmic }\end{array}$ & 0.82 & 0.09 \\
\hline B4DR61;P61619;Q8TC24 & $\begin{array}{l}\text { SEC61A1;SEC61A } \\
2\end{array}$ & $\begin{array}{l}\text { Protein transport protein } \\
\text { Sec61 subunit alpha } \\
\text { isoform } 1\end{array}$ & 0.23 & 0.09 \\
\hline Q9BUQ8 & DDX23 & $\begin{array}{l}\text { Probable ATP-dependent } \\
\text { RNA helicase DDX23 }\end{array}$ & 0.42 & 0.09 \\
\hline Q9NVJ2 & ARL8B & $\begin{array}{l}\text { ADP-ribosylation factor-like } \\
\text { protein } 8 \mathrm{~B}\end{array}$ & 0.25 & 0.09 \\
\hline Q9BYT8;E9PCB6 & NLN & Neurolysin, mitochondrial & 0.83 & 0.09 \\
\hline P07737;K7EJ44 & PFN1 & Profilin-1 & 0.25 & 0.09 \\
\hline $\begin{array}{l}\text { P46783;F6U211;A0A1W2PQS } \\
\text { 6;S4R435;Q9NQ39 }\end{array}$ & $\begin{array}{l}\text { RPS10;RPS10- } \\
\text { NUDT3;RPS10P5 }\end{array}$ & $\begin{array}{l}40 S \text { ribosomal protein } \\
\text { S10;Putative } 40 \text { S ribosomal } \\
\text { protein } 510 \text {-like }\end{array}$ & 0.11 & 0.09 \\
\hline Q14739;C9JXK0 & LBR & Lamin-B receptor & 0.32 & 0.09 \\
\hline Q15084 & PDIA6 & $\begin{array}{l}\text { Protein disulfide-isomerase } \\
\text { A6 }\end{array}$ & 1.06 & 0.09 \\
\hline $\begin{array}{l}\text { O94973;A0A0G2JS82;A0A0G2 } \\
\text { JQM1 }\end{array}$ & AP2A2 & $\begin{array}{l}\text { AP-2 complex subunit } \\
\text { alpha-2 }\end{array}$ & 0.28 & 0.09 \\
\hline P62191 & PSMC1 & $\begin{array}{l}26 S \text { protease regulatory } \\
\text { subunit } 4\end{array}$ & 1.29 & 0.09 \\
\hline $\begin{array}{l}\text { Q15043;E5RIP4;E5RFZ8;E5R } \\
\text { GA7;E5RJ40;E5RJG5 }\end{array}$ & SLC39A14 & Zinc transporter ZIP14 & 0.38 & 0.09 \\
\hline $\begin{array}{l}\text { D6RE83;P09936;D6R956;D6R } \\
974\end{array}$ & UCHL1 & $\begin{array}{l}\text { Ubiquitin carboxyl-terminal } \\
\text { hydrolase;Ubiquitin } \\
\text { carboxyl-terminal hydrolase } \\
\text { isozyme L1 }\end{array}$ & 0.22 & 0.09 \\
\hline Q9GZL7 & WDR12 & $\begin{array}{l}\text { Ribosome biogenesis } \\
\text { protein WDR12 }\end{array}$ & 0.94 & 0.09 \\
\hline A6NEM5;Q92643;B1AK81 & PIGK & GPI-anchor transamidase & 0.47 & 0.09 \\
\hline E9PKV2;Q9NRX2 & MRPL17 & $\begin{array}{l}39 \mathrm{~S} \text { ribosomal protein L17, } \\
\text { mitochondrial }\end{array}$ & 0.24 & 0.09 \\
\hline P25788 & PSMA3 & $\begin{array}{l}\text { Proteasome subunit alpha } \\
\text { type-3 }\end{array}$ & 0.21 & 0.09 \\
\hline O43852 & CALU & Calumenin & 0.73 & 0.09 \\
\hline H3ВРЕ7;Р35637 & FUS & RNA-binding protein FUS & 0.25 & 0.09 \\
\hline Q9Y4W6 & AFG3L2 & AFG3-like protein 2 & 0.28 & 0.09 \\
\hline O96011 & PEX11B & $\begin{array}{l}\text { Peroxisomal membrane } \\
\text { protein } 11 \mathrm{~B} \\
\text { Glutamate dehydrogenase }\end{array}$ & 0.48 & 0.09 \\
\hline P00367;P49448 & GLUD1;GLUD2 & $\begin{array}{l}\text { 1, mitochondrial;Glutamate } \\
\text { dehydrogenase } 2 \text {, } \\
\text { mitochondrial }\end{array}$ & 1.16 & 0.09 \\
\hline O60568 & PLOD3 & $\begin{array}{l}\text { Procollagen-lysine,2- } \\
\text { oxoglutarate 5-dioxygenase } \\
3\end{array}$ & 0.16 & 0.09 \\
\hline P12931 & $\mathrm{SRC}$ & $\begin{array}{l}\text { Proto-oncogene tyrosine- } \\
\text { protein kinase Src }\end{array}$ & 0.41 & 0.09 \\
\hline
\end{tabular}




\begin{tabular}{|c|c|}
\hline Q99643 & $\mathrm{SDHC}$ \\
\hline 014828 & SCAMP3 \\
\hline $\begin{array}{l}\text { P62195;J3QQM1;J3QSA9;J3K } \\
\text { RP2;J3QLH6 }\end{array}$ & PSMC5 \\
\hline E7EPT4;P19404 & NDUFV2 \\
\hline P31040;D6RFM5;A0A087X113 & SDHA \\
\hline $\begin{array}{l}\text { F5GXX5;P61803;F5H895;A0A } \\
\text { 0B4J239 }\end{array}$ & DAD1 \\
\hline O75531 & BANF1 \\
\hline $\begin{array}{l}\text { E9PRM7;A0A0J9YWM3;A0A0 } \\
\text { 24RCG2;Q96BI1 }\end{array}$ & SLC22A18 \\
\hline O00767 & SCD \\
\hline Q8N5N7 & MRPL50 \\
\hline P30044 & PRDX5 \\
\hline Q8IV08 & PLD3 \\
\hline F8WF48;Q99442;F8WCJ7 & SEC62 \\
\hline J3KPP4;O95232;D6RDI2 & LUC7L3 \\
\hline O14818;H0Y586;Q8TAA3 & PSMA7;PSMAE \\
\hline Q14566 & MCM6 \\
\hline P55072 & VCP \\
\hline G3V1C3;Q9BZZ5;H0YER7 & API5 \\
\hline $\begin{array}{l}\text { P22570;A0A0C4DFN8;A0A0A0 } \\
\text { MSZ4;A0A0AOMTN9;A0A0A0 } \\
\text { MTR6;A0A0C4DGN7;A0A0A0 } \\
\text { MT64;J3QQX3 }\end{array}$ & FDXR \\
\hline P30048 & PRDX3 \\
\hline $\begin{array}{l}\text { Q01085;E7ETJ9;E7ETC0;A6N } \\
\text { KZ9;C9JTN7;F8W8I6;P31483 }\end{array}$ & TIAL1;TIA1 \\
\hline P62888;E5RI99;A0A0C4DH44 & RPL30 \\
\hline P11216 & PYGB \\
\hline Q9BVV7;J3QRI1 & TIMM21 \\
\hline A2A274;Q99798 & $\mathrm{ACO} 2$ \\
\hline P36542 & ATP5C1 \\
\hline Q9NX00 & TMEM160 \\
\hline Q8IXB1 & DNAJC10 \\
\hline Q15459 & SF3A1 \\
\hline Q9NZM1;H0YD14 & MYOF \\
\hline $\begin{array}{l}\text { S4R3Q9;J3KNA0;Q15070;E7E } \\
\text { VY0 }\end{array}$ & OXA1L \\
\hline
\end{tabular}

Succinate dehydrogenase cytochrome b560 subunit, mitochondrial

Secretory carrier-

associated membrane

protein 3

26S protease regulatory

subunit 8

NADH dehydrogenase

[ubiquinone] flavoprotein 2,

mitochondrial

Succinate dehydrogenase

[ubiquinone] flavoprotein

subunit, mitochondrial

Dolichyl-

diphosphooligosaccharide--

protein glycosyltransferase

subunit DAD1

Barrier-to-autointegration

factor;Barrier-to-

autointegration factor, $\mathrm{N}$ -

terminally processed

Solute carrier family 22

member 18

Acyl-CoA desaturase

$39 S$ ribosomal protein L50,

mitochondrial

Peroxiredoxin-5,

mitochondrial

Phospholipase D3

Translocation protein

SEC62

Luc7-like protein 3

0.29

0.09

0.35

0.09

0.53

0.09

0.91

0.09

Proteasome subunit alpha

type-7;Proteasome subunit

alpha type-7-like

DNA replication licensing factor MCM6

Transitional endoplasmic reticulum ATPase

Apoptosis inhibitor 5

0.33

0.10

0.12

0.10

0.28

0.10

0.44

0.10

0.30

0.10

0.25

0.10

0.38

0.10

0.31

0.10

0.46

0.10

0.19

0.10

0.47

0.10

0.40

0.10

0.29

0.10

NADPH:adrenodoxin

oxidoreductase,

0.46

0.10

Thioredoxin-dependent

peroxide reductase,

mitochondrial

Nucleolysin

TIAR;Nucleolysin TIA-1

isoform p40

$60 S$ ribosomal protein L30

Glycogen phosphorylase,

brain form

Mitochondrial import inner

membrane translocase

subunit Tim21

Aconitate hydratase,

mitochondrial

ATP synthase subunit

gamma, mitochondrial

Transmembrane protein

160

DnaJ homolog subfamily $\mathrm{C}$ member 10

Splicing factor $3 A$ subunit 1 


\begin{tabular}{|c|c|c|c|c|}
\hline Q13895 & BYSL & Bystin & 0.44 & 0.10 \\
\hline P33993 & MCM7 & $\begin{array}{l}\text { DNA replication licensing } \\
\text { factor MCM7 }\end{array}$ & 0.60 & 0.10 \\
\hline Q14344 & GNA13 & $\begin{array}{l}\text { Guanine nucleotide-binding } \\
\text { protein subunit alpha-13 }\end{array}$ & 0.28 & 0.10 \\
\hline B4DY09;Q12905 & ILF2 & $\begin{array}{l}\text { Interleukin enhancer- } \\
\text { binding factor } 2\end{array}$ & 0.85 & 0.10 \\
\hline P00390 & GSR & $\begin{array}{l}\text { Glutathione reductase, } \\
\text { mitochondrial }\end{array}$ & 0.52 & 0.10 \\
\hline Q9NX62 & IMPAD1 & $\begin{array}{l}\text { Inositol monophosphatase } \\
3 \\
\text { Isocitrate dehydrogenase }\end{array}$ & 0.14 & 0.10 \\
\hline $\begin{array}{l}\text { A0A087WZN1;O43837;A0A08 } \\
\text { 7X2E5;A0A0D9SG66 }\end{array}$ & IDH3B & $\begin{array}{l}\text { [NAD] subunit, } \\
\text { mitochondrial;Isocitrate } \\
\text { dehydrogenase [NAD] } \\
\text { subunit beta, mitochondrial }\end{array}$ & 0.35 & 0.10 \\
\hline Q7Z7N9;G3V185 & TMEM179B & $\begin{array}{l}\text { Transmembrane protein } \\
179 B\end{array}$ & 0.28 & 0.10 \\
\hline P35998;A0A1W2PQS1 & PSMC2 & $\begin{array}{l}26 S \text { protease regulatory } \\
\text { subunit } 7 \\
\text { Inhibitor of nuclear factor }\end{array}$ & 0.44 & 0.10 \\
\hline Q70UQ0 & IKBIP & $\begin{array}{l}\text { kappa-B kinase-interacting } \\
\text { protein }\end{array}$ & 0.57 & 0.10 \\
\hline Q8TCT9;A0A075B6F6 & HM13 & $\begin{array}{l}\text { Minor histocompatibility } \\
\text { antigen } \mathrm{H} 13 \\
\text { Serine/threonine-protein }\end{array}$ & 0.46 & 0.10 \\
\hline Q96HS1 & PGAM5 & $\begin{array}{l}\text { phosphatase PGAM5, } \\
\text { mitochondrial }\end{array}$ & 0.83 & 0.10 \\
\hline $\begin{array}{l}\text { A0A087X0W7;Q86TX2;G3V4F } \\
\text { 2;A0A087WT95;P49753 }\end{array}$ & АCOT2;ACOT1 & $\begin{array}{l}\text { Acyl-coenzyme A } \\
\text { thioesterase } 1 \text {;Acyl- } \\
\text { coenzyme A thioesterase 2, } \\
\text { mitochondrial }\end{array}$ & 0.69 & 0.10 \\
\hline Q07021;|3L3Q7;|3L3B0 & C1QBP & $\begin{array}{l}\text { Q subcomponent-binding } \\
\text { protein, mitochondrial }\end{array}$ & 0.25 & 0.10 \\
\hline E7EWK3;Q9H2U1 & $\mathrm{DHX} 36$ & $\begin{array}{l}\text { ATP-dependent RNA } \\
\text { helicase DHX36 }\end{array}$ & 0.32 & 0.10 \\
\hline Q9NVP1 & DDX18 & $\begin{array}{l}\text { ATP-dependent RNA } \\
\text { helicase DDX18 }\end{array}$ & 0.45 & 0.10 \\
\hline O60506;B7Z645 & SYNCRIP & $\begin{array}{l}\text { Heterogeneous nuclear } \\
\text { ribonucleoprotein } Q\end{array}$ & 0.71 & 0.10 \\
\hline $\begin{array}{l}\text { A0A087WYF7;Q6UXV4;A0A08 } \\
\text { 7WUX8 }\end{array}$ & APOOL & $\begin{array}{l}\text { MICOS complex subunit } \\
\text { MIC27 }\end{array}$ & 0.78 & 0.10 \\
\hline P07237;H7BZ94 & $\mathrm{P} 4 \mathrm{HB}$ & Protein disulfide-isomerase & 0.92 & 0.10 \\
\hline $\begin{array}{l}\text { Q9UNM6;A0A087WUL9;J3KN } \\
\text { Q3;E9PL38;H0YD73 }\end{array}$ & PSMD13 & $\begin{array}{l}26 S \text { proteasome non- } \\
\text { ATPase regulatory subunit } \\
13\end{array}$ & 0.37 & 0.10 \\
\hline Q9H3K2 & GHITM & $\begin{array}{l}\text { Growth hormone-inducible } \\
\text { transmembrane protein }\end{array}$ & 0.32 & 0.10 \\
\hline Q9NPA0;HOYDX2;H0YDT8 & EMC7 & $\begin{array}{l}\text { ER membrane protein } \\
\text { complex subunit } 7\end{array}$ & 0.41 & 0.10 \\
\hline $\begin{array}{l}\text { J3QS48;I3L295;J3KTK8;J3QQ } \\
\text { Z4;J3KT75;J3QW43;J3QRD5; } \\
\text { O75352;J3KSI4;I3L405;I3L261; } \\
\text { I3L1D2;I3L4E0 }\end{array}$ & MPDU1 & $\begin{array}{l}\text { Mannose-P-dolichol } \\
\text { utilization defect } 1 \text { protein }\end{array}$ & 0.16 & 0.10 \\
\hline Q16531;F5GY55 & DDB1 & $\begin{array}{l}\text { DNA damage-binding } \\
\text { protein } 1\end{array}$ & 0.50 & 0.10 \\
\hline B4E1G1;Q9BUN8;E5RGY0 & DERL1 & Derlin-1 & 0.97 & 0.10 \\
\hline Q96QK1 & VPS35 & $\begin{array}{l}\text { Vacuolar protein sorting- } \\
\text { associated protein } 35\end{array}$ & 0.25 & 0.11 \\
\hline Q9BQ39;A0A087WVC1 & DDX50 & $\begin{array}{l}\text { ATP-dependent RNA } \\
\text { helicase DDX50 }\end{array}$ & 0.08 & 0.11 \\
\hline O60701 & UGDH & $\begin{array}{l}\text { UDP-glucose 6- } \\
\text { dehydrogenase }\end{array}$ & 0.23 & 0.11 \\
\hline $\begin{array}{l}\text { A0A1B0GTG2;A0A1B0GW77; } \\
\text { P49419;A0A1B0GUA1;A0A1B } \\
\text { 0GW82;A0A1B0GTY9;A0A1B0 } \\
\text { GTJ4;A0A1B0GV49 }\end{array}$ & ALDH7A1 & $\begin{array}{l}\text { Alpha-aminoadipic } \\
\text { semialdehyde } \\
\text { dehydrogenase }\end{array}$ & 0.32 & 0.11 \\
\hline P61106;X6RFL8 & RAB14 & Ras-related protein Rab-14 & 0.84 & 0.11 \\
\hline P53618 & COPB1 & Coatomer subunit beta & 0.13 & 0.11 \\
\hline
\end{tabular}


F8VVA7;P61923;F8W651;F8V YK5;F8VXB1;F8VUC5;F8W15 6;F8VXR1;F8VYZ4

P12956;B1AHC9

Q96TC7;H0YMB1;HOYLG5

P04114

P07355;HOYN42;HOYMD0;H0 YMU9;HOYM50;A6NMY6;HOY N28;HOYL33;HOYKS4;HOYNP5

Q9UBM7;E9PM00;E9PJ54

P63244;J3KPE3;D6RAC2;HOY AF8;H0Y8W2;D6RHH4;D6REE 5;D6R9Z1;HOYAM7;D6R9L0;D 6RFX4

Q969X6;H3BSH7;A0A0J9YW M9

D6REX3;O94979;D6RHZ5;H7 BXG7;HOYAB3

F5H6P7;P61326;Q96A72

Q5JTH9

F5GZS6;J3KPF3;P08195

Q14554

Q7KZN9

Q8NFH3

E7EPB3;P50914

P46977

Q96EC8

H0Y997;Q96J42;H0Y928

Q15427;Q5SZ64

P19367

Q92820

P51659;E7EWE5;E7ER27;G5 E9S2;E7ET17

P61313;E7EQV9;E7ENU7;E7E $\mathrm{X} 53$

P14625

Q9BXK5;F2Z2C3;A0A087WW 80;A0A0A0MR90;E9PDD6

MOR0F0;P46782;MOR0R2;M0 QZN2

Q8NG11;H7BXY6;A6NEP9
COPZ1

XRCC6

RMDN3

APOB

ANXA2;ANXA2P2

DHCR7

CIRH1A

SEC31A

MAGOHB;MAGOH

RRP12

SLC3A2

PDIA5

$\operatorname{cox} 15$

NUP43

RPL14

STT3A

YIPF6

TXNDC15

SF3B4

HK1

GGH

HSD17B4

RPL15

HSP90B1

BCL2L13

RPS5

TSPAN14
Delta-1-pyrroline-5-

carboxylate

synthase;Glutamate 5-

kinase;Gamma-glutamyl

0.23

0.11

phosphate reductase

Coatomer subunit zeta-1

0.34

0.11

X-ray repair cross-

complementing protein 6

Regulator of microtubule

dynamics protein 3

Apolipoprotein B-

100;Apolipoprotein B-48

Annexin

A2;Annexin;Putative annexin A2-like protein

7-dehydrocholesterol

reductase

0.56

0.11

0.37

0.11

0.15

0.11

1.26

0.11

Guanine nucleotide-binding

protein subunit beta-2-like

1;Guanine nucleotide-

binding protein subunit

beta-2-like $1, \mathrm{~N}$-terminally

processed

0.49

0.11

Cirhin

0.36

0.11

Protein transport protein

Sec31A

0.17

0.11

Protein mago nashi

homolog;Protein mago

nashi homolog 2

RRP12-like protein

0.17

0.11

4F2 cell-surface antigen

heavy chain

Protein disulfide-isomerase

A5

Cytochrome c oxidase assembly protein COX15 homolog

Nucleoporin Nup43

0.44

0.11

60 S ribosomal protein L14

0.11

0.53

0.11

Dolichyl-

diphosphooligosaccharide--

protein glycosyltransferase

0.11 subunit STT3A

Protein YIPF6

0.11

Thioredoxin domain-

containing protein 15

Splicing factor 3B subunit 4

0.11

Hexokinase-1

0.11

0.11

0.11

Gamma-glutamyl hydrolase

0.11

Peroxisomal multifunctional enzyme type 2;(3R)-

hydroxyacyl-CoA

dehydrogenase;Enoyl-CoA

hydratase 2

$60 \mathrm{~S}$ ribosomal protein

L15;Ribosomal protein L15

Endoplasmin

0.39

0.11

Bcl-2-like protein 13

0.61

0.11

$40 \mathrm{~S}$ ribosomal protein

$\mathrm{S} 5 ; 40 \mathrm{~S}$ ribosomal protein

$\mathrm{S} 5, \mathrm{~N}$-terminally processed

(1)

0.11

Tetraspanin-14;Tetraspanin

0.36

0.12

0.35

0.12 


\begin{tabular}{|c|c|c|c|c|}
\hline Q7L8L6 & FASTKD5 & $\begin{array}{l}\text { FAST kinase domain- } \\
\text { containing protein } 5\end{array}$ & 0.46 & 0.12 \\
\hline P12004 & PCNA & $\begin{array}{l}\text { Proliferating cell nuclear } \\
\text { antigen }\end{array}$ & 0.29 & 0.12 \\
\hline P62258 & YWHAE & 14-3-3 protein epsilon & 0.21 & 0.12 \\
\hline Q9Y224;G3V4C6 & C14orf166 & $\begin{array}{l}\text { UPF0568 protein } \\
\text { C14orf166 }\end{array}$ & 0.54 & 0.12 \\
\hline P11021 & HSPA5 & $\begin{array}{l}78 \mathrm{kDa} \text { glucose-regulated } \\
\text { protein }\end{array}$ & 1.37 & 0.12 \\
\hline $\begin{array}{l}\text { O00161;H3BNE1;H3BR18;H3B } \\
\text { M38;H3BPJ0 }\end{array}$ & SNAP23 & $\begin{array}{l}\text { Synaptosomal-associated } \\
\text { protein } 23 ; \text { Synaptosomal- } \\
\text { associated protein }\end{array}$ & 0.31 & 0.12 \\
\hline Q01650 & SLC7A5 & $\begin{array}{l}\text { Large neutral amino acids } \\
\text { transporter small subunit } 1 \\
116 \text { kDa U5 small nuclear }\end{array}$ & 0.36 & 0.12 \\
\hline Q15029 & EFTUD2 & $\begin{array}{l}\text { ribonucleoprotein } \\
\text { component } \\
\text { Endoplasmic reticulum- }\end{array}$ & 0.75 & 0.12 \\
\hline Q969X5 & ERGIC1 & $\begin{array}{l}\text { Golgi intermediate } \\
\text { compartment protein } 1\end{array}$ & 0.94 & 0.12 \\
\hline Q8IWB1 & ITPRIP & $\begin{array}{l}\text { Inositol 1,4,5-trisphosphate } \\
\text { receptor-interacting protein }\end{array}$ & 0.52 & 0.12 \\
\hline Q9H5Q4 & TFB2M & $\begin{array}{l}\text { Dimethyladenosine } \\
\text { transferase } 2 \text {, mitochondrial }\end{array}$ & 0.35 & 0.12 \\
\hline $\begin{array}{l}\text { A0A0D9SFB3;A0A0D9SG12;A } \\
\text { OA0D9SF53;O00571 }\end{array}$ & DDX3X & $\begin{array}{l}\text { ATP-dependent RNA } \\
\text { helicase DDX } 3 X \\
\text { Dihydrolipoyllysine-residue } \\
\text { acetyltransferase } \\
\text { component of pyruvate }\end{array}$ & 0.82 & 0.12 \\
\hline P10515;H0YDD4;E9PEJ4 & DLAT & $\begin{array}{l}\text { dehydrogenase complex, } \\
\text { mitochondrial;Acetyltransfer } \\
\text { ase component of pyruvate } \\
\text { dehydrogenase complex }\end{array}$ & 0.50 & 0.12 \\
\hline P31942 & HNRNPH3 & $\begin{array}{l}\text { Heterogeneous nuclear } \\
\text { ribonucleoprotein } \mathrm{H} 3 \\
\mathrm{NADH} \text { dehydrogenase }\end{array}$ & 0.28 & 0.12 \\
\hline O43676;C9JKQ2 & NDUFB3 & $\begin{array}{l}\text { [ubiquinone] } 1 \text { beta } \\
\text { subcomplex subunit } 3 \\
\text { Eukaryotic translation } \\
\text { initiation factor } 2 \text { subunit }\end{array}$ & 0.27 & 0.12 \\
\hline P41091;Q2VIR3;F8W810 & EIF2S3;EIF2S3L & $\begin{array}{l}\text { 3;Putative eukaryotic } \\
\text { translation initiation factor } 2 \\
\text { subunit 3-like protein }\end{array}$ & 0.49 & 0.12 \\
\hline Q9H497;Q5W0C6 & TOR3A & Torsin-3A & 0.26 & 0.12 \\
\hline A0A0C4DFM1;Q92544 & TM9SF4 & $\begin{array}{l}\text { Transmembrane } 9 \\
\text { superfamily member } 4\end{array}$ & 0.51 & 0.12 \\
\hline O00461;F8W785 & GOLIM4 & $\begin{array}{l}\text { Golgi integral membrane } \\
\text { protein } 4\end{array}$ & 0.14 & 0.12 \\
\hline E9PLK3;P55786 & NPEPPS & $\begin{array}{l}\text { Puromycin-sensitive } \\
\text { aminopeptidase }\end{array}$ & 0.42 & 0.12 \\
\hline Q92973 & TNPO1 & Transportin-1 & 0.50 & 0.12 \\
\hline P08238 & HSP90AB1 & $\begin{array}{l}\text { Heat shock protein HSP } 90 \text { - } \\
\text { beta }\end{array}$ & 0.22 & 0.12 \\
\hline $\begin{array}{l}\text { J3KQ96;E7ETY2;Q13428;H0Y } \\
\text { A99 }\end{array}$ & TCOF1 & Treacle protein & 0.32 & 0.12 \\
\hline Q8IWA0 & WDR75 & $\begin{array}{l}\text { WD repeat-containing } \\
\text { protein } 75\end{array}$ & 0.33 & 0.12 \\
\hline Q07812;K4JQN1 & BAX & Apoptosis regulator BAX & 0.43 & 0.12 \\
\hline 095453 & PARN & $\begin{array}{l}\text { Poly(A)-specific } \\
\text { ribonuclease PARN }\end{array}$ & 0.63 & 0.12 \\
\hline Q96AG4 & LRRC59 & $\begin{array}{l}\text { Leucine-rich repeat- } \\
\text { containing protein } 59 \\
\text { Cytochrome b-c1 complex } \\
\text { subunit Rieske, } \\
\text { mitochondrial:Cytochrome }\end{array}$ & 0.61 & 0.12 \\
\hline P47985;P0C7P4 & $\begin{array}{l}\text { UQCRFS1;UQCR } \\
\text { FS1P1 }\end{array}$ & $\begin{array}{l}\text { mitochonarial;Cytocnrome } \\
\text { b-c1 complex subunit } \\
11 ; \text { Putative cytochrome b- } \\
\text { c1 complex subunit Rieske- } \\
\text { like protein } 1\end{array}$ & 0.63 & 0.12 \\
\hline Q6P2Q9 & PRPF8 & $\begin{array}{l}\text { Pre-mRNA-processing- } \\
\text { splicing factor } 8\end{array}$ & 0.16 & 0.12 \\
\hline
\end{tabular}




\begin{tabular}{|c|c|c|c|c|}
\hline Q96PD2 & DCBLD2 & $\begin{array}{l}\text { Discoidin, CUB and LCCL } \\
\text { domain-containing protein } 2\end{array}$ & 0.45 & 0.12 \\
\hline $\begin{array}{l}\text { P51398;V9GZ03;V9GYL9;V9G } \\
\text { YJ9;V9GYA7 }\end{array}$ & DAP3 & $\begin{array}{l}28 \text { S ribosomal protein S29, } \\
\text { mitochondrial }\end{array}$ & 0.48 & 0.12 \\
\hline P49736;H0Y8E6 & MCM2 & $\begin{array}{l}\text { DNA replication licensing } \\
\text { factor MCM2 }\end{array}$ & 0.28 & 0.12 \\
\hline Q6DKI1;R4GMU7 & RPL7L1 & $\begin{array}{l}60 \text { S ribosomal protein L7- } \\
\text { like } 1\end{array}$ & 0.45 & 0.13 \\
\hline D6RBS5;Q8IZ81;D6RHX2 & ELMOD2 & $\begin{array}{l}\text { ELMO domain-containing } \\
\text { protein } 2 \\
\text { Acetyl-CoA }\end{array}$ & 0.46 & 0.13 \\
\hline P24752 & ACAT1 & $\begin{array}{l}\text { acetyltransferase, } \\
\text { mitochondrial }\end{array}$ & 0.34 & 0.13 \\
\hline O43390;B4DT28 & HNRNPR & $\begin{array}{l}\text { Heterogeneous nuclear } \\
\text { ribonucleoprotein R } \\
\text { Adenosine 3-phospho 5- }\end{array}$ & 0.77 & 0.13 \\
\hline Q8TB61 & SLC35B2 & $\begin{array}{l}\text { phosphosulfate transporter } \\
1 \\
\text { Eukaryotic translation } \\
\text { initiation factor } 3 \text { subunit }\end{array}$ & 0.49 & 0.13 \\
\hline Q99613;B5ME19 & EIF3C;EIF3CL & $\begin{array}{l}\text { C;Eukaryotic translation } \\
\text { initiation factor } 3 \text { subunit C- } \\
\text { like protein }\end{array}$ & 0.75 & 0.13 \\
\hline Q9Y265;H7C4G5;E7ETR0 & RUVBL1 & RuvB-like 1 & 0.39 & 0.13 \\
\hline P19784;H3BSA1;H3BV19 & CSNK2A2 & $\begin{array}{l}\text { Casein kinase II subunit } \\
\text { alpha }\end{array}$ & 0.70 & 0.13 \\
\hline A0A087WUB9;Q8WYA6 & CTNNBL1 & Beta-catenin-like protein 1 & 0.58 & 0.13 \\
\hline Q13190;H7C3X5 & STX5 & Syntaxin-5 & 0.53 & 0.13 \\
\hline P04083;Q5T3N1 & ANXA1 & Annexin A1;Annexin & 0.48 & 0.13 \\
\hline $\begin{array}{l}\text { Q9BWF3;E9PB51;Q9BQ04;E9 } \\
\text { PLB0;E9PM61;D6R9K7;U3KQ } \\
\text { D5;J3QRR5 }\end{array}$ & RBM4;RBM4B & $\begin{array}{l}\text { RNA-binding protein } \\
\text { 4;RNA-binding protein 4B }\end{array}$ & 0.85 & 0.13 \\
\hline Q9BZE4 & GTPBP4 & $\begin{array}{l}\text { Nucleolar GTP-binding } \\
\text { protein } 1\end{array}$ & 0.59 & 0.13 \\
\hline P23284 & PPIB & $\begin{array}{l}\text { Peptidyl-prolyl cis-trans } \\
\text { isomerase } \mathrm{B}\end{array}$ & 0.58 & 0.13 \\
\hline $\begin{array}{l}\text { A0A024R4M0;P46781;B5MCT } \\
\text { 8;C9JM19 }\end{array}$ & RPS9 & $40 S$ ribosomal protein $\$ 9$ & 0.46 & 0.13 \\
\hline O75396 & SEC22B & $\begin{array}{l}\text { Vesicle-trafficking protein } \\
\text { SEC22b }\end{array}$ & 0.99 & 0.13 \\
\hline $\begin{array}{l}\text { P20645;F5GXE0;F5GXU0;F5H } \\
\text { 883;F5GX30 }\end{array}$ & M6PR & $\begin{array}{l}\text { Cation-dependent } \\
\text { mannose-6-phosphate } \\
\text { receptor }\end{array}$ & 0.48 & 0.13 \\
\hline Q8N183 & NDUFAF2 & Mimitin, mitochondrial & 0.46 & 0.13 \\
\hline $\begin{array}{l}\text { A0A140TA86;Q5XKP0;K7EIR2 } \\
\text {;A0A140TA84 }\end{array}$ & QIL1;C19orf70 & Protein QIL1 & 0.34 & 0.13 \\
\hline Q8WVX9;E9PNW8 & FAR1 & Fatty acyl-CoA reductase 1 & 1.14 & 0.13 \\
\hline P33992;B1AHB1 & MCM5 & $\begin{array}{l}\text { DNA replication licensing } \\
\text { factor MCM5;DNA helicase }\end{array}$ & 0.50 & 0.13 \\
\hline Q5BKZ1 & ZNF326 & $\begin{array}{l}\text { DBIRD complex subunit } \\
\text { ZNF326 }\end{array}$ & 0.42 & 0.13 \\
\hline $\begin{array}{l}\text { Q9NX40;D6RBN5;D6RG39;D6 } \\
\text { RIT9;D6RDK6 }\end{array}$ & OCIAD1 & $\begin{array}{l}\text { OCIA domain-containing } \\
\text { protein } 1\end{array}$ & 1.61 & 0.13 \\
\hline Q86UP2 & KTN1 & Kinectin & 1.11 & 0.13 \\
\hline $\begin{array}{l}\text { Q9P0J0;B4DEZ3;K7EJE1;E7E } \\
\text { NQ6 }\end{array}$ & NDUFA13 & $\begin{array}{l}\text { NADH dehydrogenase } \\
\text { [ubiquinone] } 1 \text { alpha } \\
\text { subcomplex subunit } 13\end{array}$ & 0.50 & 0.13 \\
\hline $\begin{array}{l}\text { P34932;A0A087WYC1;A0A087 } \\
\text { WTS8 }\end{array}$ & HSPA4 & $\begin{array}{l}\text { Heat shock } 70 \text { kDa protein } \\
4 \\
\text { U3 small nucleolar RNA- }\end{array}$ & 0.26 & 0.13 \\
\hline Q9Y5J1 & UTP18 & $\begin{array}{l}\text { associated protein } 18 \\
\text { homolog }\end{array}$ & 0.58 & 0.14 \\
\hline P50750 & CDK9 & Cyclin-dependent kinase 9 & 0.64 & 0.14 \\
\hline Q9UBQ7;U3KQ56 & GRHPR & $\begin{array}{l}\text { Glyoxylate } \\
\text { reductase/hydroxypyruvate } \\
\text { reductase }\end{array}$ & 0.36 & 0.14 \\
\hline Q9H2D1 & SLC25A32 & $\begin{array}{l}\text { Mitochondrial folate } \\
\text { transporter/carrier }\end{array}$ & 0.61 & 0.14 \\
\hline
\end{tabular}




\begin{tabular}{|c|c|c|c|c|}
\hline O14980 & XPO1 & Exportin-1 & 0.92 & 0.14 \\
\hline $\begin{array}{l}\text { P50213;HOYL72;HOYMU3;HOY } \\
\text { LI6 }\end{array}$ & IDH3A & $\begin{array}{l}\text { Isocitrate dehydrogenase } \\
{[N A D] \text { subunit alpha, }} \\
\text { mitochondrial }\end{array}$ & 0.96 & 0.14 \\
\hline P17152 & TMEM11 & $\begin{array}{l}\text { Transmembrane protein } 11 \text {, } \\
\text { mitochondrial }\end{array}$ & 0.84 & 0.14 \\
\hline Q13242;H0YIB4;S4R3G0 & SRSF9 & $\begin{array}{l}\text { Serine/arginine-rich splicing } \\
\text { factor } 9\end{array}$ & 0.40 & 0.14 \\
\hline $\begin{array}{l}\text { E9PMM3;Q9Y5Y5;E9PQW0;E } \\
\text { 9PLS4;E9PP98 }\end{array}$ & PEX16 & $\begin{array}{l}\text { Peroxisomal membrane } \\
\text { protein PEX16 }\end{array}$ & 0.33 & 0.14 \\
\hline B1AH87;P30536 & TSPO & Translocator protein & 0.50 & 0.14 \\
\hline O95395 & GCNT3 & $\begin{array}{l}\text { Beta-1,3-galactosyl-O- } \\
\text { glycosyl-glycoprotein beta- } \\
1,6-\mathrm{N}- \\
\text { acetylglucosaminyltransfera } \\
\text { se } 3\end{array}$ & 0.43 & 0.14 \\
\hline E9PF19;Q9Y4P3;Q96E41 & TBL2 & $\begin{array}{l}\text { Transducin beta-like protein } \\
2\end{array}$ & 0.73 & 0.14 \\
\hline $\begin{array}{l}\text { A0A024R412;A0A024R3W6;Q } \\
\text { 7LBX6;X5D2Q8;O60462 }\end{array}$ & NRP2 & Neuropilin-2 & 0.49 & 0.14 \\
\hline Q8NC56 & LEMD2 & $\begin{array}{l}\text { LEM domain-containing } \\
\text { protein } 2\end{array}$ & 0.38 & 0.14 \\
\hline Q15393 & SF3B3 & Splicing factor 3B subunit 3 & 1.34 & 0.14 \\
\hline O15460 & P4HA2 & $\begin{array}{l}\text { Prolyl 4-hydroxylase } \\
\text { subunit alpha-2 }\end{array}$ & 0.38 & 0.14 \\
\hline Q13405;H0YDP7 & MRPL49 & $\begin{array}{l}39 S \text { ribosomal protein L } 49 \text {, } \\
\text { mitochondrial }\end{array}$ & 0.90 & 0.14 \\
\hline O00410;H0Y8C6 & IPO5 & Importin-5 & 0.36 & 0.14 \\
\hline P40926;G3XAL0 & $\mathrm{MDH} 2$ & $\begin{array}{l}\text { Malate dehydrogenase, } \\
\text { mitochondrial;Malate } \\
\text { dehydrogenase }\end{array}$ & 0.83 & 0.14 \\
\hline O75947 & ATP5H & $\begin{array}{l}\text { ATP synthase subunit } d \text {, } \\
\text { mitochondrial }\end{array}$ & 0.27 & 0.14 \\
\hline $\begin{array}{l}\text { Q15366;H3BRU6;F8VZX2;F8 } \\
\text { W0G4;F8VXH9;F8W1G6;J3QT } \\
\text { 27;E9PFP8;P57721 }\end{array}$ & РCBP2;РCBP3 & $\begin{array}{l}\text { Poly(rC)-binding protein } \\
\text { 2;Poly(rC)-binding protein } 3\end{array}$ & 0.77 & 0.14 \\
\hline J3QT28;O43684;J3QSX4 & BUB3 & $\begin{array}{l}\text { Mitotic checkpoint protein } \\
\text { BUB3 }\end{array}$ & 0.54 & 0.14 \\
\hline P51571;A6NLM8 & SSR4 & $\begin{array}{l}\text { Translocon-associated } \\
\text { protein subunit delta }\end{array}$ & 1.06 & 0.14 \\
\hline C9JZR2;O60716 & CTNND1 & Catenin delta-1 & 0.93 & 0.14 \\
\hline O95994;B5MC07;C9J3E2 & AGR2 & $\begin{array}{l}\text { Anterior gradient protein } 2 \\
\text { homolog }\end{array}$ & 0.62 & 0.14 \\
\hline Q9BVP2 & GNL3 & $\begin{array}{l}\text { Guanine nucleotide-binding } \\
\text { protein-like } 3\end{array}$ & 0.43 & 0.14 \\
\hline P35221;G3XAM7 & CTNNA1 & Catenin alpha-1 & 0.78 & 0.14 \\
\hline O75915 & ARL6IP5 & PRA1 family protein 3 & 0.59 & 0.14 \\
\hline $\begin{array}{l}\text { A0A087WZK9;B3KS98;O1537 } \\
\text { 2;E5RJT0 }\end{array}$ & EIF3H & $\begin{array}{l}\text { Eukaryotic translation } \\
\text { initiation factor } 3 \text { subunit } \mathrm{H} \\
\text { Serine }\end{array}$ & 0.44 & 0.14 \\
\hline P34897;H0YIZ0;G3V2Y4 & SHMT2 & $\begin{array}{l}\text { hydroxymethyltransferase, } \\
\text { mitochondrial;Serine } \\
\text { hydroxymethyltransferase }\end{array}$ & 1.01 & 0.15 \\
\hline J3QRS3;P19105;O14950 & MYL12A;MYL12B & $\begin{array}{l}\text { Myosin regulatory light } \\
\text { chain 12A;Myosin } \\
\text { regulatory light chain 12B }\end{array}$ & 0.46 & 0.15 \\
\hline Q6RW13 & AGTRAP & $\begin{array}{l}\text { Type-1 angiotensin II } \\
\text { receptor-associated protein }\end{array}$ & 0.60 & 0.15 \\
\hline $\begin{array}{l}\text { P62879;E7EP32;C9JIS1;C9JX } \\
\text { A5;C9JZN1 }\end{array}$ & GNB2 & $\begin{array}{l}\text { Guanine nucleotide-binding } \\
\text { protein } G(I) / G(S) / G(T) \\
\text { subunit beta-2 }\end{array}$ & 0.89 & 0.15 \\
\hline Q9H3Z4 & DNAJC5 & $\begin{array}{l}\text { DnaJ homolog subfamily } \mathrm{C} \\
\text { member } 5\end{array}$ & 0.30 & 0.15 \\
\hline O00148;K7EQN7 & DDX39A & $\begin{array}{l}\text { ATP-dependent RNA } \\
\text { helicase DDX39A }\end{array}$ & 0.33 & 0.15 \\
\hline $\begin{array}{l}\text { A6NNI4;G8JLH6;P21926;A0A0 } \\
\text { 87WU13 }\end{array}$ & CD9 & Tetraspanin;CD9 antigen & 0.32 & 0.15 \\
\hline Q93050;B7Z641;B7Z2A9 & ATP6V0A1 & $\begin{array}{l}\text { V-type proton ATPase } 116 \\
\mathrm{kDa} \text { subunit a isoform } 1 ; \mathrm{V} \text { - }\end{array}$ & 0.42 & 0.15 \\
\hline
\end{tabular}




\begin{tabular}{|c|c|}
\hline O75477;B0QZ43 & ERLIN1 \\
\hline P51970 & NDUFA8 \\
\hline $\begin{array}{l}\text { J3KPX7;Q99623;F5GY37;F5G } \\
\text { WA7;F5H3X6 }\end{array}$ & PHB2 \\
\hline K7ESP4;Q8WVC6 & DCAKD \\
\hline $\begin{array}{l}\text { Q9BWS9;E9PI70;E9PIP0;E9P } \\
\text { RL3;E9PPH0;E9PPA0;E9PKF1 }\end{array}$ & CHID1 \\
\hline Q92890;C9J6N9;C9IZG3 & UFD1L \\
\hline $\begin{array}{l}\text { C9JW69;P18754;C9JRH2;C9J } \\
\text { MJ4;C9J3R0;C9JQZ4 }\end{array}$ & $\mathrm{RCC} 1$ \\
\hline G3V150;O94766;E9PNA1 & B3GAT3 \\
\hline $\begin{array}{l}\text { A0A0R4J2E8;A8MXP9;P43243 } \\
\text {;D6REM6;D6R991 }\end{array}$ & MATR3 \\
\hline $\begin{array}{l}\text { C9J9K3;A0A0C4DG17;P08865 } \\
\text {;F8WD59 }\end{array}$ & RPSA \\
\hline P02545;Q3BDU5;Q5TCI8 & LMNA \\
\hline Q8NBJ5 & COLGALT1 \\
\hline H0Y9V7;B4E2Q0;P98194 & ATP2C1 \\
\hline Q9NUQ7;H0YA18;D6RGX2 & UFSP2 \\
\hline P61009 & SPCS3 \\
\hline Q9P2R3 & ANKFY1 \\
\hline Q13813;A0A0D9SGF6 & SPTAN1 \\
\hline $\begin{array}{l}\text { P32969;D6RAN4;HOY9V9;HOY } \\
\text { 9R4 }\end{array}$ & RPL9 \\
\hline P62318 & SNRPD3 \\
\hline Q99714;Q5H928 & HSD17B10 \\
\hline A0A087WUK2;O14979 & HNRNPDL \\
\hline P29317 & EPHA2 \\
\hline P62277;J3KMX5 & RPS13 \\
\hline P35241 & $\mathrm{RDX}$ \\
\hline Q9H0V9 & LMAN2L \\
\hline $\begin{array}{l}\text { P56537;B7ZBH1;A0A0U1RQV } \\
5\end{array}$ & EIF6 \\
\hline O00264 & PGRMC1 \\
\hline $\begin{array}{l}\text { E9PM69;R4GNH3;P17980;E9 } \\
\text { PKD5;E9PMD8;E9PN50 }\end{array}$ & PSMC3 \\
\hline P30101 & PDIA3 \\
\hline P06703;R4GN98 & S100A6 \\
\hline P22307 & SCP2 \\
\hline H3BN98;H3BPJ2;Q15041 & ARL6IP1 \\
\hline P82912;H0YL99 & MRPS11 \\
\hline $\begin{array}{l}\text { A0A087WWS1;Q96FV9;R4GM } \\
\text { N4 }\end{array}$ & THOC1 \\
\hline
\end{tabular}

type proton ATPase subunit

a

Erlin-1

1.49

0.15

NADH dehydrogenase

[ubiquinone] 1 alpha

subcomplex subunit 8

Prohibitin-2

0.33

0.15

Dephospho-CoA kinase

domain-containing protein

Chitinase domain-

containing protein 1

Ubiquitin fusion degradation

protein 1 homolog

Regulator of chromosome

condensation

Galactosylgalactosylxylosyl

protein 3-beta-

glucuronosyltransferase 3

Matrin-3

1.16

0.15

0.74

0.15

0.12

0.15

0.41

0.15

0.45

0.15

0.41

0.15

0.44

0.15

40S ribosomal protein SA

0.15

Prelamin-A/C;Lamin-A/C

Procollagen

galactosyltransferase 1

Calcium-transporting

ATPase;Calcium-

transporting ATPase type

2C member 1

Ufm1-specific protease 2

Signal peptidase complex subunit 3

Rabankyrin-5

Spectrin alpha chain, nonerythrocytic 1

60S ribosomal protein L9

Small nuclear

ribonucleoprotein Sm D3

3-hydroxyacyl-CoA

dehydrogenase type-2

Heterogeneous nuclear

ribonucleoprotein D-like

Ephrin type-A receptor 2

0.40

0.15

3.05

0.64

0.15

0.35

0.15

0.68

0.15

0.68

0.16

0.45

0.16

0.29

0.16

0.52

0.16

0.22

0.16

0.81

0.16

0.38

0.16

$40 S$ ribosomal protein $\mathrm{S} 13$

0.16

0.75

Radixin

VIP36-like protein

Eukaryotic translation

initiation factor 6

Membrane-associated

progesterone receptor

component 1

26S protease regulatory

subunit $6 \mathrm{~A}$

Protein disulfide-isomerase

A3

Protein S100-A6; Protein

S100

Non-specific lipid-transfer

protein

ADP-ribosylation factor-like

protein 6-interacting protein 1

$28 \mathrm{~S}$ ribosomal protein S11, mitochondrial

THO complex subunit 1
0.16

0.16

0.16

0.40

0.47

0.56

0.16

0.43

0.74

0.16

0.44

0.16

2.63

0.16

0.42

0.16

0.73

0.16

0.67

0.16

0.15

0.16

0.44

0.17 


\begin{tabular}{|c|c|c|c|c|}
\hline $\begin{array}{l}\text { Q9NY93;G3V0G3;H7C3E9;F8 } \\
\text { WDT8 }\end{array}$ & DDX56 & $\begin{array}{l}\text { Probable ATP-dependent } \\
\text { RNA helicase DDX56 }\end{array}$ & 0.97 & 0.17 \\
\hline Q9Ul12;G3V126 & ATP6V1H & $\begin{array}{l}\text { V-type proton ATPase } \\
\text { subunit H }\end{array}$ & 1.04 & 0.17 \\
\hline E7EQ29;P16278 & GLB1 & Beta-galactosidase & 0.58 & 0.17 \\
\hline Q96AY3;H0Y827 & FKBP10 & $\begin{array}{l}\text { Peptidyl-prolyl cis-trans } \\
\text { isomerase FKBP10 } \\
\text { Heterogeneous nuclear } \\
\text { ribonucleoprotein }\end{array}$ & 0.49 & 0.17 \\
\hline P52597 & HNRNPF & $\begin{array}{l}\text { F;Heterogeneous nuclear } \\
\text { ribonucleoprotein F, N- } \\
\text { terminally processed } \\
\text { Dolichyl- }\end{array}$ & 0.49 & 0.17 \\
\hline P04844 & RPN2 & $\begin{array}{l}\text { diphosphooligosaccharide-- } \\
\text { protein glycosyltransferase } \\
\text { subunit } 2\end{array}$ & 0.16 & 0.17 \\
\hline P78527 & PRKDC & $\begin{array}{l}\text { DNA-dependent protein } \\
\text { kinase catalytic subunit }\end{array}$ & 0.81 & 0.17 \\
\hline B9A018;Q53GS9;A0A087X1B2 & USP39 & $\begin{array}{l}\text { U4/U6.U5 tri-snRNP- } \\
\text { associated protein } 2\end{array}$ & 1.45 & 0.17 \\
\hline P19338;H7BY16 & NCL & Nucleolin & 1.22 & 0.17 \\
\hline $\begin{array}{l}\text { Q96S97;C9JZL8;C9J5M0;C9J } \\
\text { C07;C9JJV6 }\end{array}$ & MYADM & Myeloid-associated & 1.33 & 0.17 \\
\hline 095782 & AP2A1 & $\begin{array}{l}\text { AP-2 complex subunit } \\
\text { alpha-1 }\end{array}$ & 0.48 & 0.17 \\
\hline $\begin{array}{l}\text { M0R3D4;Q9UI14;M0QXH1;M0 } \\
\text { R1H9 }\end{array}$ & RABAC1 & $\begin{array}{l}\text { Prenylated Rab acceptor } \\
\text { protein } 1\end{array}$ & 1.11 & 0.17 \\
\hline $\begin{array}{l}\text { Q14103;H0Y8G5;H0YA96;D6R } \\
\text { AF8;D6RF44;D6RBQ9 }\end{array}$ & HNRNPD & $\begin{array}{l}\text { Heterogeneous nuclear } \\
\text { ribonucleoprotein D0 } \\
\text { 3-hydroxyisobutyrate }\end{array}$ & 0.79 & 0.17 \\
\hline P31937;H7BZL2 & HIBADH & $\begin{array}{l}\text { dehydrogenase, } \\
\text { mitochondrial }\end{array}$ & 0.44 & 0.17 \\
\hline Q92621 & NUP205 & $\begin{array}{l}\text { Nuclear pore complex } \\
\text { protein Nup205 }\end{array}$ & 0.35 & 0.17 \\
\hline P43897 & TSFM & $\begin{array}{l}\text { Elongation factor Ts, } \\
\text { mitochondrial }\end{array}$ & 0.88 & 0.18 \\
\hline 095716 & RAB3D & Ras-related protein Rab-3D & 0.00 & 0.18 \\
\hline O76031 & CLPX & $\begin{array}{l}\text { ATP-dependent Clp } \\
\text { protease ATP-binding } \\
\text { subunit clpX-like, } \\
\text { mitochondrial }\end{array}$ & 0.75 & 0.18 \\
\hline P14866;M0QXS5 & HNRNPL & $\begin{array}{l}\text { Heterogeneous nuclear } \\
\text { ribonucleoprotein } \mathrm{L}\end{array}$ & 0.34 & 0.18 \\
\hline $\begin{array}{l}\text { MOR0N4;M0QYZ2;P53680;M0 } \\
\text { QZ21;X6R390 }\end{array}$ & AP2S1 & $\begin{array}{l}\text { AP-2 complex subunit } \\
\text { sigma }\end{array}$ & 0.78 & 0.18 \\
\hline P21281;H0YC04 & ATP6V1B2 & $\begin{array}{l}\text { V-type proton ATPase } \\
\text { subunit } B \text {, brain isoform }\end{array}$ & 0.56 & 0.18 \\
\hline P27348;E9PG15 & YWHAQ & 14-3-3 protein theta & 0.24 & 0.18 \\
\hline Q9BYG3;C9J6C5;C9J808 & NIFK & $\begin{array}{l}\text { MKI67 FHA domain- } \\
\text { interacting nucleolar } \\
\text { phosphoprotein }\end{array}$ & 0.35 & 0.18 \\
\hline Q5RI15 & $\operatorname{cox} 20$ & $\begin{array}{l}\text { Cytochrome c oxidase } \\
\text { protein } 20 \text { homolog }\end{array}$ & 0.41 & 0.18 \\
\hline Q9P015;E5RIZ4;E5RHF4 & MRPL15 & $\begin{array}{l}\text { 39S ribosomal protein L15, } \\
\text { mitochondrial } \\
\text { RNA-binding motif protein, } \\
\text { X chromosome;RNA- }\end{array}$ & 0.56 & 0.18 \\
\hline $\begin{array}{l}\text { P38159;H0Y6E7;H3BT71;Q96 } \\
\text { E39;H3BUY5 }\end{array}$ & RBMX;RBMXL1 & $\begin{array}{l}\text { binding motif protein, } X \\
\text { chromosome, N-terminally } \\
\text { processed;RNA binding } \\
\text { motif protein, } X \text {-linked-like-1 }\end{array}$ & 1.08 & 0.18 \\
\hline Q99536 & VAT1 & $\begin{array}{l}\text { Synaptic vesicle membrane } \\
\text { protein VAT-1 homolog }\end{array}$ & 0.55 & 0.18 \\
\hline Q2TB90 & HKDC1 & $\begin{array}{l}\text { Putative hexokinase } \\
\text { HKDC1 }\end{array}$ & 0.57 & 0.18 \\
\hline G5EA06;Q92552;D6RH20 & MRPS27 & $\begin{array}{l}28 \mathrm{~S} \text { ribosomal protein } \mathrm{S} 27 \text {, } \\
\text { mitochondrial }\end{array}$ & 1.19 & 0.18 \\
\hline Q86UY8 & NT5DC3 & $\begin{array}{l}\text { 5-nucleotidase domain- } \\
\text { containing protein } 3\end{array}$ & 0.33 & 0.18 \\
\hline O75083;D6RD66 & WDR1 & $\begin{array}{l}\text { WD repeat-containing } \\
\text { protein } 1\end{array}$ & 0.72 & 0.18 \\
\hline
\end{tabular}




\begin{tabular}{|c|c|}
\hline P38606 & ATP6V1A \\
\hline A2A2V1;P04156 & PRNP \\
\hline O95864 & FADS2 \\
\hline M0QZC5;P62280 & RPS11 \\
\hline $\begin{array}{l}\text { A0A0A0MRP6;B7ZLQ5;P2837 } \\
0\end{array}$ & SMARCA1 \\
\hline Q14690 & PDCD11 \\
\hline $\begin{array}{l}\text { P13804;HOYL12;HOYLU7;HOY } \\
\text { K49;HOYNX6;HOYKFO }\end{array}$ & ETFA \\
\hline Q9BVK6 & TMED9 \\
\hline O95881 & TXNDC12 \\
\hline P80723 & BASP1 \\
\hline P49721;A0A087WVV1 & PSMB2 \\
\hline Q96199;E9PDQ8;H0Y852 & SUCLG2 \\
\hline P20618 & PSMB1 \\
\hline $\begin{array}{l}\text { P11142;E9PKE3;E9PNE6;E9P } \\
\text { N89;A8K7Q2 }\end{array}$ & HSPA8 \\
\hline Q5SQP8;P56545 & CTBP2 \\
\hline O75976 & CPD \\
\hline Q8N4V1 & MMGT1 \\
\hline I3L1P8;Q02978 & SLC25A11 \\
\hline E9PEX6;P09622 & DLD \\
\hline B8ZZA8;B8ZZC5 & GLS \\
\hline P00167 & CYB5A \\
\hline Q8NE86 & MCU \\
\hline O15127 & SCAMP2 \\
\hline P13498 & CYBA \\
\hline $\begin{array}{l}\text { P61247;D6RG13;E9PFI5;H0Y9 } \\
\text { Y4;D6RAT0;H0Y8L7;D6RB09; } \\
\text { D6R9B6 }\end{array}$ & RPS3A \\
\hline P20700;E9PBF6;A0A0D9SFE5 & LMNB1 \\
\hline P38919 & EIF4A3 \\
\hline P30084 & ECHS1 \\
\hline P26373;J3QSB4 & RPL13 \\
\hline $\begin{array}{l}\text { O14521;H0YD96;HOYD41;G3V } \\
\text { 173;E9PK73;H3BRW5 }\end{array}$ & SDHD \\
\hline J3QLR8;Q9Y3D9 & MRPS23 \\
\hline P42704 & LRPPRC \\
\hline
\end{tabular}

V-type proton ATPase

catalytic subunit A

Major prion protein

1.41

0.18

Fatty acid desaturase 2

0.66

0.19

40 S ribosomal protein $\$ 11$

1.53

0.19

Probable global

transcription activator

SNF2L1

Protein RRP5 homolog

0.46

0.64

0.23

0.69

flavoprotein subunit alpha,

mitochondrial

Transmembrane emp24

domain-containing protein 9

Thioredoxin domain-

containing protein 12

Brain acid soluble protein 1

Proteasome subunit beta

type-2

Succinyl-CoA ligase [GDP-

forming] subunit beta,

mitochondrial

Proteasome subunit beta

type-1

Heat shock cognate $71 \mathrm{kDa}$

protein

C-terminal-binding protein 2

Carboxypeptidase D

Membrane magnesium

transporter 1

Mitochondrial 2-

oxoglutarate/malate carrier

protein

Dihydrolipoyl

dehydrogenase;Dihydrolipo

yl dehydrogenase,

mitochondrial

0.79

0.94

0.47

0.77

1.45

0.19

0.93

0.19

1.43

0.19

0.95

0.19

0.28

0.19

0.51

0.19

1.07

0.19

1.28

0.19

1.21

0.19

Cytochrome b5

0

0.19

Calcium uniporter protein,

mitochondrial

Secretory carrier-

associated membrane

protein 2

Cytochrome b-245 light

chain

0.55

0.56

0.19

0.69

0.19

0.79

0.19

40 S ribosomal protein S3a

0.19

Lamin-B1

0.19

Eukaryotic initiation factor

4A-III;Eukaryotic initiation

factor $4 \mathrm{~A}$-III, $\mathrm{N}$-terminally

processed

Enoyl-CoA hydratase

mitochondrial

60S ribosomal protein L13

Succinate dehydrogenase

[ubiquinone] cytochrome b

small subunit, mitochondrial

28 S ribosomal protein S23,

mitochondrial

0.88

1.15

0.20

作

containing protein,

mitochondrial 
E9PK01;A0A087X1X7;E9PRY
8;P29692;E9PPR1;E9PL12;E9
PQ49;E9PI39;E9PMW7;E9PIZ
1;E9PL71;H0YCK7;E9PQZ1

E7EU96;P68400;Q8NEV1

P10253

A0A087WU53;Q9H0U3

Q9NUJ1

Q9NYH9

P61978

Q8IVT2

Q53TN4

P07711

P04040

Q9Y6A9;C9JBL1;X6R2S6

Q8WY22

Q9UIG0

B0QY89;Q9Y262;B0QY90

075533

Q7L576;H7C229;E7EVJ5;Q96 F07;E7EW33;A0A0G2JR96;A0 A0G2JQT1

G3V325;C9JJT5;C9JU26;P561 34

Q8IY81

P42285

$\mathrm{P} 55060$

P49411

J3KNN5;Q9UJV9

Q96JB5;J3QRM1

Q9Y676;A0A0G2JIC6

Q5TEC6

Q8WUM4

Q15907;H3BMH2;H3BSC1;P6 2491

P10606

060763

P06576;HOYH81
EEF1D

Elongation factor 1-delta

0.71

1.15

A3

GAA

MAGT1

ABHD10

UTP6

HNRNPK

MISP

CYBRD1

CTSL

CAT

SPCS1

BRI3BP

BAZ1B

EIF3L

SF3B1

CYFIP1;CYFIP2

ATP5J2PTCD1;ATP5J2

FTSJ3

SKIV2L2

CSE1L

TUFM

DDX41

CDK5RAP3

MRPS18B

HIST2H3PS2

PDCD6IP

RAB11B;RAB11A

COX5B

USO1

ATP5B

Casein kinase II subunit

alpha;Casein kinase II

subunit alpha 3

Lysosomal alpha-

glucosidase;76 kDa

glucosidase;70 kDa

ysosomal alpha-

glucosidase

Magnesium transporter

protein 1

Mycophenolic acid acyl-

glucuronide esterase,

mitochondrial

associated protein 6

homolog

Heterogeneous nuclear

ribonucleoprotein $\mathrm{K}$

Mitotic interactor and

substrate of PLK1

Cytochrome $b$ reductase 1

Cathepsin L1;Cathepsin L1

heavy chain;Cathepsin L1

light chain

Catalase

1.59

1.10

0.59

1.20

0.78

0.76

0.33

0.16

0.68

Signal peptidase complex

subunit 1

BRI3-binding protein

0.77

1.21

BAZ1B

Eukaryotic translation

initiation factor 3 subunit $L$

Splicing factor $3 \mathrm{~B}$ subunit 1

Cytoplasmic FMR1-

interacting protein

1;Cytoplasmic FMR1.

interacting protein 2

ATP synthase subunit $f$,

mitochondrial

pre-rRNA processing

protein FTSJ3

Superkiller viralicidic activity 2-like 2

Exportin-2

Elongation factor Tu,

mitochondrial

Probable ATP-dependent

RNA helicase DDX41

CDK5 regulatory subunit-

associated protein 3

$28 \mathrm{~S}$ ribosomal protein

$\mathrm{S} 18 \mathrm{~b}$, mitochondrial

Histone H3

Programmed cell death 6-

interacting protein

Ras-related protein Rab-

11B;Ras-related protein

Rab-11A

Cytochrome $\mathrm{c}$ oxidase

subunit $5 B$, mitochondrial

General vesicular transport

factor p 115

ATP synthase subunit beta,

mitochondrial;ATP lysosomal alpha-

U3 small nucleolar RNA-

synthase subunit beta
0.20

0.20

0.20

0.20

0.20

0.20

0.20

0.20

0.20

0.21

0.21

0.21

0.21

0.21

0.21

0.21

0.21

0.21

0.21

0.21

0.21

0.21

0.21

0.21

0.21

0.21

0.22

0.22

0.22

0.22

0.22 


\begin{tabular}{|c|c|c|c|c|}
\hline Q92900 & UPF1 & $\begin{array}{l}\text { Regulator of nonsense } \\
\text { transcripts } 1\end{array}$ & 0.52 & 0.22 \\
\hline 000186 & STXBP3 & Syntaxin-binding protein 3 & 0.47 & 0.22 \\
\hline Q99575 & POP1 & $\begin{array}{l}\text { Ribonucleases P/MRP } \\
\text { protein subunit POP1 }\end{array}$ & 0.94 & 0.22 \\
\hline $\begin{array}{l}\text { D6R9P3;D6RD18;D6RBZ0;Q9 } \\
9729\end{array}$ & HNRNPAB & $\begin{array}{l}\text { Heterogeneous nuclear } \\
\text { ribonucleoprotein } A / B\end{array}$ & 1.27 & 0.22 \\
\hline A1L0T0;M0R026 & ILVBL & $\begin{array}{l}\text { Acetolactate synthase-like } \\
\text { protein }\end{array}$ & 0.44 & 0.22 \\
\hline P18206 & VCL & Vinculin & 0.47 & 0.22 \\
\hline Q9BX68 & HINT2 & $\begin{array}{l}\text { Histidine triad nucleotide- } \\
\text { binding protein } 2 \text {, } \\
\text { mitochondrial }\end{array}$ & 0.57 & 0.22 \\
\hline Q9NUQ2 & AGPAT5 & $\begin{array}{l}\text { 1-acyl-sn-glycerol-3- } \\
\text { phosphate acyltransferase } \\
\text { epsilon }\end{array}$ & 1.02 & 0.22 \\
\hline Q9BS26 & ERP44 & $\begin{array}{l}\text { Endoplasmic reticulum } \\
\text { resident protein } 44\end{array}$ & 1.10 & 0.22 \\
\hline $\begin{array}{l}\text { R4GMR5;P48556;K7EJC1;K7E } \\
\text { JR3 }\end{array}$ & PSMD8 & $\begin{array}{l}26 S \text { proteasome non- } \\
\text { ATPase regulatory subunit } \\
8\end{array}$ & 0.61 & 0.23 \\
\hline $\begin{array}{l}\text { H0Y8R1;F5H5I6;H0YAK1;Q12 } \\
849\end{array}$ & GRSF1 & G-rich sequence factor 1 & 0.63 & 0.23 \\
\hline $\begin{array}{l}\text { H0YNG3;P67812;H0YNX5;H0 } \\
\text { YNA5 }\end{array}$ & SEC11A & $\begin{array}{l}\text { Signal peptidase complex } \\
\text { catalytic subunit } \\
\text { SEC11;Signal peptidase } \\
\text { complex catalytic subunit } \\
\text { SEC11A;Signal peptidase I } \\
\text { U3 small nucleolar RNA- }\end{array}$ & 0.95 & 0.23 \\
\hline Q8TED0;H0Y8P4 & UTP15 & $\begin{array}{l}\text { associated protein } 15 \\
\text { homolog }\end{array}$ & 0.49 & 0.23 \\
\hline E5RHW4;094905 & ERLIN2 & Erlin-2 & 1.29 & 0.23 \\
\hline $\begin{array}{l}\text { Q12907;D6RBV2;D6RIU4;D6R } \\
\text { DX1 }\end{array}$ & LMAN2 & $\begin{array}{l}\text { Vesicular integral- } \\
\text { membrane protein VIP36 }\end{array}$ & 1.11 & 0.23 \\
\hline $\begin{array}{l}\text { Q86TM6;HOYCR6;E9PN88;E9 } \\
\text { PMA1;E9PK19 }\end{array}$ & SYVN1 & $\begin{array}{l}\text { E3 ubiquitin-protein ligase } \\
\text { synoviolin } \\
\text { 26S proteasome non- }\end{array}$ & 0.74 & 0.23 \\
\hline O00231 & PSMD11 & $\begin{array}{l}\text { ATPase regulatory subunit } \\
11\end{array}$ & 0.31 & 0.23 \\
\hline P25205;J3KQ69 & MCM3 & $\begin{array}{l}\text { DNA replication licensing } \\
\text { factor MCM3 }\end{array}$ & 1.55 & 0.23 \\
\hline $\begin{array}{l}\text { E9PN51;F8W9K7;E9PKH6;E9 } \\
\text { PPW7;O00217 }\end{array}$ & NDUFS8 & $\begin{array}{l}\text { NADH dehydrogenase } \\
\text { [ubiquinone] iron-sulfur } \\
\text { protein } 8, \text { mitochondrial }\end{array}$ & 0.50 & 0.23 \\
\hline Q92520;C9JP35;C9JMN4 & FAM3C & Protein FAM3C & 0.77 & 0.23 \\
\hline P16188;P30447 & HLA-A & $\begin{array}{l}\text { HLA class I } \\
\text { histocompatibility antigen, } \\
\text { A-30 alpha chain;HLA class } \\
\text { I histocompatibility antigen, } \\
\text { A-23 alpha chain }\end{array}$ & 1.04 & 0.23 \\
\hline $\begin{array}{l}\text { Q13838;A0A0G2JJZ9;Q5STU3 } \\
\text {;A0A140T9X3;F6WLT2;A0A14 } \\
\text { OT996;A0A0A0MT12;F6TRA5; } \\
\text { A0A140T9X9;F6S4E6;F6UJC5 } \\
\text {;A0A140TA18 }\end{array}$ & DDX39B & $\begin{array}{l}\text { Spliceosome RNA helicase } \\
\text { DDX39B }\end{array}$ & 2.93 & 0.24 \\
\hline Q9H8H0;J3QLQ6 & NOL11 & Nucleolar protein 11 & 0.82 & 0.24 \\
\hline Q12931 & TRAP1 & $\begin{array}{l}\text { Heat shock protein } 75 \mathrm{kDa} \text {, } \\
\text { mitochondrial }\end{array}$ & 0.20 & 0.24 \\
\hline O75367;B4DJC3 & H2AFY & $\begin{array}{l}\text { Core histone macro- } \\
\text { H2A.1;Histone H2A }\end{array}$ & 1.79 & 0.24 \\
\hline A6NGW1;O95070;E9PIZ0 & YIF1A & Protein YIF1A & 0.46 & 0.24 \\
\hline $\begin{array}{l}\text { O15258;Q5T092;A0A0A0MR0 } \\
\text { 6;Q5T091;Q5T093 }\end{array}$ & RER1 & Protein RER1 & 0.68 & 0.24 \\
\hline Q03135;E9PCT5;C9JKI3 & CAV1 & Caveolin-1;Caveolin & 1.00 & 0.24 \\
\hline F8W7Q4;Q96A26;E9PH05 & FAM162A & Protein FAM162A & 1.18 & 0.24 \\
\hline $\begin{array}{l}\text { U3KQC1;A0A0A0MQU0;Q9BV } \\
\text { 38;K7EIR0 }\end{array}$ & WDR18 & $\begin{array}{l}\text { WD repeat-containing } \\
\text { protein } 18\end{array}$ & 1.17 & 0.24 \\
\hline
\end{tabular}




\begin{tabular}{|c|c|c|c|c|}
\hline P38117 & ETFB & $\begin{array}{l}\text { Electron transfer } \\
\text { flavoprotein subunit beta }\end{array}$ & 1.28 & 0.24 \\
\hline P28072 & PSMB6 & $\begin{array}{l}\text { Proteasome subunit beta } \\
\text { type- } 6\end{array}$ & 0.49 & 0.24 \\
\hline $\begin{array}{l}\text { Q8NFH5;C9IYQ7;F8WCF5;F8 } \\
\text { WEL4 }\end{array}$ & NUP35 & Nucleoporin NUP53 & 0.73 & 0.24 \\
\hline P55735;A8MXL6 & SEC13 & Protein SEC13 homolog & 0.57 & 0.24 \\
\hline P20020;E7ERY9 & ATP2B1 & $\begin{array}{l}\text { Plasma membrane calcium- } \\
\text { transporting ATPase } \\
1 ; \text { Calcium-transporting } \\
\text { ATPase }\end{array}$ & 1.56 & 0.24 \\
\hline P08754 & GNAI3 & $\begin{array}{l}\text { Guanine nucleotide-binding } \\
\text { protein } G(k) \text { subunit alpha }\end{array}$ & 1.06 & 0.24 \\
\hline Q13263;M0R0K9 & TRIM28 & $\begin{array}{l}\text { Transcription intermediary } \\
\text { factor 1-beta }\end{array}$ & 1.08 & 0.24 \\
\hline Q9NYY8 & FASTKD2 & $\begin{array}{l}\text { FAST kinase domain- } \\
\text { containing protein } 2\end{array}$ & 0.59 & 0.25 \\
\hline M0QXB5;O95571;M0QY80 & ETHE1 & $\begin{array}{l}\text { Persulfide dioxygenase } \\
\text { ETHE1, mitochondrial }\end{array}$ & 0.89 & 0.25 \\
\hline Q13185;S4R2Y4 & CBX3 & $\begin{array}{l}\text { Chromobox protein } \\
\text { homolog } 3\end{array}$ & 1.53 & 0.25 \\
\hline $\begin{array}{l}\text { A0A1W2PNP0;Q969N2;F6W9 } \\
\text { 83;A0A1W2PP53;A0A1W2PP5 } \\
\text { 7;A0A1W2PPC3;A0A1W2PPS } \\
\text { 0;A0A1W2PQN1;A0A1W2PPR } \\
\text { 6;A0A1W2PQY1;A0A1W2PPQ } \\
\text { 7;A0A1W2PQ52;A0A1W2PP13 } \\
\text {;A0A1W2PRZ8 }\end{array}$ & PIGT & $\begin{array}{l}\text { GPI transamidase } \\
\text { component PIG-T }\end{array}$ & 2.55 & 0.25 \\
\hline $\begin{array}{l}\text { G3V1A4;E9PK25;P23528;E9P } \\
\text { P50;E9PQB7;E9PLJ3 }\end{array}$ & CFL1 & Cofilin-1 & 1.99 & 0.25 \\
\hline P05783;F8VZY9 & KRT18 & $\begin{array}{l}\text { Keratin, type I cytoskeletal } \\
18 \\
\text { Phosphoglycerate mutase }\end{array}$ & 2.93 & 0.25 \\
\hline P18669;P15259 & PGAM1;PGAM2 & 1;Phosphoglycerate mutase & 1.22 & 0.25 \\
\hline O76021;J3QSV6;I3L3U9 & RSL1D1 & $\begin{array}{l}\text { Ribosomal L1 domain- } \\
\text { containing protein } 1\end{array}$ & 1.05 & 0.25 \\
\hline $\begin{array}{l}\text { J3QLS3;Q9Y2R9;J3QQS1;J3Q } \\
\text { KW2;J3KSI8 }\end{array}$ & MRPS7 & $\begin{array}{l}28 \mathrm{~S} \text { ribosomal protein } \mathrm{S} 7 \text {, } \\
\text { mitochondrial }\end{array}$ & 0.51 & 0.25 \\
\hline P60468 & SEC61B & $\begin{array}{l}\text { Protein transport protein } \\
\text { Sec61 subunit beta }\end{array}$ & 1.16 & 0.26 \\
\hline Q96QD8;F8VUY8 & SLC38A2 & $\begin{array}{l}\text { Sodium-coupled neutral } \\
\text { amino acid transporter } 2\end{array}$ & 0.87 & 0.26 \\
\hline Q9HC07;V9GY93 & TMEM165 & $\begin{array}{l}\text { Transmembrane protein } \\
165\end{array}$ & 0.90 & 0.26 \\
\hline $\begin{array}{l}\text { K7ELQ9;Q6UW68;K7EM09;K7 } \\
\text { EPR0 }\end{array}$ & TMEM205 & $\begin{array}{l}\text { Transmembrane protein } \\
205\end{array}$ & 0.74 & 0.26 \\
\hline Q8NFJ5 & GPRC5A & $\begin{array}{l}\text { Retinoic acid-induced } \\
\text { protein } 3 \\
\text { Non-POU domain- }\end{array}$ & 1.26 & 0.26 \\
\hline Q15233;H7C367 & NONO & $\begin{array}{l}\text { containing octamer-binding } \\
\text { protein }\end{array}$ & 0.58 & 0.26 \\
\hline Q92499;F1T0B3;A0A087X2G1 & DDX1 & $\begin{array}{l}\text { ATP-dependent RNA } \\
\text { helicase DDX1 } \\
\text { Neutral amino acid }\end{array}$ & 0.84 & 0.26 \\
\hline Q15758;M0QXM4 & SLC1A5 & $\begin{array}{l}\text { transporter } \mathrm{B}(0) \text {;Amino acid } \\
\text { transporter } \\
\text { Cathepsin } \mathrm{B} ; \text { Cathepsin B }\end{array}$ & 1.49 & 0.27 \\
\hline P07858 & CTSB & $\begin{array}{l}\text { light chain;Cathepsin B } \\
\text { heavy chain }\end{array}$ & 1.23 & 0.27 \\
\hline $\begin{array}{l}\text { E9PJK1;E9PRJ8;HOYDL9;HOY } \\
\text { DJ9;E9PIF1;A6NMH8;P60033 }\end{array}$ & CD81 & Tetraspanin;CD81 antigen & 0.74 & 0.27 \\
\hline Q14318;U3KQ64 & FKBP8 & $\begin{array}{l}\text { Peptidyl-prolyl cis-trans } \\
\text { isomerase FKBP8 }\end{array}$ & 2.16 & 0.27 \\
\hline $\begin{array}{l}\text { E9PEP6;O14786;Q5JWQ6;E7 } \\
\text { EX60;Q5T7F0 }\end{array}$ & NRP1 & Neuropilin-1 & 0.71 & 0.27 \\
\hline $\begin{array}{l}\text { G8JLB6;P31943;E9PCY7;D6R } \\
\text { BM0;D6RIT2;E7EN40;D6RIU0; } \\
\text { H0YB39 }\end{array}$ & HNRNPH1 & $\begin{array}{l}\text { Heterogeneous nuclear } \\
\text { ribonucleoprotein } \\
\text { H;Heterogeneous nuclear } \\
\text { ribonucleoprotein } \mathrm{H}, \mathrm{N}- \\
\text { terminally processed }\end{array}$ & 1.05 & 0.27 \\
\hline Q7Z3B4 & NUP54 & Nucleoporin p54 & 0.22 & 0.27 \\
\hline
\end{tabular}




\begin{tabular}{|c|c|c|c|c|}
\hline & & & & \\
\hline F5GXU9;F5H5P2;P12694 & BCKDHA & $\begin{array}{l}\text { 2-oxoisovalerate } \\
\text { dehydrogenase subunit } \\
\text { alpha, mitochondrial }\end{array}$ & 0.00 & 0.27 \\
\hline F8VU90;Q9NYL4 & FKBP11 & $\begin{array}{l}\text { Peptidyl-prolyl cis-trans } \\
\text { isomerase;Peptidyl-prolyl } \\
\text { cis-trans isomerase } \\
\text { FKBP11 }\end{array}$ & 1.39 & 0.27 \\
\hline P10909;H0YC35;H0YAS8 & CLU & $\begin{array}{l}\text { Clusterin;Clusterin beta } \\
\text { chain;Clusterin alpha } \\
\text { chain;Clusterin }\end{array}$ & 0.94 & 0.27 \\
\hline Q9C0E8 & LNP & Protein lunapark & 1.75 & 0.27 \\
\hline Q13501;E7EMC7;E9PFW8 & SQSTM1 & Sequestosome-1 & 1.59 & 0.28 \\
\hline Q5TIH2;O95562 & SFT2D2 & $\begin{array}{l}\text { Vesicle transport protein } \\
\text { SFT2B }\end{array}$ & 3.53 & 0.28 \\
\hline $\begin{array}{l}\text { P60842;J3KT12;J3KTB5;J3QS } \\
\text { 69;J3QL43;J3QR64 }\end{array}$ & EIF4A1 & $\begin{array}{l}\text { Eukaryotic initiation factor } \\
4 \mathrm{~A}-\mathrm{I}\end{array}$ & 0.56 & 0.28 \\
\hline Q13769;H7C072;F8WCP5 & THOC5 & $\begin{array}{l}\text { THO complex subunit } 5 \\
\text { homolog }\end{array}$ & 0.65 & 0.28 \\
\hline E7EQR4;P15311 & EZR & Ezrin & 0.94 & 0.28 \\
\hline Q15365 & PCBP1 & Poly $(\mathrm{rC})$-binding protein 1 & 1.06 & 0.28 \\
\hline A0A0A0MSJ0;Q86XP3 & DDX42 & $\begin{array}{l}\text { ATP-dependent RNA } \\
\text { helicase DDX42 }\end{array}$ & 1.16 & 0.28 \\
\hline Q00059;H7BYN3 & TFAM & $\begin{array}{l}\text { Transcription factor A, } \\
\text { mitochondrial }\end{array}$ & 0.74 & 0.28 \\
\hline Q8N5M9 & JAGN1 & Protein jagunal homolog 1 & 1.00 & 0.29 \\
\hline $\begin{array}{l}\text { P62266;D6RD47;D6RDJ2;D6R } \\
\text { IX0;D6R9I7 }\end{array}$ & RPS23 & $40 S$ ribosomal protein S23 & 0.97 & 0.29 \\
\hline C9JPM4;P18085;C9JAK5 & ARF4 & ADP-ribosylation factor 4 & 1.12 & 0.29 \\
\hline O00232 & PSMD12 & $\begin{array}{l}26 S \text { proteasome non- } \\
\text { ATPase regulatory subunit } \\
12\end{array}$ & 0.61 & 0.29 \\
\hline P27797;K7EJB9 & CALR & Calreticulin & 1.37 & 0.29 \\
\hline $\begin{array}{l}\text { B7Z2R7;Q5T8D3;X6RDD7;Q5 } \\
\text { T8E0 }\end{array}$ & ACBD5 & $\begin{array}{l}\text { Acyl-CoA-binding domain- } \\
\text { containing protein } 5 \\
\text { Nucleoside diphosphate }\end{array}$ & 1.40 & 0.30 \\
\hline $\begin{array}{l}\text { Q32Q12;J3KPD9;P22392;E7E } \\
\text { RL0;F6XY72;E5RHP0;O60361 }\end{array}$ & $\begin{array}{l}\text { NME1- } \\
\text { NME2;NME2;NME } \\
\text { 1;NME2P1 }\end{array}$ & $\begin{array}{l}\text { kinase;Nucleoside } \\
\text { diphosphate kinase } \\
\text { B;Putative nucleoside } \\
\text { diphosphate kinase }\end{array}$ & 1.89 & 0.30 \\
\hline P62753;A2A3R5 & RPS6 & 40 S ribosomal protein $\mathrm{S} 6$ & 1.36 & 0.30 \\
\hline A0A1C7CYX9;Q16555 & DPYSL2 & $\begin{array}{l}\text { Dihydropyrimidinase- } \\
\text { related protein } 2\end{array}$ & 0.21 & 0.30 \\
\hline $\begin{array}{l}\text { H3BNX8;P20674;H3BRM5;H3 } \\
\text { BV69 }\end{array}$ & COX5A & $\begin{array}{l}\text { Cytochrome c oxidase } \\
\text { subunit } 5 A \text {, mitochondrial }\end{array}$ & 2.89 & 0.30 \\
\hline E9PIN3;Q9UBU9;B4E227 & NXF1 & $\begin{array}{l}\text { Nuclear RNA export factor } \\
1\end{array}$ & 0.80 & 0.30 \\
\hline P26368;K7ENG2 & U2AF2 & $\begin{array}{l}\text { Splicing factor U2AF } 65 \\
\text { kDa subunit } \\
\text { Heterogeneous nuclear } \\
\text { ribonucleoproteins }\end{array}$ & 1.45 & 0.30 \\
\hline $\begin{array}{l}\text { G3V4W0;B4DY08;B2R5W2;G3 } \\
\text { V4C1;G3V2Q1;P07910;G3V57 } \\
\text { 6;G3V555;G3V575;G3V5X6;G }\end{array}$ & $\begin{array}{l}\text { HNRNPC;HNRNP } \\
\text { CI } 4 \cdot \text { HNRNPCI } 1 \cdot \mathrm{H}\end{array}$ & $\begin{array}{l}\text { C1/C2; Heterogeneous } \\
\text { nuclear ribonucleoprotein } \\
\text { C-like 4;Heterogeneous }\end{array}$ & & \\
\hline $\begin{array}{l}\text { 3V3K6;G3V251;B4DSU6;G3V2 } \\
\text { D6;A0A0G2JPF8;A0A0G2JNQ } \\
\text { 3;P0DMR1;O60812;B7ZW38;B } \\
\text { 2RXH8 }\end{array}$ & $\begin{array}{l}\text { CL4;HNRNPCL1; } \\
\text { NRNPCL3;HNRNP } \\
\text { CL2 }\end{array}$ & $\begin{array}{l}\text { nuclear ribonucleoprotein } \\
\text { C-like } 1 \text {; Heterogeneous } \\
\text { nuclear ribonucleoprotein } \\
\text { C-like 3;Heterogeneous } \\
\text { nuclear ribonucleoprotein } \\
\text { C-like } 2 \\
\text { Trifunctional enzyme }\end{array}$ & 1.40 & 0.30 \\
\hline P55084;F5GZQ3;B5MD38 & HADHB & $\begin{array}{l}\text { subunit beta, } \\
\text { mitochondrial;3-ketoacyl- } \\
\text { CoA thiolase }\end{array}$ & 2.42 & 0.30 \\
\hline $\begin{array}{l}\text { P60866;E5RIP1;E5RJX2;G3X } \\
\text { AN0 }\end{array}$ & RPS20 & $40 S$ ribosomal protein S20 & 0.96 & 0.30 \\
\hline O14548;E5RJZ1;H0YBD2 & COX7A2L & $\begin{array}{l}\text { Cytochrome c oxidase } \\
\text { subunit 7A-related protein, } \\
\text { mitochondrial }\end{array}$ & 1.42 & 0.31 \\
\hline
\end{tabular}


P26232;A0AOAOMTJ6;A0AOA0 MRI5

B8ZZA8;B8ZZC5

P09382

Q99808

H7C1U8;Q9BUR5;G3V1B6

P13073;H3BN72;H3BNV9;H3B PG0

$\mathrm{P} 12814$
Q09666

Q14444;E9PLA9;G3V153

Q9NWH9;H7C3F4

P30405

P09601;B1AHA8

P62857

P00403

Q12996

Q9C0B5;H0YEF4

P11166

A0A0C4DFU2;P04179;A0A0C 4DFU1;F5H3C5;F5H4R2;F5G YZ5;G8JLJ2;A0A0C4DG56

O43707;F5GXS2

P30038

P49257

A0A087WTT1;P11940;E7EQV 3;E7ERJ7;HOYAR2

O15427;J3QQS9;J3QQV2;J3Q SC3

Q71DI3

P60228;E5RGA2

P00156

P05023

Q96KR1

E7ESL0;J3KQY1;Q9NWU5

P53985

P62263;H0YB22;E5RH77

Q9UBU6

Q9Y2Q3;E9PFN5;C9JNT3

P26038
CTNNA2

GLS

LGALS1

SLC29A1

APOO

COX4l1

ACTN1

AHNAK

CAPRIN1

SLTM

PPIF

HMOX1

RPS28

MT-CO2

CSTF3

ZDHHC5

SLC2A1

SOD2

ACTN4

ALDH4A1

LMAN1

PABPC1

SLC16A3

HIST2H3A

EIF3E

MT-CYB

ATP1A1

ZFR

MRPL22

SLC16A1

RPS14

FAM8A1

GSTK1

MSN
Catenin alpha-2

0.82

Galectin-1

Equilibrative nucleoside transporter 1

Apolipoprotein $\mathrm{O}$

Cytochrome c oxidase

subunit 4 isoform 1 ,

mitochondrial

Alpha-actinin-1

Neuroblast differentiationassociated protein AHNAK

Caprin-1

SAFB-like transcription

modulator

Peptidyl-prolyl cis-trans

isomerase $\mathrm{F}$, mitochondrial

Heme oxygenase 1

40 S ribosomal protein S28

Cytochrome c oxidase

subunit 2

Cleavage stimulation factor

subunit 3

Palmitoyltransferase

ZDHHC5;Palmitoyltransfera

Solute carrier family 2 ,

facilitated glucose

transporter member 1

Superoxide

dismutase;Superoxide

dismutase [Mn]

mitochondrial

Alpha-actinin-4

Delta-1-pyrroline-5-

carboxylate

dehydrogenase,

mitochondrial

Protein ERGIC-53

Polyadenylate-binding

protein;Polyadenylate-

binding protein 1

Monocarboxylate

transporter 4

Histone H3.2

Eukaryotic translation initiation factor 3 subunit $E$

Cytochrome b

Sodium/potassium-

transporting ATPase

subunit alpha-1

Zinc finger RNA-binding

protein

39S ribosomal protein L22,

mitochondrial

Monocarboxylate

transporter 1

40S ribosomal protein S14

Protein FAM8A1

Glutathione S-transferase

kappa 1

Moesin
1.14

1.38

1.8

0.89

1.31

2.90

2.13

2.13

0.96

0.00

0.37

3.84

0.42

1.83

0.87

1.67

2.32

1.48

0.35

0.35

2.07

0.36

1.10

0.36

2.35

0.36

1.25

0.36

1.57

0.92

0.37

0.37

0.37

4.40

0.37

1.21

0.38

0.42

0.38

1.53

0.38

2.27

1.60

0.39

0.39

1.80

0.39

1.62

31

32

32

32

32

32

.33

33

.34

34

34

35

.35

35

35

31

34

5




Q5QPL9;Q9UKM9;Q5QPM1;Q
5QPM0;Q5QPM2
Q02878
E9PFW3;Q96CW1;A0A087WY
71;C9JJ47
Q07666

A0A0A0MRG2;E9PG40;P0506 7;H7COV9

HOYD13;P16070;H0Y2P0;HOY E40

Q93009;H3BND8

Q9NZ18

P62851

P55795

A0A0J9YYL3;A0A0J9YXJ8;A0

A0J9YVP6;A0A0J9YXX5;Q9U

HX1;A0A0J9YVR6;E9PQ56;A0

A0J9YWM1;HOYEM1

Q9UKR5

P50402;Q5HY57

K7EQ02;K7EQ55;K7EK33;Q96

EP5

Q8NCA5;E9PH82

MOR210;P62249;M0R3H0

A0A087WTP3;Q92945;M0R015

H0Y3P2;D3DQV9;P78344

P11387

Q9Y5B9

E9PEB5;Q96AE4

P09669

P42167;G5E972;H0YJH7

LOR6Q1

Q15637

Q7Z434

E7EX73;E9PGM1;E7EUU4;Q0

4637

P23246

Q53FV1;F8VXD5
RALY

RPL6

AP2M1

KHDRBS1

APP

CD44

USP7

IGF2BP1

RPS25

HNRNPH2

PUF60

C14orf1

EMD

DAZAP1

FAM98A

RPS16

KHSRP

EIF4G2

TOP1

SUPT16H

FUBP1

cox6C

TMPO

SLC35A4

SF1

MAVS

EIF4G1

SFPQ

ORMDL2
RNA-binding protein Raly

0.71

1.45

1.02

1.69

RNA-binding, signal

transduction-associated

protein 1

Amyloid beta A4 protein; $\mathrm{N}$ -

APP;Soluble APP.

alpha;Soluble APP-

beta;C99;Beta-amyloid

protein 42;Beta-amyloid

protein

40;C83;P3(42);P3(40);C80;

1.54

0.40

terminal fragment

59;Gamma-secretase C-

terminal fragment

57; Gamma-secretase Cterminal fragment $50 ; \mathrm{C} 31$

CD44 antigen

0.96

0.41

Ubiquitin carboxyl-terminal hydrolase 7;Ubiquitin carboxyl-terminal hydrolase

Insulin-like growth factor 2 mRNA-binding protein 1

40 S ribosomal protein S25

Heterogeneous nuclear ribonucleoprotein $\mathrm{H} 2$

0.76

0.41

Poly(U)-binding-splicing factor PUF60

Probable ergosterol biosynthetic protein 28

Emerin

1.91

0.41

1.41

0.43

2.00

0.43

4.46

0.43

DAZ-associated protein 1

Protein FAM98A

40 S ribosomal protein $\mathrm{S} 16$

Far upstream element-

binding protein 2

Eukaryotic translation initiation factor 4 gamma 2

DNA topoisomerase 1

FACT complex subunit SPT16

Far upstream element-

binding protein 1

Cytochrome $\mathrm{c}$ oxidase

subunit $6 \mathrm{C}$

Lamina-associated

polypeptide 2 , isoforms

beta/gamma;Thymopoietin; Thymopentin

Splicing factor 1

Mitochondrial antiviralsignaling protein

ukaryotic translation initiation factor 4 gamma 1 Splicing factor, proline- and glutamine-rich

ORM1-like protein 2
0.63

2.96

0.72

0.67

1.03

0.68 


\begin{tabular}{|c|c|c|c|c|}
\hline Q12906 & ILF3 & $\begin{array}{l}\text { Interleukin enhancer- } \\
\text { binding factor } 3\end{array}$ & 1.54 & 0.81 \\
\hline $\begin{array}{l}\text { Q16778;P33778;P23527;P068 } \\
\text { 99;Q8N257 }\end{array}$ & $\begin{array}{l}\text { HIST2H2BE;HIST } \\
\text { 1H2BB;HIST1H2B } \\
\text { O;HIST1H2BJ;HIS } \\
\text { T3H2BB }\end{array}$ & $\begin{array}{l}\text { Histone H2B type 2- } \\
\text { E;Histone H2B type 1- } \\
\text { B;Histone H2B type 1- } \\
\text { O;Histone H2B type 1- } \\
\text { J;Histone H2B type 3-B }\end{array}$ & 2.34 & 0.88 \\
\hline Q14247 & CTTN & Src substrate cortactin & 3.35 & 0.89 \\
\hline Q96PK6 & RBM14 & RNA-binding protein 14 & 4.99 & 1.09 \\
\hline
\end{tabular}

Table S2 List of detected half-tryptic and non-tryptic S-His peptides and their MS1 intensities, $30 \mu \mathrm{M}$ ARB/DMSO fold change ratios and $p$-values identified in the LiP-MS experiment. Peptides showing significant intensity decrease in ARB versus DMSO via Perseus statistical analysis are highlighted with ' + ' in 'Significant' column. 'Start position' and 'End position' columns indicate respective positions of the peptide in the amino acid sequence of $\mathrm{S}$-His.

$\begin{array}{ll}\text { Significant } & \text { Sequence } \\ + & \text { GYHLMSFPQSAPHGVVFLHVT } \\ + & \text { PQSAPHGVVFLHVT } \\ & \text { SSVLHSTQDLFLPF } \\ & \text { HSTQDLFLPF } \\ & \text { RFDNPVLPFNDGVYF } \\ & \text { RFDNPVLPFNDGVYFA } \\ & \text { RFDNPVLPFNDGVYFAST } \\ & \text { VCEFQFCNDPFLGVY } \\ & \text { HRSYLTPGDSSSGWTA } \\ & \text { HRSYLTPGDSSSGWTAGAA } \\ & \text { SYLTPGDSSSGWTA } \\ & \text { SYLTPGDSSSGWTAGA } \\ & \text { SYLTPGDSSSGWTAGAA } \\ & \text { SYLTPGDSSSGWTAGAAA } \\ & \text { RISNCVADYSVLNSA } \\ & \text { ISNCVADYSVLYNSA } \\ & \text { CYGVSPTKLNDLCFTNVY } \\ & \text { LNDLCFTNVYADSF } \\ \text { IADYNYKLPDDFTGCVIA } & \text { DYNYKLPDDFTGCVIA } \\ & \text { DYNYKLPDDFTGCVIAW } \\ & \text { KSNLKPFERDISTE } \\ & \text { KSNLKPFERDISTEIY } \\ & \text { DISTEIYQAGSTPCNGVEGF } \\ & \text { GSTPCNGVEGFNCYFPL } \\ & \text { GSTPCNGVEGFNCYFPLQSY } \\ & \text { NCYFPLQSY } \\ & \text { CVNFNFNGLTGT } \\ & \text { CVNFNFNGLTGTGVLT } \\ & \text { FLPFQQFGRDIADTT } \\ & \text { GRDIADTTDAVRDPQTL } \\ & \text { DIADTTDAVRDPQTL } \\ & \text { DAVRDPQTL } \\ & \text { VYSTGSNVF } \\ & \end{array}$

\begin{tabular}{|c|c|c|c|}
\hline $\begin{array}{c}\text { Start } \\
\text { position }\end{array}$ & $\begin{array}{l}\text { End } \\
\text { position }\end{array}$ & $\begin{array}{l}-\log 10(p- \\
\text { value })\end{array}$ & $\begin{array}{c}\text { Log2 fold change } 30 \\
\mu M \text { ARB/DMSO }\end{array}$ \\
\hline 1046 & 1066 & 6.64 & -2.58 \\
\hline 1053 & 1066 & 5.78 & -2.87 \\
\hline 45 & 58 & 5.91 & -1.32 \\
\hline 49 & 58 & 0.00 & 0.37 \\
\hline 78 & 92 & 0.10 & 0.22 \\
\hline 78 & 93 & 1.65 & -1.23 \\
\hline 78 & 95 & 1.93 & -2.02 \\
\hline 130 & 144 & 1.00 & -1.16 \\
\hline 245 & 260 & 0.00 & -0.81 \\
\hline 245 & 263 & 0.00 & -1.81 \\
\hline 247 & 260 & 0.00 & -2.01 \\
\hline 247 & 262 & 0.00 & \\
\hline 247 & 263 & 2.03 & -2.62 \\
\hline 247 & 264 & 0.00 & \\
\hline 357 & 372 & 0.00 & \\
\hline 358 & 372 & 3.56 & -2.20 \\
\hline 379 & 396 & 0.00 & \\
\hline 387 & 400 & 0.00 & -1.60 \\
\hline 418 & 435 & 7.37 & -1.59 \\
\hline 420 & 435 & 0.00 & -1.12 \\
\hline 420 & 436 & 1.43 & -1.81 \\
\hline 458 & 471 & 0.00 & \\
\hline 458 & 473 & 0.00 & -0.70 \\
\hline 467 & 486 & 0.00 & \\
\hline 476 & 492 & 0.00 & 0.37 \\
\hline 476 & 495 & 0.42 & -0.34 \\
\hline 487 & 495 & 0.77 & -0.44 \\
\hline 538 & 549 & 0.00 & \\
\hline 538 & 553 & 0.00 & \\
\hline 559 & 573 & 0.00 & 0.08 \\
\hline 566 & 582 & 0.14 & -0.31 \\
\hline 568 & 582 & 2.73 & -0.54 \\
\hline 574 & 582 & 0.48 & -0.89 \\
\hline 635 & 643 & 0.00 & -0.61 \\
\hline
\end{tabular}




TMSLGAENSVAY
ICGDSTECSNLLL
ICGDSTECSNLLLQYGF
ALTGIAVEQDKNTQE
SFIEDLLFNKV
SFIEDLLFNVT
SFIEDLLFNVTL
SFIEDLLFNKTLA
VTLADAGFIKQY
TLADAGFIKQY
LADAGFIKQY
DAGFIKQY
DAGFIKQYGDCLGDIA
DLICAQKFNGL
SALLAGTIT
LAGTITSGW
GTITSGWTFGA
SGWTFGAGA
SGWTFGAGAAL
TFGAGAAL
IQDSLSSTASAL
GKLQDVVNQNAQAL
LQDVVNQNAQAL
GYHLMSFPQSAPHGVVF
GYHLMSFPQSAPHGVVFL
GYHLMSFPQSAPHGVVFLHV
HLMSFPQSAPHGVVF
HLMSFPQSAPHGVVFLHVT
MSFPQSAPHGVVF
PQSAPHGVVF
NFYEPQIITT
NNTFVSGNCDVVIGIVNNT
NHTSPDVDLGDISGINA
NHTSPDVDLGDISGINASVV
NLNESLIDLQELGKY
NLNESLIDLQELGKYE
NLNESLIDLQELGKYEQY
NESLIDLQELGKY
NESLQELGKY
IDKYEQY

\begin{tabular}{|c|c|c|c|}
\hline 696 & 707 & 0.00 & 2.73 \\
\hline 742 & 754 & 0.73 & 0.29 \\
\hline 742 & 759 & 0.06 & -0.04 \\
\hline 766 & 780 & 1.00 & -0.71 \\
\hline 816 & 826 & 0.75 & -0.63 \\
\hline 816 & 827 & 1.56 & -0.89 \\
\hline 816 & 828 & 0.63 & -0.40 \\
\hline 816 & 829 & 1.87 & -0.66 \\
\hline 826 & 837 & 5.78 & -1.77 \\
\hline 827 & 837 & 0.00 & \\
\hline 828 & 837 & 0.00 & \\
\hline 830 & 837 & 1.46 & -1.22 \\
\hline 830 & 845 & 0.00 & -1.55 \\
\hline 848 & 858 & 0.00 & \\
\hline 875 & 883 & 0.00 & 0.09 \\
\hline 878 & 886 & 0.00 & 0.11 \\
\hline 880 & 890 & 0.00 & \\
\hline 884 & 892 & 0.00 & -0.54 \\
\hline 884 & 894 & 1.05 & -1.16 \\
\hline 887 & 894 & 0.00 & -2.73 \\
\hline 934 & 945 & 1.19 & -0.32 \\
\hline 946 & 959 & 0.25 & -0.51 \\
\hline 948 & 959 & 0.87 & -0.49 \\
\hline 1046 & 1062 & 10.31 & -1.94 \\
\hline 1046 & 1063 & 6.58 & -2.03 \\
\hline 1046 & 1065 & 0.00 & \\
\hline 1048 & 1062 & 0.33 & -0.62 \\
\hline 1048 & 1066 & 2.93 & -1.46 \\
\hline 1050 & 1062 & 0.12 & -0.17 \\
\hline 1053 & 1062 & 0.00 & \\
\hline 1108 & 1117 & 1.22 & -0.39 \\
\hline 1118 & 1136 & 1.17 & 0.44 \\
\hline 1158 & 1174 & 1.05 & -0.52 \\
\hline 1158 & 1177 & 1.56 & -0.55 \\
\hline 1192 & 1206 & 0.14 & -0.08 \\
\hline 1192 & 1207 & 0.55 & -0.34 \\
\hline 1192 & 1209 & 1.20 & -0.49 \\
\hline 1194 & 1206 & 0.00 & -0.43 \\
\hline 1194 & 1207 & 0.76 & -0.15 \\
\hline 1194 & 1209 & 1.56 & -0.30 \\
\hline
\end{tabular}




\section{NMR Spectra}

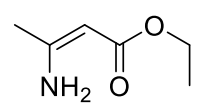

$2 \mathbf{a}$

${ }^{1} \mathrm{H}$ NMR (400 MHz, $\mathrm{CDCl}_{3}$ )

Chemical Formula: $\mathrm{C}_{6} \mathrm{H}_{11} \mathrm{NO}_{2}$

Exact Mass: 129.0790
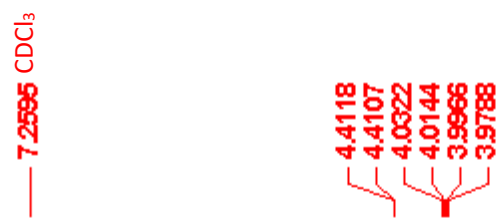
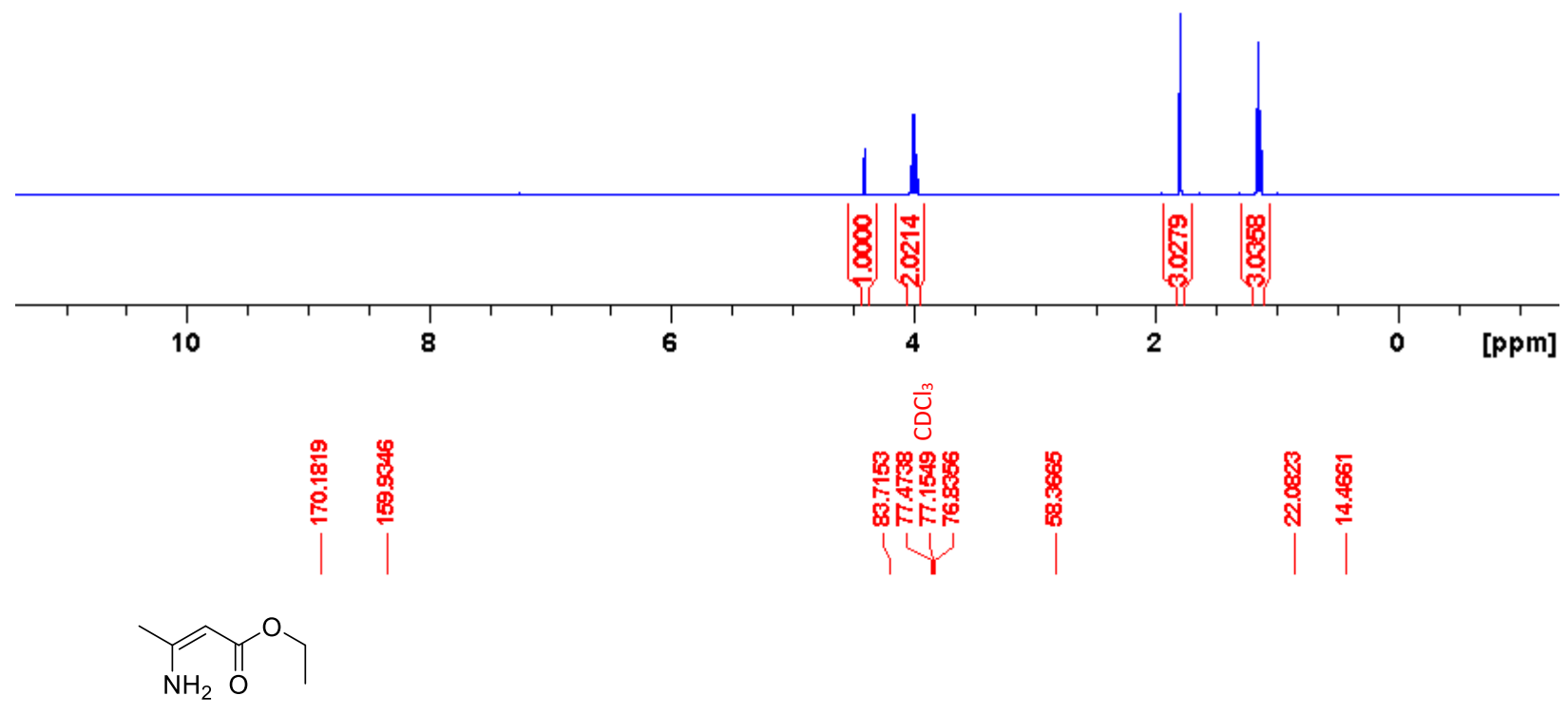

$2 a$

${ }^{13} \mathrm{C}$ NMR (100 MHz, $\mathrm{CDCl}_{3}$ )

Chemical Formula: $\mathrm{C}_{6} \mathrm{H}_{11} \mathrm{NO}_{2}$

Exact Mass: 129.0790

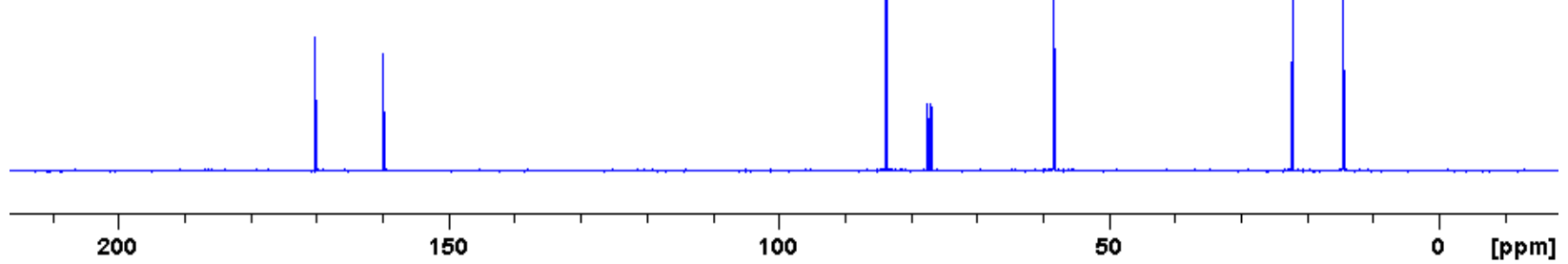



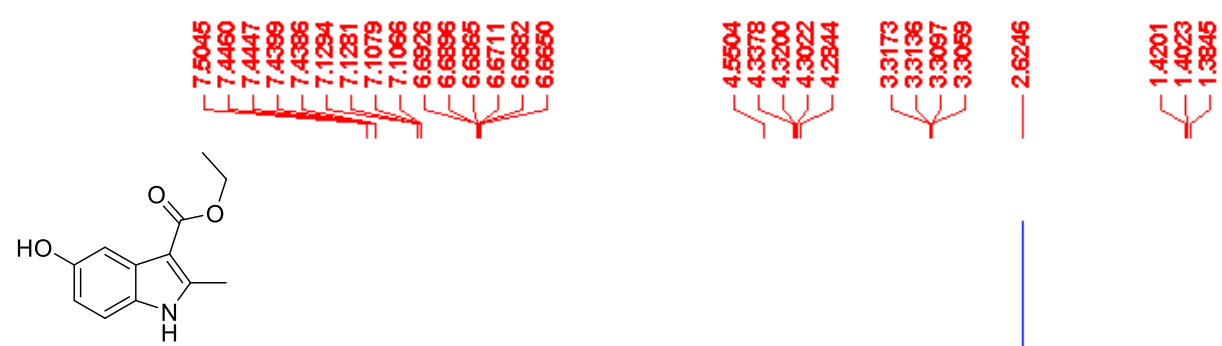

2b

${ }^{1} \mathrm{H}$ NMR $\left(400 \mathrm{MHz}, \mathrm{MeOD} / \mathrm{CDCl}_{3}\right)$

Chemical Formula: $\mathrm{C}_{12} \mathrm{H}_{13} \mathrm{NO}_{3}$

Exact Mass: 219.0895

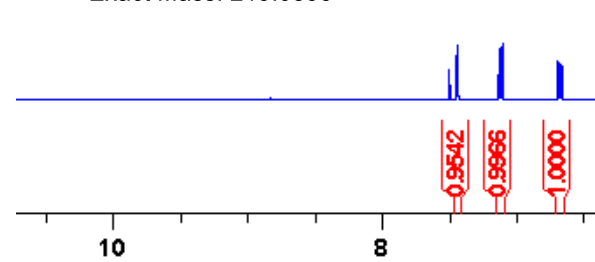

10

8

6

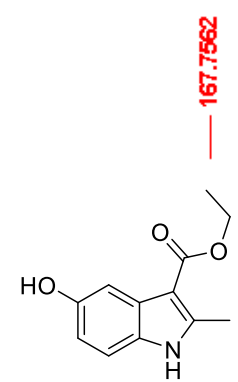

2b

${ }^{13} \mathrm{C} \mathrm{NMR}\left(100 \mathrm{MHz}, \mathrm{MeOD} / \mathrm{CDCl}_{3}\right)$

Chemical Formula: $\mathrm{C}_{12} \mathrm{H}_{13} \mathrm{NO}_{3}$

Exact Mass: 219.0895

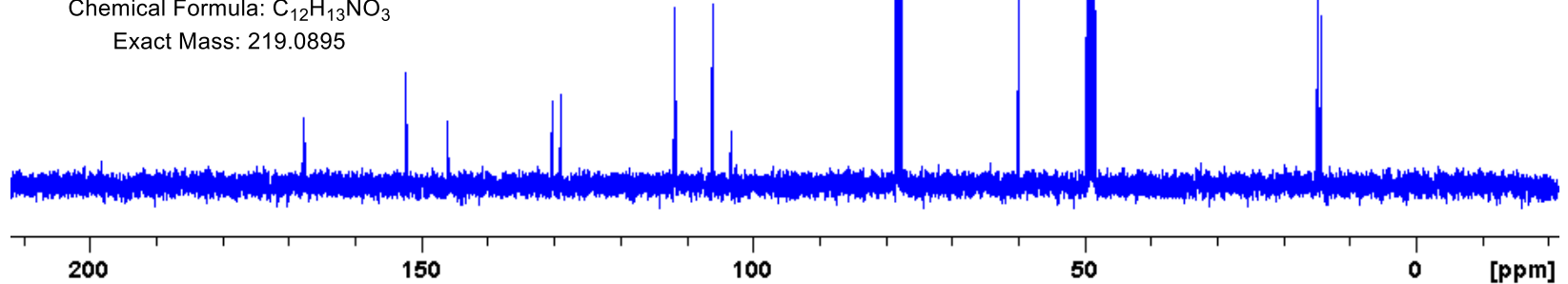



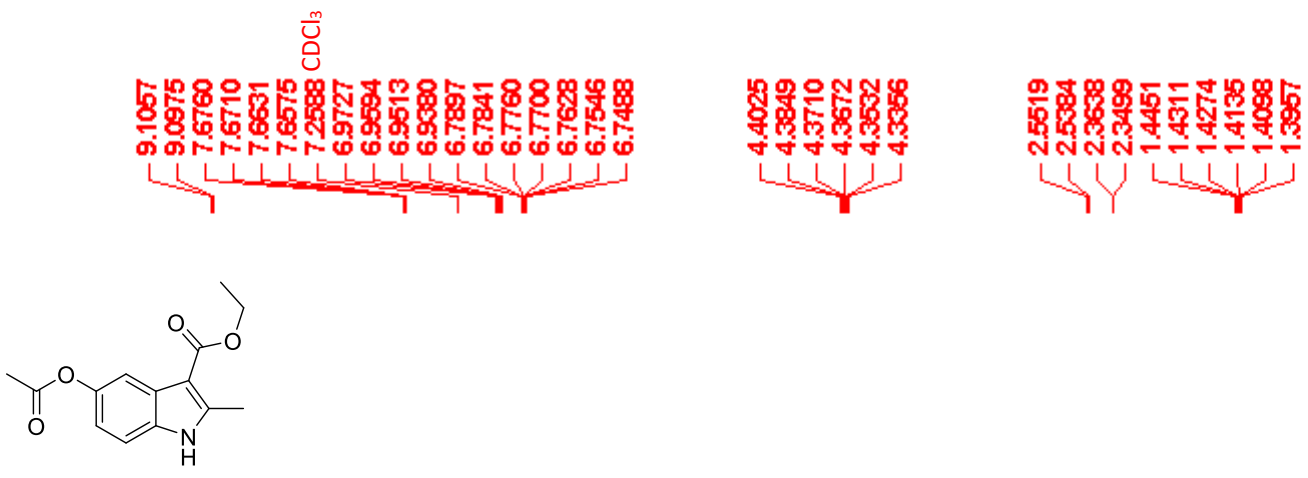

2c

${ }^{1} \mathrm{H}$ NMR $\left(400 \mathrm{MHz}, \mathrm{CDCl}_{3}\right)$

Chemical Formula: $\mathrm{C}_{14} \mathrm{H}_{15} \mathrm{NO}_{4}$

Exact Mass: 261.1001
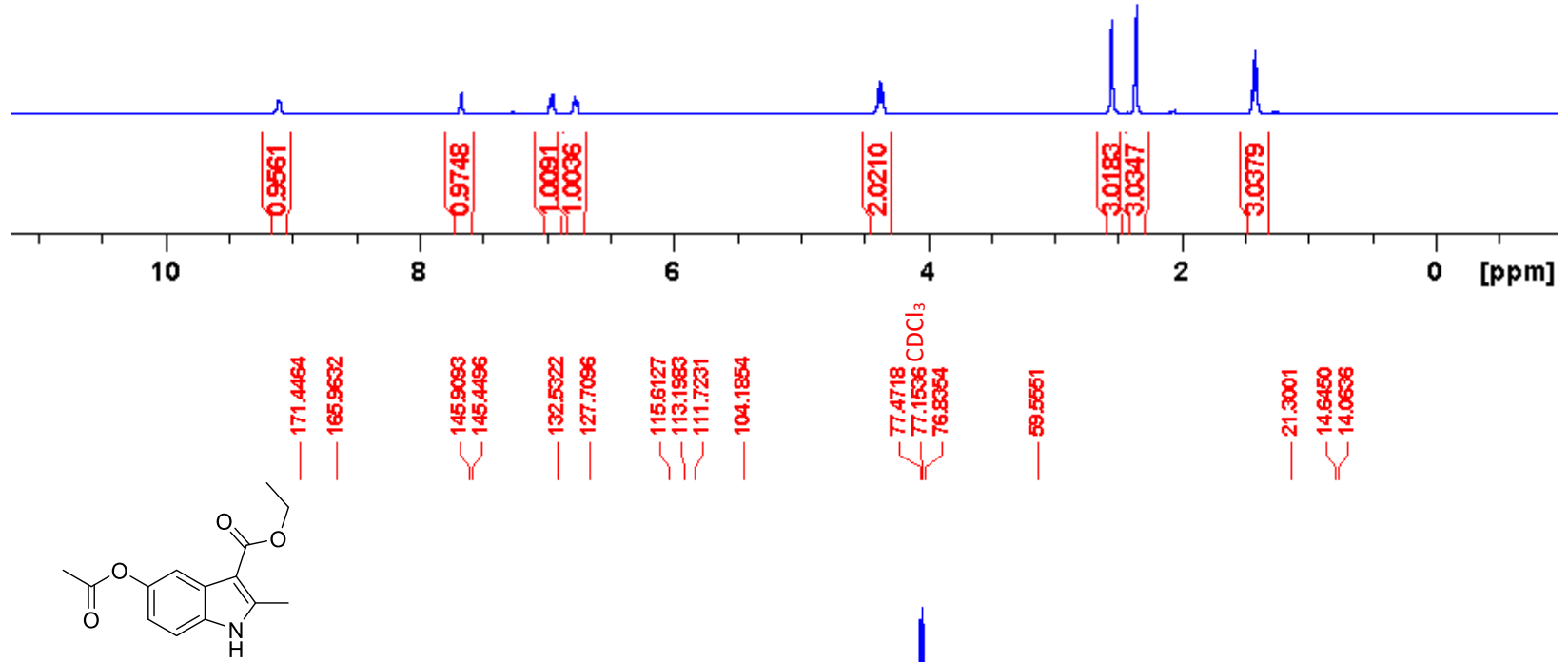

2c

${ }^{13} \mathrm{C}$ NMR $\left(100 \mathrm{MHz}, \mathrm{CDCl}_{3}\right)$ Chemical Formula: $\mathrm{C}_{14} \mathrm{H}_{15} \mathrm{NO}_{4}$

Exact Mass: 261.1001

$\mid$

赵

I
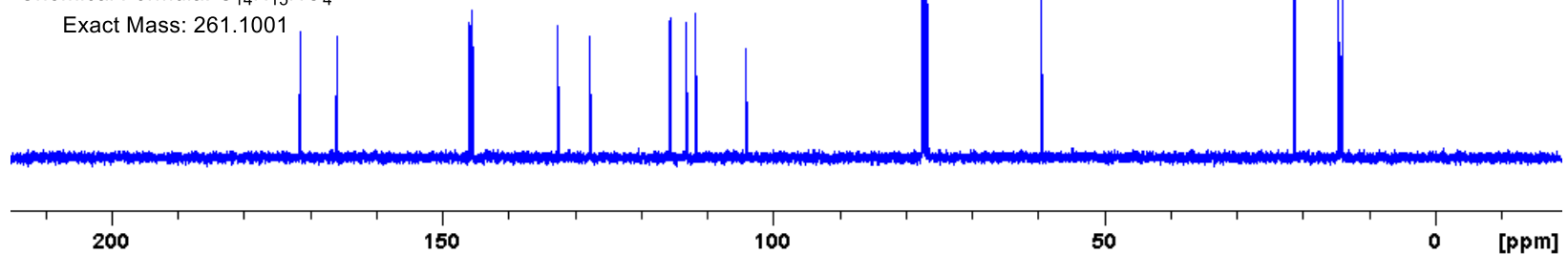

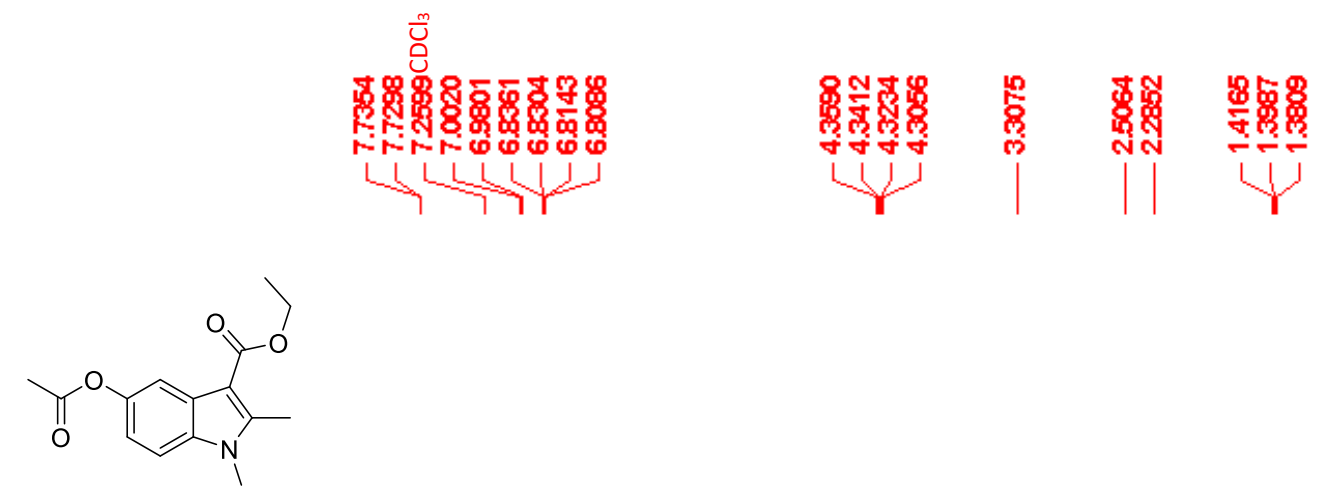

2d

. ${ }^{1} \mathrm{H}$ NMR (400 MHz, $\mathrm{CDCl}_{3}$ )

Chemical Formula: $\mathrm{C}_{15} \mathrm{H}_{17} \mathrm{NO}_{4}$

Exact Mass: 275.1158
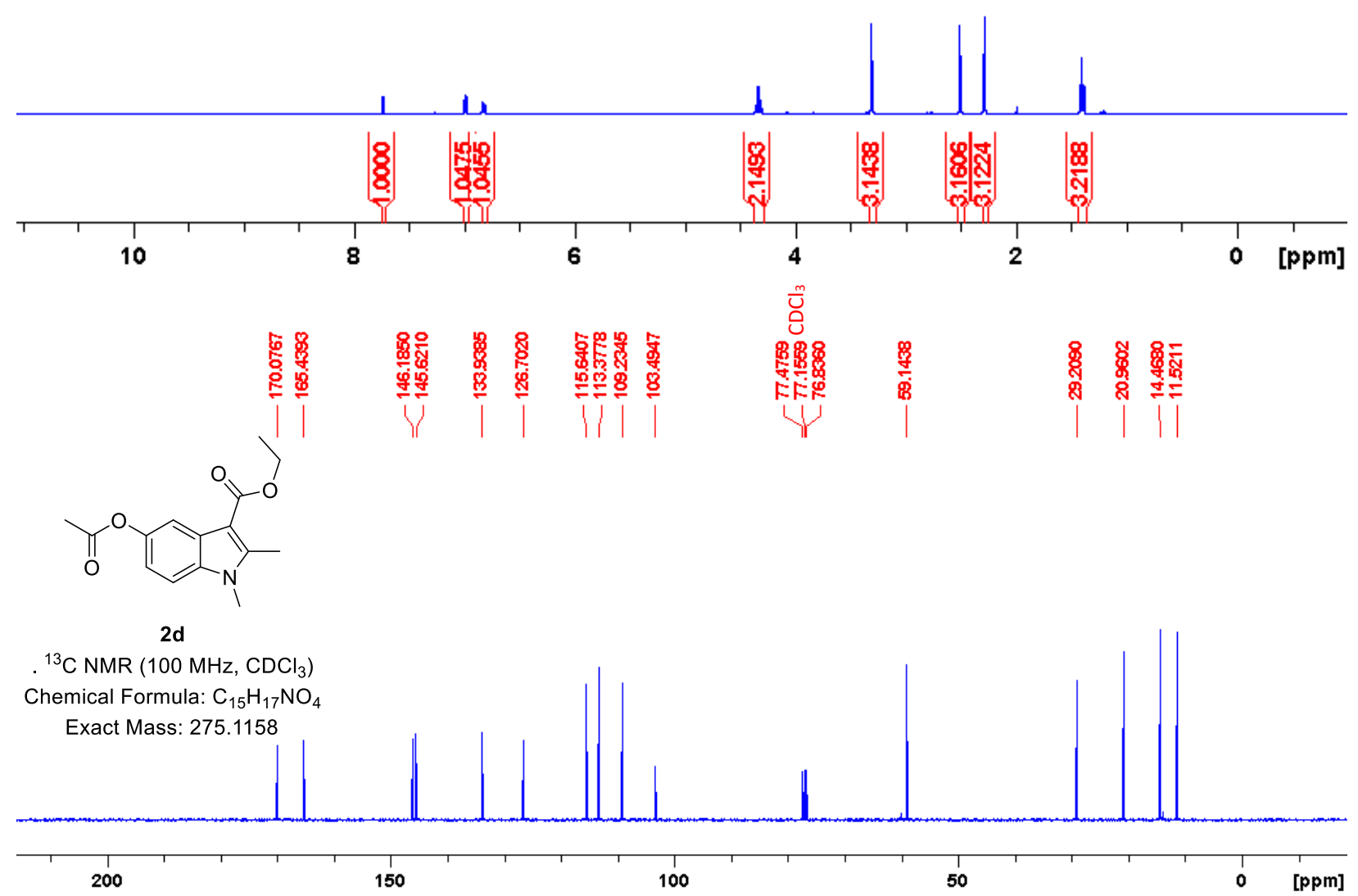

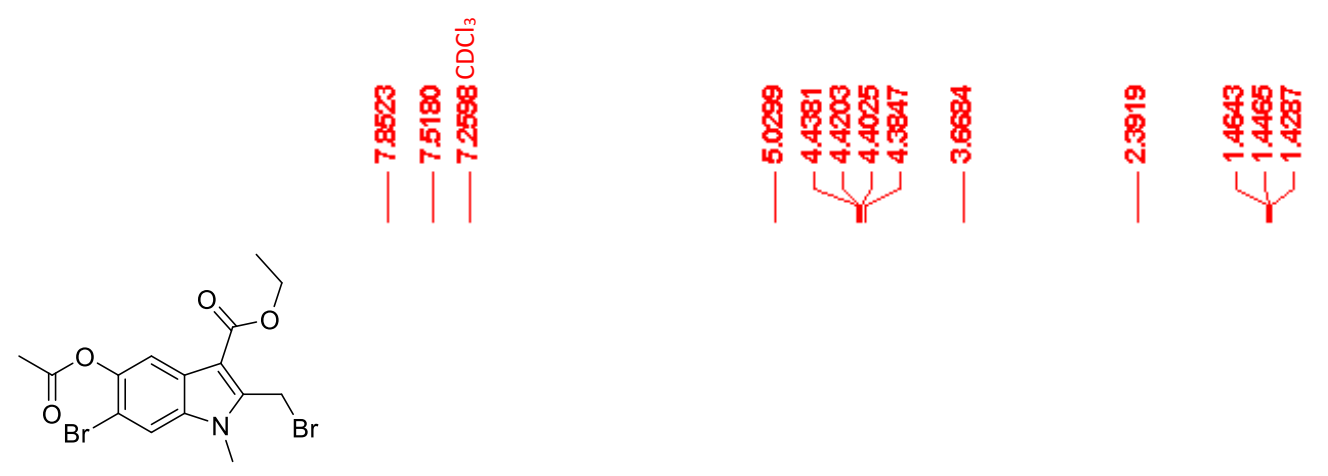

$2 \mathrm{e}$

${ }^{1} \mathrm{H}$ NMR (400 MHz, $\mathrm{CDCl}_{3}$ ) Chemical Formula: $\mathrm{C}_{15} \mathrm{H}_{15} \mathrm{Br}_{2} \mathrm{NO}_{4}$ Exact Mass: 430.9368
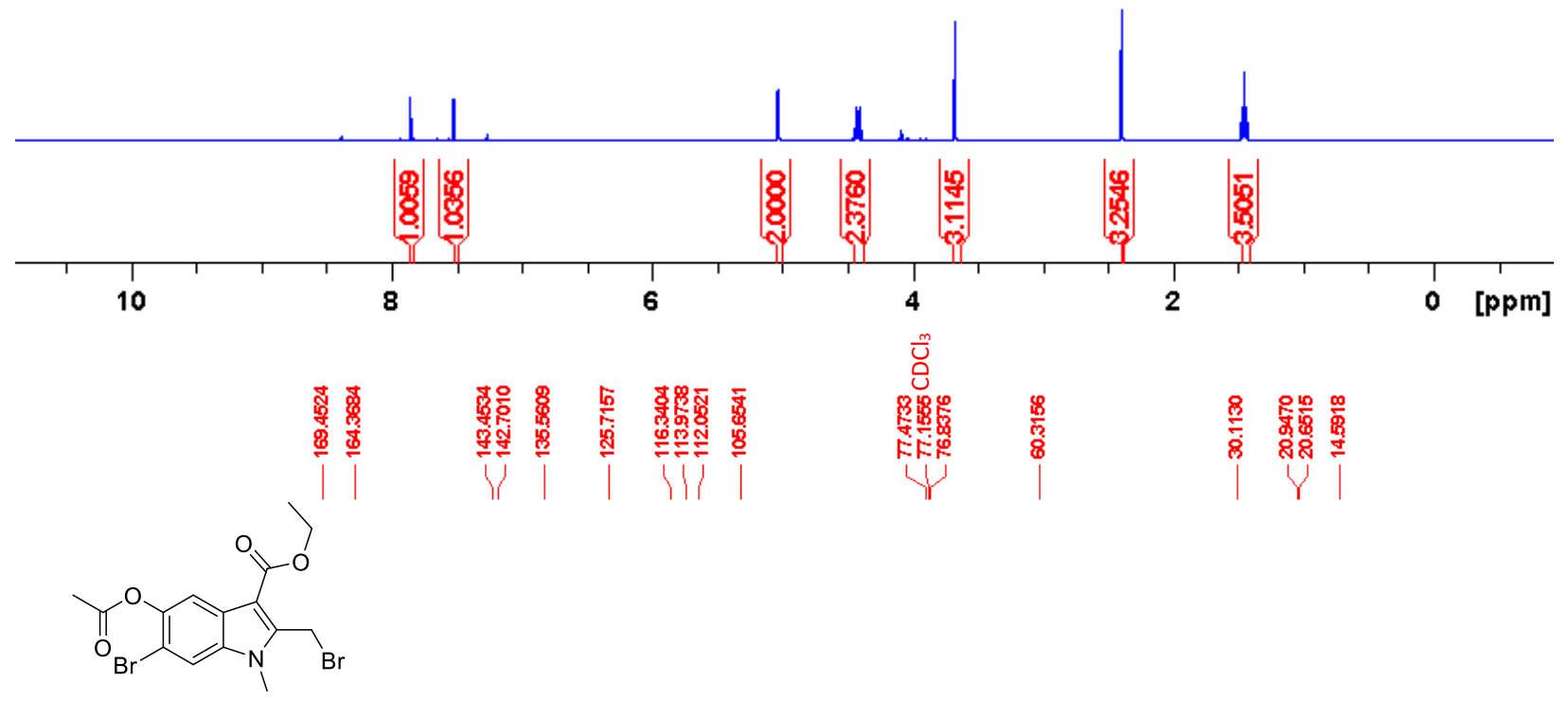

$2 e$

${ }^{13} \mathrm{C}$ NMR $\left(100 \mathrm{MHz}, \mathrm{CDCl}_{3}\right)$ Chemical Formula: $\mathrm{C}_{15} \mathrm{H}_{15} \mathrm{Br}_{2} \mathrm{NO}_{4}$ Exact Mass: 430.9368

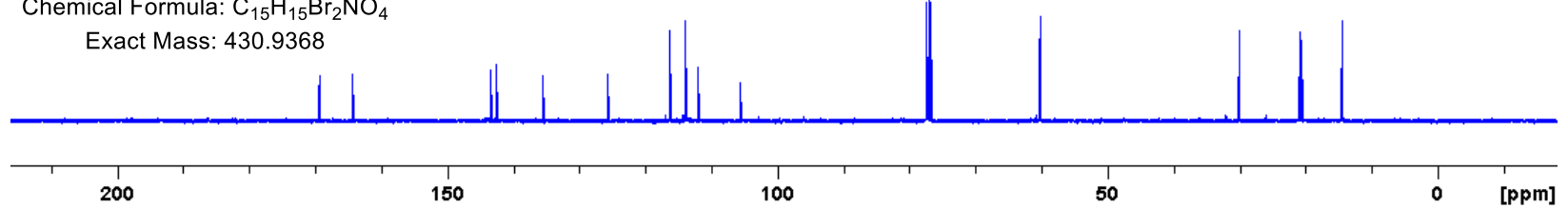



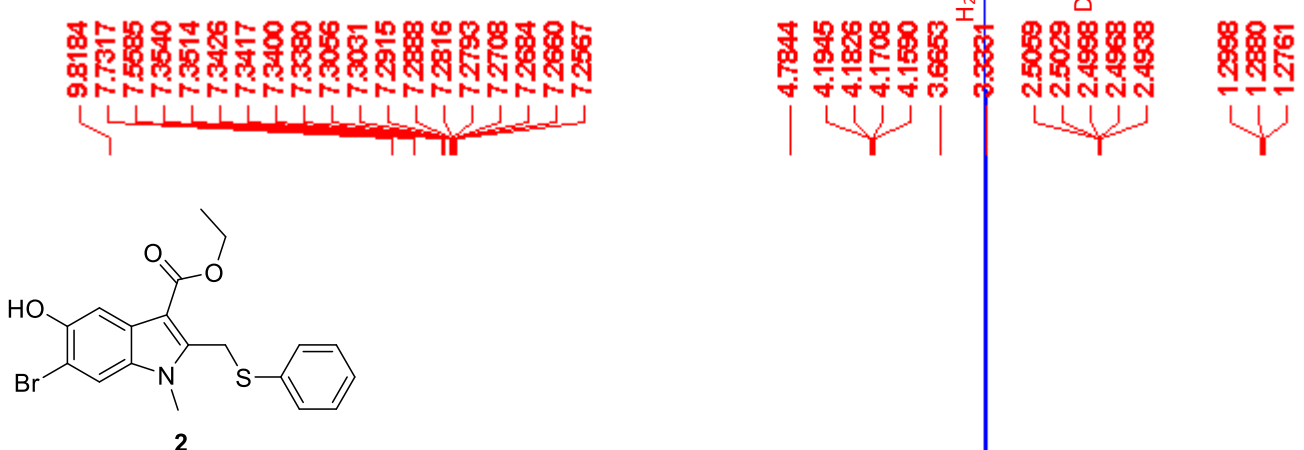

${ }^{1} \mathrm{H}$ NMR $(400 \mathrm{MHz}$, DMSO-d 6 )

Chemical Formula: $\mathrm{C}_{19} \mathrm{H}_{18} \mathrm{BrNO}_{3} \mathrm{~S}$ Exact Mass: 419.0191
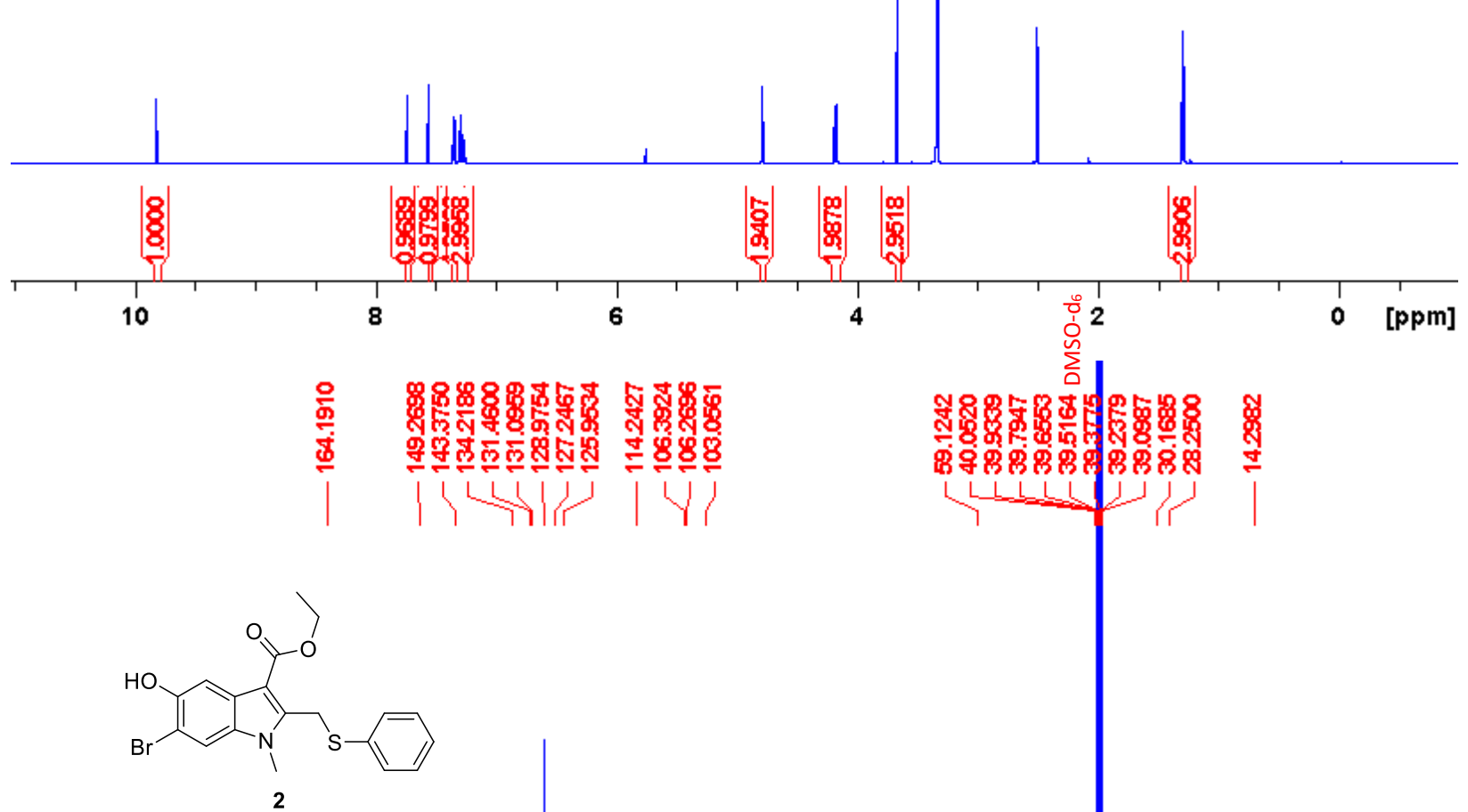

${ }^{13} \mathrm{C}$ NMR (100 MHz, DMSO-d 6 ) Chemical Formula: $\mathrm{C}_{19} \mathrm{H}_{18} \mathrm{BrNO}_{3} \mathrm{~S}$ Exact Mass: 419.0191

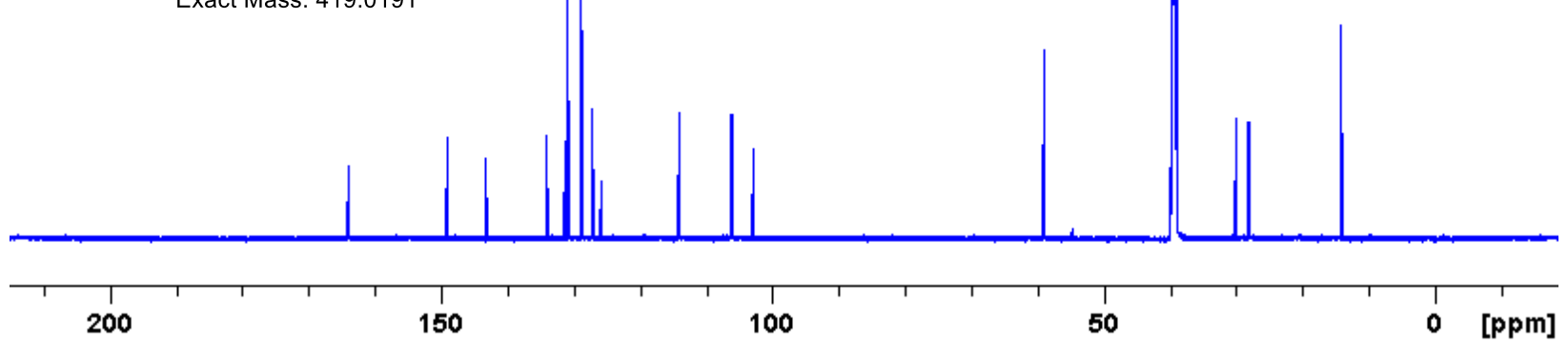



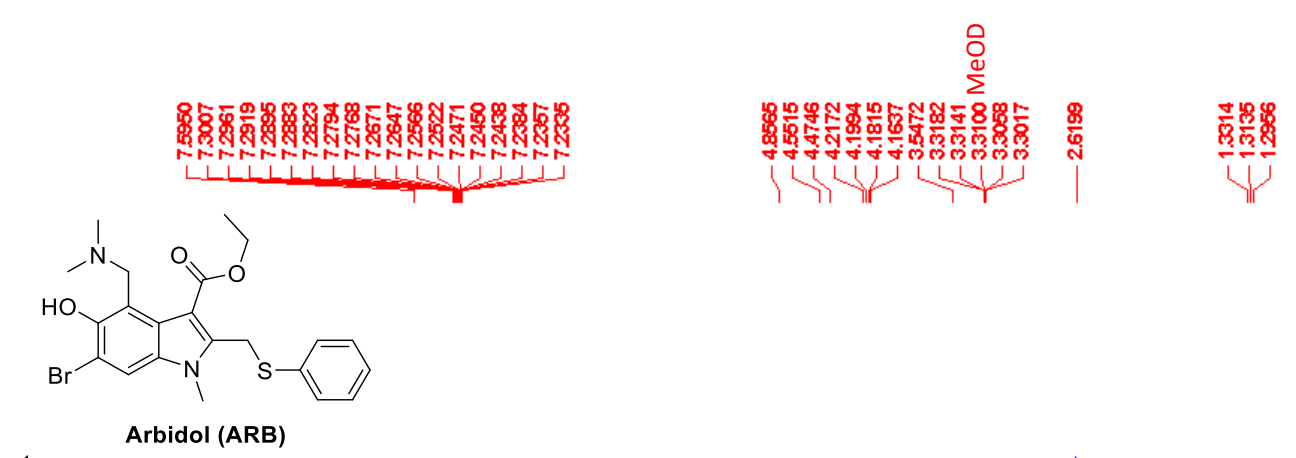

${ }^{1} \mathrm{H}$ NMR (400 MHz, MeOD/CDCl ${ }_{3}$ )

Chemical Formula: $\mathrm{C}_{22} \mathrm{H}_{25} \mathrm{BrN}_{2} \mathrm{O}_{3} \mathrm{~S}$
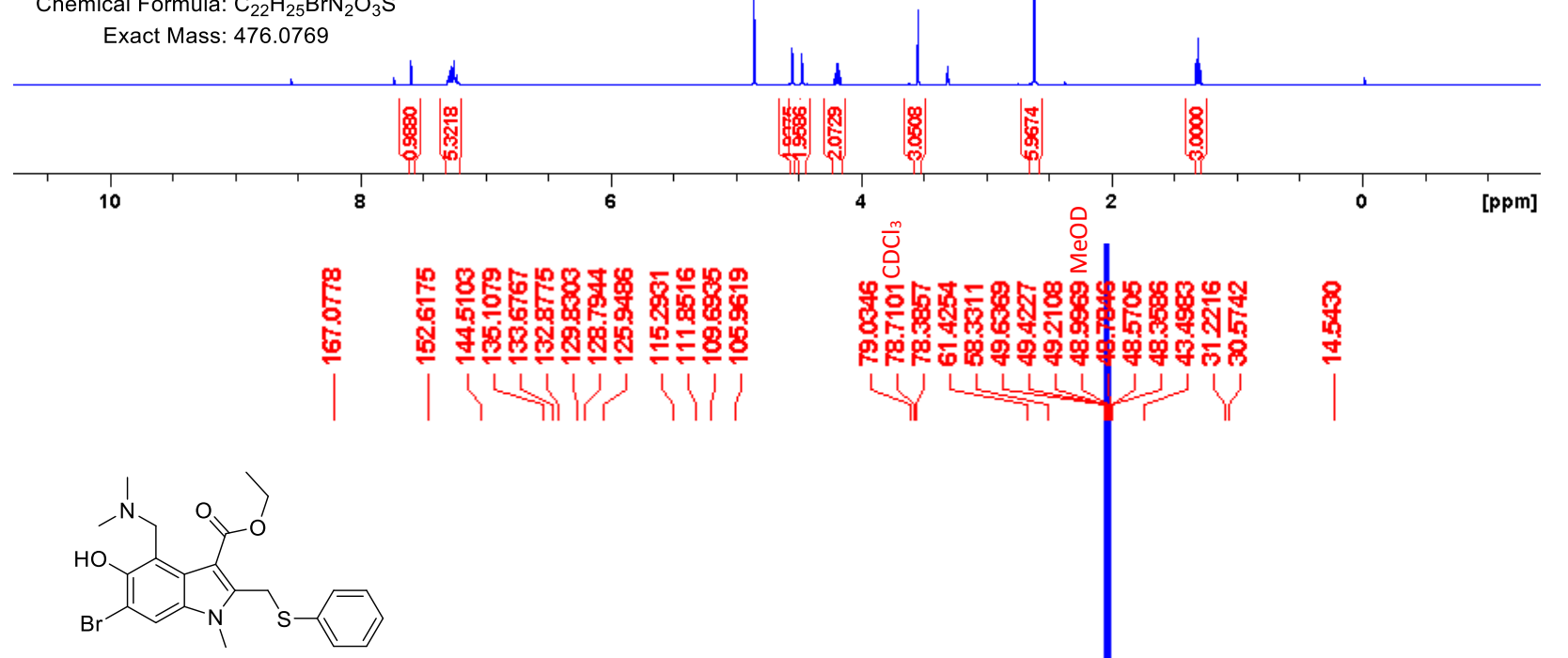

Arbidol (ARB)

${ }^{13} \mathrm{C}$ NMR (100 MHz, MeOD/CDCl $\mathrm{Cl}_{3}$ )

Chemical Formula: $\mathrm{C}_{22} \mathrm{H}_{25} \mathrm{BrN}_{2} \mathrm{O}_{3} \mathrm{~S}$

Exact Mass: 476.0769
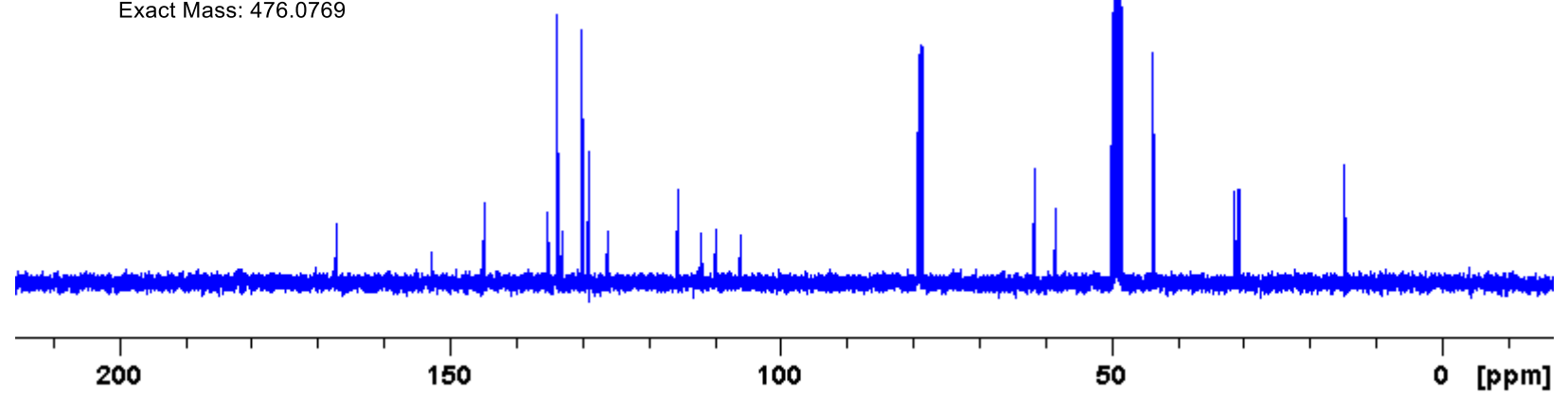

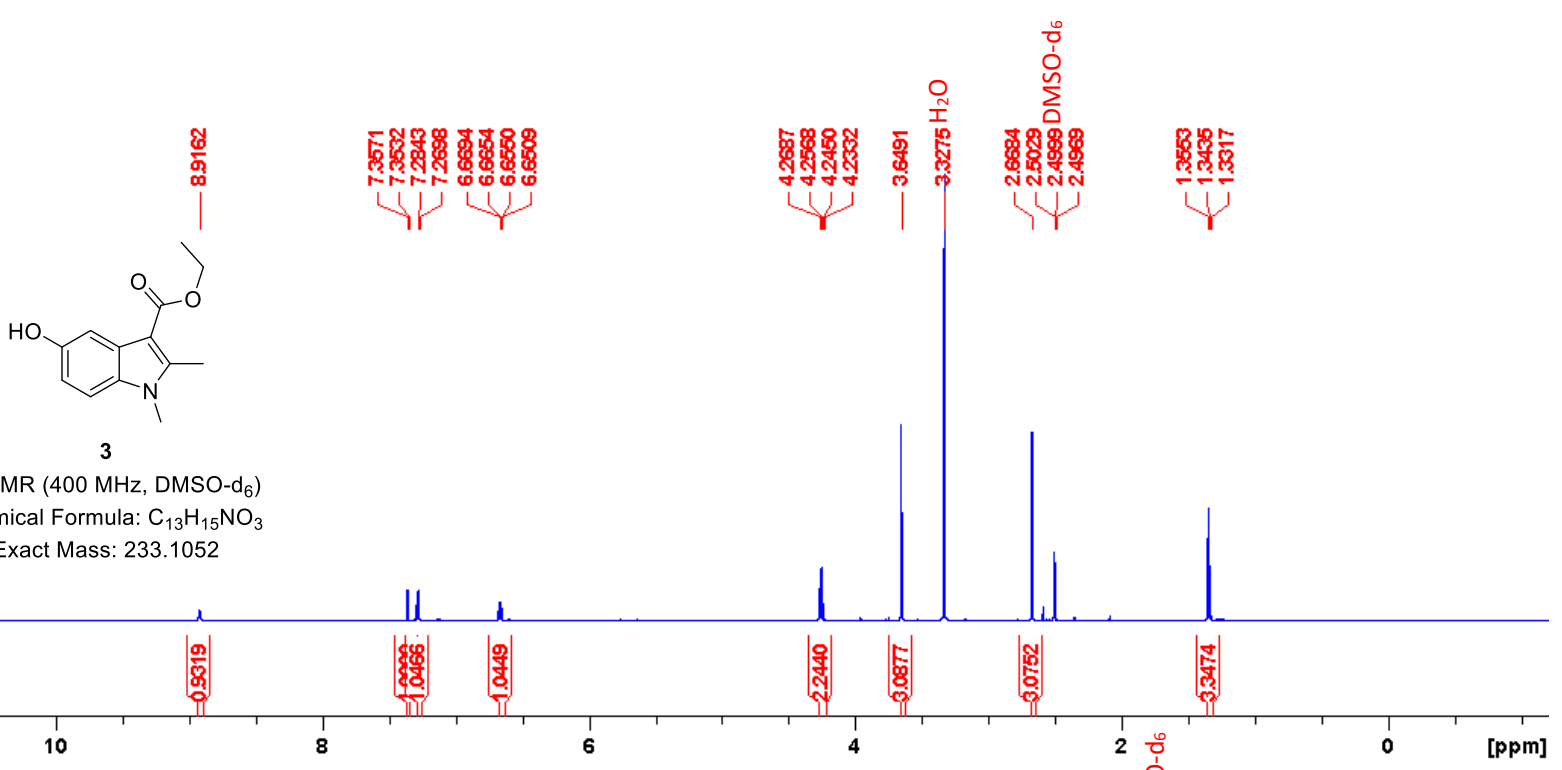

${ }^{1} \mathrm{H}$ NMR (400 MHz, DMSO-d $\mathrm{d}_{6}$ )

Chemical Formula: $\mathrm{C}_{13} \mathrm{H}_{15} \mathrm{NO}_{3}$ Exact Mass: 233.1052
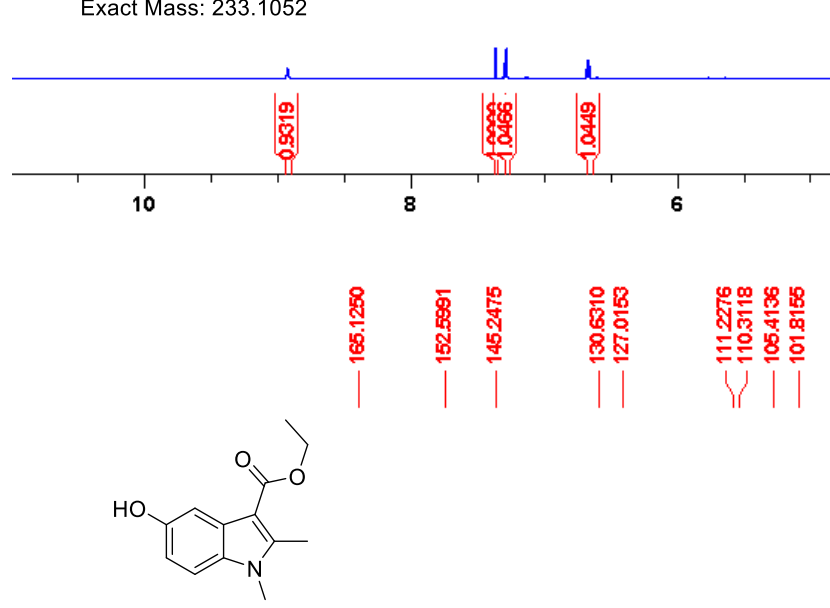

3

${ }^{13} \mathrm{C}$ NMR (100 MHz, DMSO-d $\mathrm{d}_{6}$ )

Chemical Formula: $\mathrm{C}_{13} \mathrm{H}_{15} \mathrm{NO}_{3}$

Exact Mass: 233.1052

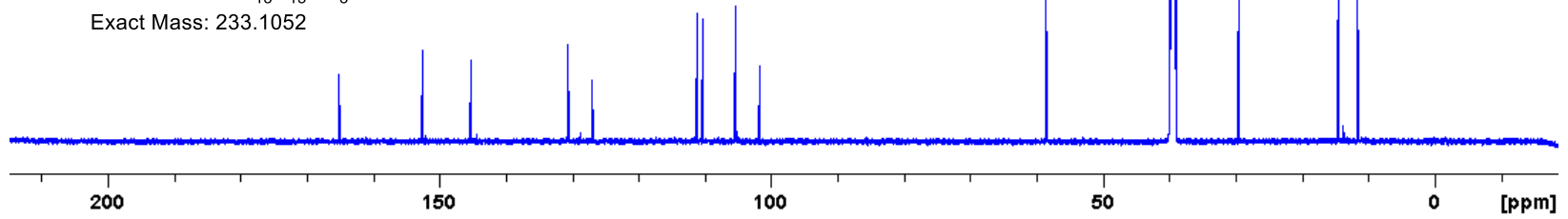




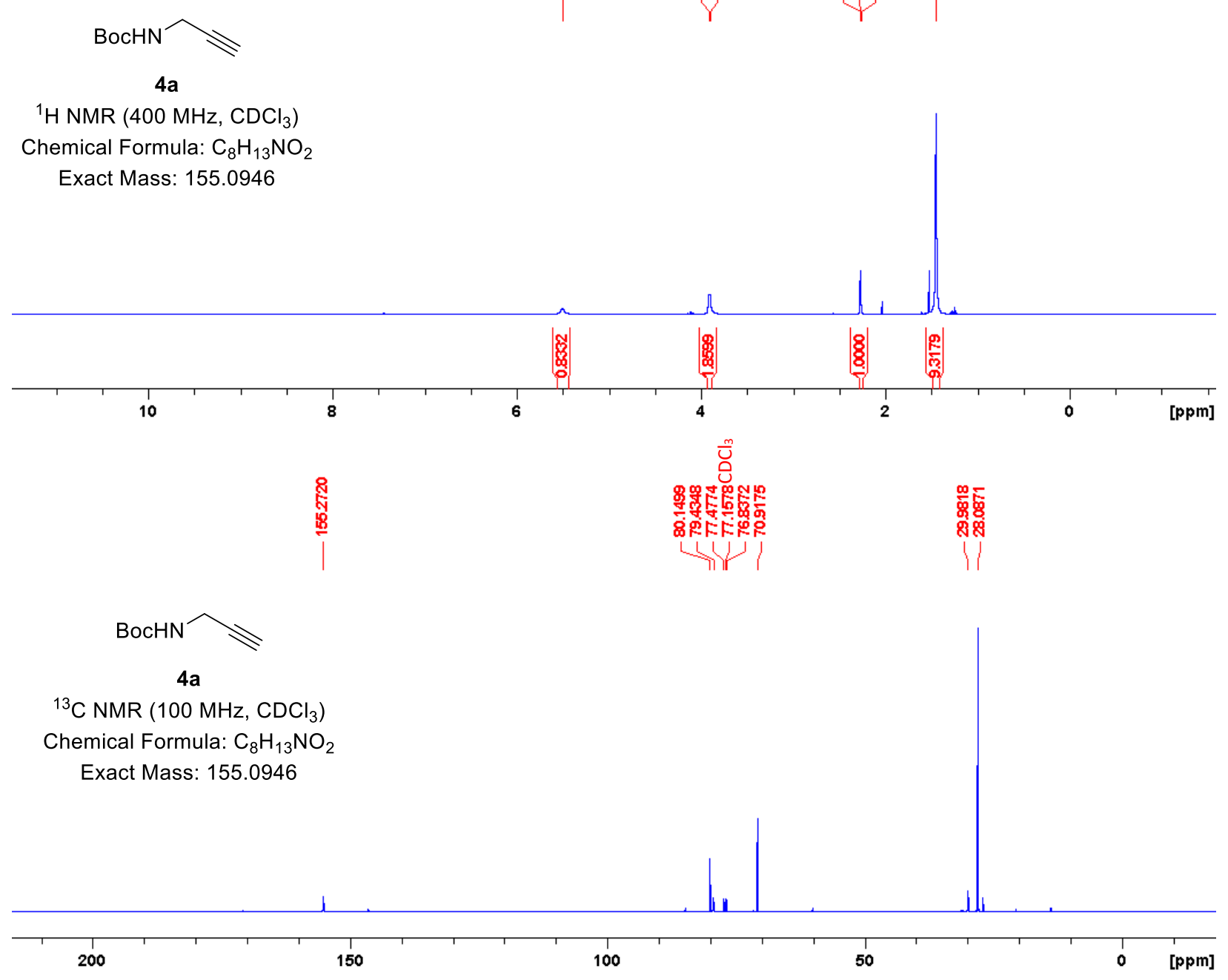



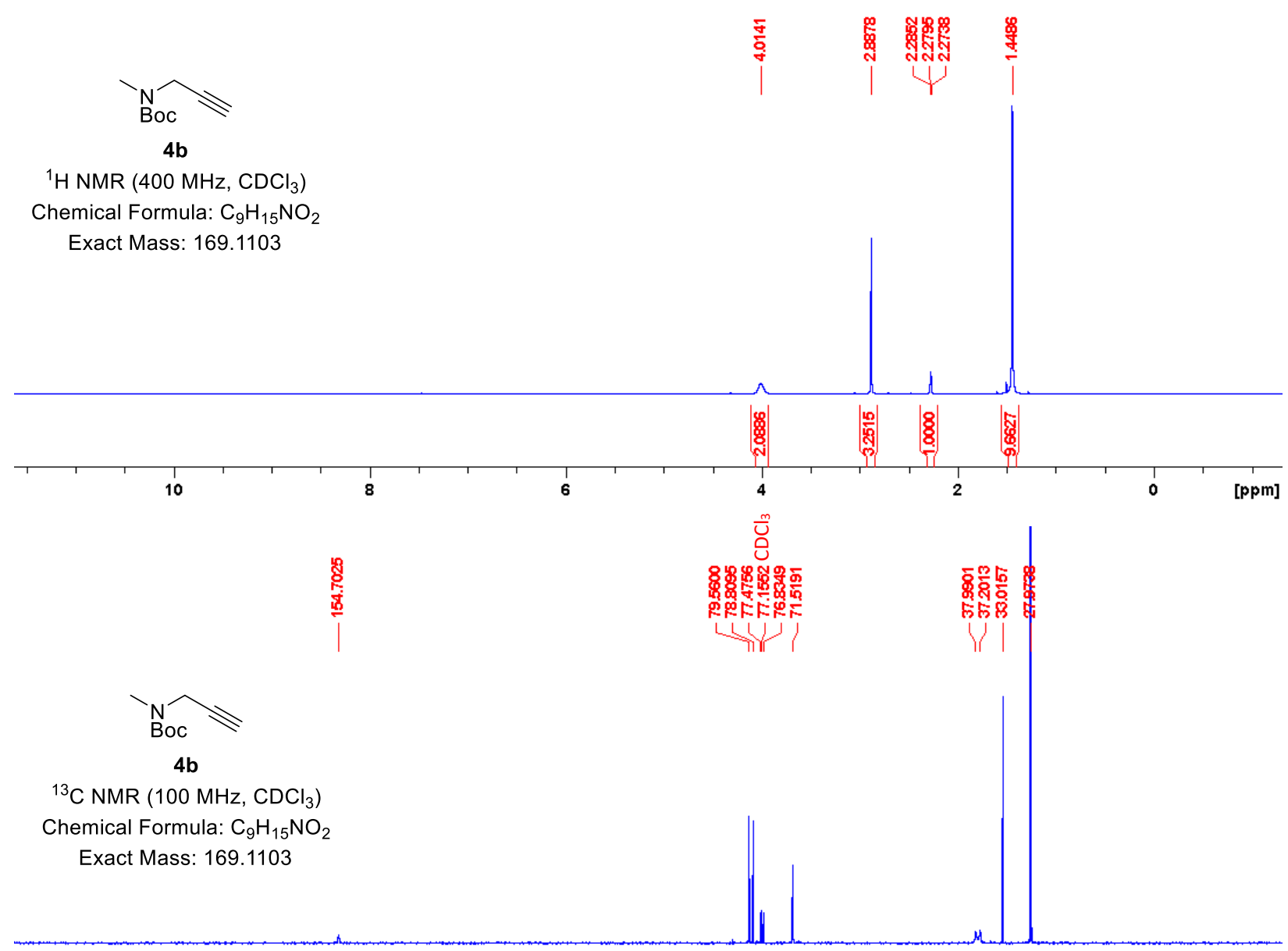

${ }^{1} \mathrm{H}$ NMR $\left(400 \mathrm{MHz}, \mathrm{CDCl}_{3}\right.$ )

Chemical Formula: $\mathrm{C}_{9} \mathrm{H}_{15} \mathrm{NO}_{2}$

Exact Mass: 169.1103

C NMR $\left(100 \mathrm{MHz}, \mathrm{CDCl}_{3}\right)$

Chemical Formula: $\mathrm{C}_{9} \mathrm{H}_{15} \mathrm{NO}_{2}$

Exact Mass: 169.1103

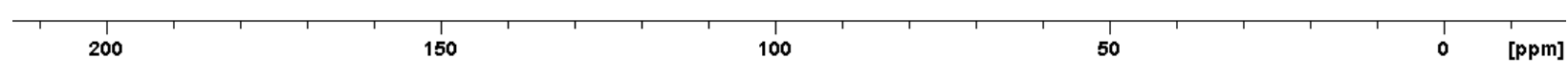



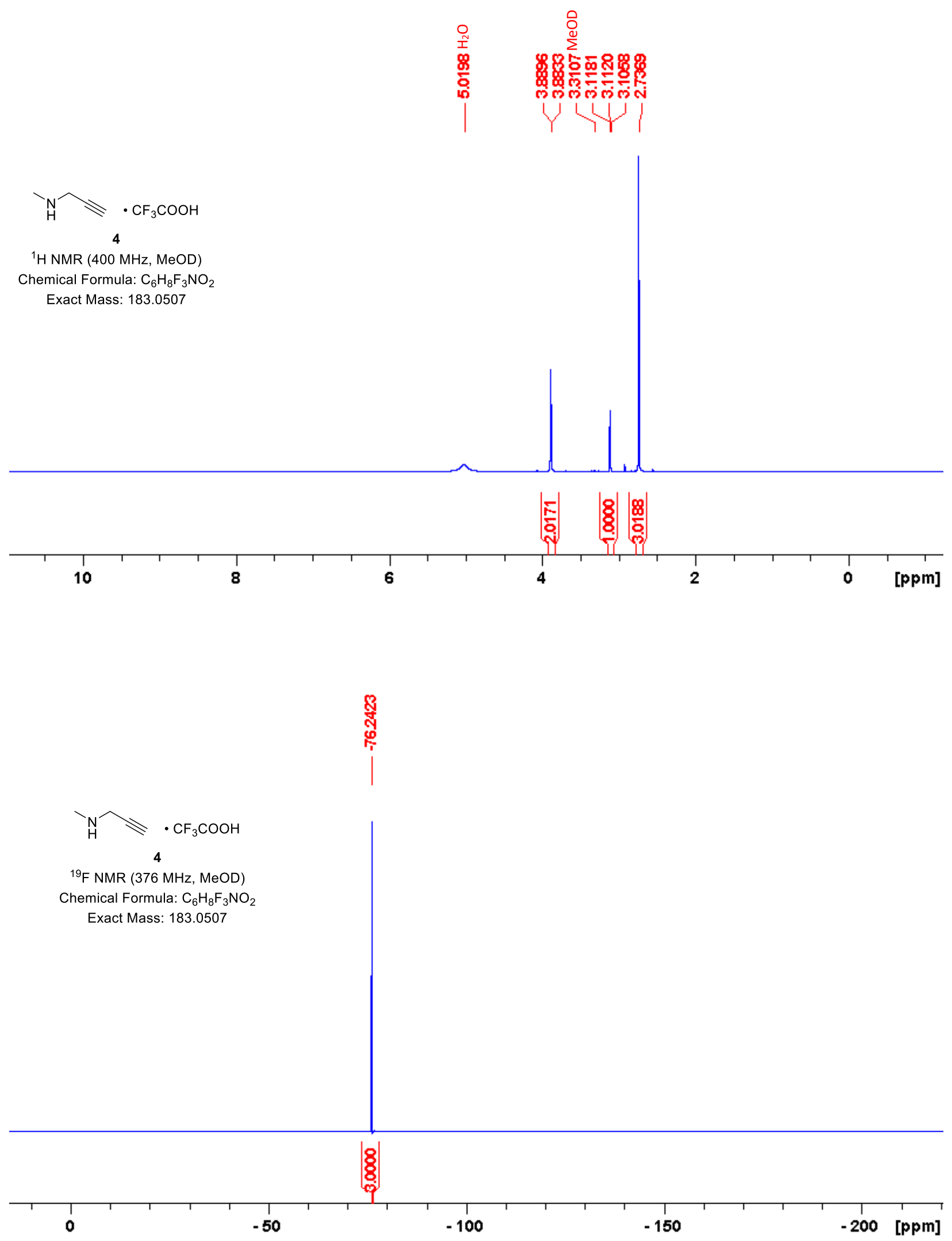


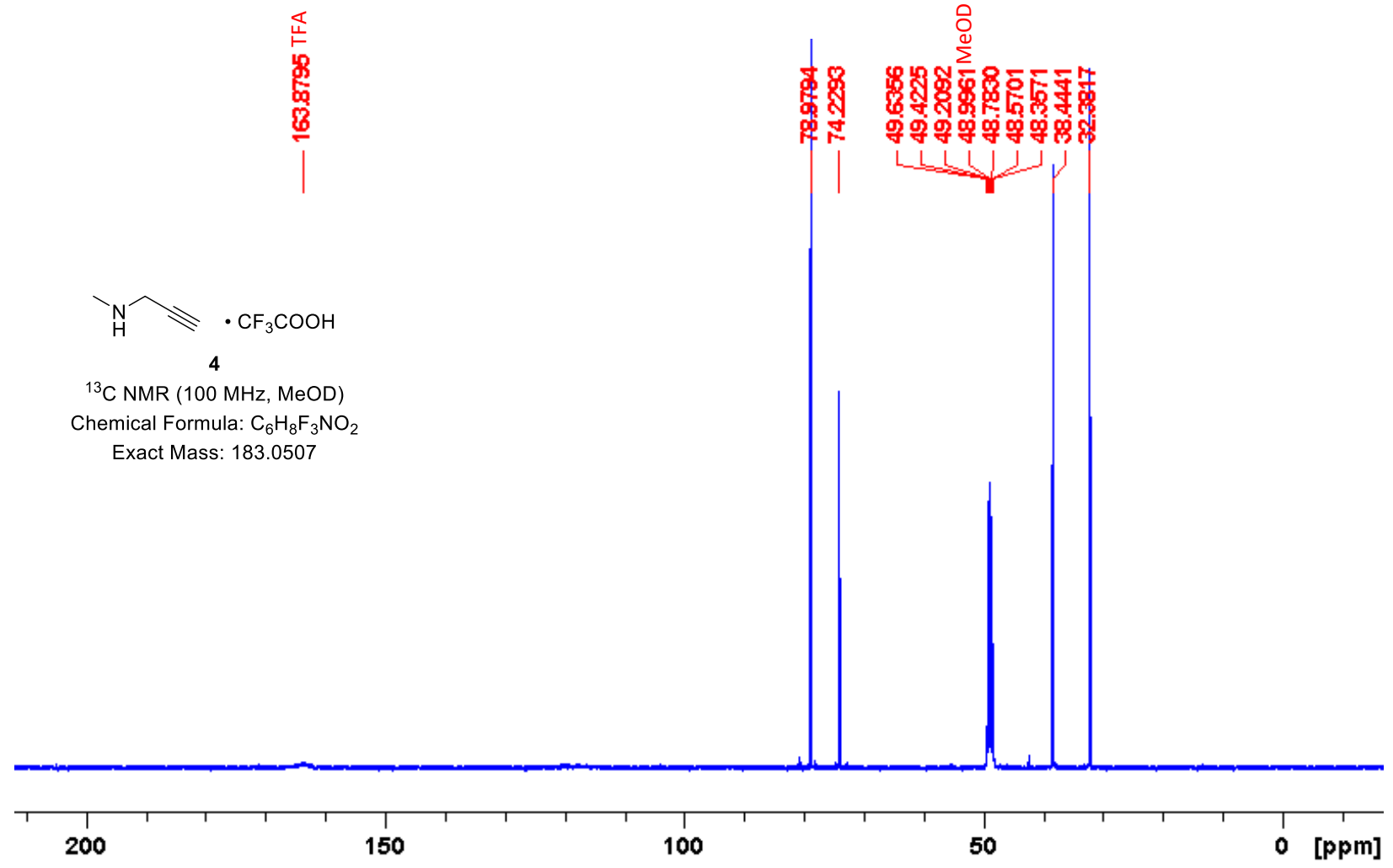




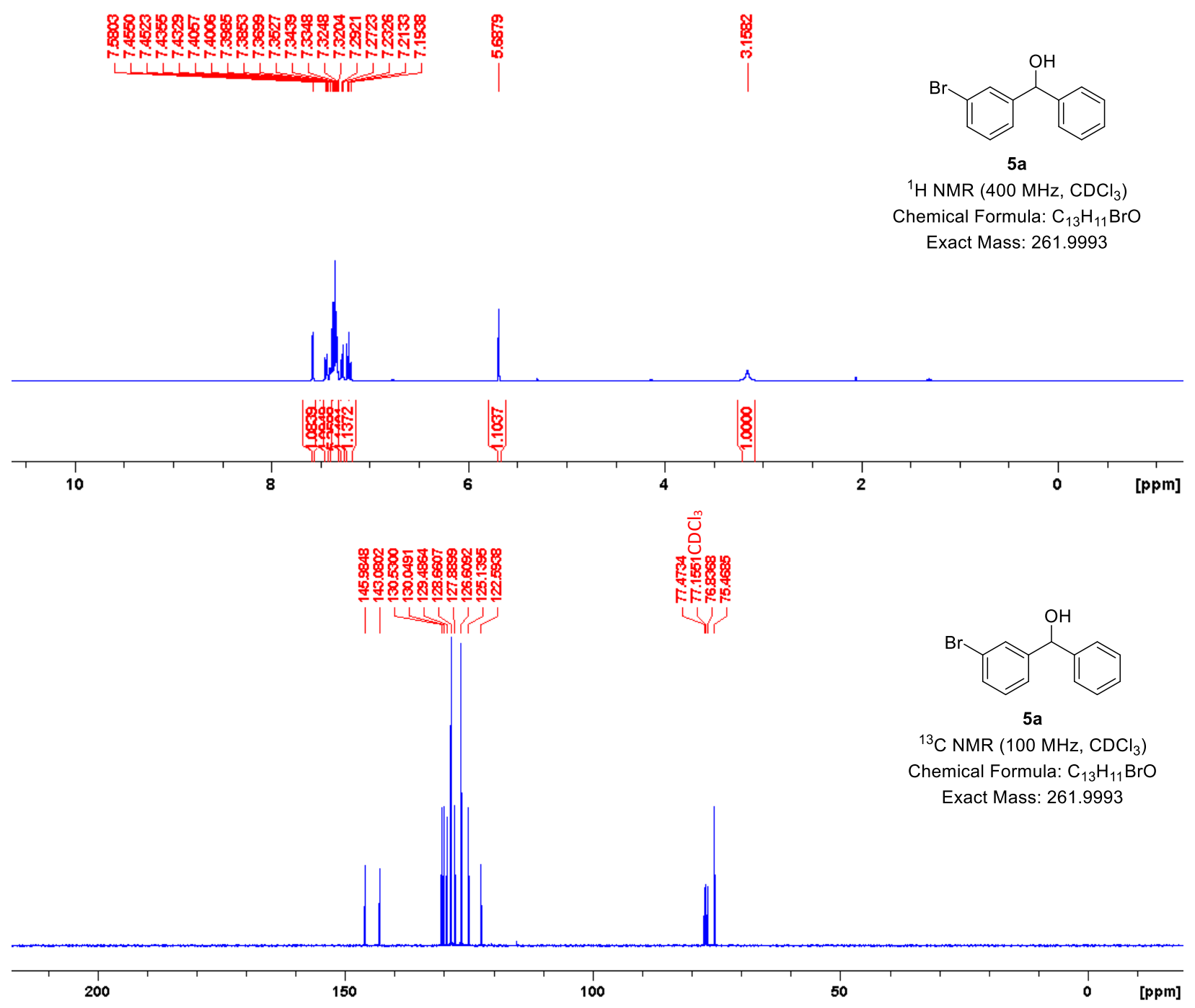



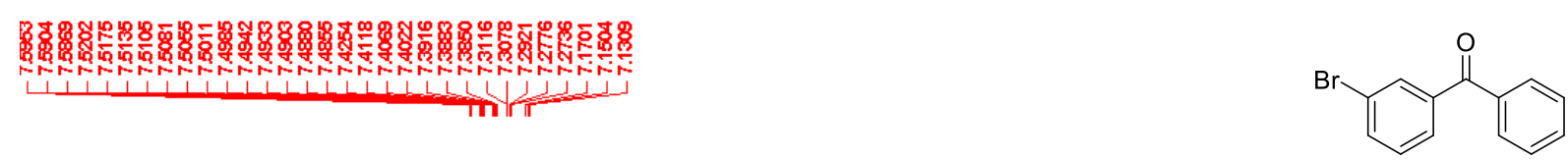

$5 b$

${ }^{1} \mathrm{H}$ NMR (400 MHz, $\mathrm{CDCl}_{3}$ ) Chemical Formula: $\mathrm{C}_{13} \mathrm{H}_{9} \mathrm{BrO}$

Exact Mass: 259.9837

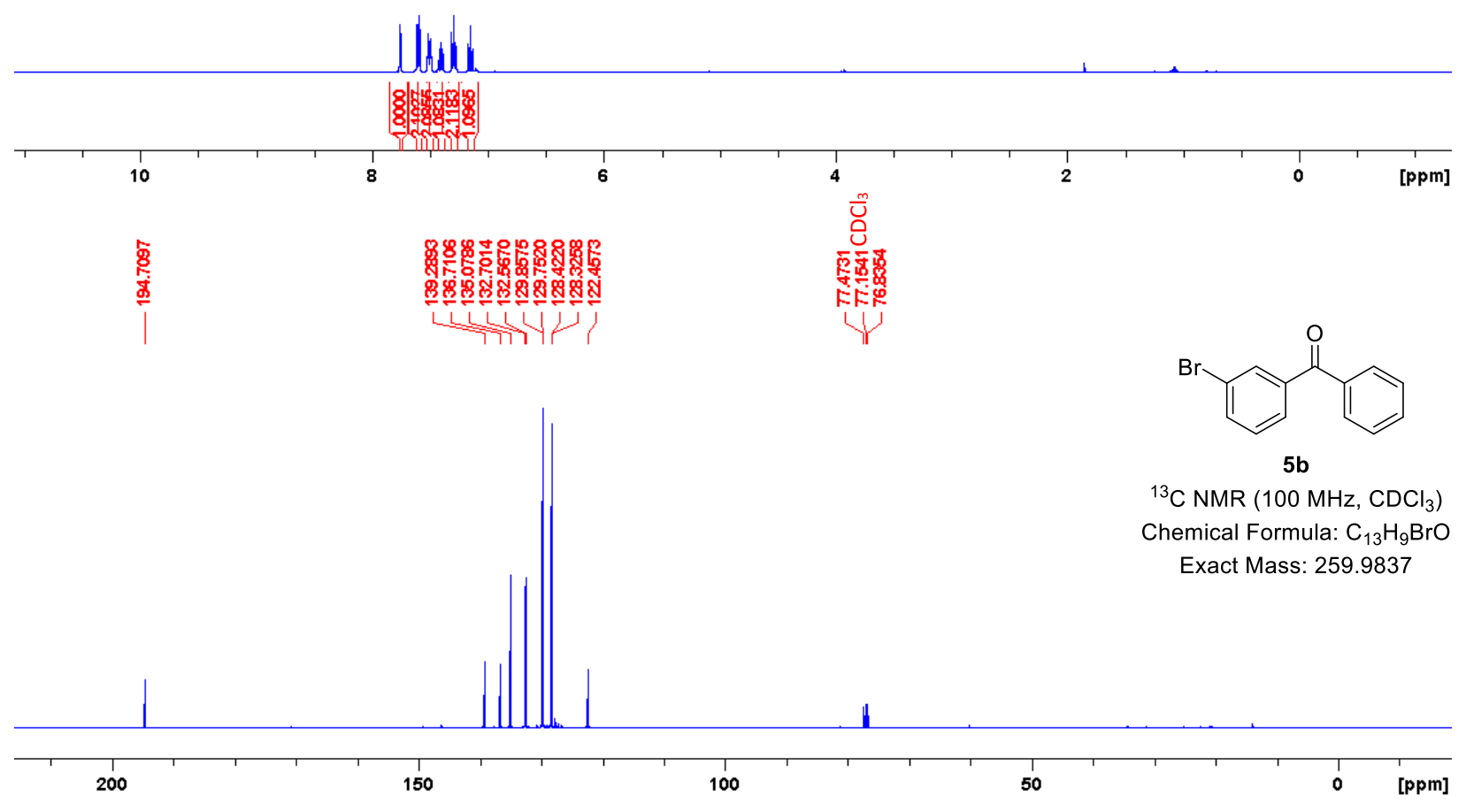



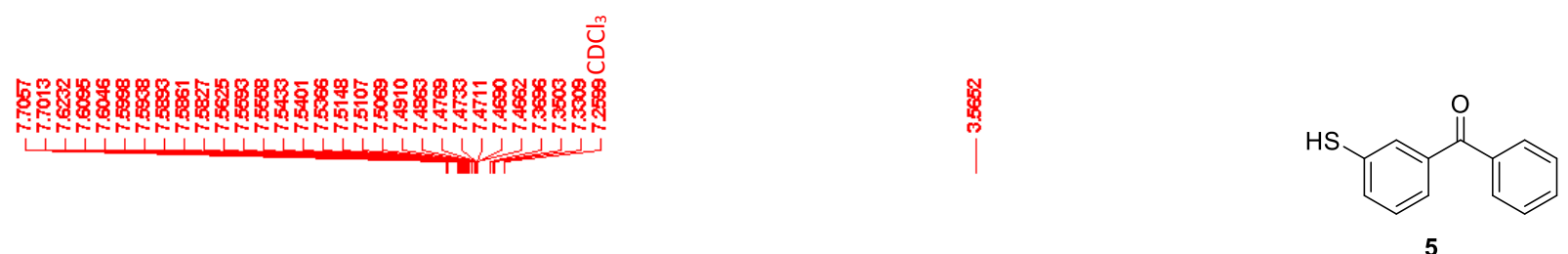

${ }^{1} \mathrm{H}$ NMR $\left(400 \mathrm{MHz}, \mathrm{CDCl}_{3}\right)$ Chemical Formula: $\mathrm{C}_{13} \mathrm{H}_{10} \mathrm{OS}$

Exact Mass: 214.0452

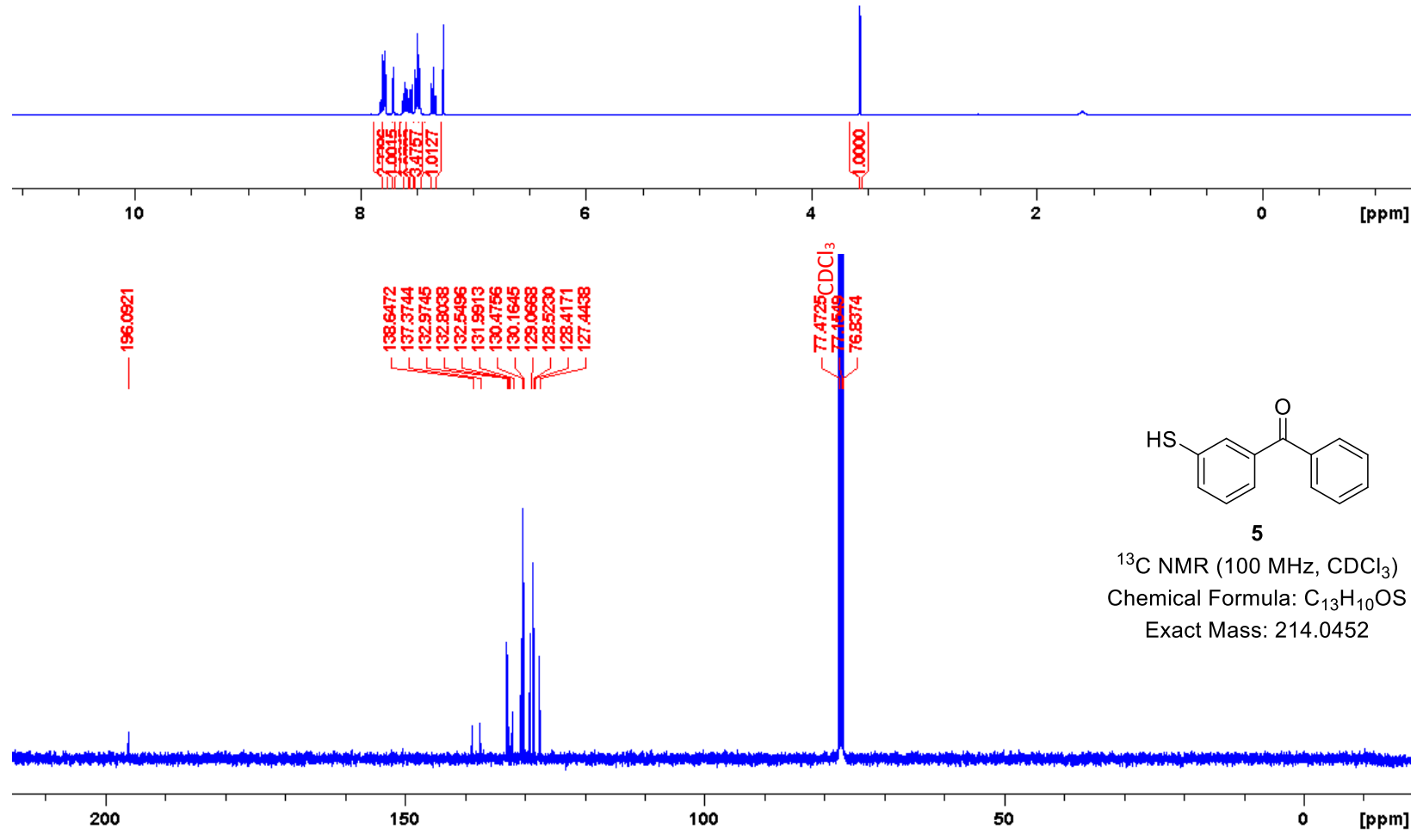



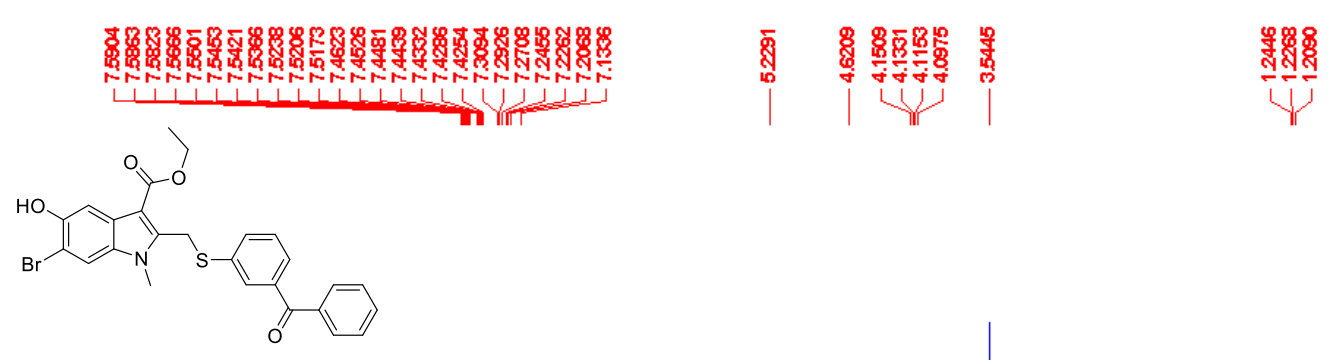

1 a

${ }^{1} \mathrm{H}$ NMR (400 MHz, $\mathrm{CDCl}_{3}$ ) Chemical Formula: $\mathrm{C}_{26} \mathrm{H}_{22} \mathrm{BrNO}_{4} \mathrm{~S}$ Exact Mass: 523.0453
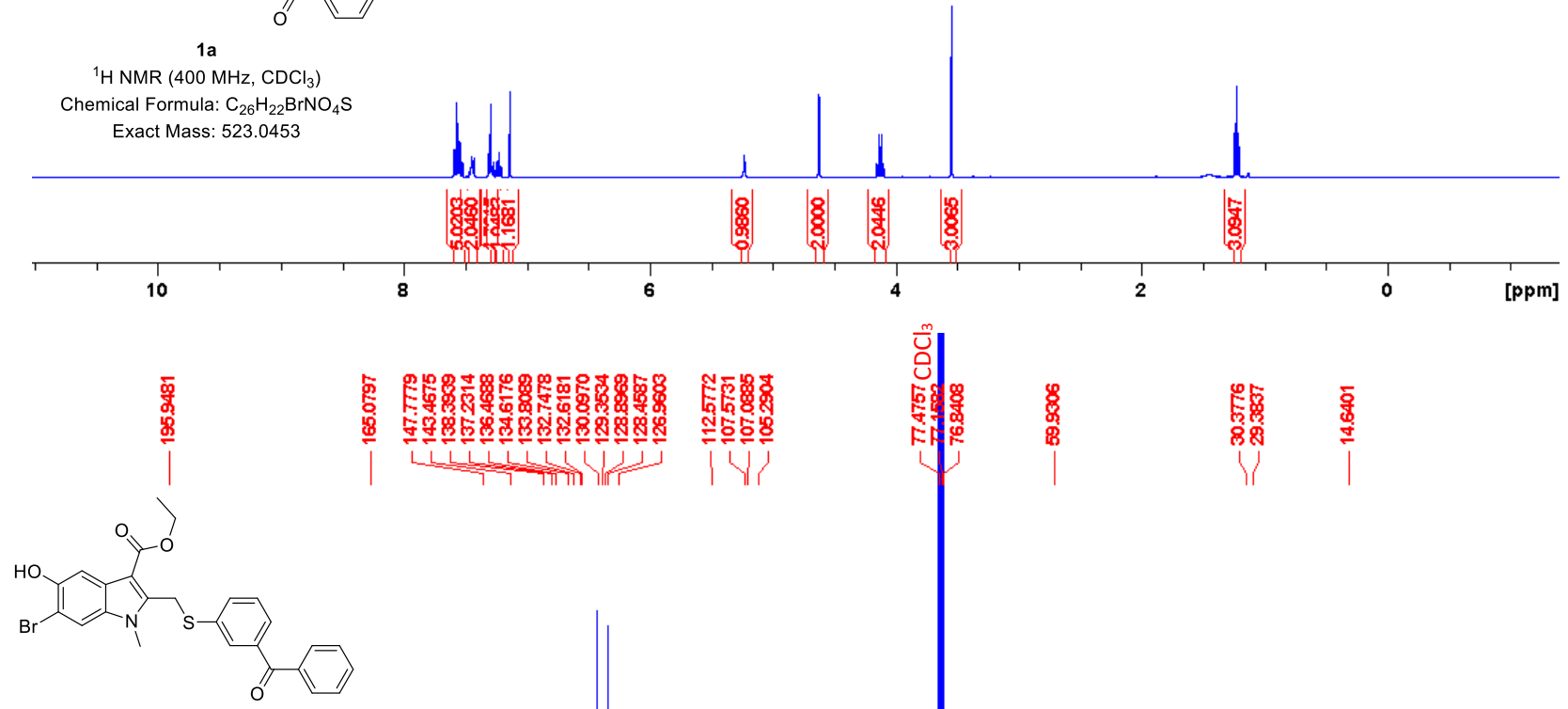

$1 a$

${ }^{13} \mathrm{C}$ NMR $\left(100 \mathrm{MHz}, \mathrm{CDCl}_{3}\right)$ Chemical Formula: $\mathrm{C}_{26} \mathrm{H}_{22} \mathrm{BrNO}_{4} \mathrm{~S}$

Exact Mass: 523.0453
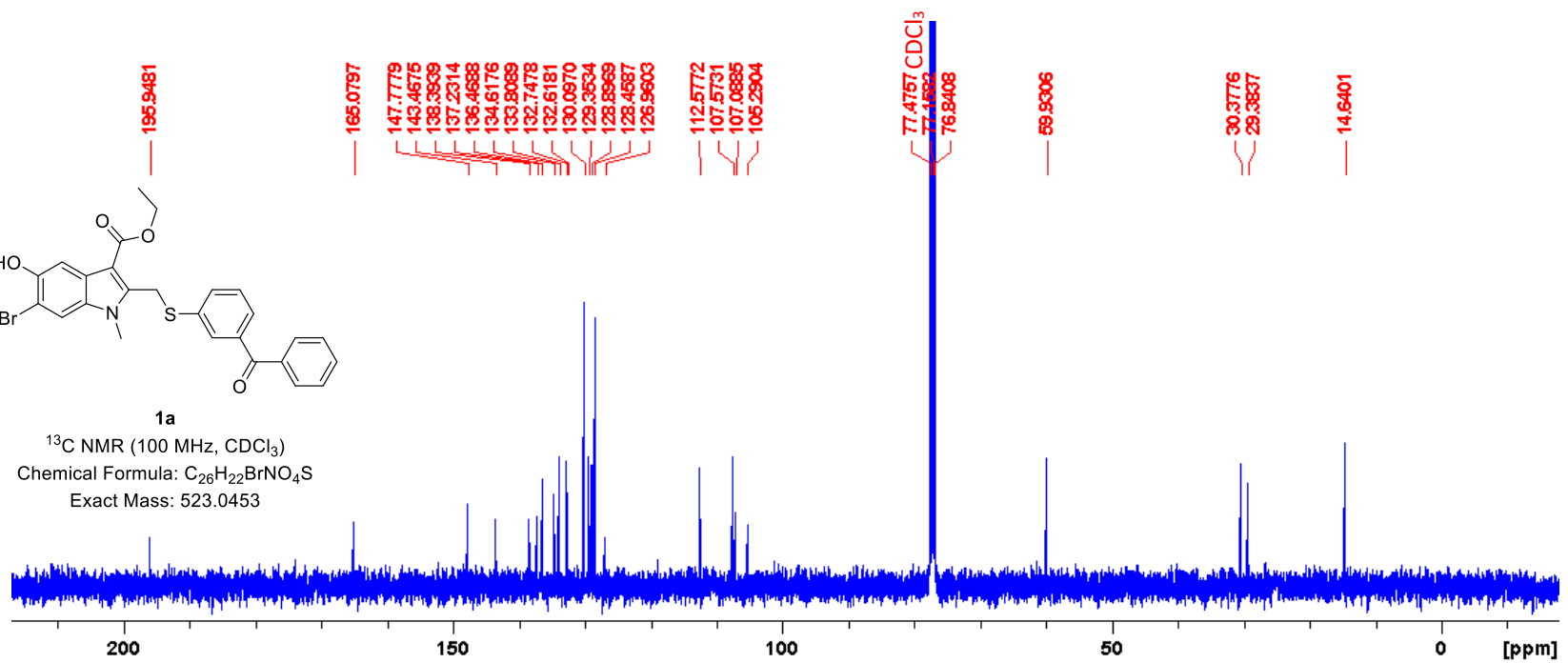

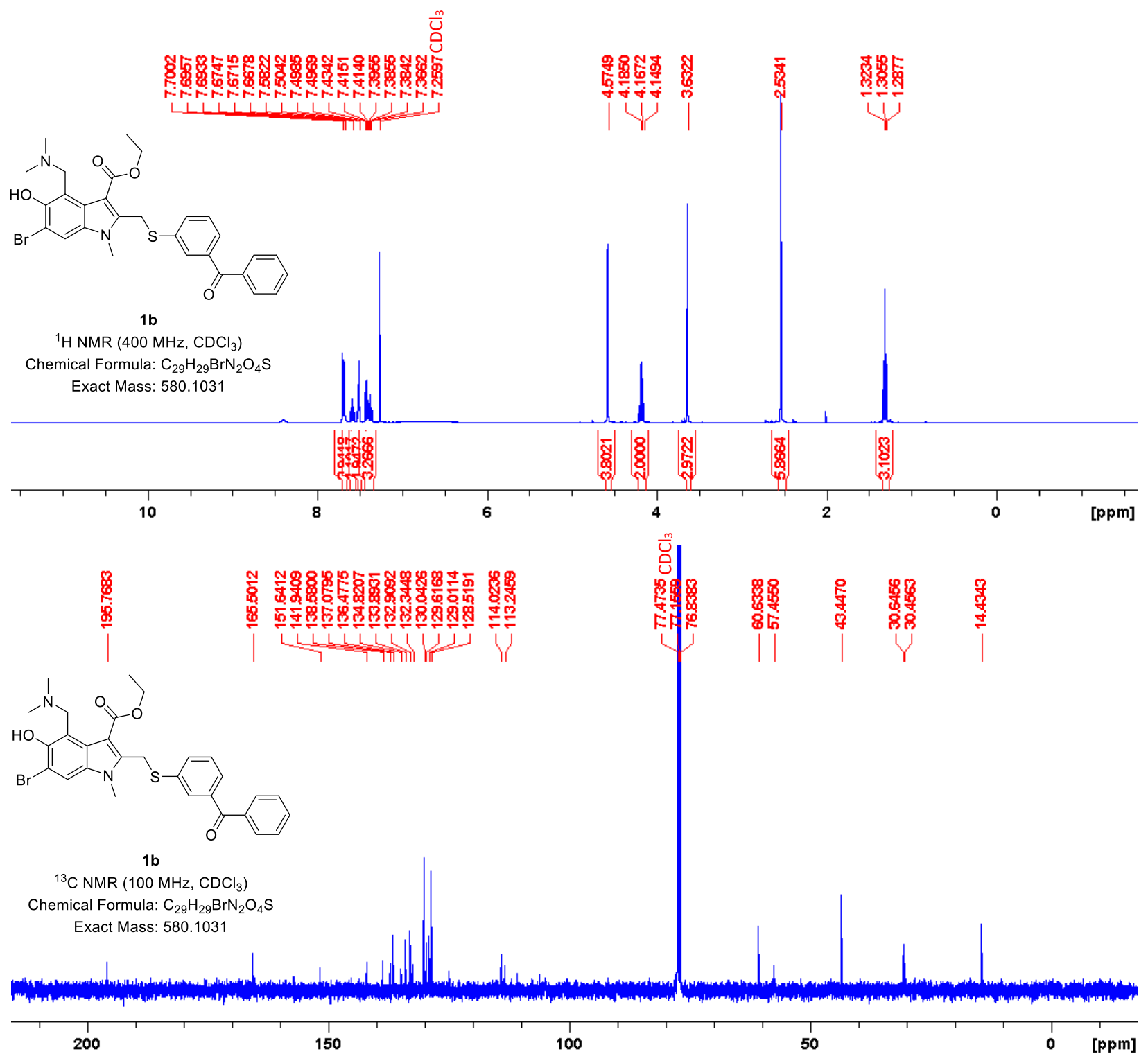

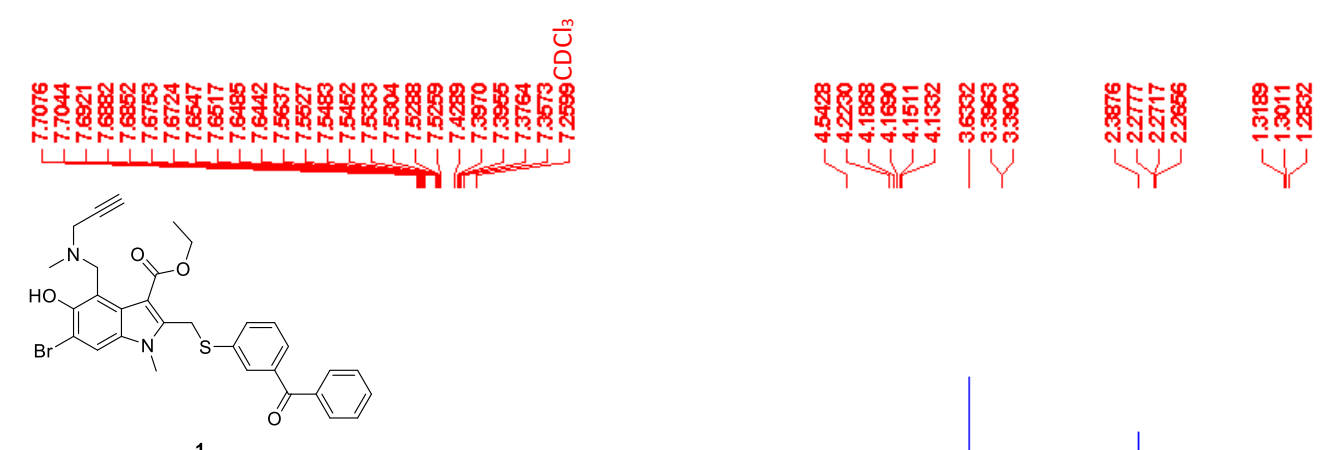

1

${ }^{1} \mathrm{H} \mathrm{NMR}\left(400 \mathrm{MHz}, \mathrm{CDCl}_{3}\right)$

Chemical Formula: $\mathrm{C}_{31} \mathrm{H}_{29} \mathrm{BrN}_{2} \mathrm{O}_{4} \mathrm{~S}$ Exact Mass: 604.1031
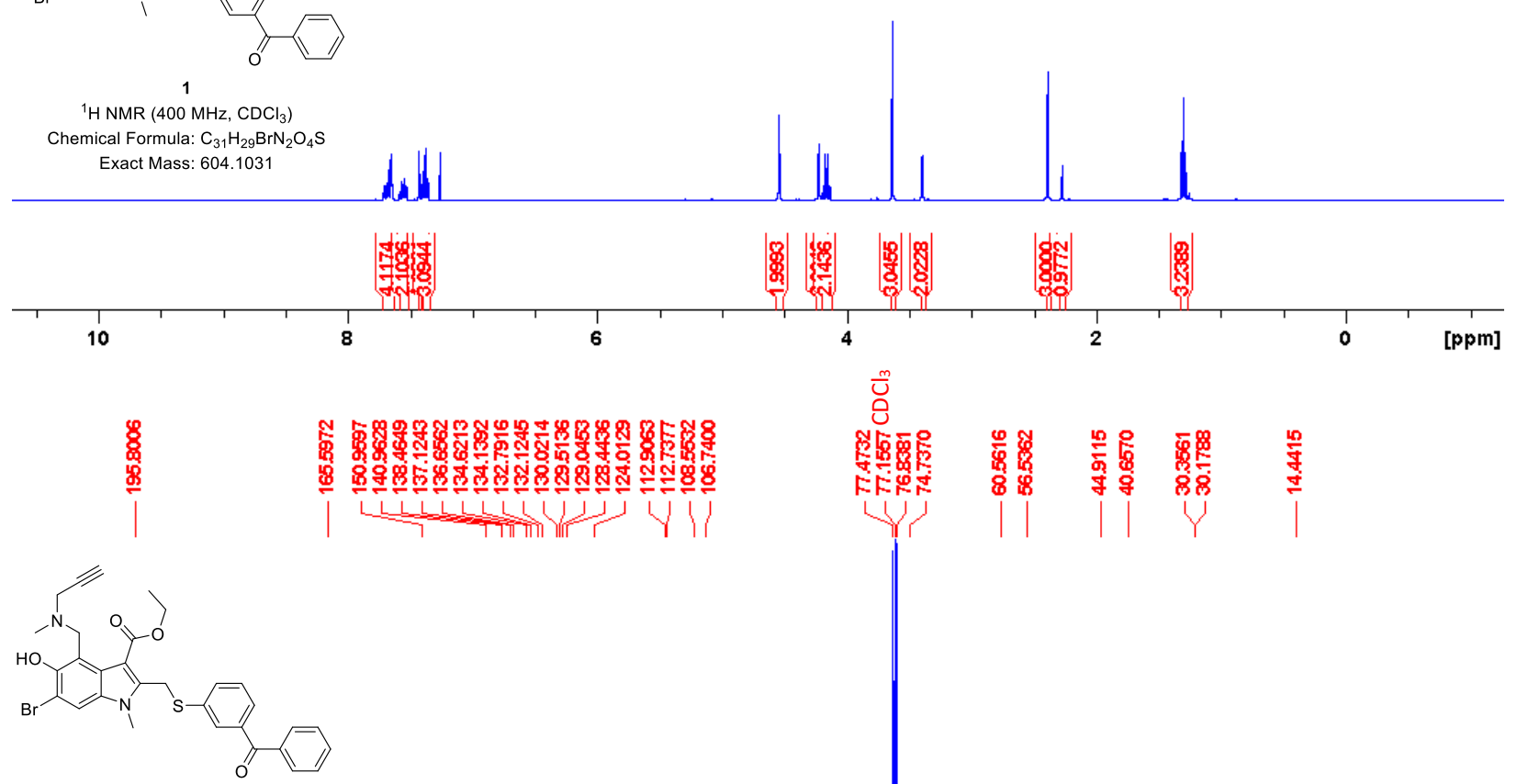

${ }^{13} \mathrm{C}$ NMR $\left(100 \mathrm{MHz}, \mathrm{CDCl}_{3}\right)$

Chemical Formula: $\mathrm{C}_{31} \mathrm{H}_{29} \mathrm{BrN}_{2} \mathrm{O}_{4} \mathrm{~S}$

Exact Mass: 604.1031

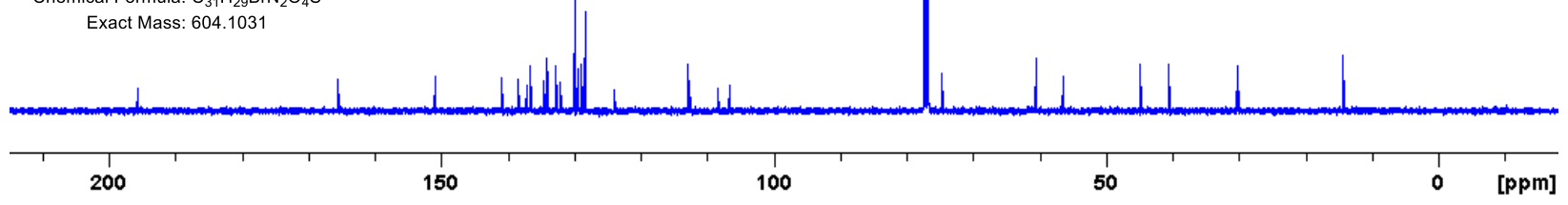




\section{$\underline{\text { References }}$}

(1) Wright, Z. V. F.; Wu, N. C.; Kadam, R. U.; Wilson, I. A.; Wolan, D. W. Structure-Based Optimization and Synthesis of Antiviral Drug Arbidol Analogues with Significantly Improved Affinity to Influenza Hemagglutinin. Bioorg. Med. Chem. Lett. 2017, 27 (16), 3744-3748. https://doi.org/10.1016/j.bmcl.2017.06.074.

(2) Liu, Y.; Kim, J.; Seo, H.; Park, S.; Chae, J. Copper(II)-Catalyzed Single-Step Synthesis of Aryl Thiols from Aryl Halides and 1,2-Ethanedithiol. Adv. Synth. Catal. 2015, 357 (10), 2205-2212. https://doi.org/10.1002/adsc.201400941.

(3) Ou, X.; Liu, Y.; Lei, X.; Li, P.; Mi, D.; Ren, L.; Guo, L.; Guo, R.; Chen, T.; Hu, J.; Xiang, Z.; Mu, Z.; Chen, X.; Chen, J.; Hu, K.; Jin, Q.; Wang, J.; Qian, Z. Characterization of Spike Glycoprotein of SARS-CoV-2 on Virus Entry and Its Immune CrossReactivity with SARS-CoV. Nat. Commun. 2020, 11 (1), 1620. https://doi.org/10.1038/s41467-020-15562-9.

(4) Gordon, D. E.; Jang, G. M.; Bouhaddou, M.; Xu, J.; Obernier, K.; White, K. M.; O’Meara, M. J.; Rezelj, V. V.; Guo, J. Z.; Swaney, D. L.; Tummino, T. A.; Hüttenhain, R.; Kaake, R. M.; Richards, A. L.; Tutuncuoglu, B.; Foussard, H.; Batra, J.; Haas, K.; Modak, M.; Kim, M.; Haas, P.; Polacco, B. J.; Braberg, H.; Fabius, J. M.; Eckhardt, M.; Soucheray, M.; Bennett, M. J.; Cakir, M.; McGregor, M. J.; Li, Q.; Meyer, B.; Roesch, F.; Vallet, T.; Mac Kain, A.; Miorin, L.; Moreno, E.; Naing, Z. Z. C.; Zhou, Y.; Peng, S.; Shi, Y.; Zhang, Z.; Shen, W.; Kirby, I. T.; Melnyk, J. E.; Chorba, J. S.; Lou, K.; Dai, S. A.; Barrio-Hernandez, I.; Memon, D.; Hernandez-Armenta, C.; Lyu, J.; Mathy, C. J. P.; Perica, T.; Pilla, K. B.; Ganesan, S. J.; Saltzberg, D. J.; Rakesh, R.; Liu, X.; Rosenthal, S. B.; Calviello, L.; Venkataramanan, S.; Liboy-Lugo, J.; Lin, Y.; Huang, X.-P.; Liu, Y.; Wankowicz, S. A.; Bohn, M.; Safari, M.; Ugur, F. S.; Koh, C.; Savar, N. S.; Tran, Q. D.; Shengjuler, D.; Fletcher, S. J.; O’Neal, M. C.; Cai, Y.; Chang, J. C. J.; Broadhurst, D. J.; Klippsten, S.; Sharp, P. P.; Wenzell, N. A.; Kuzuoglu-Ozturk, D.; Wang, H.-Y.; Trenker, R.; Young, J. M.; Cavero, D. A.; Hiatt, J.; Roth, T. L.; Rathore, U.; Subramanian, A.; Noack, J.; Hubert, M.; Stroud, R. M.; Frankel, A. D.; Rosenberg, O. S.; Verba, K. A.; Agard, D. A.; Ott, M.; Emerman, M.; Jura, N.; von Zastrow, M.; Verdin, E.; Ashworth, A.; Schwartz, O.; d’Enfert, C.; Mukherjee, S.; Jacobson, M.; Malik, H. S.; Fujimori, D. G.; Ideker, T.; Craik, C. S.; Floor, S. N.; Fraser, J. S.; Gross, J. D.; Sali, A.; Roth, B. L.; Ruggero, D.; Taunton, J.; Kortemme, T.; Beltrao, P.; Vignuzzi, M.; García-Sastre, A.; Shokat, K. M.; Shoichet, B. K.; Krogan, N. J. A SARS-CoV-2 Protein Interaction Map Reveals Targets for Drug Repurposing. Nature 2020, 583 (7816), 459-468. https://doi.org/10.1038/s41586-020-2286-9.

(5) Chan, K. K.; Dorosky, D.; Sharma, P.; Abbasi, S. A.; Dye, J. M.; Kranz, D. M.; Herbert, A. S.; Procko, E. Engineering Human ACE2 to Optimize Binding to the Spike Protein of SARS Coronavirus 2. Science 2020, 369 (6508), 1261-1265. https://doi.org/10.1126/science.abc0870.

(6) Schneider, C. A.; Rasband, W. S.; Eliceiri, K. W. NIH Image to ImageJ: 25 Years of Image Analysis. Nat. Methods 2012, 9 (7), 671-675. https://doi.org/10.1038/nmeth.2089.

(7) Cox, J.; Mann, M. MaxQuant Enables High Peptide Identification Rates, Individualized p.p.b.-Range Mass Accuracies and Proteome-Wide Protein Quantification. Nat. Biotechnol. 2008, 26 (12), 1367-1372. https://doi.org/10.1038/nbt.1511.

(8) Tyanova, S.; Temu, T.; Sinitcyn, P.; Carlson, A.; Hein, M. Y.; Geiger, T.; Mann, M.; Cox, J. The Perseus Computational Platform for Comprehensive Analysis of (Prote)Omics Data. Nat. Methods 2016, 13 (9), 731-740. https://doi.org/10.1038/nmeth.3901.

(9) Zhang, L.; Jackson, C. B.; Mou, H.; Ojha, A.; Peng, H.; Quinlan, B. D.; Rangarajan, E. S.; Pan, A.; Vanderheiden, A.; Suthar, M. S.; Li, W.; Izard, T.; Rader, C.; Farzan, M.; Choe, H. SARS-CoV-2 Spike-Protein D614G Mutation Increases Virion Spike Density and Infectivity. Nat. Commun. 2020, 11 (1), 6013. https://doi.org/10.1038/s41467-020-19808-4. 